\title{
Development of innovative methods for induction of European eel (Anguilla anguilla) spermatogenesis
}

\author{
Ph.D. Candidate: Christoffer Rozenfeld
}

This Thesis has been submitted in accordance with the requirements for the degree of

Doctor at the Universitat Politècnica de València.

Esta Tesis ha sido presentada de acuerdo con los requisitos para el grado de Doctor en

la Universitat Politècnica de València.

Valencia, July 2019

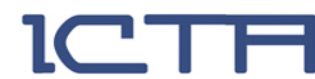

\section{$\underline{\text { THESIS SUPERVISORS }}$}

Dr. Juan F. Asturiano Nemesio

Grupo de Acuicultura y Biodiversidad, Instituto de Ciencia y Tecnología Animal, Universitat Politècnica de València, Valencia, Spain

\section{Dr. Finn-Arne Weltzien}

Norwegian University of Life Sciences, Faculty of Veterinary Medicine, Department of Basic Sciences and Aquatic Medicine, Oslo, Norway 


\section{TABLE OF CONTENTS}

TABLE OF CONTENTS

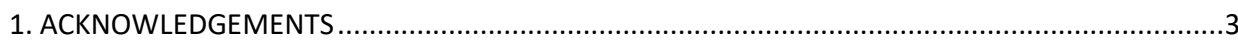

2. SUMMARIES

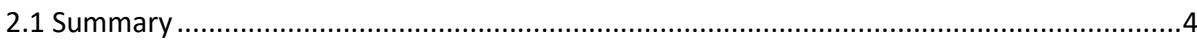

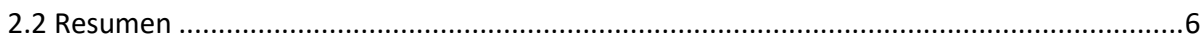

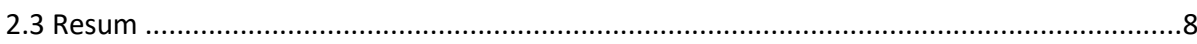

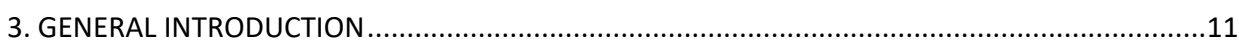

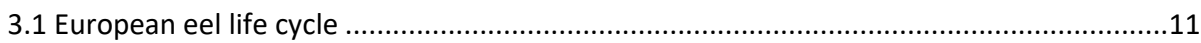

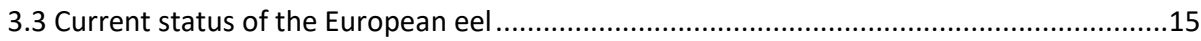

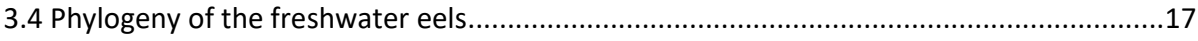

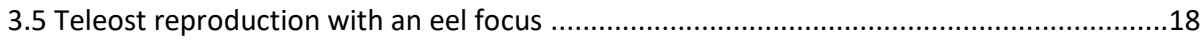

3.6 Artificial manipulation of teleost sexual maturation ..........................................................24

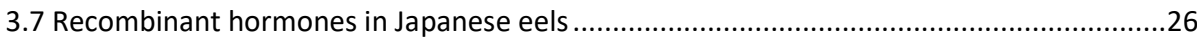

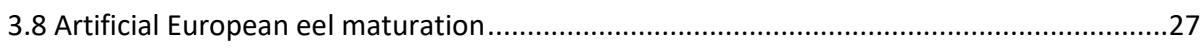

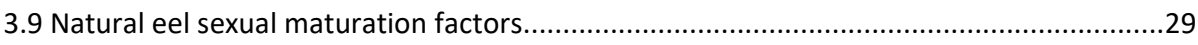

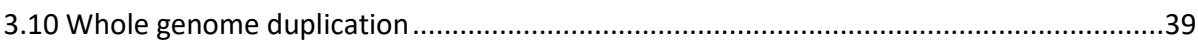

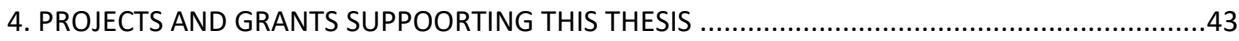

5. OBJECTIVES

5.1 Specific objectives:

6. CHAPTER 1: Using specific recombinant gonadotropins to induce spermatogenesis and

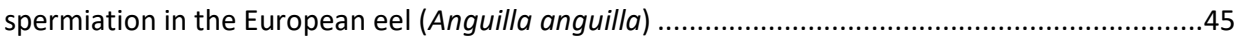

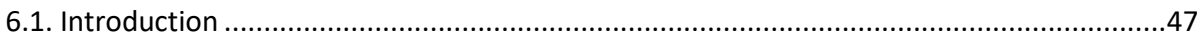

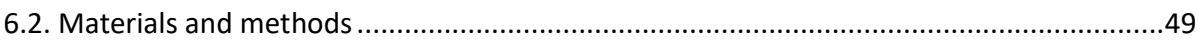

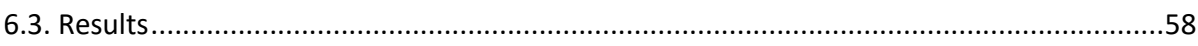

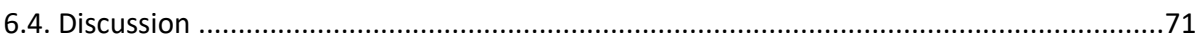

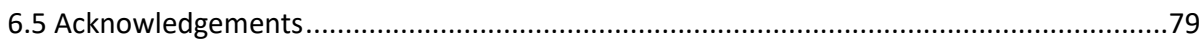


7. CHAPTER 2: Cold seawater induces early maturational stages in the BPG axis of European eel males

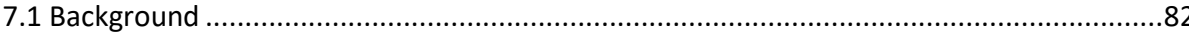

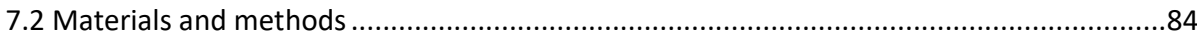

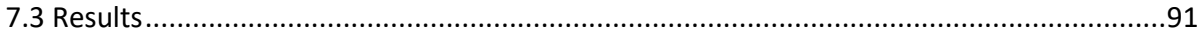

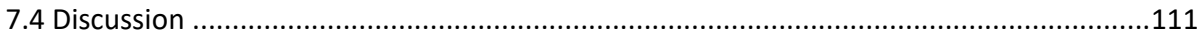

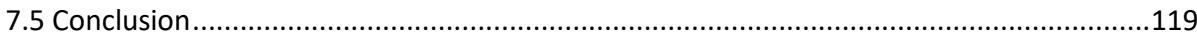

8. CHAPTER 3: de novo European eel transcriptome provides insights into the evolutionary history

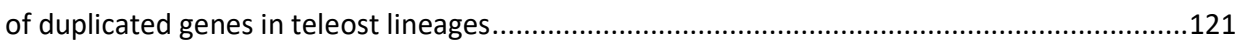

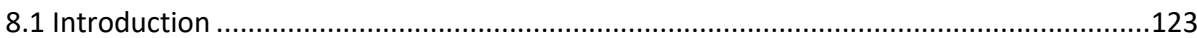

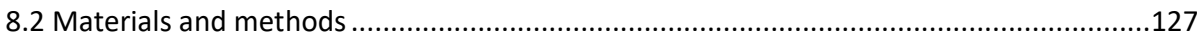

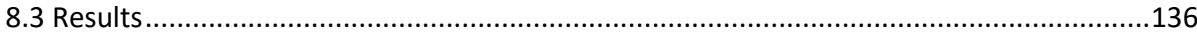

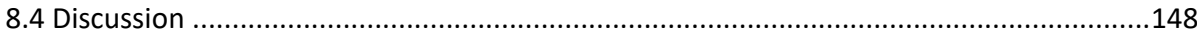

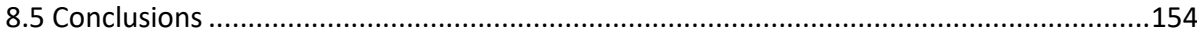

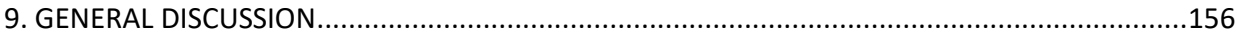

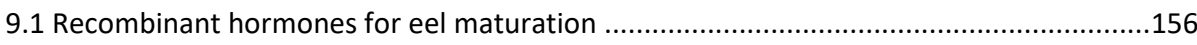

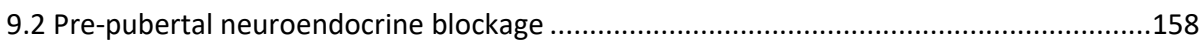

9.3 A deeper look at the cold seawater treatment experiment............................................161

9.4 Did the European eel lineage experience a WGD after 3R? ..........................................174

9.5 Potentially important recently duplicated genes found in eels ......................................180

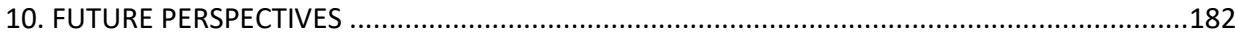

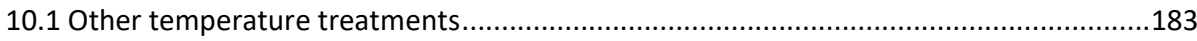

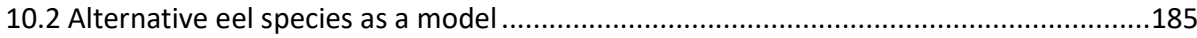

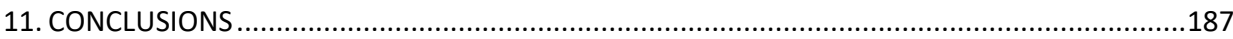

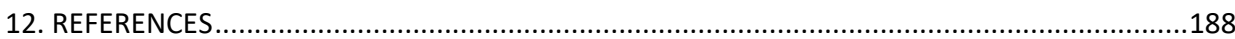




\section{ACKNOWLEDGEMENTS}

First of all, thanks to my colleagues. When I arrived here in this strange country without knowing the language and most importantly without my wife, I felt a lot of comfort from being immediately accepted and taken care of from everyone in the group. I deeply appreciate how you all have made an effort to speak English when I was around, and I apologize for not having learned Spanish better, you deserve better.

Specifically, thank you Johnny, for giving me the opportunity to do this $\mathrm{PhD}$. It has been almost 4 years with ups and downs, but the one consistent thing at work has been your support, trust, and leadership. I feel lucky that I had you as a supervisor, as you surely have done more than could be expected of you for me and my project. Thank you for driving me around Valencia for my bureaucracy appointments, for the many good advice, for babysitting my fish, allowing flexible work hours when my family needed me and for correcting my work in record times. I could not have asked for more.

Thanks also to Luz, for you friendly and welcoming attitude, for the many little gifts for my girls from you and Johnny, for the dinners at your place, for our many talks and coffees, and all the professional help and advice. David, thank you for your great teaching and help with my molecular work, for taking the fight with our collaborations, for your advices and for your outstanding attitude in times of trouble. You really managed to put a lid on the frustrations during the more difficult times.

Thank you Victor, for your great mood and keeping the focus during our breaks (punto positivo para ti), thank you for inviting me out to see birds or play sports, and for always knowing what to see and where to go. Thank you Morini, and Mamen for being wonderful colleagues, and especially for all you did in my first months here to help me and make me feel welcome, I still have a little note Mamen wrote me, which simply said "have a nice weekend, see $U:$ :)". I also want to thank Pepa, for mothering the group, for inviting us all to her place, for giving up her desk for me when I first came here and for all the baby advice and equipment. Andrés, thanks for all your advice and for having welcomed me as one of yours from the beginning, especially thank you for trying to teach me some Spanish and for practicing your English with me. Last but not least, form the group, thank you German for being my buddy in this adventure. Thank you for always being ready to help if I needed you and for always listening to my wining (from which there has been a lot). You are a great friend, and one of the most knowledgeable people I know (regarding obscure things I find interesting).

My PhD has also included several trips abroad to training schools conferences and secondments. These would not have been the same without my IMPRESS brothers and sisters: Aurora, Elia, Elena, Ben, Carlos, Bruno, Carina, Rasheed, Hannah, Mitch, Daan, Sophia, Ishwar, German, and Sahana. Thank you all for the good times, for indulging my board games need in the wilderness of France and for playing Mafia and CAH in the suburbs of Vodnany. Thanks for midnight sightseeing in Berlin, for pub crawl in Leiden, and for river rafting in the Loir river. May you all get post docs and avoid future in situs!

Finally, a huge thanks to my family, my mom, dad and sister for always supporting my and building me to be who I am. Thank you for listening to me and supporting me whenever I needed it.

Thank to my amazing daughters Laura and Sara for brightening up my days and showing me what is most important. And most importantly thank to my wounderfugl wife Filipa for being my partner in crime, my muse, my love, and my life. 


\section{SUMMARIES}

\subsection{Summary}

As an expensive fish from one of the most ancient teleost lineages, with a mysterious life cycle, exceptional aquaculture potential, and cultural associations and fishing activity in almost every country in Europe, the European eel possess huge socioeconomic value. This value only adds to the misfortune of the current critically endangered state of the wild European eel population. As the eel lifecycle has not yet been closed in captivity, the species will not be salvable if it went extinct in the wild. Closing the life-cycle of the European eel has thus been the ultimate objective of several studies. However, despite the substantial scientific investigation, since the 1930s, several aspects of eel maturation, such as the mechanism which blocks eel sexual maturation at the pre-pubertal stage in captivity, is still poorly understood. Therefore, it is necessary to broaden our knowledge of eel reproduction to induce better hypotheses and therethrough achieve substantial progress. In order to further this field, this thesis was conducted with the specific objective of developing innovative methods for induction of eel maturation and add to the pool of knowledge of European eel maturation processes.

The hormonal procedures currently used for artificial eel sexual maturation are probably not inducing the natural maturation process. Therefore, this thesis has evaluated the potential of eel specific recombinant hormones to induce a more natural maturation process. This specific study showed that full spermatogenesis and spermiation can be induced with recombinant eel specific gonadotropins; however, the resulting gamete quality is still inferior to the results of established protocols. Nevertheless, the utilization of recombinant hormones holds a large potential for future implementation. Furthermore, the 
recombinant gonadotropin experiment has generated novel insights into the effect of homologous gonadotropins on the BPG axis of European eels.

Previous work has led to the hypothesis that the right thermal environmental treatment may reduce or partially replace the standard hormonal treatments for sexual maturation of European eel, or may improve gamete quality and/or quantity. In this thesis, the effect of various thermal regimes was tested on the BPG axis of pre-pubertal European eel males, without administration of hormones. The results clearly show that a 2 week cold $\left(10^{\circ} \mathrm{C}\right)$ seawater treatment effects the BPG-axis of European eel males. Specific results included an increase in the synchronization of spermatogonial cells, elevated testosterone and 11-ketotestosterone plasma levels, clustering of BPG-axis transcriptome samples from the cold seawater treated group and possibly increased levels of pituitary luteinizing hormone $\beta$-subunit protein. Differentially transcribed genes alluded to several interesting genes, processes, and pathways, which appears to be involved in early "natural" eel maturation and may prove to be suitable biomarkers for the stages of this process. However, further studies are needed to evaluate the biomarker potential of these genes and whether a cold seawater treatment can improve the response of European eels to artificial hormonal treatment, as the results suggest.

In order for proper analysis of the transcriptomic data, a de novo European eel transcriptome was assembled. This de novo transcriptome was proven to have superior completeness to the available European eel genome and is thus a useful tool for further analysis of specific genes. An analysis of this transcriptome revealed a large number of paralog gene pairs, which showed low synonymous sequence divergence. Among the potential hypothesis regarding the origin of these paralog gene pairs, the hypothesis of a $4 R$ whole genome duplication is among the most parsimonious. Several of these duplicated genes were involved in reproduction and the onset of puberty. Regardless of the origin, further 
analysis of these genes may reveal eel specific adaptations, which could help to better understand the exceptional reproductive system of eels.

\subsection{Resumen}

Como pez de gran valor económico, procedente de una de las líneas de teleósteos más antiguas, con un ciclo de vida misterioso, un potencial de acuicultura excepcional, y con importancia cultural y actividades de pesca en casi todos los países de Europa, la anguila europea posee un enorme valor socioeconómico. Este valor se suma a la desgraciada situación actual en peligro crítico de población natural de anguilas europeas. Como el ciclo de vida de la anguila aún no se ha conseguido cerrar en cautiverio, si la especie se extingue en la naturaleza, no seremos capaces de recuperarla. El cierre del ciclo de vida de la anguila europea ha sido, por lo tanto, el objetivo final de varios estudios. Sin embargo, a pesar de una investigación científica sustancial, desde la década de 1930, varios aspectos de la maduración de la anguila, como el mecanismo que bloquea la maduración de la anguila en la etapa prepúber en cautiverio, aún no se conocen bien. Por lo tanto, es necesario ampliar nuestro conocimiento sobre la reproducción de la anguila para inducir mejores hipótesis y lograr un progreso sustancial. Para profundizar en este campo, esta tesis se realizó con el objetivo específico de desarrollar métodos innovadores para la inducción de la maduración de la anguila y aumentar el conjunto de conocimientos sobre los procesos europeos de maduración de la anguila.

Los procedimientos hormonales utilizados actualmente para la maduración sexual de la anguila artificial probablemente no induzcan el proceso natural de maduración. Por lo tanto, esta tesis ha evaluado el potencial de las hormonas recombinantes específicas de la anguila para inducir un proceso de maduración más natural. Este estudio específico mostró que la espermatogénesis completa y la espermiación se pueden inducir con gonadotropinas específicas de anguila 
recombinante; sin embargo, la calidad del gameto resultante es aún inferior a los resultados de los protocolos establecidos. Sin embargo, la utilización de hormonas recombinantes tiene un gran potencial para futuras implementaciones. Además, el experimento de gonadotropina recombinante ha generado nuevos detalles sobre el efecto de las gonadotropinas homólogas en el eje BPG de las anguilas europeas.

Trabajos previos han llevado a la hipótesis de que un tratamiento térmico adecuado puede reducir o reemplazar parcialmente los tratamientos hormonales estándar para la maduración sexual de la anguila europea, o puede mejorar la calidad y / o cantidad de gametos. En esta tesis, se probó el efecto de varios regímenes térmicos en el eje BPG de machos de anguila europeos prepúberes, sin administración de hormonas. Los resultados muestran claramente que un tratamiento de agua de mar fría durante 2 semanas $\left(10^{\circ} \mathrm{C}\right)$ afecta el eje BPG de los machos de anguila europeas. Los resultados específicos incluyeron un aumento en la sincronización de espermatogonias, niveles elevados de testosterona y 11-ketotestosterona en plasma, agrupamiento de muestras de transcriptomas del eje BPG del grupo tratado con agua de mar fría y posiblemente niveles aumentados de la proteína subunidad $\beta$ de la hormona luteinizante de la hipófisis. Los genes transcritos diferencialmente incluyeron varios genes, procesos y vías interesantes, que parecen estar involucrados en la maduración "natural" temprana de la anguila y que pueden ser biomarcadores adecuados para las distintas etapas de este proceso. Sin embargo, se necesitan más estudios para evaluar el potencial como biomarcadores de estos genes, y si un tratamiento con agua de mar fría puede mejorar la respuesta de las anguilas europeas al tratamiento hormonal artificial, como sugieren los resultados. Para un análisis adecuado de los datos transcriptómicos, se creó un transcriptoma de anguila europea de novo. Se demostró que este transcriptoma de novo posee una superior integridad al genoma de anguila europea disponible 
y, por lo tanto, es una herramienta útil para el análisis adicional de genes específicos. Un análisis de este transcriptoma reveló un gran número de pares de genes parálogos, que mostraron una baja divergencia entre secuencias sinónimas. Entre las hipótesis potenciales sobre el origen de estos pares de genes parálogos, la hipótesis de una duplicación del genoma completo $4 \mathrm{R}$ se encuentra entre las más parsimoniosas. Varios de estos genes duplicados están involucrados en la reproducción y el inicio de la pubertad. Independientemente del origen, un análisis más profundo de estos genes puede revelar adaptaciones específicas de la anguila, lo que podría ayudar a comprender mejor el sistema reproductivo excepcional de las anguilas.

\subsection{Resum}

Com a espècie de renom culinari que pertany a un dels llinatges teleostis més antics, amb un cicle vital misteriós, un potencial d'aqüicultura excepcional, i una tradició pesquera a gairebé tots els països d'Europa, l'anguila europea posseeix un enorme valor socioeconòmic. No obstant això, aquest valor només fa que augmentar la preocupació de la seva població, que actualment es troba catalogada com "en perill crític d'extinció". Atès que el cicle de vida de les anguiles encara no ha estat tancat en captivitat, l'espècie no serà salvable en el cas que s'extingeixi en estat natural, per la qual cosa tancar el cicle de vida d'aquesta espècie ha estat l'objectiu final de diversos grups d'investigació durant els últims anys.. No obstant això, i malgrat la investigació científica de qualitat duta a terme des de la dècada de 1930, encara hi han diversos aspectes de la maduració de les anguiles -com el mecanisme que bloqueja la maduració sexual de l'anguila a l'etapa pre-puberal en captivitat- que son poc coneguts en l'actualitat. Per tal d'ampliar els coneixements sobre la reproducció de les anguiles i aconseguir un progrés substancial, aquesta tesi es va dur a terme amb l'objectiu específic de desenvolupar mètodes innovadors per a la inducció de la 
maduració de l'anguila europea, a més de afegir-hi el coneixement en els processos de maduració bàsics d'aquesta espècie.

Els procediments hormonals utilitzats actualment per a la maduració artificial de l'anguila europea no acaben d'induir el procés de maduració natural tal i com probablement es dóna a la natura. Doncs, en primer lloc, aquesta tesi va avaluar el potencial d'hormones recombinants específiques d'anguila europea per induir un procés de maduració molt més natural. Aquest estudi específic va mostrar que mitjançant estes gonadotropines específiques d'anguila europea és possible induir l'espermatogènesi i l'espermiació completes. Tot i que els resultats van mostrar que la qualitat dels gamets va ser inferior als resultats que generen els protocols establerts fins ara amb un altre tipus d'hormones (generalment d'origen humà), la utilització d'hormones recombinants específiques es presenta amb un gran potencial per a la seva implementació futura en la inducció de la maduració sexual de l'anguila europea, ja que l'estudi va generar noves idees sobre l'efecte de les gonadotropines l'eix BPG de l'anguila europea.

En segon lloc, i treballant amb la hipòtesi que un tractament tèrmic adequat pot reduir o substituir parcialment els tractaments hormonals estàndards per a la maduració sexual de l'anguila europea, en aquesta tesi es va provar l'efecte de diversos règims tèrmics (sense administració d'hormones) en l'eix BPG dels mascles europeus pre-puberals amb l'objectiu de millorar la qualitat i / o quantitat dels gamets. Els resultats mostraren clarament que un tractament d'aigua de mar de 2 setmanes a baixa temperatura $\left(10^{\circ} \mathrm{C}\right)$ va afectar l'eix BPG dels mascles europeus d'anguila. Resultats més específics van mostrar un augment de la sincronització de les espermatogonies, elevats nivells plasmàtics de testosterona i 11-ketotestosterona, una agrupació de mostres de transcriptoma de l'eix BPG del grup tractat amb aigua de mar freda i, possiblement, un augment dels nivells de la proteïna de la subunitat $\beta$ de la 
hormona luteinitzant de la hipofisi. Els gens transcrits diferencials van al-ludir a diversos gens, processos i vies interessants, que semblen estar implicats en la maduració inicial de l'anguila "natural" i podrien resultar biomarcadors adequats per a les etapes d'aquest procés. No obstant això, es necessiten estudis addicionals per avaluar el potencial dels biomarcadors d'aquests gens $\mathrm{i}$, de manera complementària, comprovar si un pre-tractament d'aigua de mar freda pot millorar la resposta de les anguiles europees a un tractament hormonal artificial, com suggereixen els resultats.

Finalment, amb l'objectiu de fer un anàlisi adequat de les dades transcriptòmiques, es va utilitzar el transcriptoma de novo d'anguila europea. S'ha demostrat que aquest transcriptoma té una integritat superior al genoma europeu disponible de l'anguila i, per tant, pot ser una eina útil per a l'anàlisi posterior de gens específics. L'anàlisi d'aquest transcriptoma va revelar un gran nombre de parells de gens paralògics, que mostraven una divergència baixa de seqüències. Entre les hipòtesis potencials sobre l'origen d'aquests parells de gens paralògics, la hipòtesi d'una quarta duplicació del genoma (4R) es troba entre les més parsimonioses. Atenent a aquesta hipòtesi, diversos d'aquests gens duplicats estarien implicats en la reproducció i l'aparició de la pubertat. No obstant això, i independentment de l'origen, l'anàlisi posterior d'aquests gens podria revelar adaptacions específiques de l'anguila, que podrien ajudar a entendre millor l'excepcional sistema reproductiu d'aquesta espècie. 


\section{GENERAL INTRODUCTION}

\subsection{European eel life cycle}

Reproduction of the European eel (Anguilla anguilla L., 1758) has been a source of wondering for millennia, with the first text hypothesizing about the phenomenon dating back to 350 B.C. The author of this text, Aristotle, hypothesized that eels spontaneously came to be from the mud during rain (Aristotle 1910). Centuries later, in 23 A.C., a new hypothesis was proposed in which adult eels would rub their skin against rocks, and the new generation would emerge from the pealing pieces of eel skin (Elder 1855). Although seemingly silly, these hypotheses were scientifically sound, as they concurred with the experimental data available at the time. In particular, the immature gonad of eel was not known until discovered by Syrski in 1874, who consequently named the organ. Furthermore, these hypotheses had not been experimentally opposed, as other means of reproduction had not been observed for eels. Today more experimental data and observations are available. However, these still paint the picture of the European eel as a unique fish with a complex and mysterious lifecycle.

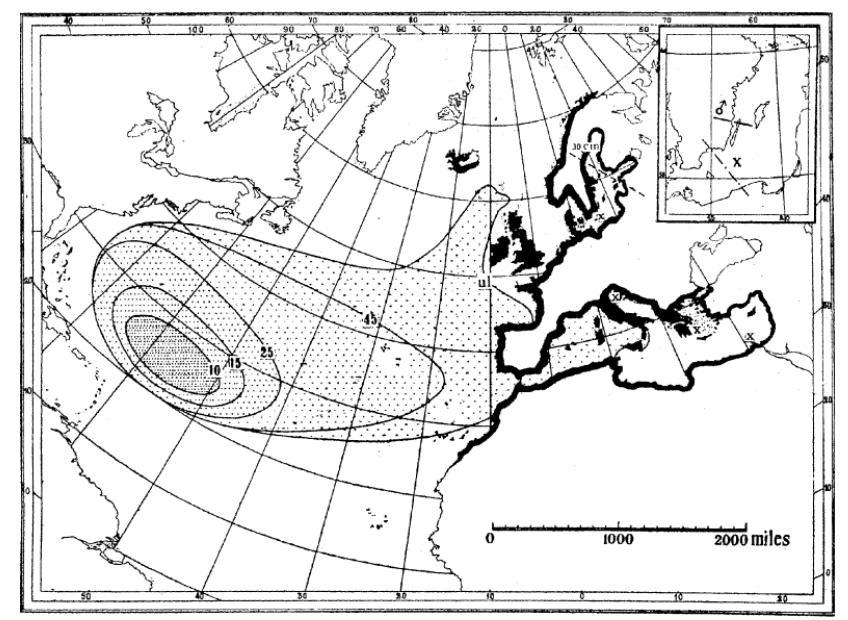

Figure 1. Distribution patterns of eel larvae with the size of the larvae in $\mathrm{mm}$, from Schmidt (1923) 
The catadromous European eel is believed to hatch and begin its journey at $\sim 200$ $m$ depth under the seaweed islands of the Sargasso Sea (Fig. 1). This hypothesis is based on the pioneer observations of the Danish explorer Johannes Schmidt (Schmidt 1923) who caught European eel larvae in the open Atlantic Ocean and by larvae size distribution determined their origin to the Sargasso Sea. However, no spawning adult European eel or European eel eggs have been caught in the Sargasso Sea. From laboratory hatching experiments the newly hatch larvae have been observed. These look like an oil droplet with a tail, presenting no clear eye or mouth (Sørensen et al. 2016). In the wild, it is believed that these larvae will be passively transported by the Gulf Stream towards Europe. Within a few days ( $\sim 3$ days) the oral opening of the larvae will appear and after $\sim 14$ days the larvae will be capable of feeding (Sørensen et al. 2016), although first feeding has not been observed before day 16 (Butts et al. 2016). The natural diet of these larvae is unknown, and their teeth seem unpractically large and are protruding out from the mouth (Fig. 2).

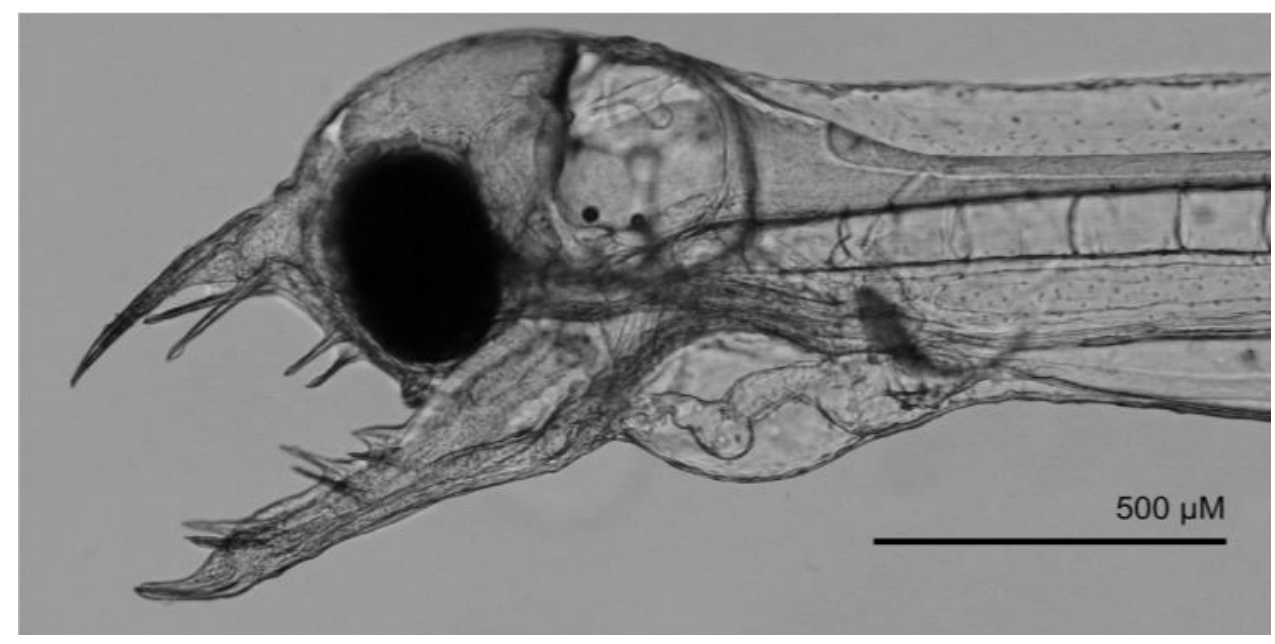

Figure 2. Lateral view of head morphology of European eel larvae at 40xmagnification. 12 days post-hatching. Scale bar: $0.5 \mathrm{~mm}$. Picture is modified from Sørensen et al. (2016). 
Together with the odd teeth, the bite force and gape of these larvae further seem to limit even the hypothetical food sources such an animal could ingest (Bouilliart et al. 2015).

Hereafter, the larvae are believed to transform into the leptocephalus larvae stage. At this stage the body shape of the larvae vastly changes, it becomes laterally compressed and sagittally elongated, resembling a willow leaf drifting with the current. This larval stage was once believed to be a species of its own and it was only after the Italian scientists Giovanne Battista Grassi and Salvatore Calandruccio brought some of these specimens home and observed their transformation in the lab that it was discovered that they, in fact, were European eels (Grassi 1896). The time it takes these larvae to reach the European cost has been yet another topic of controversy (Bonhommeau et al. 2010) as some estimates indicate a journey of fewer than 10 months (Lecomte-Finiger 1994), while others indicate that it takes more than 2 years (Bonhommeau et al. 2009; Martin et al. 2010) for the leptocephalus to reach the coastal waters of Europe and North Africa. Regardless of their age, the larvae here undergo yet another metamorphosis in which they gain the classic eel body shape, although without pigmentation (Tesch 2003; Fig. 3).

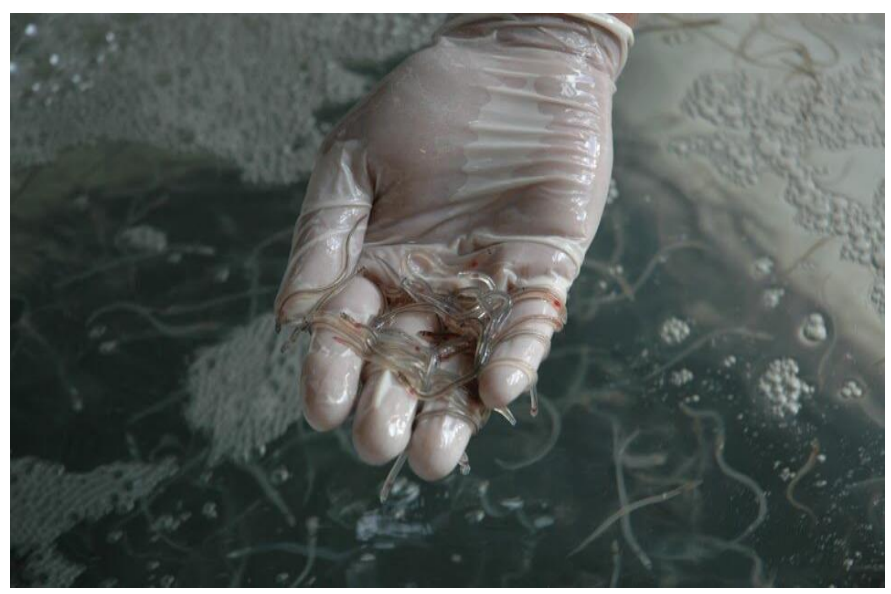

Figure 3. Glass eels of European eel in latex glow covered human hand. The picture was taken by Dr. Victor Gallego of ICTA. 
These transparent eels are called glass eels and are the seed for most inland aquaculture production. The glass eels migrate into coastal water and estuaries mostly from mid fall to mid spring. Here they gain pigmentation and become elvers which then migrate further into coastal freshwaters where they feed and grow. Larger elvers gain a yellow ventral site and are thus named yellow eels. As yellow eels, they can reach the most remote lakes and streams, where they undertake a sedentary grow out phase. This phase commonly lasts 2-25 years (Tesch 2003); however, specific individuals have been observed to stay for more than 50 years in poor growing conditions, and more than 150 years if migration is obstructed (https://www.smithsonianmag.com/smart-news/rip-worldsoldest-eel-180952306/). At the end of the growth phase, the yellow eels start their descent towards the coastal waters and undertake yet another metamorphosis-like event called silvering. Along with other changes, this transformation turns their ventral side white or silver, and their dorsal side turns darker. Silvering is a process related to puberty, which along with some sexual maturation prepares the eels for their oceanic migration (Aroua et al. 2005). This preparation for the oceanic migration includes enlargement of the eyes and degeneration of the digestive tract since eels do not feed during migration. The migration itself is among the longest in the animal kingdom, stretching more than $5000 \mathrm{~km}$ if the shortest possible route is considered. Recent satellite tag studies have, however, generated evidence that the eel rarely takes the shortest route, and some individuals have been registered to have covered more than $6900 \mathrm{~km}$ before they reached the midway point on the way to the Sargasso sea (Righton et al. 2016). Additionally, the eels undergo daily vertical migrations of $\sim 500 \mathrm{~m}$. As different eel species appear to swim deeper during full moon than during new moon (Chow et al. 2015; Schabetsberger et al. 2013), this behavior is likely an attempt to minimize the light environment as this may affect important reproductive hormones (Liu et al. 2014; Burgerhout et al. 2018) or simply minimize the chance of being spotted by predators (Righton et al. 2016; 
Wahlberg et al. 2014). However, the daily vertical migration could also be implemented as a mean of controlling the thermal environment as eel at later stages of migration appear to dive even deeper during the day, where they reach similar temperatures $\left(\sim 10{ }^{\circ} \mathrm{C}\right)$ as those experienced during early migration (Wysujack et al. 2015). This behavior may explain peculiar early findings, that eel eyes not only increase before migration but continues to increase during migration and maturation (Boëtius and Boëtius 1967 and Chapter 1). Moreover, the behavior to favor darkness seems to start with migration, since eels have been hypothesized to only migrate during the darkness of night and not migrate if the water is too shallow for them to find darkness in the depths (Lennox et al. 2018). Although the entire migration can be covered by the eels in 6-7 months, the satellite data suggests that some eels simply give up on reaching the spawning ground in time for the coming spawning season and slow down as to arrive for the spawning of the following season (Righton et al. 2016). At the end of the tremendous migration, the adult European eels are believed to die after securing the next generation through spawning. As spawning of European eels has never been observed in the wild this process is largely unknown. However, spawning is possibly synchronized by the moon phases in related eel species (Tsukamoto et al. 2011), and genetic data strongly suggest that eels spawn in panmixia (Palm et al. 2009; Als et al. 2011; Pujolar et al. 2014), which technically leaves all European eels from North Africa to Iceland part of one single population.

\subsection{Current status of the European eel}

In the year 1085 the first Normand king of England ordered a survey of all taxable properties from all landowners in his kingdom. The results filled a book today known as "the Domesday book". From this book, eel catches have been estimated to potentially exceeding 500 tons from only a portion of England (Dekker and Beaulaton 2015). Although large uncertainty is associated with 
these numbers, it is highly likely that the total catches of adults eels far exceeds recent catches from the area of 30 tons (Dekker and Beaulaton 2015). Similarly, between 1574 and 1582, under the reign of King Philip II, questionaries regarding the wealth, means, and history of the people was distributed through central Spain (Clavero and Hermoso 2015). From these questionaries $66.8 \%$ of freshwater fisheries accounts included eels. Today eels have completely disappeared from the vast majority of this area (Clavero and Hermoso 2015). Thus it seems eels have been extremely aboundant in Europe through history and the eel stock has likely declined gradually for centuries (Dekker and Beaulaton 2015). However, the common consensus of a declining eel stock was not held until after the glass eel crash of 1980 (Dekker and Beaulaton 2015). Due to the long life history, large body, late maturation, long reproductive migration and semelparous nature of the European eel, it is particularly vulnerable to anthropogenic intervention, and thus the glass eel recruitment crash is likely a result of anthropogenic factors. This is further supported by the wide array of exploitation means currently in action, as such the European eel are being fished in fresh, brackish, and coastal waters and in all life stages from glass eels to silver eels (Dekker 2004, 2000). Furthermore, other factors such as the construction of hydropower plants also constitute a major threat to the European eel. Currently, the European eel is considered critically endangered (Jacoby and Gollock 2014). In 2009 the glass eel recruitment indices were reported to be below $5 \%$ of the levels from the 1960s and 1970s in Europe, and less than $1 \%$ in the North Sea (Dekker and Beaulaton 2015). Due to the troubling state of the eels, large conservation initiatives were launched, e.g. the European Council Regulation (EC) 1100/2007. This Regulation requires EU member states to produce and implement eel management plans, which should raise the minimum escapement of eels to $40 \%$ of the levels estimated to be the case in the absence of an anthropogenic impact. Although the regulation has been implemented since 2009 , only 16 out of the 76 eel management units of the EU 
have managed to live up to the requirements (ICES 2018). However, potentially as a result of these efforts, the recruitment has increased in the past years, although still remaining between 2 and 10\% (ICES 2018). Greater improvement has been seen for yellow eel recruitment which has risen to $29 \%$ of the levels of the 1960s and 1970s (ICES 2018); however, these improvements are not enough for the eel to be classified as simply endangered.

\subsection{Phylogeny of the freshwater eels}

The European eel is a species of the Anguillidae family commonly referred to as freshwater eels. These are part of the Anguilliform order, which in turn are part of the Elopomorpha cohort (Applegate et al. 1967), which all share the leptocephalus larval stage (Chen et al. 2014). The freshwater eel family has been suggested to originate about 20-50 million years ago (Minegishi et al. 2005) it includes 19 species and subspecies, which are distributed over tropical, subtropical and temperate areas. The phylogeny of the eels, like its reproduction, have been quite a conundrum, with the predominantly selected hypotheses changing until recent years. In 2010 a hypothesis was proposed that the freshwater eels originated from a deep-sea ancestor (Inoue et al. 2010) and in 2011 a new common ancestor was found for the anguilliforms (Johnson et al. 2011). As late as 2015 it was commonly accepted that the clade of the freshwater eels, the Elopomorpha clade, was among the most basal note of the teleosts tree with the Osteoglossomorphas clade branching off at a later stage from the remaining teleosts. However, as omics results have become more frequent, this hypothesis has been challenged and newer studies based on more data now more often supports the hypothesis that Elopomorphs and Osteoglosomorphas branched of together as one of the most basal teleosts clades and only later formed sister clades (Bian et al. 2016; Ravi and Venkatesh 2018; and Chapter 3). In all cases, the Elopomorphs are among the most basal 
teleosts and studies of these fish may thus provide insights into the ancestral regulatory functions of teleosts.

\subsection{Teleost reproduction with an eel focus}

\subsubsection{Spermatogenesis}

Spermatogenesis is the process in which primordial germ cells differentiate and proliferate to form spermatozoa, and it is controlled by Sertoli and Leydig cells (Schulz et al. 2010). The process starts at a stage of spermatogonial renewal in which primordial germ cells or spermatogonia (SPG) proliferate or differentiate. Each SPG cell is surrounded by the extensions of a single Sertoli cell. The most undifferentiated SPG cells are called undifferentiated SPG type A (SPGAund) cells. Those SPGAund cells which proliferate assure the next generation of germ cells while those SPGAund cells which differentiate start the developmental process to become spermatozoa. Two types of SPGAund can be distinguished; however, it is unclear whether they possess different stem cell potential or simply are different phenotypes of the same cell type (Schulz et al. 2010; Fig. 19 Chapter 2).

Development of SPGAund creates differentiated SPG type A (SPGAdiff) cells, which occur during a stage of spermatogonial proliferation, where the number of SPG can be multiplied many fold (Schulz et al. 2010). Due to this proliferation SPG cell now appears in cysts of multiple cells. Each cyst is surrounded by the extensions of one Sertoli cell, and all cells within one cyst differentiate synchronously. SPGAdiff cells then differentiate into early SPG type B (early SPGB) cells, which is the most differentiated stage found in captive European eel males due to a neuroendocrine blockage of puberty which effects all eels (Vidal et al., 2004). In teleosts, early SPGB cells differentiate into late SPGB cells which in turn differentiate into spermatocytes. This change is further the last mitotic 
stage of spermatogenesis, and primary spermatocytes thus differentiate into secondary spermatocytes and further into haploid spermatids through meiosis. Spermatids are still classical round cells; however, these are the cells which can form a condensed nucleus/head, and a flagellum to become immotile spermatozoa, in the process called spermiogenesis (Aida and Tsukamoto 2003).

\subsubsection{The brain of the gonadotropic axis}

In teleosts, as in higher vertebrates, reproduction is controlled by the BrainPituitary-Gonad (BPG) axis. Here, the brain is responsible for gonadotropinreleasing hormone $(\mathrm{GnRH})$ release along with other inhibitory or stimulatory factors (Zohar et al. 2010; Lethimonier et al. 2004). One such stimulating factor is kisspeptin, which specifically has been shown to be involved in the onset of puberty, through its regulation of gonadotropins from the pituitary (Roa et al. 2008) and GnRH from the brain (Zohar et al. 2010). Specifically, in European eel 3 kisspeptin receptors have been shown to be differentially expressed in the BPG axis during maturation (Pasquier et al. 2012). Therefore, kisspeptine may be an important piece in the puzzle of eel reproduction. One of the most important inhibitory factors released by the teleost brain is dopamine (DA), which is seen as the counteraction of $\mathrm{GnRH}$. In particular, DA has been shown to drive an inhibitory control of gonadotrope activity (Peter et al. 1986; Vidal et al. 2004; Dufour et al. 2005), especially at later stages of maturation. Specifically, this inhibition may be projected through the inhibition of luteinizing hormone (Lh) release (Dufour et al. 2010). DA inhibition of maturation has been shown to be especially strong in cyprinids (e.g. Cyprinus carpio; Yaron 1995), catfishes (e.g. Silurus glanis; Brzuska 2001), mullets (e.g. Mugil cephalus; Aizen et al. 2005) and eels. Different from other teleosts, DA appears to inhibit maturation at an earlier stage in eels and possibly induce an effect which is much harder to overcome (Dufour et al. 1988, 2005, 2010; Vidal et al. 2004). This was shown through experimental injections of $\mathrm{GnRH}$ and androgens which commonly are sufficient 
to induce early stages of maturation in teleosts (Crim and Evans 1983; Holland et al. 1998; Kumakura et al. 2003). However, in eels, a DA antagonist was also needed (Dufour et al. 1988, 2005; Vidal et al. 2004). Therefore, DA tone is commonly seen as the key factor of the neuroendocrine blockage that inhibits progression of puberty in eels. In this regard eel males and females have shown some differences. In particular, in males, a low gonadotrophic release has been seen without the administration of a DA antagonist (Olivereau et al. 1986; Palstra et al. 2008). Although, Kagawa et al. (2009) observed that GnRHa did not affect maturation (i.e. no increase of GSI) in farmed male Japanese eels (Anguilla japonica). These results thus suggest a weaker DA inhibition in eel males compared to female although ultimately puberty is blocked by dopamine in male eels as well. As triggers for maturation are likely similar between eel sexes, eel males can be seen as a preferred model to test various factors on eel maturation.

\subsubsection{The pituitary of the gonadotropic axis}

When not inhibited by DA, GnRH stimulates gonadotropin [Lh and folliclestimulating hormone (Fsh)] production from the pituitary (Burns and Matzuk 2002). In semelparous teleosts, like salmonids (e.g. Oncorhynchus mykiss), Fsh is often found in high concentrations at early maturational stages (Gomez et al. 1999; Schulz et al. 2010) while Lh is often found in higher concentrations at later stages (Gomez et al. 1999; Schulz et al. 2010). However, in multiple spawners e.g. European sea bass (Dicentrarchus labrax; Mateos et al. 2003), red seabream (Pagrus major; Gen et al. 2000), goldfish (Carassius auratus; Kobayashi et al. 1997), the blue gourami (Trichogaster trichopterus; Jackson et al. 1999), and the Japanese flounder (Paralichthys olivaceus; Kajimura et al. 2001b) Fsh and Lh release follows specific and synchronized projections during spermatogenesis. In artificially matured eel males and females, $I h b$ and $f s h b$ have been shown to be differentially transcribed in the pituitary during gametogenesis (Schmitz et al. 2005; Peñaranda et al. 2010b; Yoshiura et al. 1999; Jeng et al. 2007; Saito et al. 
2003). Generally, an early maximum in $f s h b$ and a late maximum of $/ h b$ is observed (Schmitz et al. 2005; Peñaranda et al. 2010b; Yoshiura et al. 1999; Jeng et al. 2007; Saito et al. 2003). However, the respective projection of eel Fsh and Lh might be more complex than simply decrease of Fsh and increase of Lh. In particular, a local peak of Fsh has been observed in European, Japanese, and marble (Anguilla marmorata) eel females around the mid-vitellogenic stage (Schmitz et al. 2005; Huang et al. 2009; Saito et al. 2003; Pérez et al. 2011). Furthermore, increasing Fsh levels, until the mid-vitellogenic stage, have also been seen in Japanese conger (Conger myriaster) and New Zealand longfinned eels (Anguilla dieffenbachii) during their natural maturation (without hormonal injections; Saito et al. 2003; Kajimura et al. 2001a). In male European eels, this phenomenon was not observed (Peñaranda et al. 2010b). Similar but opposite projection are also seen for Lh as the generally increasing tendency seems to slow down or even decrease around the mid-vitellogenic stage or midspermatogenesis in European, Japanese, and marble female eels, and European eel males (Schmitz et al. 2005; Saito et al. 2003; Huang et al. 2009; Peñaranda et al. 2010b).

\subsubsection{The gonad of the gonadotropic axis}

After secretion from the pituitary, Lh and Fsh are transported by the bloodstream to the gonad where they can activate their respective membrane receptors (Fshr and Lhr). Most commonly Fsh will regulate Sertoli cell activity involved in gametogenesis, while Lh regulates Leydig cell steroidogenesis (Schulz et al. 2010). However, these common gonadotropin functions in the gonads are not the entire picture as teleost Leydig cells have also been shown to express Fshr and Fsh have been shown as a steroidogenic hormone (García-López et al. 2009; Ohta et al. 2007; Zmora et al. 2007). Furthermore, Lh has been shown to stimulate Fshr in some teleosts (Bogerd et al. 2001; So et al. 2005; Chauvigne et al. 2012). Indeed, both gonadotropins have been shown to induce testosterone 
$(\mathrm{T})$ and 11-ketotestosterone $(11 \mathrm{KT})$ production from testes of eel males (Kazeto et al. 2008; and Chapter 1).

\subsubsection{The steroids of the gonadotropic axis}

The BPG-axis possibly also include mechanisms of self-regulation since a feedback mechanism of steroids on gonadotropins are seen in teleosts (Planas and Swanson 1995; Amer et al. 2001). In particular, in eels, androgens have been shown to stimulate $/ \mathrm{hb}$ transcription (Huang et al. 1997) and suppress fshb (Aida and Tsukamoto 2003) from the pituitary (Schmitz et al. 2005).

However, the main function of steroids resulting from the gonadotropin activation is to drive the further development of the teleostean gonad, possibly in coorperation with a variety of growth factors (Schulz et al. 2010). In particular, T has been shown to increase in the plasma during maturation of teleost males (Fostier et al. 1983). However, in eels, an early (1-4 week) maximum of T plasma levels are seen followed by gradual decreases through artificial maturation (Peñaranda et al. 2016a; Khan et al. 1987; Peñaranda et al. 2010b). In the enzymatic process of DA synthesis, the protein tyrosine hydroxylase (TH) is likely the bottleneck enzyme in teleosts (Weltzien et al. 2006), and TH transcription is thus often used as an indicator of DA tone. Interestingly, increase in Thas been shown to upregulate TH specifically in European eel brain and pituitary, and in the brain of Japanese eel, a relatively low aromatase level has been shown, indicating that even a low T level could result in significant effects (Jeng et al. 2005). Therefore, T might also be involved in the inhibition of maturation in eels (Weltzien et al. 2006).

Another important androgen is $11 \mathrm{KT}$, which is a major androgen in teleost species. $11 \mathrm{KT}$ is produced by Leydig cells and can possibly activate Sertoli cells, which play a major role in spermatogenesis (Miura et al. 1991c). 11KT has been 
shown to increase in concentration during silvering of Japanese and European eel (Sudo et al. 2012; Lokman and Young 1998) and to reach maximum plasma levels early during artificially induced testicular development of European eel, often reaching levels of $\sim 100 \mathrm{ng} / \mathrm{ml}$ (Khan et al. 1987; Peñaranda et al. 2016a). Furthermore, $11 \mathrm{KT}$ has been shown to induce increases in GSI and eye index in both female Japanese and shortfinned New Zealand eel (Anguilla australis; Setiawan et al. 2012; Sudo et al. 2012). Interestingly, in male Japanese eels 11KT has been shown to induce the complete spermatogenesis in vitro (Ohta et al. 2007; Miura et al. 1991b) and 11KT is thus considered the major androgen for eel testis development. However, these results could not be reproduced in vivo in shortfinned New Zealand eel (Lokman et al. 2016). Although estrogens and specifically estradiol-17 (E2) are commonly associated with female vertebrates, it has shown strong presence and importance in male teleost as well (Miura et al. 1999; Amer et al. 2001). As seen for T, E2 also increased in European eel males as a response to saltwater acclimation (Morini et al. 2017b), and T and E2 have been shown to affect GnRH levels in European eel brain and pituitary (Montero et al. 1995). In Japanese eels, E2 has been shown to stimulate mitotic divisions in the testis and thus induce spermatogonia stem cell renewal (Miura et al. 1999). Miura et al. (1999) further showed that Sertoli cell in Japanese eel testis expresses E2-receptors and thus hypothesized that the effect of E2 is mediated through these cells. E2 was only able to induce mitosis and not meiosis and was thus hypothesized mainly to be important at early development (Miura et al., 1999). The effect of E2 was seen at concentrations as low as $10 \mathrm{pg} / \mathrm{ml}$ in vitro, which is very low compared to the main androgen $11 \mathrm{KT}$, which only showed an effect at $10 \mathrm{ng} / \mathrm{ml}$ (Miura et al. 1991b). Furthermore, Miura et al. (1999) demonstrated that the renewed spermatogonia stem cell produced after E2 stimulation was able to differentiate fully into spermatozoa after the introduction of $11 \mathrm{KT}$. 


\subsection{Artificial manipulation of teleost sexual maturation}

Fish maturation is commonly manageable simply through regulating the housing environmental conditions (Bromage et al. 2001; Mañanós et al. 2009). In particular, light and temperature regimes are commonly used to induce fish maturation. However, for many economically important aquaculture species, reproductive challenges hinder large scale propagation (Mylonas et al. 2010; Duncan et al. 2013). In many cases, these challenges can only be overcome with the administration of exogenous hormones (Mylonas et al. 2017). The purpose and effect of the hormonal treatments applied varies greatly among fish species, from improved seminal volume as seen in catfishes (Siluridae sp.; Cacot et al. 2003; Viveiros et al. 2002), to activation of the complete processes as seen in eels (see section below) and golden rabbitfish (Siganus guttatus; Komatsu et al. 2006). Although, in some species Fsh has been shown to induce the full process of spermatogenesis and spermiation (Mazón et al. 2014; Zhang et al. 2015a; Chu et al. 2015), most hormonal treatments have used Lh preparations, which acts on the gonad level or GnRH's, which have the effect of Lh release from the pituitary (Mylonas et al. 2017). A commonly used Lh preparation is pituitary extracts (PEs) from spawning fish (commonly carp or salmon). These contain many unknown compounds; however, mainly Lh and to a lesser extent Fsh (Mylonas et al. 2017). Pituitary extract has been widely used to enhance fish maturation e.g. in common tench (Tinca tinca; Linhart et al. 1995), common bream (Abramis brama; Kucharczyk et al. 1997), European catfish (Silurus glanis; Linhart et al. 2004), streaked prochilod (Prochilodus lineatus; Viveiros et al. 2010) and many others (Mylonas et al. 2017). However, since pituitary extracts may vary in concentration of hormones and since the exact cocktail of included compounds is not known these treatments sometimes produces variable results

(Le Gac et al. 1993; Cyr and Eales 1996; Negatu et al. 1998). Therefore, purified hormones or recombinant hormones are often preferred when available. One 
of the most widely used purified hormones is of mammalian origin namely human chorionic gonadotropin (hCG; Mylonas et al. 2017), which is purified from the urine of pregnant human women. hCG is an Lh analog (Mylonas et al. 2017) and the effect of hCG I plausibly mediated through an Lh receptor since these have been shown to be activated by hCG (Mcfarland et al. 1989; Kwok et al. 2005). Subsequently, hCG has been shown to induce steroidogenesis in catfish through activation of Lhr (Kumar et al., 2001). hCG further has the advantages of a long half-life in circulation (Ohta and Tanaka 1997), rapid response in the gonad, and its availability world-wide due to it being used in assisted reproduction of humans.

The use of recombinant gonadotropins has recently gained attention. As species-specific variations of gonadotropin functions (Gomez et al. 1999; Mateos et al. 2003) and sequence exist between teleosts (Levavi-Sivan et al. 2010), recombinant homologous gonadotropin injections may give superior results to pituitary extract injections in any given species. Recombinant proteins are produced through the cloning of the DNA sequence of the protein into a vector. This vector is then transfected into a selected host organism or cell type, which then produces the protein. Most hormone proteins are glycoproteins, and correct glycosylation is required for the correct function of the hormone. Therefore, mammalian cells are often preferred as host cells for hormone production as these have the most sophisticated glycosylation mechanism (Demain and Vaishnav 2009). Recombinant gonadotropins have been successfully produced and used via injection for zebrafish (Danio rerio; So et al. 2005), channel catfish (Ictalurus punctatus; Zmora et al. 2007) goldfish (Hayakawa et al. 2008b), European sea bass (Molés et al. 2011b), Senegalese sole (Solea senegalensis; Chauvigné et al. 2012) and others (Mylonas et al. 2017). Although the stimulation of these recombinant gonadotropins of their respective receptors was often more potent in vitro than in vivo. As such, 
recombinant hormones have a high potential for use in aquaculture, although procedures of both production and administration still need improvement (Mylonas et al. 2017).

\subsection{Recombinant hormones in Japanese eels}

In particular in the Japanese eel recombinant hormones have been substantially tested since 2003 (Kamei et al. 2003), with increasing success. In 2006, Kamei et al. injected Japanese eel males with recombinant Japanese eel Fsh, and thereby induced increased 11KT production and minor progression of spermatogenesis although the experiment only lasted 12 days (Kamei et al. 2006a). As a production organisms Kamei et al. used the yeast Pichia pastoris (Kamei et al. 2006a), this organism may not generate the optimal glycosylation of the proteins, which could be an important factor for correct gonadotropin function. In 2008, Kazeto et al. changed the host organism to Drosophila S2 cells and produced bioactive recombinant Japanese eel Fsh and Lh. These hormones were further tested for glycosylation and induced a strong reaction in vitro including increased $11 \mathrm{KT}$ and full spermatogenesis from both gonadotropins separately. However, little to no effect was observed in vivo, with slightly further developmental stages of spermatogonia observed in Fsh injected males. Kazeto et al. (2008) hypothesized that the differences between in vitro and in vivo result may be due to a short half-life of the hormones in vivo. Also in 2008, Hayakawa et al. had more success using recombinant goldfish Fsh and Lh, which were produced by the baculovirus-silkworm (Bombyx mori) larvae system. In particular, spermatogenesis was induced until the stage of spermatozoa in vivo in Japanese eels using only the recombinant goldfish Lh, although with only minor increases of GSI at the highest dosages and no spermiation was observed (Hayakawa et al. 2008b). The same production system (baculovirus-silkworm larvae) was later used to create Japanese eel specific gonadotropins, with similar results (Kobayashi et al. 2010). In particular, both gonadotropins induced 
spermatogenesis until spermatozoa; however, only minor increases in GSI and no spermiation was seen (Kobayashi et al. 2010). Full Japanese eel spermiation was recently achieved using injections of $500 \mu \mathrm{g} / \mathrm{kg}$ bodyweight recombinant $\mathrm{Lh}$, produced by $\mathrm{CHO}$ cells (Ohta et al. 2017), similar to the protocol described in Chapter 1. Ohta et al. (2017) further hypothesized that a possible reason for the poor in vivo results of previous experiments may be a high metabolic clearance of protein with a non-vertebrate type of glycosylation (Ohta et al. 2017).

\subsection{Artificial European eel maturation}

Eels in captivity do not spontaneously mature due to a dopaminergic blockage that inhibits the progression of puberty. Therefore, extensive hormonal maturation is needed for the eel to mature in captivity. Although European and Japanese eel are closely related and able to hybridize (Müller et al. 2018; Burgerhout et al. 2011), significant differences have been observed between these fish in their response to artificial hormonal maturation. E.g. European eels appear to show greater individual viability and a slower response to the hormonal treatment (Palstra et al. 2005; Pérez et al. 2009; Herranz-Jusdado et al. 2019). Furthermore, Japanese eel males appear to be more sexually advanced at the start of migration (Boëtius and Boëtius 1967). Nevertheless, researches working on the reproduction of these species have traditionally looked to one another for inspiration. In the early days of eel reproductive science, European scientist were ahead, since the first artificially matured European eel males were produced in the 1930s (Fontaine 1936), using intraperitoneal injections of urine from pregnant women, and the first sexually mature female European eel was produced in 1964 using carp PE (CPE; Fontaine et al. 1964). Meanwhile, the first artificial maturation of Japanese eel was attempted in the late 1960s. Hereafter the Japanese scientist advanced faster in their research and the first documented Japense eel egg fertilization was achieved in 1973 with the first larvae of Japanese eel obtained in the same year (Yamamoto and Yamauchi 
1974). These experiments utilized salmon PE (SPE) injections for female eel maturation and a combination of SPE and hCG for males. Learning from these milestone achievements the first documented fertilization of European eel eggs were achieved in 1980 (Boëtius and Boëtius 1980) using a combination of CPE and hCG twice a week, while the first European eel larvae in captivity were hatched in 1983 (Bezdenezhnykh et al. 1983). In these cases, however, the larvae died before the transition to the leptocephalus larval stage, possibly due to starvation. It took additionally almost 30 years for the breakthrough of successful exogenous feeding and metamorphosis into the leptocephalus stage of Japanese eel larvae, which was first achieved in 2001 (Tanaka et al. 2001). To induce female maturation they used SPE injections followed by a $17,20 \beta$ dihydroxy-4-pregnen-3-one (DHP) injection for ovulation induction, while the males were injected with hCG. The main achievement responsible for this milestone was the identification of a suitable pre-leptocephalus larvae food item, freeze-dried shark egg yolk, which was supplied to the larvae from 8 days post-hatching. From here on development accelerated as an F1 generation of glass eels were already acquired in 2003 (Tanaka et al. 2003), using the same hormonal treatments with the addition of an SPE primer $24 \mathrm{~h}$ before the DHP injection of the females. The pre-leptocephalus diet was also similar although including the additives: krill hydrolysate, soybean peptide, vitamins, and minerals. Finally, in 2010 the successful closing of the Japanese eel lifecycle was completed in captivity (Masuda et al. 2012).

Regarding the European eel, 30 years have already passed since the first successful production of larvae (Bezdenezhnykh et al. 1983); however, high variability in hormone response, fertilization, hatching, and larval survival rates are still the norm and the leptocephalus larvae stage has not been reached yet. This achievement may not be far away as European eel larvae production has steadily improved over the years and the first successful exogenous feeding of 
European eel larvae has been achieved (Butts et al. 2016). The current state-ofthe-art of European eel maturation involves a weekly intraperitoneal injection of recombinant hCG for the males (Asturiano et al. 2005, 2006; Gallego et al. 2012; Herranz-Jusdado et al. 2019). For females, weekly intraperitoneal injections of CPE or SPE are used, followed by a CPE or SPE primer when a significant weight increase is observed and oocytes biopsies show the appropriate oocyte stage (determined by lipid droplet size). Twenty-four hours after the priming a DHP induction of spawning is administered (F.G. da Silva et al. 2018). It should, however, be noted that a consensus of the exact protocol for European eel maturation has not been reached and variation is common between protocols of different research groups e.g. (Chai et al. 2010; Mordenti et al. 2012; Lokman et al. 2015; Di Biase et al. 2016; Kucharczyk et al. 2016; Vílchez et al. 2016). In particular, in some protocols spawning is induced by stripping, while other protocols allow for spontaneous spawning which often results in superior fertilization results (Di Biase et al. 2016). Furthermore, feminization of farmed broodstock by E2 administration through the diet, during the early growth phase, is sometimes used (Chai et al. 2010; Davey and Jellyman 2005) and pre- or co-treatment with androgens have been used in some eel species with success (Lokman et al. 2015; Mordenti et al. 2017; Di Biase et al. 2017).

\subsection{Natural eel sexual maturation factors}

As described above, eels can be artificially matured via hormonal injection; however, the procedures often results in high individual variation and low gamete quality (Durif et al. 2006; Kagawa et al. 2005; Pedersen 2004; Ohta et al. 2001; Burgerhout et al. 2018). Part of the explanation for the problems with artificial eel sexual maturation may be that the treatments do not exactly induce the natural maturation process. In particular, the hormonal induction of male eels sexual maturation, using hCG, likely bypasses the BPG-axis and works 
directly on the testis level (Boëtius and Boëtius 1967; Khan et al. 1987). Furthermore, pituitary extracts of other teleosts are unlikely to have exactly the same compound levels and efficiencies as eel pituitary compounds during natural eel maturation (Aida and Tsukamoto 2003; Mylonas et al. 2017). Previously, it has also been considered evidence of unnatural maturation of hormonally matured eels, that a discrepancy exists between observed batch spawning development of eel oocytes and a gonadotropin profile which indicates that eels should mature all gametes at once (Aida and Tsukamoto 2003). However, the capture of wild naturally matured Japanese eels also indicated the existence of polycyclic ovaries with the potential for multiple (group-synchronous) spawning (Ijiri et al. 2011). Therefore, in order to improve current artificial eel maturation protocols, either by lowering the total dosages of hormones needed or improving gamete quality and/or quantity, a more natural maturation should be desired (Ijiri et al. 2011; Gallego et al. 2012; Burgerhout et al. 2018). In this regard, it is likely that the right environmental conditions may be beneficial or even induce natural maturation as seen in many other fish species (Mylonas et al. 2010, 2017; Taranger et al. 2010; Wang et al. 2010; Duncan et al. 2013). Substituting some hormonal injections with simple environmental changes may; furthermore, lower the stress level induced in the fish during this procedure. Reduced stress is another commonly observed factor of improved reproductive success (Schreck 2010). Natural sexual maturation of eels likely happens during or after migration (van Ginneken et al. 2005; Palstra et al. 2010), therefore the environmental condition of the migration and spawning ground are good candidates to potentially induced sexual maturation of eels. Although final eel maturation likely happens after or at late stages of the reproductive migration (van Ginneken et al. 2005; Palstra et al. 2010), earlier stages of eel maturation might be induced by environmental conditions of earlier stages of migration (Bast and Klinkhardt 1988). Each of these maturational stages could be more susceptible to artificial hormonal maturation 
than the previous. E.g. even the progression through the proposed 5 freshwater eel stages, from yellow eels to migratory silver eels, are associated with maturational progression (Durif et al. 2005) and eels which have progressed further towards silvering have been shown to be better responders for artificial hormonal maturation (Aroua et al. 2005; Durif et al. 2006; Mordenti et al. 2013; Dirks et al. 2014; Burgerhout et al. 2016). Furthermore, different Anguilla species are found to show different stages of maturation at the initiation of migration (Durif et al. 2005; Hagihara et al. 2012; Lokman et al. 1998; Lokman and Young 1998). These observations support the hypothesis that eel maturation progresses through different stages from the onset of migration.

In line with the above mentioned views, several environmental factors have been proposed to affect eel maturation. E.g. since eels are believed not to feed during migration and are commonly not feed during artificial maturation the nutritional condition of pre-maturation eels have been suggested as a factor which may influence eel maturation. Nutritional status has been observed to influence fertility in animals for more than a century (Darwin 1859) and it is likely a natural cue on which eels bases their individual decision of initiating migration (Durif et al. 2005). Therefore, this factor has received some attention in the field of eel reproduction (St øttrup et al. 2013; Baeza et al. 2014, 2015a; da Silva et al. 2016; Støttrup et al. 2016). In particular, da Silva et al. (2016) showed that dietary fatty acids can influence gonadal development and individual eels response to hormonal treatment (Baeza et al. 2015a; da Silva et al. 2016). Additionally, another factor which might influence eel maturation is the fasting itself, which is commonly assumed to occur naturally during migration and thus be beneficial for artificial eel maturation. However, experiments in which feed was offered to maturing broodstock, no clear disadvantages were observed in the resulting maturation (Mordenti et al. 2012), and the fasting state of artificially maturing eels could thus be reconsidered. 
After maturing to the silver eel stage, eels start their reproductive migration (Durif et al. 2005), which in most cases starts during autumn. An effect of the time of year of maturation was seen in some of the earliest studies of eel reproduction (Boëtius and Boëtius 1967), and this factor may thus be important for eel maturation although until today this factor has not received a lot of attention.

Another environmental factor which might influence eel maturation is the light regime. During continental migration, eels appear to prefer low light environments (Righton et al. 2016; Aarestrup et al. 2009; Wysujack et al. 2015; Lennox et al. 2018; Chow et al. 2015). Based on this behavior it has been suggested that light should be considered as a factor involved in eel maturation and even the earliest documented eel reproduction experiments hypothesized about the importance of light for eel maturation (Fontaine 1936). So far, a few experiments have been conducted on this environmental factor e.g. Boëtius and Boëtius (1967) showed that maturation will progress normally with standard hormonal injections at all tested light regimes. More interestingly, however, Parmeggiani et al. (2015) showed increased E2 and T levels, and increased GSI in eel kept in a dark environment (Parmeggiani et al. 2015) and Mordenti et al. (2012) showed that eels kept in darkness, matured earlier, and with a higher success rate than eels kept in a 14:10 light cycle. In fact 4 out of 4 eels kept in complete darkness ovulated in this study (Mordenti et al. 2012), which is impressive compared to the maturation rates of other studies (Pedersen 2004; Kagawa et al. 2005; Palstra et al. 2005). Molecularly there is some support for the importance of the light environment on eel reproduction, although opposite to what the results indicate. In particular, melatonin which is released during low light regimes (Falcón et al. 2010; Saha et al. 2018; Zohar et al. 2010) have been shown to upregulate $\mathrm{TH}$, and downregulate $f s h b$ and $L h b$ transcription in European eels (Sebert et al. 2008). These results were further followed by 
decreasing steroid levels, thus it appears plausible that high melatonin levels are a strong reinforce of the DA block of European eel puberty (Sebert et al. 2008). Therefore, it appears that more light rather than less light might release the DA blockage of eel maturation trough decreased melatonin secretion (Burgerhout et al. 2018).

Later, during migration, eels enter marine waters and thus experiences a drastic change in salinity of their environment. The transition from freshwater to saltwater has been shown to induce several maturation associated factors. E.g. increased eye size even compared to hormonally injected eels (Nowosad et al. 2014). Furthermore, increased GSI and oocyte diameter, and faster response to hormonal treatment was observed in Japanese eels after 3 months of saltwater rearing (Kagawa et al. 1998). Additionally, fshb and E2 are often observed to increase in eel after saltwater acclimatization (Aida and Tsukamoto 2003; Peñaranda et al. 2010b, 2016a). Although maturation can be induced in freshwater (Horváth et al. 2011) a lower rate of retarded development and a faster maturation have been observed in saltwater (Boëtius and Boëtius 1967). Therefore, salinity also appears to be an important environmental factor of eel maturation.

After some migratory distance in saltwater the eels leave the continental shelf $\left(>10^{\circ}\right.$ West longitude; Fig. 1), and from hereon migrates at relatively stable temperatures (average of $\sim 10{ }^{\circ} \mathrm{C}$ ), ranging from up to $\sim 12{ }^{\circ} \mathrm{C}$ at night and down to $\sim 8{ }^{\circ} \mathrm{C}$ during the day, due to daily vertical migration (Righton et al. 2016; Aarestrup et al. 2009; Wysujack et al. 2015). Temperature is considered among the most important environmental factors for teleosts sexual maturation (Migaud et al. 2010; Bromage et al. 2001). However, eels do commonly not mature fully at such low temperature (Boëtius and Boëtius 1967; Gallego et al. 2012; Baeza et al. 2014), possibly due to low progestin synthesis (Peñaranda et al. 2016a), and constant low temperature is thus not a candidate as a cue of 
spontaneous full maturation. Although, a study has reported on the observation of a single female European eel with a GSI of 10 and with gonads containing advanced oocyte stages, caught close to the Azores in the Atlantic ocean (Bast and Klinkhardt 1988). Furthermore, several studies have indicated that low temperatures does have an effect on the PBG axis of European eels, other than simply blocking maturation (Baeza et al. 2014; Pérez et al. 2011; Mazzeo et al. 2014; Ahn et al. 2012; Gallego et al. 2012; Peñaranda et al. 2016a). This effect has also been hypothesized to potentially be a result of melatonin regulation (Burgerhout et al. 2018; Saha et al. 2018; Sebert et al. 2008). E.g. low temperatures have been suggested to accelerate the last stages of silvering (Durif et al. 2005; Vøllestad et al. 1994). Moreover, Mazzeo et al. (2014) showed an increase in $11 \mathrm{KT}, \mathrm{E} 2$ and aromatase levels at $10^{\circ} \mathrm{C}$ (compared to $18^{\circ} \mathrm{C}$ ) in $\mathrm{CPE}$ injected European eel females. Some studies have also indicated that lower temperatures during artificial maturation or an increasing temperature regime may improve resulting gamete quality. E.g. Pérez et al. (2011) showed that a variable temperature regime starting from $10{ }^{\circ} \mathrm{C}$, slowly increasing to $20^{\circ} \mathrm{C}$, induced early maturation faster than a constant $20{ }^{\circ} \mathrm{C}$ rearing in female European eel. These eels furthermore had increased Fshb and $L h b$ transcription in their pituitaries, higher esr1 and vtg2 transcription in the ovary during early vitellogenesis, and higher levels of E2 in their blood. Interestingly, in this study, the specific projection of Fsh and Lh until the mid-vitellogenesis stage appeared more similar to those observed from naturally maturing Elopomorphs (Saito et al. 2003; Kajimura et al. 2001a).

In hormonally treated European eel males kept at $10^{\circ} \mathrm{C}$ and later introduced to gradually warmer water spermiation was induced with increasing motility, volume, and progressive motility throughout the experiment. At the termination of the experiment this group showed close to the highest observed motility values of any other group in the experiment, and it is thus open for speculation 
whether the increasing tendencies would have continued (Gallego et al. 2012). Furthermore, Kucharczyk et al. (2016) showed that lower temperatures (15 C) during artificial maturation improved egg quality and increased the rate of spontaneous spawning. Interestingly, in that study, spontaneous spawning was induced successfully simply by raising the water temperature after the significant weight increase (30\%) that eel females experiences at the end of maturation (Kucharczyk et al. 2016).

Low temperature has also been shown beneficial in Japanese eel maturation E.g. higher oocyte diameters and oil droplet formation was observed when Japanese eels were kept at lower temperatures during early maturation (Sudo et al. 2011), and other authors have suggested benefits of thermal regimes increasing from low temperatures (Unuma et al. 2011; ljiri et al. 2011) or ending with lower than common temperatures $\left(20^{\circ} \mathrm{C}\right.$; Yoshikawa 2012). It should also be noted that full maturation can be induced in the anguilla family related species the Japanese conger (Conger myriaster) simply by manipulating temperature (Utoh et al. 2013). As an added benefit of lower rearing temperatures during eel maturation, generally, reduce mortality seems to follow cold water experiments (Mordenti et al. 2012; Pérez et al. 2011).

Another environmental factor to consider regarding eel maturation is the social interaction of migratory eels. It has been shown that males eels can significantly increase their swimming efficiency by swimming in groups (Burgerhout et al. 2013), and thus it should be considered whether the interacting with other eels or maybe mature eels could promote maturation. Some studies have supplied support of such hypothesis, indicating that mature eel indeed promote maturation of other European eel males (Huertas et al. 2006; Pérez et al. 2000). However, the effect is also seen when immature eels are only exposed to the water of mature individuals and the signal must thus be considered chemical rather than social. 
Swimming is another significant aspect of the oceanic migration and in the case of European eel represents and extraordinary endurance challenge due to the duration, distance and apparent complete fasting state of the eel during migration (van Ginneken et al. 2005). Therefore, resources have been allocated to construct swim-tunnels and conduct extensive swim trial (van Ginneken et al. 2007; Palstra et al. 2007, 2008, 2009; Burgerhout et al. 2013; Mes et al. 2016). One of the earliest experiments testing the effects of swimming on eel maturation was in fact set up to test the metabolic characteristics of migrating eels (van Ginneken et al. 2007). From this experiment van Ginneken et al. (2007) unexpectedly observed increased oocyte diameter, E2 plasma levels and increased Lh pituitary concentration in eels exposed to $>5000 \mathrm{~km}$ swimming. Later, the result of increased oocyte diameter was reproduced for eels swimming in freshwater, together with an apparently increased oil droplet incorporation into the oocytes (Palstra et al. 2007). Furthermore, results have been published showing significant increases of Ihb transcription and GSI from wild eel males which had swum for 3 months (Palstra et al. 2008); however, these results could not be reproduced with farmed silver eel males (Burgerhout et al. 2013). Further studies of swimming seems to suggest an inhibition of maturation in swimming females rather than increased maturation, evident by decreased vitellogenin (vtg) expression (Palstra et al. 2010, 2007), which supports an hypothesis that eel maturation (from vitellogenesis) happens after the oceanic migration (Palstra et al. 2010). Interestingly, eel males appear to mature faster while females mature slower after swimming (Palstra et al. 2009), but preliminary trials does not seem to indicate increased hormonal sensitivity of eels after swimming (Palstra et al. 2009), thus the effect of swimming does not appear to accumulate to a net benefit (Burgerhout et al. 2018). An interesting argument for swimming as an important maturation inducing factor is the observation that lipid droplets and yolk globules appear simultaneous in hormonally injected eels (Palstra et al. 2010). While a large built up of lipid 
droplets are observed in swimming eels with no yolk globules, which is probably due to the low levels of vtg (Palstra et al. 2010, 2007). It should, however, be noted that lipid droplets and yolk globules not always appear simultaneous in hormonally injected eels. E.g. in CPE injected eels kept at $18{ }^{\circ} \mathrm{C}, 25 \%$ of fish only contained lipid droplets in their oocytes after 4 weeks of CPE injection (Mazzeo et al. 2014), while in another study oocytes of $20 \%$ of CPE injected eels did not contain yolk globules after 4 weeks at $20{ }^{\circ} \mathrm{C}$ (Pérez et al. 2011). Even after 13 weeks of SPE treatment $\sim 12 \%$ of the eel of yet another experiment did not present yolk globules (da Silva et al. 2016), although these should be considered as non-responders. Furthermore, at 15 ㄷ Coocytes without yolk globules appears to be the norm after 3 weeks of CPE injection (Nowosad et al. 2015). Also, vitellogenesis seems to be induced simply by the environmental factor of salinity in the Japanese eel (Kagawa et al. 1998), and at the early stages of migration observed in nature of the New Zealand eels (Anguilla dieffenbachii and Anguilla australis; Lokman et al. 1998).

As a culmination of the current state of research Mes et al. (2016) attempted to mimic several parameters of the eel migration including temperature, salinity, social interaction, light regime, and swimming. This study showed a $\sim 4.5$ fold increase in plasma T levels of male European eel kept at $11.7^{\circ} \mathrm{C}$ while swimming compared to male European eel kept at $23.5^{\circ} \mathrm{C}$, without swimming. This study further show a $\sim 1$ fold increase in $T$ level between male European eel kept at variable temperature $\left(10.1-11.7^{\circ} \mathrm{C}\right)$ in saltwater, while swimming, compared to male European eel kept at $11.5{ }^{\circ} \mathrm{C}$ in freshwater, while swimming. However, these effects seem similar to equivalent studies of salinity and temperature without swimming treatment. Interestingly, however, hormonal injections were subsequently administered to some of the fish, which received the simulated migration treatment, which resulted in $79 \%$ maturation of females and $100 \%$ maturation of males, which must be considered as high (Mes et al. 2016). 
Although it should be noted that only $23 \%$ of the females which matured produced fertilizable eggs.

After the eel leave the continental shelf, as stated above, their daily vertical migration pattern takes them down to $\sim 700 \mathrm{~m}$ during the day, at which the water pressure is 70 times higher than at the surface (Righton et al. 2016). As migration progresses, migration likely decent to even greater depths, of around 1000 m during the day (Righton et al. 2016; Wysujack et al. 2015). As such, eel probably experiences high hydrostatic pressure around the time of maturation in nature and pressure has thus been considered as a potential trigger for maturation. Some of the earliest pressure treatment experiments of eels tested the effect of 101 atm under laboratory conditions (Sebert and Barthelemy 1985), which is roughly equivalent to the highest pressures eel commonly migrate at (Righton et al. 2016). Unfortunately, however, these results indicated no maturational progression. Interestingly, similar experiments in the field, where cages of eels were sunk to $450 \mathrm{~m}$ depth for 3 months revealed more positive results (Dufour and Fontaine 1985). In particular, increased GSI and a tremendous increase of 27 -fold of Lh were observed in treated eels. More recently, Sebert et al. (2007) have furthered this particular field and found that 3 weeks pressure treatment appear to increase E2, and vtg levels, increase the ratio of $/ h b / f s h b$ and inhibit TH transcription in eel brains (Sébert et al. 2007). Therefore, pressure also appears to be an important environmental factor of eel maturation.

Finally, the oxygen concentration is also worth considering as an environmental factor influencing eel maturation, since the depths in which eels probably migrate may show high variations in oxygen levels. To my knowledge; however, this factor has not been experimentally tested to date. 
In summary, it is clear that environmental factors do affect eel maturation, and it is plausible that the right regimes of these factors can promote maturation. As more developed eels have been shown to be more responsive to hormonal treatment (Aroua et al. 2005; Durif et al. 2006; Mordenti et al. 2013; Burgerhout et al. 2016; Dirks et al. 2014), manipulation of these environmental factors before hormonal injections might thus improve artificial European eel sexual maturation results. In particular temperature and pressure seems like good candidates for pretreatments while salinity and light regime alterations also show potential; however, to this day these latter factors are less studied.

\subsection{Whole genome duplication}

Although whole genome duplications (WGDs) are presumed to be extremely rare in mammals (Mable et al. 2004), this is not the case for eukaryotes in general (Hufton and Panopoulou 2009; Parisod et al. 2010). Specifically, WGDs are recurrently found in amphibians crustaceans reptiles and insects (Otto and Whitton 2000; Van De Peer et al. 2017), and are frequently suggested in fungi (Albertin and Marullo 2012; Blischak et al. 2018; Sémon and Wolfe 2007a) and plants (Schmutz et al. 2010; Del Pozo and Ramirez-Parra 2015; Soltis et al. 2014) especially in angiosperms (Masterson 1994; Soltis et al. 2014). Even in mammals, which are presumed to be exceptionally intolerant of polypliodism (Ganem et al. 2009; Hufton and Panopoulou 2009) WGDs do occur although, as presumed, these cases are rare (Gallardo et al. 2004). Recent WGD event has traditionally been observed by cytological studies through the observation of additional chromosomes and chromosome behavior (Soltis et al. 2014). However, ancient WGD event can only be discovered through whole genome or transcriptome analysis because these are often hidden by massive gene losses (Inoue et al. 2015; Wolfe 2001; Kassahn et al. 2009; Wendel 2000) and fusion or loss of chromosomes (Wang et al. 2015; Glasauer and Neuhauss 2014; Albertin and Marullo 2012; Chester et al. 2012; Gordon et al. 2011). Specifically, the loss of 
genes, often seen after WGD events, is hypothesized to be driven by the functional redundancy of duplicated genes (Ohno 1970), while chromosome loss or fusion may in part be driven by meiotic and mitotic abnormalities, which is expected with increased chromosome number (Albertin and Marullo 2012; Gordon et al. 2011). These processes are vastly accelerated after WGD events, thus such events can quickly be undetectable by traditional methods (Sémon and Wolfe 2007b; Inoue et al. 2015).

In particular, in teleosts, gene loss (Pasquier et al. 2017; Inoue et al. 2015) and large and small scale genome rearrangements (Nakatani and Mclysaght 2017; Blischak et al. 2018) have been shown to happen quickly and greatly affect gene compliments and synteny patterns after WGD events. The resulting underestimation of WGD event from these factors has been suggested as an explanation for the observation that species that are currently polyploid outnumber ancient WGDs by several orders of magnitude (Soltis et al. 2015; Van De Peer et al. 2017). Due to these phenomena, several authors have hypothesized that the discoveries of WGD events in eukaryotes will accelerate as sequencing techniques become more capable and available (Parisod et al. 2010; Soltis et al. 2014; Sémon and Wolfe 2007a; Blanc 2004; Mable et al. 2004; Glasauer and Neuhauss 2014). To some extent these predictions have already come true, e.g. development of sequencing techniques have already allowed for the discovery of WGDs in species that previously were considered highly unlikely to have experienced such events. E.g. in Arabidopsis thaliana, which has a very small genome of 157Mb and only five chromosome pairs (Bennett et al. 2003), 2 or maybe 3 additional WGD events were suggested after whole genome sequencing (Vision et al. 2000; Bowers et al. 2003). Similarly, in fungi genetics, low chromosome numbers and hardly available data made WGD events seem rare or even absent; however, recent advances have strongly challenged this hypothesis (Albertin and Marullo 2012; Cottrill et al. 2009). Recently, the rate of 
WGD discoveries has reached new heights, best illustrated by a study currently in progress and described by Blischak et al. (2018). So far in this study 1.173 plant and algae genomes and transcriptomes have been analyzed and 240 ancient WGD events have been strongly suggested including over 150 previously unknown events. Thus, strongly supporting the common hypothesis that WGD event discoveries will keep drastically increasing following the development of sequencing techniques (Parisod et al. 2010; Soltis et al. 2014; Sémon and Wolfe 2007a; Blanc 2004; Mable et al. 2004; Glasauer and Neuhauss 2014). Furthermore, all indications point to the same phenomenon occurring in fish (Glasauer and Neuhauss 2014).

Conserved duplicated genes can end up sharing the original function of the ancestral singleton (subfunctionalization) or gain entirely new functions (neofunctionalization; Blanc 2004; Pasquier et al. 2017), which can be displayed in different transcription patterns between tissues or even developmental stages (Van De Peer et al. 2017). E.g. 76-87\% of paralog pairs in wheat (Triticum aestivum) showed differential gene transcription patterns in different tissues (Mutti et al. 2017), and 50\% of duplicated genes showed a differential transcription patterns in soybean (Glycine max; Roulin et al. 2013). These patterns have also been seen in fish (Ren et al. 2017; Blischak et al. 2018). Interestingly, in the in progress study described by Blicshak (2018) an association was also found between WGD events and key evolutionary innovations such as multicellularity, vascular systems, roots, seeds, flowers, and fruits. Such innovations of evolutionary novelty have been frequently suggested to follow WGD events and to result in improved adaptation to adverse environments (Hughes and Liberles 2008; Tautz and Domazet-lošo 2011; Soltis et al. 2014; Blischak et al. 2018). The hypothesized improved adaptation capabilities may result from the new genomic redundancy of conserved duplicated genes, which in turn creates an increased effective population size (Soltis et al. 2014; Parisod 
et al. 2010) and commonly after WGD events also creates increased heterozygosity (Van De Peer et al. 2009). In this way, the potential for novelty exists with all duplications (Ohno 1970), some authors even estimate that most evolutionary innovations in gene functions are associated in some way with gene duplication (Conant and Wolfe 2008). However, after WGDs substantially more genes, including whole pathways, can be freed for mutation which drastically increases the potential for the development of novelty (Wisecaver et al. 2017; Smith et al. 2017; Lopez-Nieves et al. 2017; Roth et al. 2007; Moriyama and Koshiba-Takeuchi 2018). This new potential has further been hypothesized to result in evolutionary advantages of polyploids which then might be a contributing factor of the relatively high occurrence of polyploids in eukaryotes (Ramsey and Schemske 2002).

Despite novel gene functions often resembling the original gene function (Conant and Wolfe 2008), slight differences in function, affinity or transcription can have significant consequences. One example of this phenomenon is the voltage-gated sodium channel gene $(S c n 4 a)$, which long after duplication has diverged in function in some teleosts. This divergence has lead one Scn $4 a$ paralog to retain the classical function of a sodium channel and the other to facilitate the myogenic electric organ of South American gymnotiform fishes, like the electric eel (Electrophorus electricus; Arnegard et al. 2010). Although duplicated genes typically become lost or silenced within 4 million years (Lynch and Conery 2000), duplicated genes which develop novel functions are presumed to be created, fixed and first hereafter optimized for a new function through selection (Conant and Wolfe 2008; Blischak et al. 2018; Thompson et al. 2016). In some cases, this process has been shown to be incredibly long term, e.g. the evolution of the Scn4a genes is believed to has occurred more than 100 million years ago following their duplication event (3R; Thompson et al. 2016). Furthermore, chromosomal rearrangement and rediploidization may also be 
processes which can be protracted in time (Robertson et al. 2017), and therefore polyploids have been hypothesized to endure a prolonged period of increased potential for alterations to genome structure, changes to gene transcription and potential for phenotypic novelty (Van De Peer et al. 2017; Blischak et al. 2018). As such, massive gene duplication events, and the age of these, plausibly have an important impact on the gene complement and phenotype of any given species (Blischak et al. 2018).

\section{PROJECTS AND GRANTS SUPPOORTING THIS THESIS}

The work composing this thesis was supported by the Spanish Ministry of Science and Innovation (REPRO-TEMP project, AGL2013-41646-R) and by the European Union's Horizon 2020 research and innovation program under the Marie Skłodowska-Curie grant agreement № 642893 (IMPRESS), including my predoctoral contract. Additionally, I was granted a Short Term Scientific Mission by the COST Office (COST Action AQUAGAMETE: Assessing and improving the quality of aquatic animal gametes to enhance aquatic resources. The need to harmonize and standardize evolving methodologies, and improve transfer from academia to industry). Finally, the Iberian Society of Ichthyology (SIBIC) granted me a travel grant from the Gasterosteus fund for participation in international congresses.

\section{OBJECTIVES}

The IMPRESS Project, from which I have my predoctoral contract, considered the long-term objective of closing the life-cycle of the European eel in captivity. Specifically, this thesis has focused on the main objective to develop innovative methods for induction of male eel maturation and add to the pool of knowledge of European eel maturation. As female eel sexual maturation is presumed to be more strongly hormonally inhibited than that of the male, while the triggers and 
mechanisms of maturation are hypothesized to be the same, we focused on male eel maturation. The following specific levels of objectives were considered for this thesis:

\subsection{Specific objectives:}

1) To test eel-specific recombinant gonadotropins for artificial eel male maturation

a. To evaluate the potency of eel-specific recombinant gonadotropins to induce eel maturation

b. To evaluate the potential of eel-specific recombinant gonadotropins to improve artificial eel male maturation

c. To obtain knowledge on specific eel gonadotropin functions

2) To test the effect of thermal treatments on eel male reproductive competence through a suite of morphological, cellular, hormonal and genetic tools.

a. To evaluate the effect of thermal treatments on eel male physiological maturation, without hormonal stimulation

b. To evaluate the effect of thermal treatments on natural eel male endocrine mechanisms during maturation

c. To evaluate the potential of thermal treatments to reduce or partially replace standard hormonal treatments of eel males

d. To obtain novel insights on the processes of natural eel maturation, potentially including identification of suitable biomarkers of eel maturation

3) To generate a new de novo transcriptome resource to improve transcriptomic analysis and further the pool of knowledge of the controversial field of eel duplicated gene evolutionary history. 


\section{CHAPTER 1: Using specific recombinant} gonadotropins to induce spermatogenesis and spermiation in the European eel (Anguilla anguilla)

D.S. Peñarandaa, V. Gallego a, C. Rozenfelda, J.G. Herranz-Jusdadoa, L. Pérez ${ }^{\mathrm{a}}$, A. Gómez ${ }^{\mathrm{b}}$, I. Giménez ${ }^{\mathrm{c}}$ and J.F. Asturiano ${ }^{\mathrm{a}}$

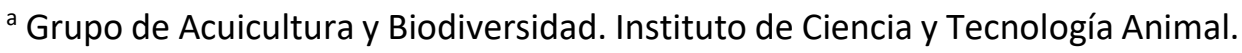
Universitat Politècnica de València. Camino de Vera s/n, 46022 Valencia, Spain.

${ }^{\mathrm{b}}$ Department of Fish Physiology and Biotechnology, Instituto de Acuicultura de Torre de la Sal (IATS), CSIC, Ribera de Cabanes, 12595 Castellón, Spain.

${ }^{\mathrm{c}}$ Rara Avis Biotec S.L., Valencia, Spain.

Published in Theriogenology 107, 6-20 (2018) 


\section{Abstract}

New specific European eel (Anguilla anguilla) recombinant gonadotropins (aarGths) produced in the ovarian cells of Chinese hamsters $(\mathrm{CHO})$ were used to induce maturation in captive male eels. In the first experiment, five different hormonal treatments were assayed: one group was given a constant dose of recombinant European eel follicle-stimulating hormone (aarFsh; $4 \mu \mathrm{g} /$ fish) for 9 weeks, and the second group received a constant dose of recombinant European eel luteinizing hormone (aarLh; $2 \mu \mathrm{g} /$ fish) also for 9 weeks. The other three groups were injected with different combinations of both aarGths (some doses constant, some variable). All five treatments stimulated androgen synthesis, but the increase was more pronounced in the fish treated with a combination of both aarGths. Unlike aarLh, aarFsh alone was able to induce spermiation, the best results were achieved in the fish that were treated with a constant dose of aarFSH and an increasing dose of aarLH, with spermiation being induced $(20 \%$ motile cells) despite the fact that these fish were immature at the start of the experiment. In order to improve sperm quality, a second experiment was performed. Immature males received three constant doses of aarFsh $(2.8,1.4$ or $0.7 \mu \mathrm{g} /$ fish) and increasing doses of aarLh (every 3 weeks; 1, 2, $6 \mu \mathrm{g} /$ fish). All the treatments induced spermiation, however the best sperm quality (with $\geq 50 \%$ motile cells) was observed in the males treated with the highest dose of aarFsh. In conclusion, these specific recombinant gonadotropins have demonstrated their capacity to induce spermatogenesis and spermiation in vivo in a teleost fish, the European eel.

Keywords: aarFsh, aarLh, maturation, sperm, testis 


\subsection{Introduction}

The European eel (Anguilla anguilla) population has decreased by $95-99 \%$, compared to levels in 1960-80 (ICES 1999), and as a result the species has been placed on the Red List of Threatened Species and listed as "Critically Endangered" by the International Union for Conservation of Nature (IUCN). However, the wild eel populations still sustain important fisheries and aquaculture industries (based on harvesting juvenile 'glass eels' from the wild) in Europe. To reduce the dependency of eel industry on wild populations, and even for stocking purposes, the development of new protocols to reproduce this species in captivity is crucial. The full life-cycle of the European eel has yet to be successfully closed in captivity, thus limiting aquaculture to ranching of wild caught glass eel. Some of the main hurdles encountered include the stagnation of puberty (Vidal et al. 2004), finding alternative treatments to induce full maturation (Gallego et al. 2012; Pérez et al. 2011) and obtaining high quality gametes (Baeza et al. 2015a).

Gonadal activity (steroidogenesis and gametogenesis) is controlled by pituitary gonadotropin hormones (Gths), responsible for the control of reproduction in both teleost fish and other vertebrates. The follicle-stimulating hormone (Fsh) regulates the Sertoli cell activities, including structural, nutritional and regulatory (paracrine) support of germ cell development, and the luteinizing hormone (Lh) regulates the Leydig cell sex steroid production (Schulz et al. 2010). Both Gths, Lh and Fsh, are considered the most important pituitary hormones regulating testicular physiology.

At present, it is possible to induce eel maturation using exogenous hormones in both males (Peñaranda et al. 2010b; Gallego et al. 2012), and females (Butts et al. 2014), but these hormonal treatments result in low rates of fertilization and hatching, mainly attributed to low gamete quality (Palstra and van den Thillart 
2009). The traditional method used to induce eel maturation has involved the use of human chorionic gonadotropin (hCG) in males (Asturiano et al. 2006) and carp or salmon pituitary extract in females (Pérez et al. 2008). However, the administration of non-native Lh or equivalents has not resulted in a reliable level of percentage of matured fish nor gamete quality (Asturiano et al. 2005; Kagawa 2003). Therefore, in order to solve the reproductive problems encountered when using the current hormonal treatments in both male and female eels, a native eel Fsh purified from immature Japanese eel (Anguilla japonica) was tested to induce spermatogenesis in vitro (Kamei et al. 2005). The native Fsh was able to stimulate androgen synthesis but, due to the difficulty in obtaining an adequate amount of native Gths, tools for producing recombinant gonadotropins (rGths) in eel were developed (Mylonas et al. 2017).

Later on, a recombinant Japanese eel Fsh (ajrFsh) was synthesized using methylotropic yeast (Pichia pastoris), and was successful in inducing steroidogenesis in the gonads of both sexes cultured in vitro (Kamei et al. 2003, 2005,2006 b). In vivo trials were also carried out on male eels, inducing testicular growth and the beginning of spermatogenesis (Kamei et al. 2006a). Subsequently, with the aim of improving the biological activity of rGths, new Japanese eel rGths were produced using a Drosophila expression system (Kazeto et al. 2008). Both recombinant Fsh and Lh induced complete spermatogenesis in in vitro conditions, but small effects were observed in vivo. In order to obtain a large-scale production of rGths, Hayakawa et al. (Hayakawa et al. 2008b) used a baculovirus-silkworm larvae system to produce rGths in Japanese eel. Complete spermatogenesis was accomplished in vivo, but no male reached spermiation (Hayakawa et al. 2008a, 2008b; Kobayashi et al. 2010).

rGths have also been tested in other teleosts (Mylonas et al. 2017). They have been successful in inducing steroidogenesis and gonad development both in vitro and in vivo, however, the in vivo results have been variable (Levavi-Sivan et 
al. 2010). rGths have been reported to induce androgenesis e.g. in zebrafish (Danio rerio; García-López et al. 2010) and Russian sturgeon (Acipenser gueldenstaedtii; Yom-Din et al. 2016) and recombinant Fsh has triggered spermatogenesis in immature European sea bass (Dicentrarchus labrax; Mazón et al. 2014). In general, the hormonal treatment was unable to induce spermiation in vivo, except in the case of goldfish (Carassius auratus; Kobayashi et al. 2003) and European sea bass (Mazón et al. 2013), but both these cases the treated fish were already sexually mature at the beginning of the experiment. $A$ different approach to the administration of rGths was to inject a plasmid containing the Gth sequence directly into the muscle. Mazón et al. (Mazón et al. 2013) reported an improvement in sperm quality of European sea bass using an Lh sequence, but again the treated fish were already sexually mature at the beginning of the experiments.

The main objective of this study was to test if new European eel recombinant gonadotropins (aarFsh and aarLh) were able to induce in vivo eel spermatogenesis and spermiation in captivity, and demonstrate the differential function of Fsh and Lh during spermatogenesis in eel.

\subsection{Materials and methods}

\subsubsection{Fish maintenance}

Immature yellow European eel males from the Valenciana de Acuicultura, S.A fish farm. (Puzol, Valencia; East coast of Spain) were moved to the aquaculture facilities at the Universitat Politècnica de València (UPV, Spain). The fish (6-8 fish/aquarium) were distributed into 150-L aquaria equipped with separate recirculation systems, a temperature control system (with heaters and coolers) and completely covered to maintain as maximum possible a constant dark photoperiod. Before the hormonal treatment, the eels were gradually 
acclimatized from freshwater to sea water $(37 \mathrm{~g} / \mathrm{L}$ ) increasing the salinity $10 \%$ each 2 days for 8 days, and 2 days more of resting at 37\%o. The temperature, oxygen level and $\mathrm{pH}$ of rearing were $20 \stackrel{\circ}{\circ}, 7-8 \mathrm{mg} / \mathrm{L}$ (thanks to aerators) and $\sim 8.2$, respectively. Finally, due to its ethology during its reproductive migration, the fish were fasted throughout the treatment.

\subsubsection{Production of recombinant gonadotropins}

Homologous single-chain recombinant Fsh and Lh, containing a modified linker, were produced in the ovarian cells of Chinese hamster $(\mathrm{CHO})$ in suspension by Rara Avis Biotec S.L. (Valencia, Spain) using in-house technology. The purity was determined by western blot using specific antibodies and the final amount of rGth was quantified by immunoassay using these same specific antibodies.

European eel $\beta$ and $\alpha$ subunits (GenBank accession numbers: CAA43373.1 ( $\alpha$ common subunit), AAN73407.1 (Bfsh), CAA43374.1 (B/h) were used to obtain the single chain Gths.

\subsubsection{Experimental setup: hormonal treatments and samplings}

Two experiments were carried out in order to evaluate the effect of specific rGths had on inducing maturation in European eels in captivity. In experiment 1 (October to December; 2015), the aim was to test the effect of aarFsh and aarLh on their own, as well as the optimum combination of both rGths. Meanwhile in experiment 2 (January to March; 2016), the objective was to improve maturation and sperm quality using the treatment that yielded the best results in terms of aquaculture purposes in experiment 1.

\section{Experiment 1}

Sixty immature male eels were used in this trial (mean body weight $=89.21 \pm 5.44$ g; mean body length $=38 \cdot 12 \pm 2.28 \mathrm{~cm}$ ). Before starting the hormonal 
treatments, 10 eels were sampled as soon as they arrived at our facilities (thus in freshwater, FW); and 10 new eels were sacrificed after they had been acclimatized to sea water (SW). Subsequently, intramuscular hormonal treatments were administered weekly using the protocol described by Asturiano et al. (Asturiano et al. 2006). The fish were anaesthetized with benzocaine (60 ppm) before receiving the hormone by intramuscular injection.

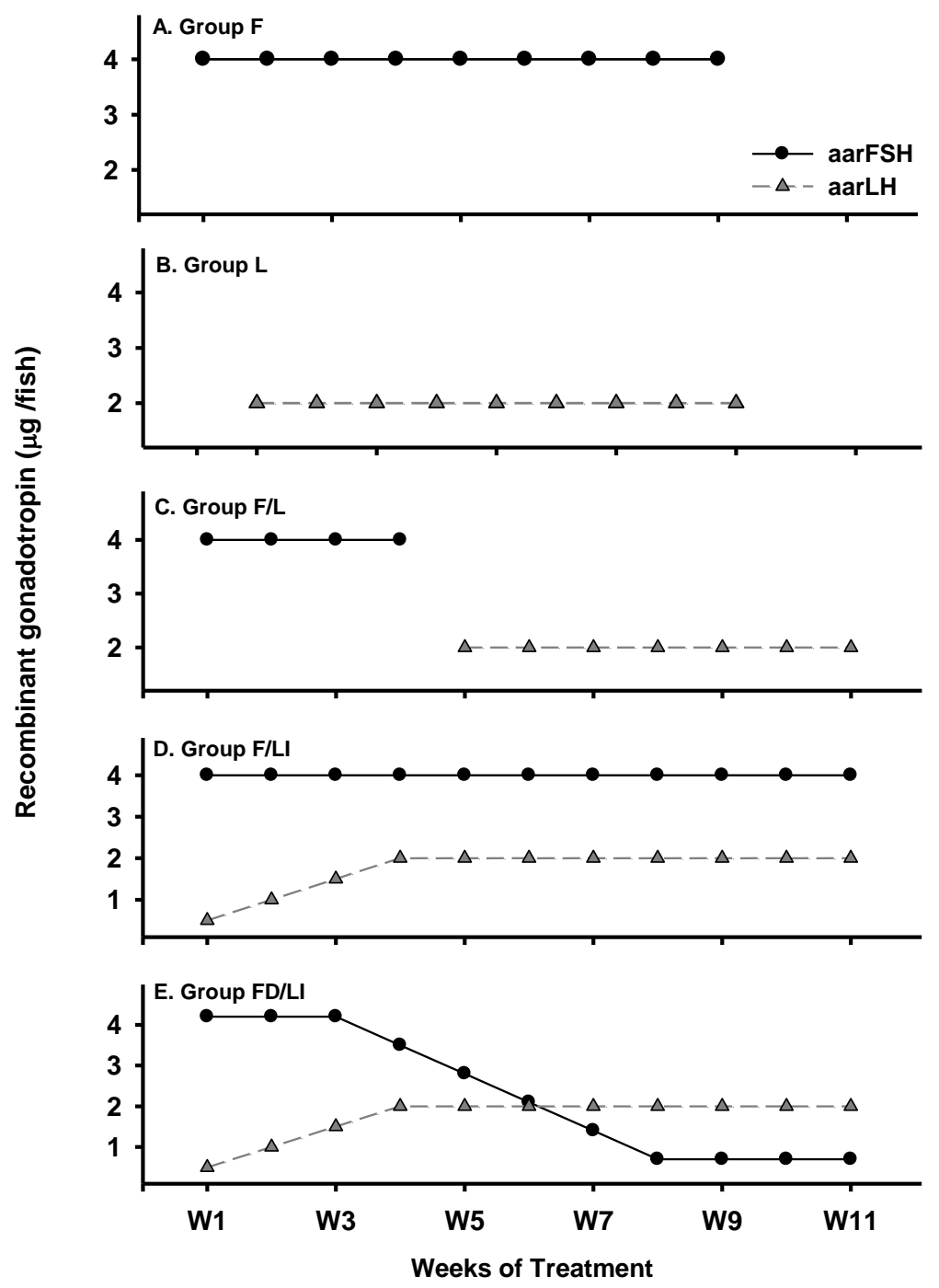

Figure 4. Descriptive diagram of the hormonal treatments for the five experimental groups in the experiment 1. 
Forty immature fish $(90.04 \pm 1.92 \mathrm{~g} ; 38.10 \pm 0.33 \mathrm{~cm})$ underwent five hormonal treatments ( 8 males per treatment; Fig. 4) for 9 or 11 weeks. Two groups, group $F$ and $L$, were injected once per week for 9 weeks only with aarFsh $(4 \mu \mathrm{g} /$ fish; Fig. 4A) or aarLh (2 $\mathrm{gg} /$ fish; Fig. 4B) respectively. The other three groups, F/L, $\mathrm{F} / \mathrm{LI}$ and $\mathrm{FD} / \mathrm{LI}$, were injected with different combinations of both hormones once per week for 11 weeks. Group F/L (Fig. 4C) was treated with $4 \mu \mathrm{g}$ aarFsh/fish for the first 4 weeks, followed by $2 \mu \mathrm{g}$ aarLh/fish for the last 8 weeks. Group F/LI (Fig. 4D) was treated with $4 \mu \mathrm{g}$ aarFsh/fish throughout the experimental period, combined with increasing doses of aarLh, from 0.5 to 2 $\mu \mathrm{g} /$ fish (between weeks 1 and 4) and then a constant dose of $2 \mu \mathrm{g}$ aarLh/fish from week 4. Group FD/LI (Fig. 4E) received decreasing doses of aarFsh from 4 to $0.5 \mu \mathrm{g} /$ fish (from week 3 to week 8 ) combined with increasing doses of aarlh from 0.5 to $2 \mu \mathrm{g} /$ fish (between week 1 and week 4) and then a constant dose of $2 \mu \mathrm{g}$ aarLh/fish from the $4^{\text {th }}$ week on.

In order to evaluate the progression of maturation, every two weeks blood samples were taken for steroids analyses, and biometric parameters, such as eye index [EI = 100 p $\left.0.25(\mathrm{Dh}+\mathrm{Dv})^{2} / \mathrm{Lt}\right)$; Lt: total length; Dh: horizontal distance; Dv: vertical distance; (Pankhurst 1982)] and fin colour (FC; $0=$ Transparent, 1= Light grey, 2= Dark grey, 4 = Black) were registered. Both biometric parameters have previously been used in eel as indicators of maturation (Peñaranda et al. 2010b).

After beginning of spermiation, samples were collected and analysed as described by Gallego et al. (Gallego et al. 2013). Once the experiment had finished, the gonadosomatic index was calculated (GSI = 100 gonad weight/total body weight) and testis samples were collected to determine the stage of development by histology.

\section{Experiment 2}

In order to improve eel maturation in captivity, new hormonal treatments were 
designed, with the treatment that yielded the best results in experiment 1 in terms of aquaculture requirements, being used as the basis. The aarFsh levels were reduced slightly, in order to find the minimum effective dose, whereas the aarlh dose was increased to enhance its effect on the spermatogenesis process.

As with experiment 1 , before starting the hormonal treatments, 8 immature eels were sampled after they had been acclimatized to sea water (SW). Subsequently, 72 immature fish $(99.98 \pm 2.01 \mathrm{~g} ; 38.56 \pm 2.28 \mathrm{~cm})$ underwent three intramuscular hormonal treatments (24 males/treatment), administered weekly for a total of 12 weeks. The males received a constant dose of aarFsh, with the Low treatment group receiving 0.7, and the Medium and High treatment groups receiving 1.4 and $2.8 \mu \mathrm{g} /$ fish respectively. This was combined with an increasing dose of aarLh: 1, 2, $6 \mu \mathrm{g} /$ fish. The aarLh dose was increased every 3 weeks, from the $3^{\text {rd }}$ week of the treatment (Fig. 5). In order to evaluate the progression of maturation, three males per treatment were sacrificed every 3 weeks to collect blood and gonad samples, and to measure biometric parameters, including GSI.

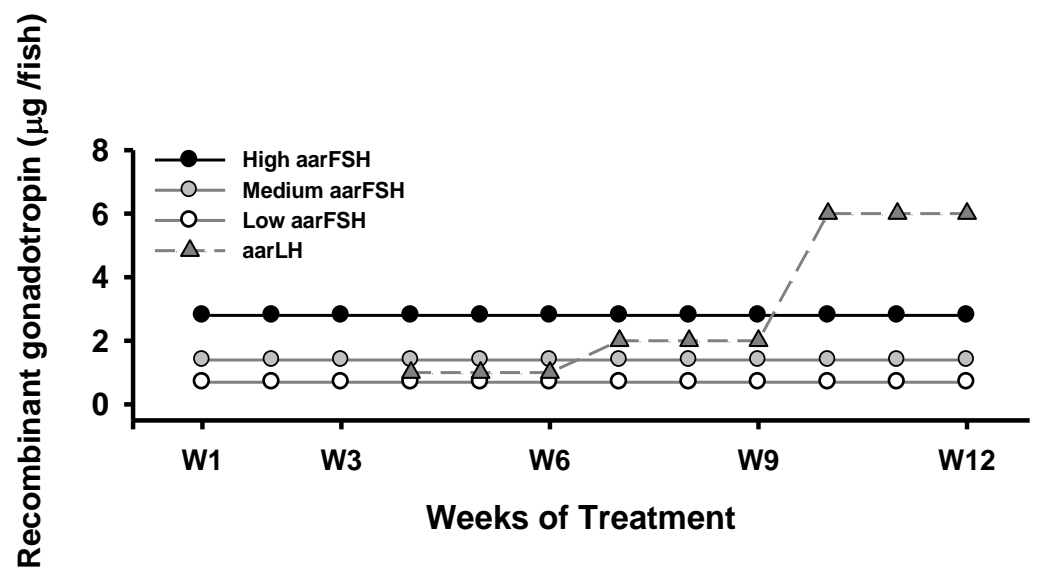

Figure 5. Descriptive diagram of hormonal treatments for the three experimental groups in the experiment 2.

During the weeks of spermiation, sperm samples were collected and analysed as described by Gallego et al. (2013). 


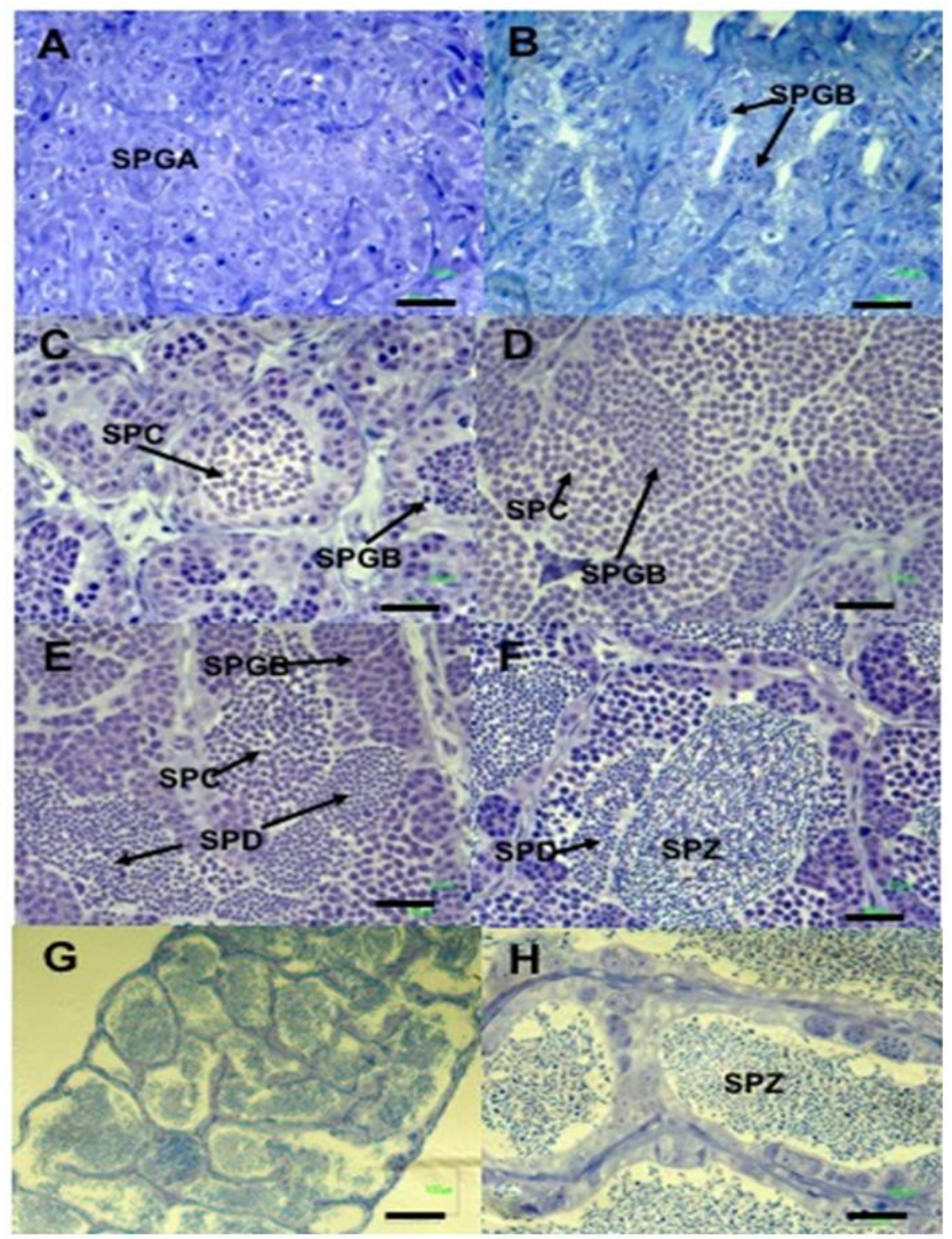

Figure 6 Histological sections of eel testis at different developmental stages. A) Testis at SPG1. B) Testis at SPG2. C) Testis at SPC1. D) Testis at SPC2. E) Testis at SPD. F) Testis at SZ1. G, H) Testis at SZ2. See main text for definition of gonad developmental stages. SPGA= Spermatogonia type $A ; S P G B=S p e r m a t o g o n i a ~ t y p e ~ B ; S P C$ : Spermatocytes; SPD: Spermatids; SPZ: Spermatozoa. Scale bars, $25 \mu \mathrm{m}(A, B, C, D, E, F, H)$ and $100 \mu m(G)$. 


\subsubsection{Gonadal histology}

For experiment 1, sections from the mid-part of testis were preserved in $4 \%$ buffered (PBS) glutaraldehyde at 4 으 overnight. The tissue was dehydrated and embedded in Technovit ${ }^{\circledR}$ 7100. Nevertheless, in the experiment 2, sections from the mid-part of testis were preserved in $10 \%$ formalin buffered at $\mathrm{pH} 7.4$, dehydrated in ethanol and embedded in paraffin. In both cases, between 10-20 sections/testis (5 $\mu \mathrm{m}$ thickness) were cut with a Microm HM325, and stained with $1 \%$ toluidine blue (Exp. 1) or with a Shandom Hypercut manual microtome and stained with haematoxylin and eosin (Exp. 2). Two slides/testis were observed with a Nikon Eclipse E-400 microscope, and pictures were taken with a Nikon DS-5M camera attached to the microscope. The stages of spermatogenesis were determined by the following parameters: germ cell types present in the testis and their relative abundance (according to Leal et al. 2009), the degree of development of the seminal tubules and the GSI by the male at the time of sacrifice (Peñaranda et al. 2016a; Fig. 6: SPG1: Dominance of $A$ spermatogonia, with a general absence of lobule lumen.

Gonad in non-proliferating stage. Stage SPG2: Dominance of A spermatogonia, with some B spermatogonia and presence of lobule lumen. Stage SPC1: Dominance of B spermatogonia and presence of spermatocytes. Stage SPC2: Dominance of spermatocytes and B spermatogonia. Stage SD: is characterized by an abundance of spermatids. Stage SPZ1: Early spermiation stage. Stage SPZ2: Stage of maximum spermiation, showing fusion of sperm lobules.

\subsubsection{Plasma steroid assays}

Blood was collected and centrifuged at 3500 r.p.m. for $15 \mathrm{~min}$, and the blood plasma was stored at $-80 \stackrel{\circ}{ } \mathrm{C}$ until steroid analysis. Plasma levels of testosterone (T) and 11-ketotestosterone were analyzed by a specific enzyme immunoassay 
(EIA) following the methods developed for European sea bass (Rodríguez et al. 2000,2005 ). The lower limits of detection ( $80 \%$ binding) were $0.00117 \mathrm{ng} / \mathrm{ml}$ for $11 \mathrm{KT}$ and $0.019 \mathrm{ng} / \mathrm{ml}$ for T. Analysis of serial dilutions of eel plasma dilutions were shown to be parallel to the standard curve. The inter-assay coefficients of variation were $9.74 \%(n=7)$ for $11 \mathrm{KT}$ and $12.6 \%(n=7)$ for T. The intra-assay coefficients of variation were $8.64 \%$ ( $n=10)$ for $11 \mathrm{KT}$ y $2.93 \%$ ( $n=4)$ for $T$.

\subsubsection{Sperm collection and evaluation}

Sperm samples were collected $24 \mathrm{~h}$ after the administration of the hormone to obtain the highest quality sperm (Asturiano et al. 2005). After the eels were anesthetized, the genital area was first cleaned with distilled water and thoroughly dried to avoid the sperm becoming contaminated with faeces, urine or sea water. The sperm was then collected by the application of gentle abdominal pressure, and with the help of a small-modified aquarium air pump which produced a vacuum the sperm was collected into plastic Falcon tubes.

The sperm was diluted (1:10) before being activated in P1 medium (Peñaranda et al. 2010a); in mM: $125 \mathrm{NaCl}, 20 \mathrm{NaHCO}_{3}, 2.5 \mathrm{MgCl}_{2} \cdot 6 \mathrm{H}_{2} \mathrm{O}, 1 \mathrm{CaCl}_{2} \cdot 2 \mathrm{H}_{2} \mathrm{O}, 30$ $\mathrm{KCl}$ ). The sperm was activated by mixing $0.5 \mu \mathrm{l}$ of this dilution with $4 \mu \mathrm{l}$ of artificial sea water and $2 \% \mathrm{BSA}(\mathrm{w} / \mathrm{v}$ ), and by adjusting the $\mathrm{pH}$ to 8.2 (Asturiano et al. 2005). All the motility analyses were performed in triplicate using the motility module of ISAS (Proiser R+D, S.L.; Paterna, Spain) as described by Gallego et al. (2013).

The sperm parameters considered in this study were total motility (TM, \%), defined as the percentage of motile cells; progressive motility (PM, \%), defined as the percentage of spermatozoa which swim in essentially a straight line; curvilinear velocity $(\mathrm{VCL}, \mu \mathrm{m} / \mathrm{s})$, defined as the time-average velocity of a sperm head along its actual curvilinear trajectory; straight line velocity (VSL, $\mu \mathrm{m} / \mathrm{s}$ ), 
defined as the time/average velocity of a sperm head along the straight line between its first detected position and its last position. Spermatozoa were considered immotile if their VCL was lower than $10 \mu \mathrm{m} / \mathrm{s}$.

\subsubsection{Statistical analysis}

The mean and standard errors were calculated for all the biometric indexes (GSI, $\mathrm{El}$, and $\mathrm{FI}$ ) and sperm parameters (volume, density, motility and rest of kinetic parameters). Shapiro-Wilk and Levene tests were used to check the normality of data distribution and variance homogeneity, respectively. One-way analyses of variance (ANOVA) and Student's $t$-test were used to analyse data (normal distribution) between groups at the same week. Significant differences between treatments were detected using the Tukey multiple range test $(P<0.05)$. For nonnormally distributed populations, Kruskal-Wallis one-way ANOVA on ranks and Mann-Whitney U-test were used. Moreover, GLM for repeated measures was used for comparing data over the weeks within the same hormonal treatment; and significant differences were also detected using the Tukey multiple range test $(P<0.05)$. All statistical analyses were performed using the statistical package SPSS version 19.0 for Windows software (SPSS Inc., Chicago, IL, USA).

\subsubsection{Human and animal rights}

This study was carried out in strict accordance with the recommendations given in the Guide for the Care and Use of Laboratory Animals of the Spanish Royal Decree 53/2013 regarding the protection of animals used for scientific purposes (BOE 2013). The protocol was approved by the Experimental Animal Ethics Committee from the Universitat Politècnica de València (UPV) and final permission was given by the local government (Generalitat Valenciana, Permit Number: 2014/VSC/PEA/00147). The fish were sacrificed using anaesthesia and all efforts were made to minimize suffering. The fish were not fed throughout 
the experiment and were handled in accordance with the European Union regulations concerning the protection of experimental animals (Dir 86/609/EEC).

\subsection{Results}

\subsubsection{Experiment 1}

Table 1. Biometric parameters (eye index and fin colour) before hormone administration (freshwater, FW; and sea water, SW) and over the weeks of hormonal treatments on the five experimental groups in the experiment 1 (groups $F$ and $L$ until $9^{\text {th }}$ week; groups $F / L, F / L I$ and $F D / L I$ until $11^{\text {th }}$ week) 6-8. Data are expressed as mean (SEM); $n=6-8$. Different letters indicates significant differences between groups at the same week and different letters indicate significant differences among weeks for the same hormonal treatment.

Eye Index

\begin{tabular}{lllllllllll}
\hline \multicolumn{3}{c}{ Group F } & \multicolumn{2}{c}{ Group L } & \multicolumn{2}{c}{ Group F/L } & \multicolumn{2}{c}{ Group F/LI } & \multicolumn{2}{c}{ Group FD/LI } \\
\hline FW & 3.8 & $(0.1) \mathrm{c}$ & 3.8 & $(0.1) \mathrm{c}$ & 3.8 & $(0.1) \mathrm{c}$ & 3.8 & $(0.1) \mathrm{d}$ & 3.8 & $(0.1) \mathrm{c}$ \\
SW & 4.7 & $(0.1) \mathrm{ab}$ & 4.7 & $(0.1) \mathrm{b}$ & 4.7 & $(0.1) \mathrm{ab}$ & 4.7 & $(0.1) \mathrm{bc}$ & 4.7 & $(0.1) \mathrm{ab}$ \\
W3 & 4.4 & $(0.2) \mathrm{abc}$ & 4.8 & $(0.2) \mathrm{b}$ & 4.4 & $(0.2) \mathrm{bc}$ & 5.3 & $(0.3) \mathrm{ab}$ & 3.9 & $(0.1) \mathrm{c}$ \\
W5 & 4.1 & $(0.1) \mathrm{bc}$ & 4.5 & $(0.1) \mathrm{b}$ & 4.3 & $(0.2) \mathrm{bc}$ & 4.5 & $(0.2) \mathrm{c}$ & 4.5 & $(0.2) \mathrm{b}$ \\
W7 & 4.2 & $(0.2) \mathrm{bc}$ & 5.1 & $(0.2)$ & 4.8 & $(0.2) \mathrm{ab}$ & 4.8 & $(0.1) \mathrm{bc}$ & 4.4 & $(0.2) \mathrm{b}$ \\
W9 & 4.9 & $(0.2) \mathrm{a}$ & 5.6 & $(0.3) \mathrm{a}$ & 5.2 & $(0.1) \mathrm{a}$ & 5.3 & $(0.2) \mathrm{ab}$ & 4.8 & $(0.1) \mathrm{ab}$ \\
W11 & & & & & 5.3 & $(0.3) \mathrm{a}$ & 5.7 & $(0.2) \mathrm{a}$ & 5.1 & $(0.2) \mathrm{a}$ \\
\hline
\end{tabular}

Fin Colour

\begin{tabular}{lllllllllll}
\hline & \multicolumn{3}{c}{ Group F } & \multicolumn{2}{c}{ Group L } & \multicolumn{2}{c}{ Group F/L } & \multicolumn{2}{c}{ Group F/LI } & \multicolumn{2}{l}{ Group } \\
\hline FW & 1.8 & $(0.3)$ & 1.8 & $(0.3)$ & 1.8 & $(0.3)$ & 1.8 & $(0.3)$ & 1.8 & $(0.3)$ \\
SW & 2.7 & $(0.4)$ & 2.7 & $(0.4)$ & 2.7 & $(0.4)$ & 2.7 & $(0.4)$ & 2.7 & $(0.4)$ \\
W3 & 3.3 & $(0.3)$ & 3.3 & $(0.2)$ & 2.1 & $(0.1)$ & 3.4 & $(0.4)$ & 3.1 & $(0.3)$ \\
W5 & 4.0 & $(0.0)$ & 3.9 & $(0.1)$ & 3.0 & $(0.3)$ & 3.8 & $(0.3)$ & 3.9 & $(0.1)$ \\
W7 & 4.0 & $(0.0)$ & 3.8 & $(0.2)$ & 4.0 & $(0.0)$ & 4.0 & $(0.0)$ & 4.0 & $(0.0)$ \\
W9 & 4.0 & $(0.0)$ & 3.8 & $(0.2)$ & 4.0 & $(0.0)$ & 4.0 & $(0.0)$ & 4.0 & $(0.0)$ \\
W11 & & & & 3.6 & $(0.2)$ & 4.0 & $(0.0)$ & 4.0 & $(0.0)$ \\
\hline
\end{tabular}


Biometric parameters: El, FC and GSI

Regarding Eye Index (El; Table 1), significant differences between the FW and SW values (before hormone administration), were observed in all the groups. Fin Colour $(\mathrm{FC})$ became progressively dark throughout the hormonal treatment, becoming almost completely black around the week 5 in groups $F, L, F / L I$ and $\mathrm{FD} / \mathrm{LI}$, and around week 7 in group $\mathrm{F} / \mathrm{L}$.

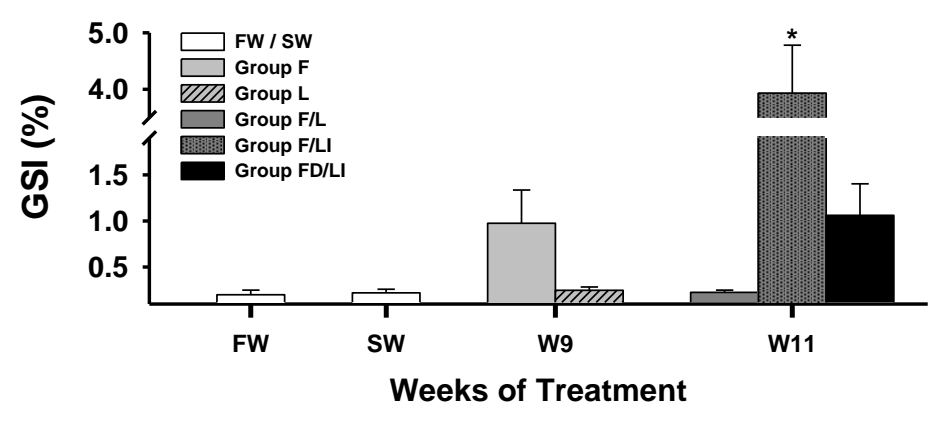

Figure 7. Gonadosomatic indexes before hormone administration (freshwater (FW) and seawater (SW) conditions) and at the end of hormonal treatments (groups F and L until $9^{\text {th }}$ week; groups $F / L, F / L I$ and $F D / L I$ until $11^{\text {th }}$ week) in the experiment 1. Data are expressed as mean \pm SEM ( $n=6-8$ per sampling and treatment). Asterisk indicates significant differences between treatments at the end of the trial.

Before hormonal treatment, the eels showed a GSI of $0.20 \pm 0.05 \%$ in FW and $0.22 \pm 0.04 \%$ in SW (Fig. 7). No significant differences were found at the end of the different hormonal treatments except in group F/LI, which showed a mean GSI of $3.83 \pm 0.84 \%$ after eleven weeks. On the other hand, eels from groups $F$ and FD/LI showed increases in GSI (of around 1\%) at week 9 and 11, respectively. The difference however was not significant compared to the initial values (FW and SW). 


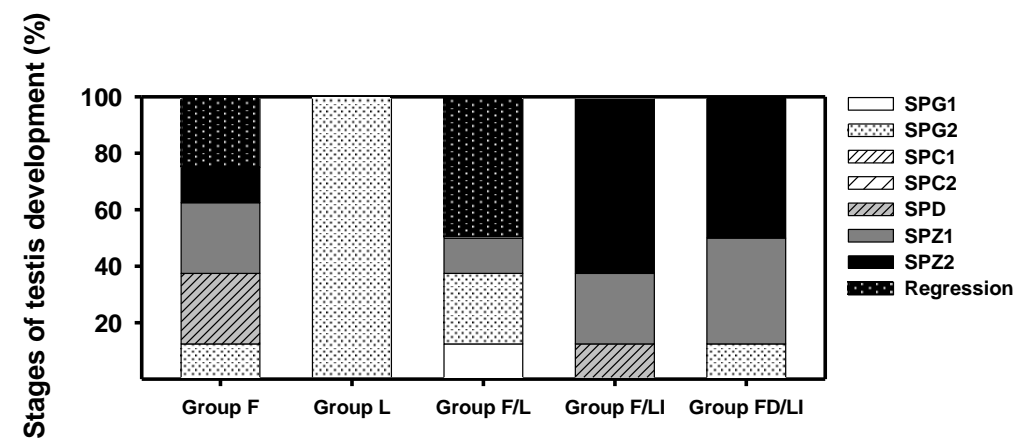

Figure 8. Relative percentages of the stages of testis development (SPG1-SPZ2) at the end of the hormonal treatments in the experiment 1 (groups $F$ and $L$ until $9^{\text {th }}$ week; groups $F / L, F / L I$ and $F D / L I$ until $11^{\text {th }}$ week; $\left.n=6-8\right)$. See main text for definition of gonad developmental stages: Stages: SPG1: Spermatogonia 1; SPG2: Spermatogonia 2; SPC1: Spermatocyte 1; SPC2: Spermatocyte 2; SD: Spermatid; SPZ1: Spermatozoa 1; SPZ2: Spermatozoa 2; Regression.

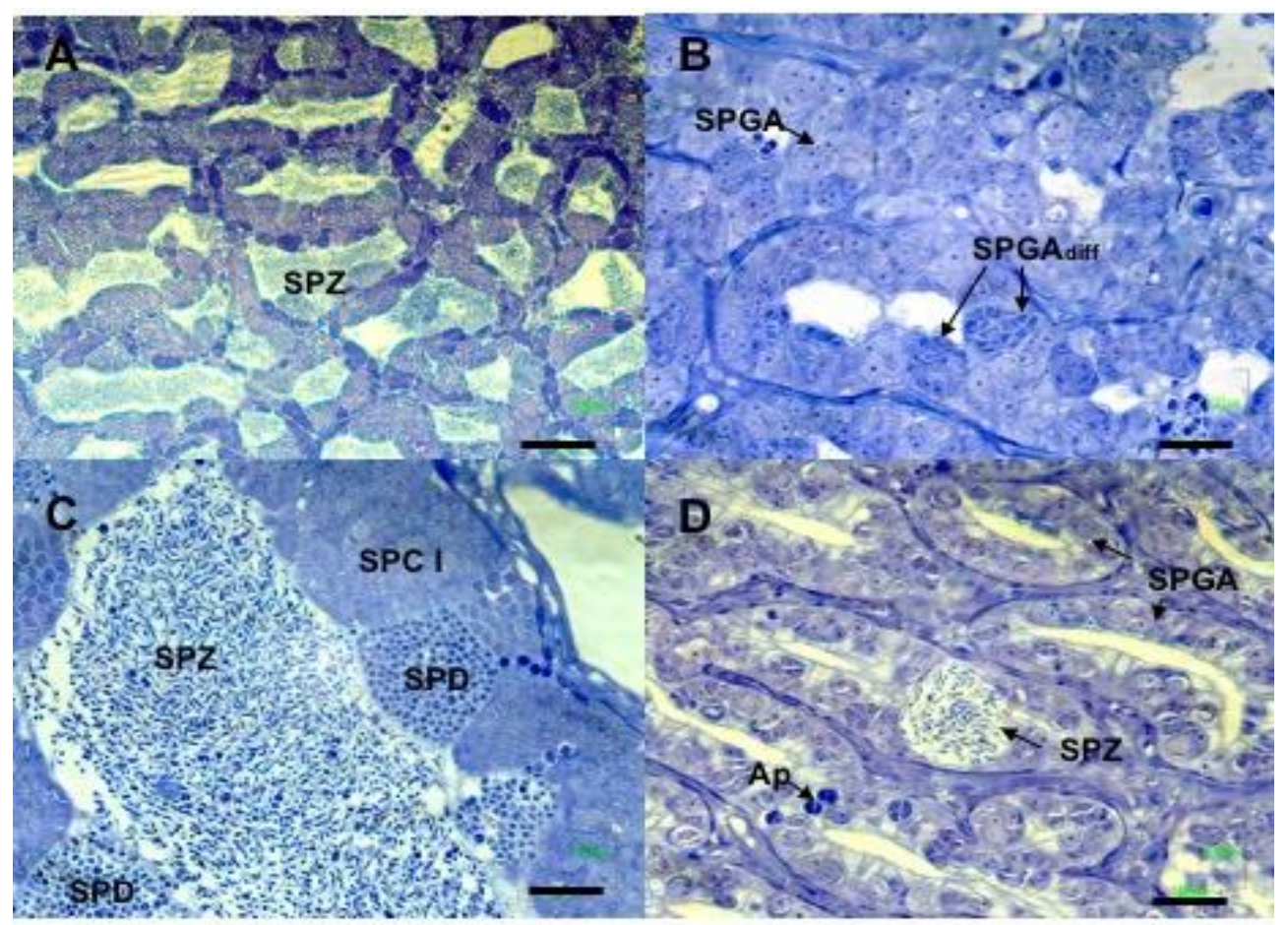

Figure 9. Histological sections of testis from different treatments (experiment 1). A) aarFsh alone, 9 weeks; stage SPZ1; B) aarLh alone, 9 weeks, SPG2 stage; C) aarFsh+aarLh, 12 weeks, SPZ2 stage; D) aarFsh+aarLh 3, 12 weeks, regression. Scale bar: $A=100 \mu \mathrm{m} ; B, C, D=10 \mu \mathrm{m}$. See main text for definition of gonad developmental stages: SPGA (spermatogonia A); SPGAdiff (spermatogonia A differenciated); SPGB (spermatogonia B); SPC I (spermatocyte I); SPD (spermatid), SPZ (spermatozoa); Ap (apoptotic cells). 


\section{Progression of gonad development}

Regarding testis development (Figs. 8 and 9), aarFsh alone was able to induce spermatozoa stages (SPZ1, SPZ2) in $37.5 \%$ of fish, and SPD stage in $25 \%$ of fish. In contrast, all aarLh treated males were less developed, with $100 \%$ being in stage SPG2, with a dominance of SPGA, clusters of differentiated SPGA (Fig. 9B), and in some cases the presence of SPGB. In groups F/LI and FD/LI, the treatments which combined aarFsh and aarLh, $87.5 \%$ of fish reached normal spermiation stages (SPZ1 and SPZ2). However, treatment F/L, also combining both hormones, induced abnormal testis development in $50 \%$ of fish: whilst the testis had the structure of stage SPG2, with dominance of SPGA, a few small spermatozoa cysts were present. We considered this to be a regressive stage, with the spermatocytes and even the SPGB having disappeared from the testis after an initial production of spermatozoa. This is supported by the fact that apoptotic cells were observed in this stage of development (Fig. 9D).

\section{Steroid evolution during hormonal treatment}

The administration of aarFsh or aarLh alone (groups $F$ and $L$, respectively) was enough to initiate steroidogenesis (Fig. 10), inducing the production of both $11 \mathrm{KT}$ and T. However, the treatment which combined both aarGths (groups F/LI and FD/LI) yielded higher levels of these steroids. On the other hand, a sequential administration of aarGths (group F/L) provided a steroid profile closer to group $\mathrm{F}$ and $\mathrm{L}$ than to the profiles showed by aarGths combined treatments (group F/LI and FD/LI).

\section{Sperm quality analyses}

Eels treated with a single Gth showed the lowest percentage of spermiating males (Fig. 11A): in the case of aarLh (group L) no spermiating males at all were observed, whereas in group $\mathrm{F}$ (aarFsh) they were only registered in weeks 8 and 
9. The percentage of spermiating males was higher when aarFsh and aarLh were combined.
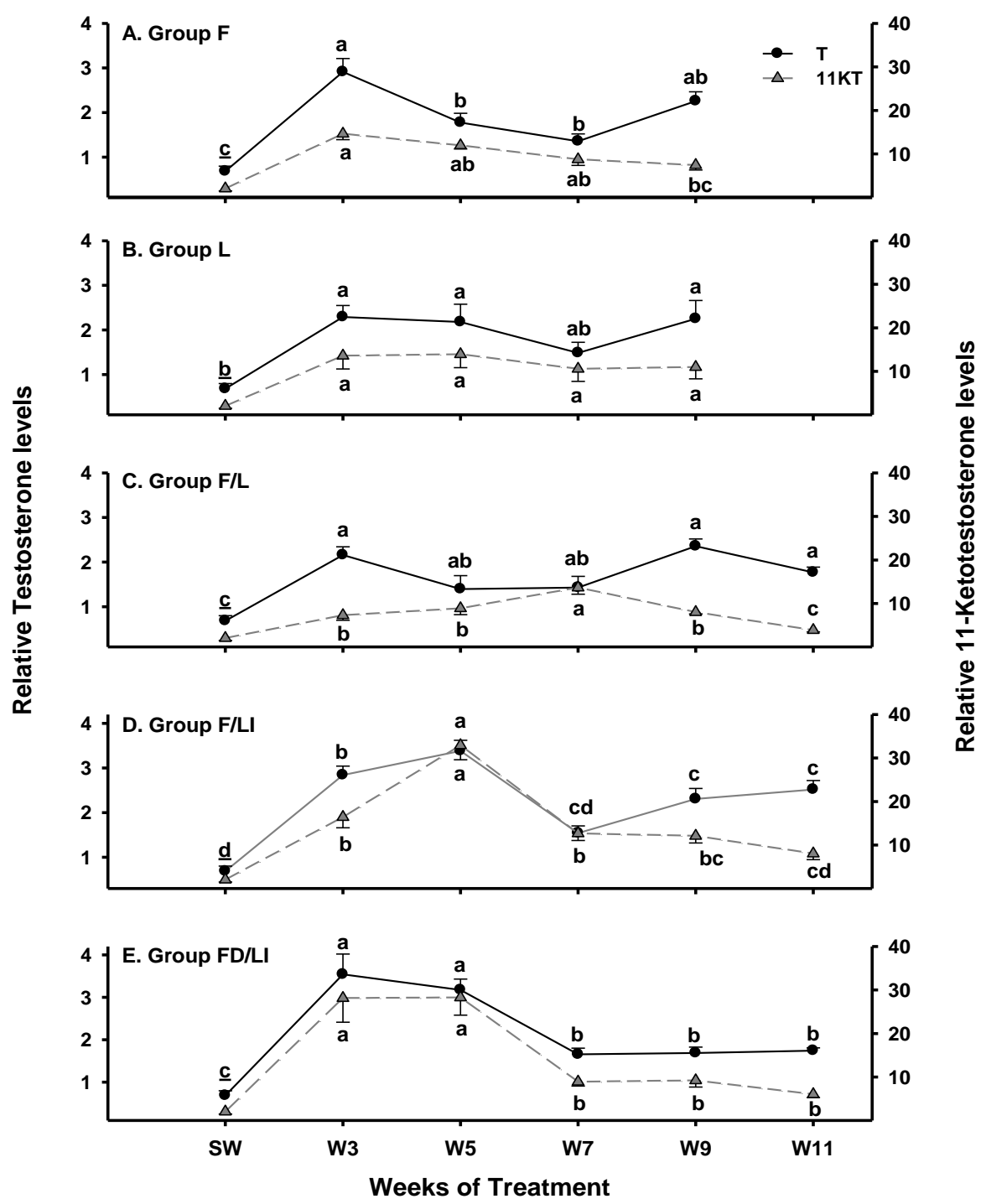

Figure 10. Profile plasma levels of testosterone $(T)$ and 11-ketotestosterone (11KT) before hormone administration (sea water conditions, SW) and throughout the hormonal treatments (groups $F$ and $L$ until $9^{\text {th }}$ week; groups $F / L, F / L I$ and $F D / L I$ until $11^{\text {th }}$ week) in the experiment 1. Steroid levels ( $T$ and $11 K T$ ) are represented as fold change with respect to the mean value of samples from freshwater fish $(1.80 \pm 0.14 \mathrm{ng} \mathrm{T} / \mathrm{ml}$ and $0.29 \pm 0.05 \mathrm{ng} 11 \mathrm{KT} / \mathrm{ml})$. Data are expressed as mean \pm SEM ( $n=6-8$ per sampling and treatment). Different letters indicate significant differences over the weeks within the same hormonal treatment. 

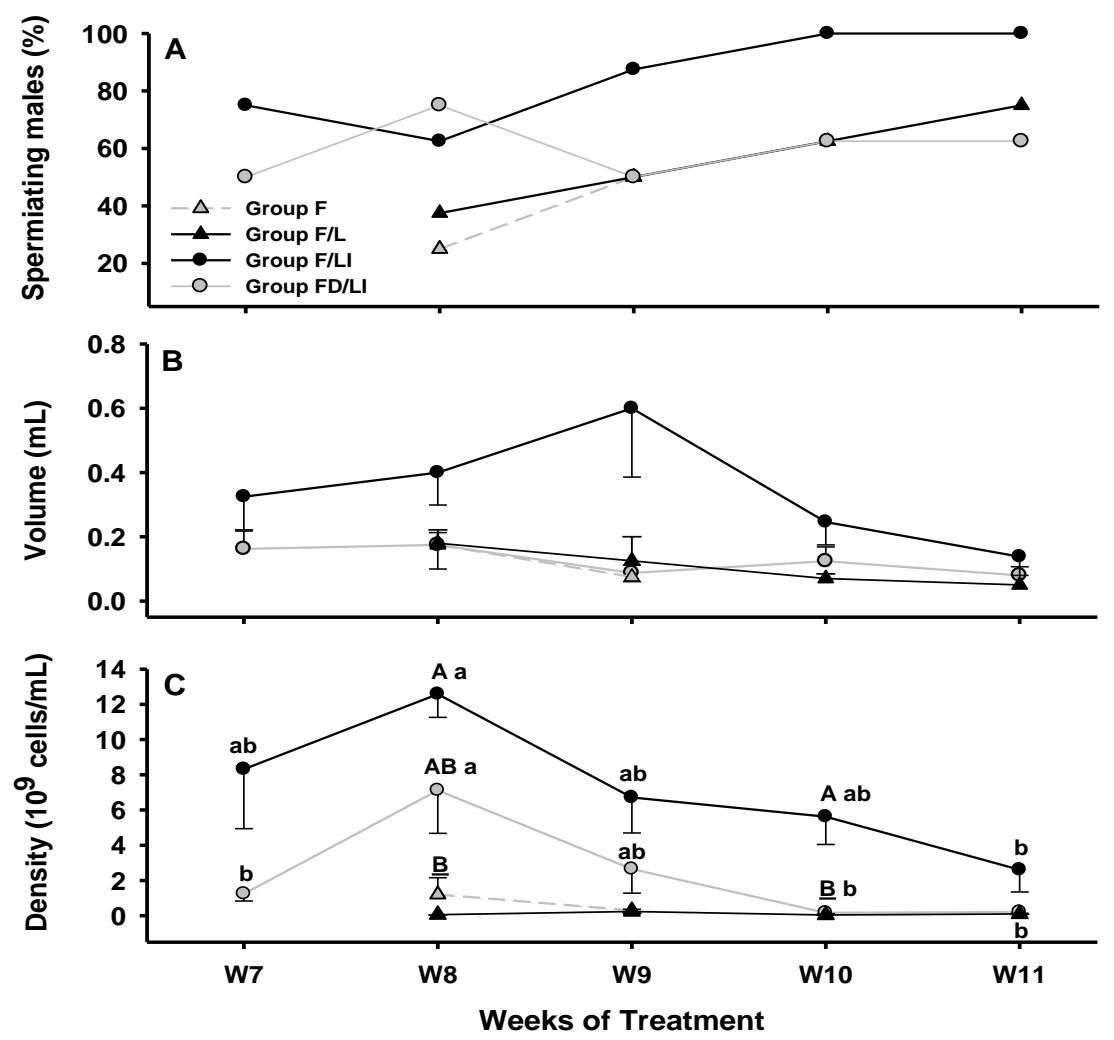

Figure 11. Evolution of sperm production parameters throughout the recombinant gonadotropin treatments (groups $F$ and $L$ until $9^{\text {th }}$ week; groups $F / L, F / L I$ and $F D / L I$ until $11^{\text {th }}$ week) in the experiment 1. A) Percentage of spermiating males; B) Sperm volume; and C) Sperm density. Data are expressed as mean \pm SEM ( $n=6-8$ per sampling and treatment). Capital letters indicate statistical differences between groups (treatments), and lowercase letters indicate statistical differences over the time in the same treatment.

Group F/LI (which received constant doses of aarFsh and increasing doses of aarLh) yielded the best results, with $100 \%$ of males reaching spermiation at weeks 10 and 11 . Sperm volumes were remarkably low in all the treatments, with no significant differences observed over the course of the weeks neither within the individual groups nor between the different treatments (Fig. 6A and 11B). The highest density values were observed in group $\mathrm{F} / \mathrm{LI}$, with significant differences observed in weeks 8 and 10 (Fig. 11C). Regarding sperm quality, total (TM) and progressive (PM) motilities (Figs. 12A and 11B) yielded the highest 
values at week 8 in group F/LI (without significant differences inter-treatments but with significant differences intra-treatment (Fig. 6B), with the maximum values reached being $20 \%$ TM and $2 \%$ PM. From the $8^{\text {th }}$ week on, males from all the treatments displayed a marked decrease in total and progressive motility. The kinetic parameters of the sperm cells (VCL and VSL; Figs. 12C and 12D) showed a similar evolution in groups $\mathrm{F} / \mathrm{LI}$ and FD/LI, with the highest peak being observed at week 8 followed by a progressive decrease until the end of the treatment. Groups F and F/L did not show any variations over the course of the weeks and the velocity values remained low and constant throughout the weeks of spermiation.
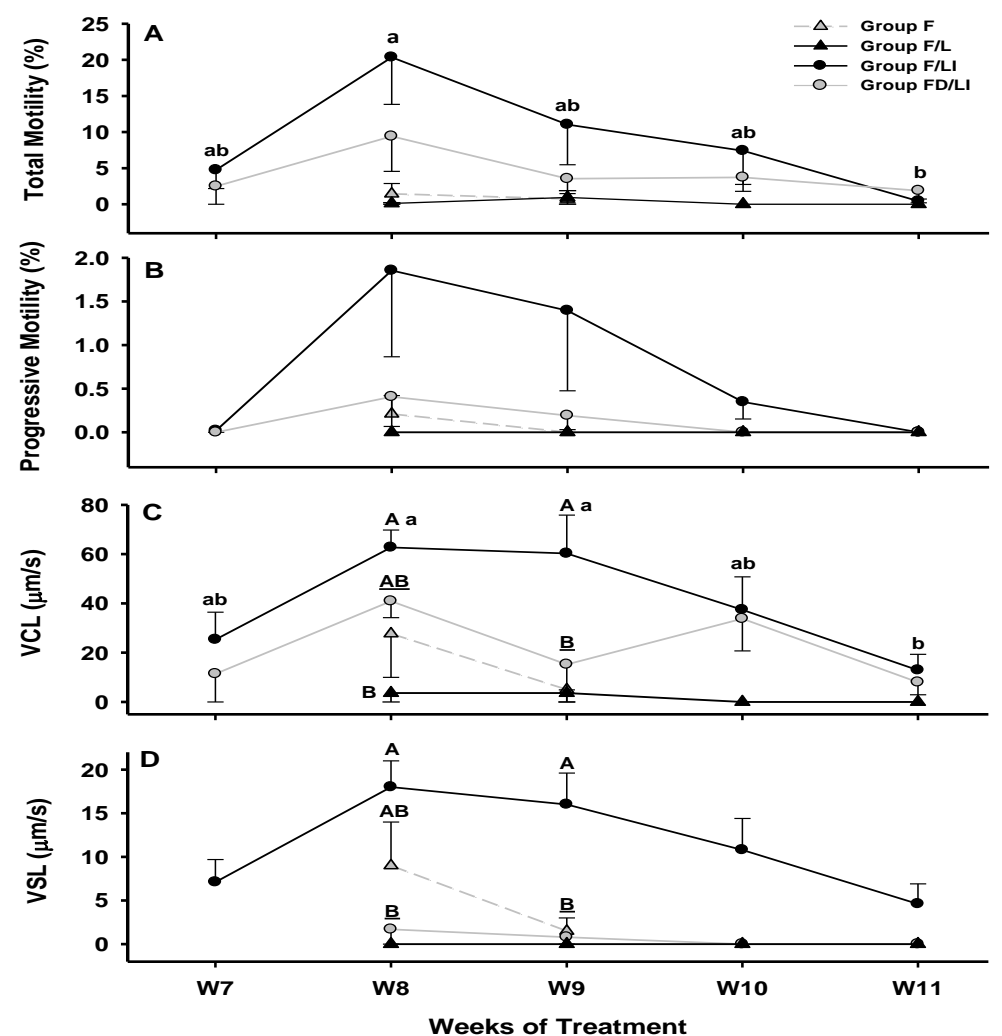

Figure 12. Evolution of sperm kinetic parameters throughout the recombinant gonadotropin treatments (groups $F$ and $L$ until $9^{\text {th }}$ week; groups $F / L, F / L I$ and $F D / L I$ until $11^{\text {th }}$ week) in the experiment 1. A) Total motility; B) Progressive motility; C) Curvilinear velocity (VCL); and D) Rectilinear velocity (VSL). Data are expressed as mean \pm SEM ( $n=6-8$ per sampling and treatment). Capital letters indicate statistical differences between groups (treatments), and lowercase letters indicate statistical differences over the time in the same treatment. 


\subsubsection{Experiment 2}

Biometric parameters: El, FC and GSI

Table 2. Biometric parameters (eye index and fin colour) over the weeks in the three experimental groups (High, Medium and Low) in the experiment 2. Data are expressed as mean (SEM); $n=3-7$. Different letters indicates significant differences between groups at the same week and different letters indicate significant differences among weeks for the same hormonal treatment.

\section{Eye Index}

\begin{tabular}{|c|c|c|c|c|c|c|}
\hline \multirow[b]{2}{*}{ sW } & \multicolumn{2}{|c|}{ High } & \multicolumn{2}{|c|}{ Medium } & \multicolumn{2}{|r|}{ Low } \\
\hline & 3.3 & $(0.2) c$ & 3.3 & $(0.2) c$ & 3.3 & $(0.2) c$ \\
\hline W3 & 4.6 & $(0.1) b$ & 4.2 & $(0.2) b$ & 4.0 & $(0.2) b c$ \\
\hline w6 & 5.0 & $(0.2) b$ & 4.4 & $(0.2) b$ & 3.8 & $(0.4) b c$ \\
\hline N9 & 5.4 & $(0.5) a$ & 6.5 & (0.7) ab & 4.7 & $(0.4) a b$ \\
\hline N12 & 7.0 & $(0.6) a$ & 5.8 & $(0.3) \mathrm{a}$ & 5.6 & $(0.2) a$ \\
\hline
\end{tabular}

Fin Colour

\begin{tabular}{|c|c|c|c|c|c|c|}
\hline \multirow[b]{2}{*}{ SW } & \multicolumn{2}{|c|}{ High } & \multicolumn{2}{|c|}{ Medium } & \multicolumn{2}{|c|}{ Low } \\
\hline & 1.0 & $(0.0)$ & 1.0 & $(0.0)$ & 1.0 & $(0.0)$ \\
\hline W3 & 2.7 & $(0.3)$ & 1.3 & $(0.3)$ & 2.0 & $(0.0)$ \\
\hline W6 & 4.0 & $(0.0)$ & 2.7 & $(0.3)$ & 3.0 & $(0.6)$ \\
\hline W9 & 4.0 & $(0.0)$ & 4.0 & $(0.0)$ & 3.3 & $(0.3)$ \\
\hline W12 & 3.7 & $(0.3)$ & 3.1 & $(0.3)$ & 3.7 & $(0.2)$ \\
\hline
\end{tabular}

Regarding El (Table 2), a significant increase was observed in all the groups between the initial SW values and the values recorded in the $3^{\text {rd }}$ week. This was followed by a continual increase in this parameter throughout the hormonal treatments, with peaks in weeks 9 and 12. FC progressively darkened, but at 
different rates depending on the treatment, becoming almost completely black in weeks 6, 9 and 12 in the High, Medium and Low treatments, respectively.

Irrespective of the treatment, no significant differences were observed in the GSI until the $12^{\text {th }}$ week, when the values became significantly higher than controls, reaching values of $0.9,1.8$ and $4.3 \%$ in the Low, Medium and High treatments, respectively (Fig. 13). In addition, significantly higher GSI values were achieved in the High treatment compared to the other treatments, thus indicating an interaction between factors (week and treatment).

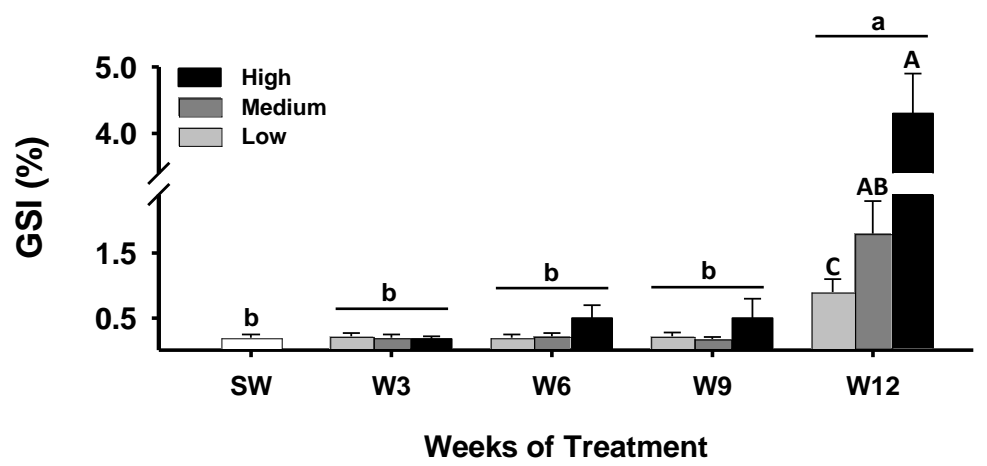

Figure 13. Gonadosomatic indexes of three experimental groups (High, Medium and Low treatments) over the weeks in the experiment 2. Data are expressed as mean \pm SEM ( $n=3-7)$. Asterisk indicates significant differences between groups at the same week and different letters indicate significant differences between weeks for the same hormonal treatment.

\section{Progression of gonad development}

Regarding testis development (Table 3), 6 weeks after the start of the treatments, the High and Medium groups demonstrated the most advanced development, with 33\% of fish from both groups having arrived at stage SPC2, with meiosis as the dominant process. The Low treatment did not induce an evident testis development until week 9 , when first spermatogonia $B$, and well developed testis lumen were observed. In all the treatments, the spermiating stages (SPZ1 and SPZ2) were reached in week 12, but only high doses of aarFsh resulted in $100 \%$ of eel males reaching the spermiation stages (SPZ1 and SPZ2), 
with the Medium and Low doses only able to induce these stages in 57\% (4/7) and $42 \%(3 / 7)$ of the fish, respectively.

Table 3. Distribution of stages of testis development reached by the different males through the samplings (W3-12) in the three experimental groups: (•) High (2.8 $\mu \mathrm{g}$ aarFsh/fish); (•) Medium (1.4 $\mu \mathrm{g}$ aarFsh/fish); and (0) Low (0.7 $\mu \mathrm{g}$ aarFsh/fish). Stages: SPG1: Spermatogonia 1; SPG2: Spermatogonia 2; SPC1: Spermatocyte 1; SPC2: Spermatocyte 2; SD: Spermatid; SPZ1: Spermatozoa 1; SPZ2: Spermatozoa 2.

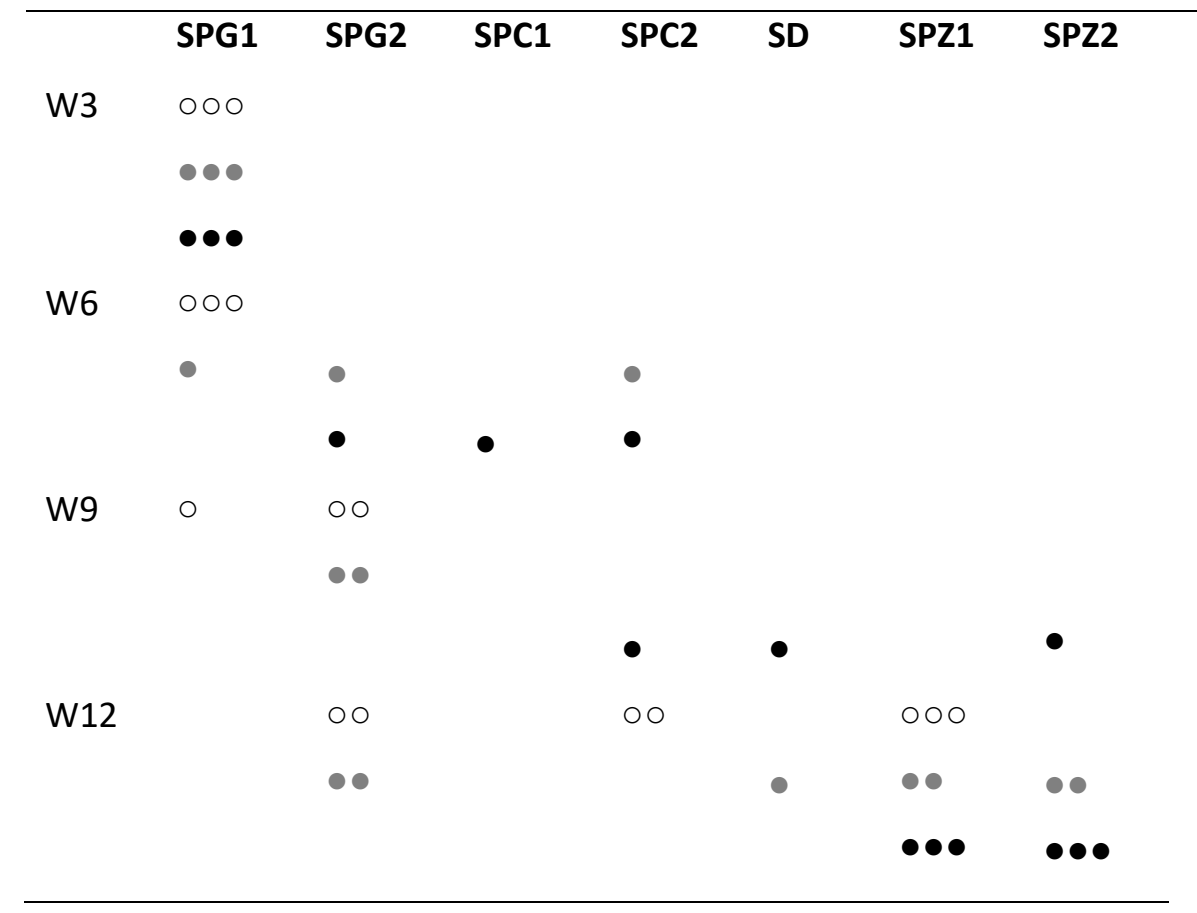

Steroid evolution during hormonal treatment

The administration of aarFsh and aarLh throughout the Low and Medium treatments was able to initiate the production of $11 \mathrm{KT}$ and $\mathrm{T}$ (Fig. 14), but without reaching significant differences in comparison to the initial levels.

However, the aarGths doses used in the High treatment generated a progressive increase in the plasma levels of both androgens, which reached their highest values in the $6^{\text {th }}$ week (Fig. 14A), followed by a progressive decrease until the end of the treatment. 


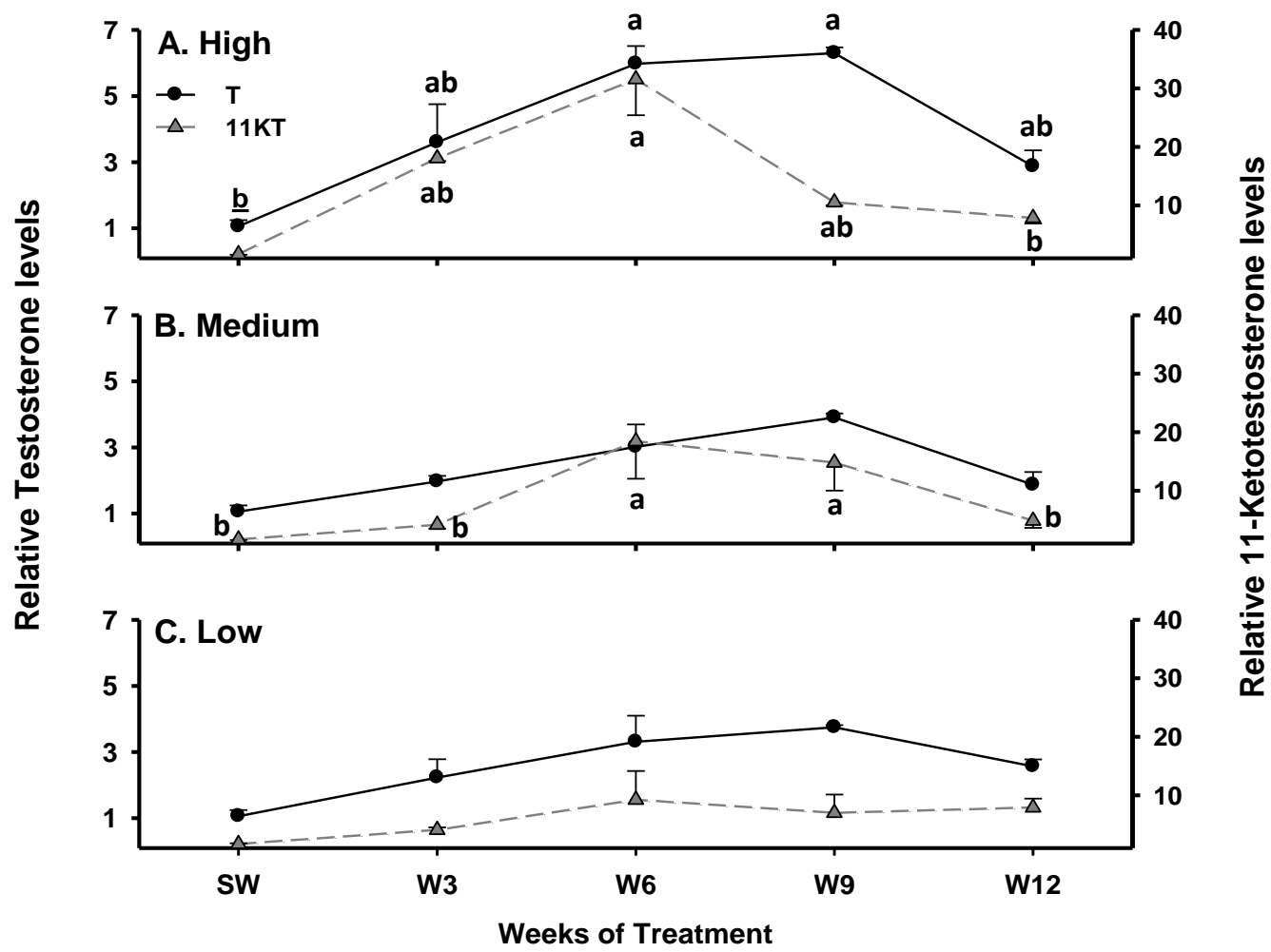

Figure 14. Profile plasma levels of testosterone (T) and 11-ketotestosterone (11KT) before hormone administration (sea water conditions, SW) and throughout the hormonal treatments (High, Medium and Low) in the experiment 2. Steroid levels ( $T$ and $11 K T$ ) are represented as fold change with respect to the mean value of samples from freshwater fish $(2.12 \pm 0.22 \mathrm{ng} \mathrm{T} / \mathrm{ml}$ and $1.80 \pm 0.21 \mathrm{ng} 11 \mathrm{KT} / \mathrm{ml})$. Data are expressed as mean \pm SEM ( $n=3-7$ per sampling and treatment). Different letters indicate significant differences over the weeks for the same hormonal treatment.

\section{Sperm quality analyses}

The percentage of spermiating males was constant (around 60\%) at High treatment for first weeks of spermiation, but then they increased to $80 \%$ at week 11 (Fig. 15A). 


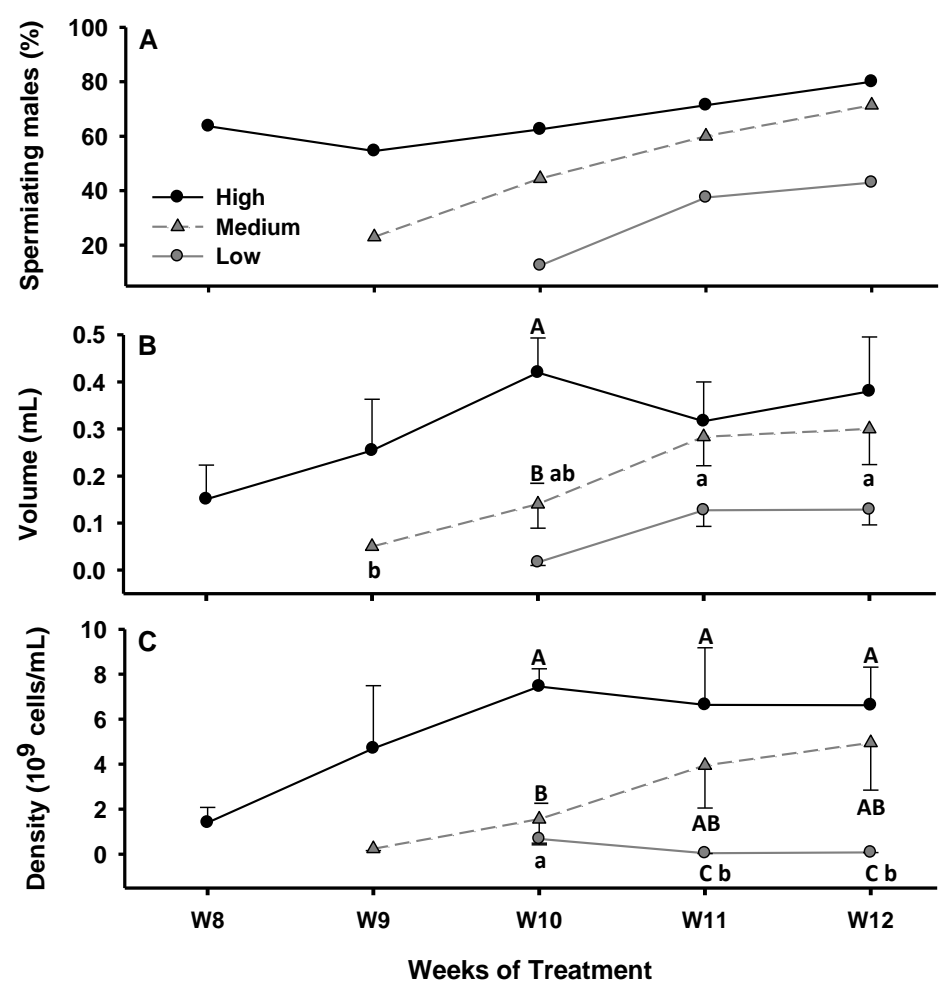

Figure 15. Evolution of sperm production parameters throughout the recombinant gonadotropin treatments (High, Medium and Low) in the experiment 2. A) Percentage of spermiating males; B) Sperm volume; and C) Sperm density. Data are expressed as mean \pm SEM ( $n=3-7$ per sampling and treatment). Capital letters indicate statistical differences between groups (treatments), and lowercase letters indicate statistical differences over the time in the same treatment.

The Medium and Low treated males did not begin to produce sperm until weeks 9 and 10, respectively, reaching approximately 40\% (Low group) and 70\% (Medium group) of spermiating males in week 12. Sperm volumes were remarkably low and showed a progressive increase over the weeks (Fig. 15B and 16A). The High treatment yielded the highest volumes every week, with the values being significantly higher than those recorded in the Medium and Low treatments at week 10 . Sperm density values followed the same pattern as volume, but with significantly lower values in the Low treatment at weeks 10, 11 and 12 (Fig. 15C). 

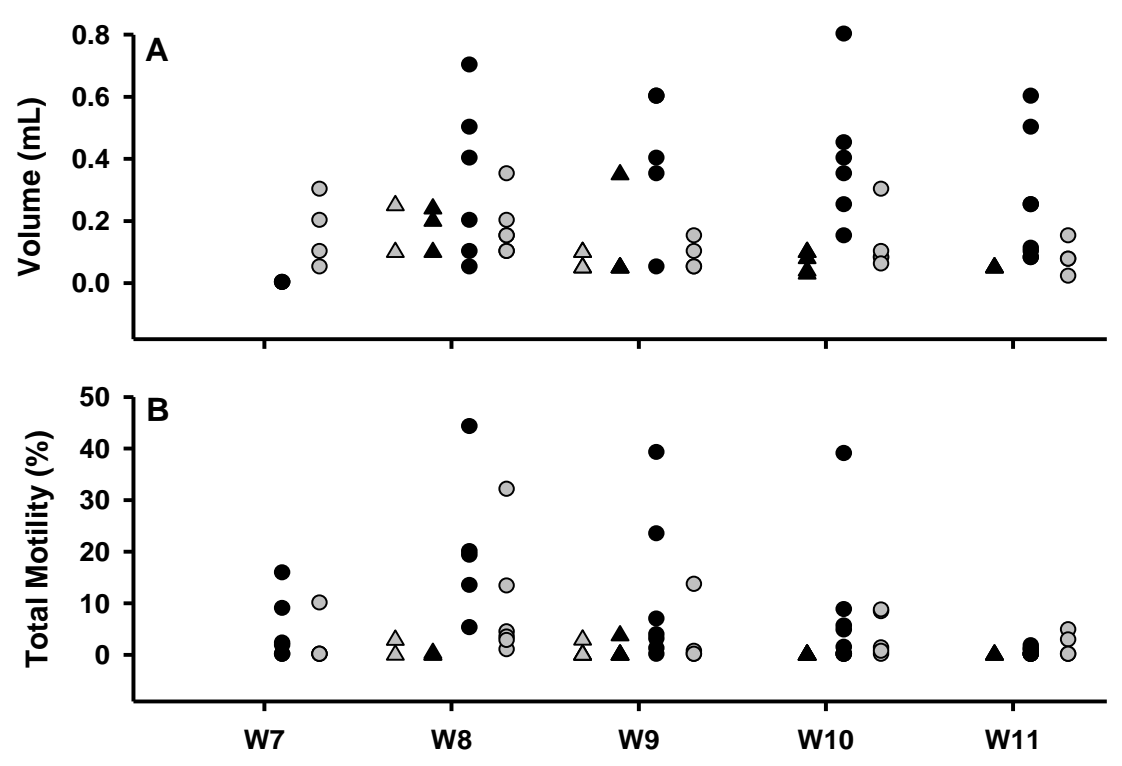

Figure 16. Evolution total motility throughout the recombinant gonadotropin treatments in the experiment 1: Group $F(\triangle)$, Group $F / L(\Delta)$, Group $F / L I(\bullet)$, and Group $F D / L I(O)$ treatment. Each point means a data from an individual male.
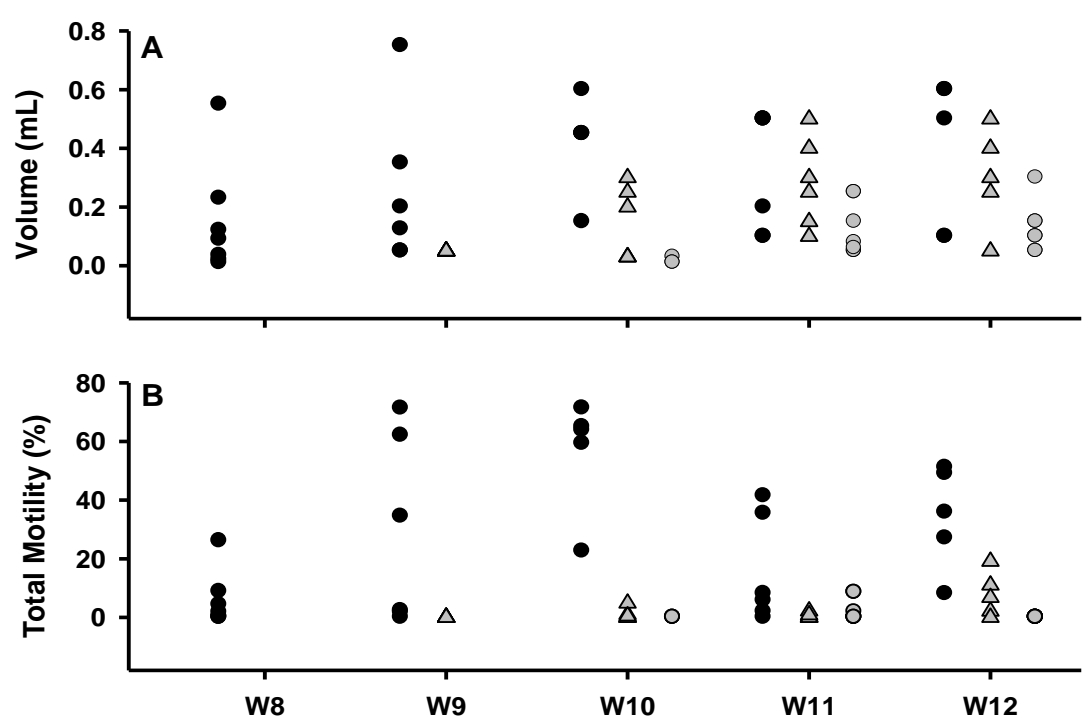

Figure 17. Evolution total motility throughout the recombinant gonadotropin treatments in the experiment 2: High $(\mathbf{)})$, Medium $(\triangle)$, and Low $(O)$ treatment. Each point means a data from an individual male. 
Regarding the kinetic parameters, total (TM) and progressive (PM) motility (Figs. $17 \mathrm{~B}, 18 \mathrm{~A}$ and $18 \mathrm{~B}$ ), yielded the best values in the High treatment, with significant differences at weeks 10 and 12, and maximum values of 60 and $30 \%$ of TM and PM, respectively. Moreover, by analyzing these parameters an interaction between factors (week and treatment) became apparent. The motility values of the sperm in the Medium and Low groups did not reach more than $50 \%$ in any week. The velocity values (VCL and VSL; Figs. 18D and 18E) were significantly higher in the group treated with the High dose of aarFsh, with the highest peak being observed in week 10 followed by a progressive decrease until the end of the treatment. Little or no variations were observed in the Medium and Low treatments over the course of the weeks, and the velocity values remained low and regular during the weeks of spermiation.

\subsection{Discussion}

\subsubsection{Experiment 1}

The present study demonstrated that the aarGths produced by a $\mathrm{CHO}$ system are biologically active and their half-life is long enough to induce in vivo effects. aarFsh alone and all the combined aarFsh and aarLh treatments were able to induce spermiation, whereas aarLh alone failed to induce completion of the maturation cycle, with the fish maturation being interrupted at the pre-meiosis stage (SPG2), with testis showing only SPGA and some lumen development.

\section{Biometric parameters: El, FC and GSI}

With the aim of monitoring the progression of maturation, different biometric parameters (El and $\mathrm{FC}$ ) were used. El changed according to the maturation stage and the treatment. Similarly, an increase in El was observed when the aarGths were combined or when aarLh alone was administered, nevertheless aarFsh alone registered a lower El. Results from previous studies corroborate our data, 
since consecutive injections with eel Lh-producing implants induced a significant increase in the El in European eel females (Ron Dirks, personal communication). Furthermore, the coexistence of duplicated Lh receptors in the European eel genome has recently been demonstrated (Maugars and Dufour 2015).
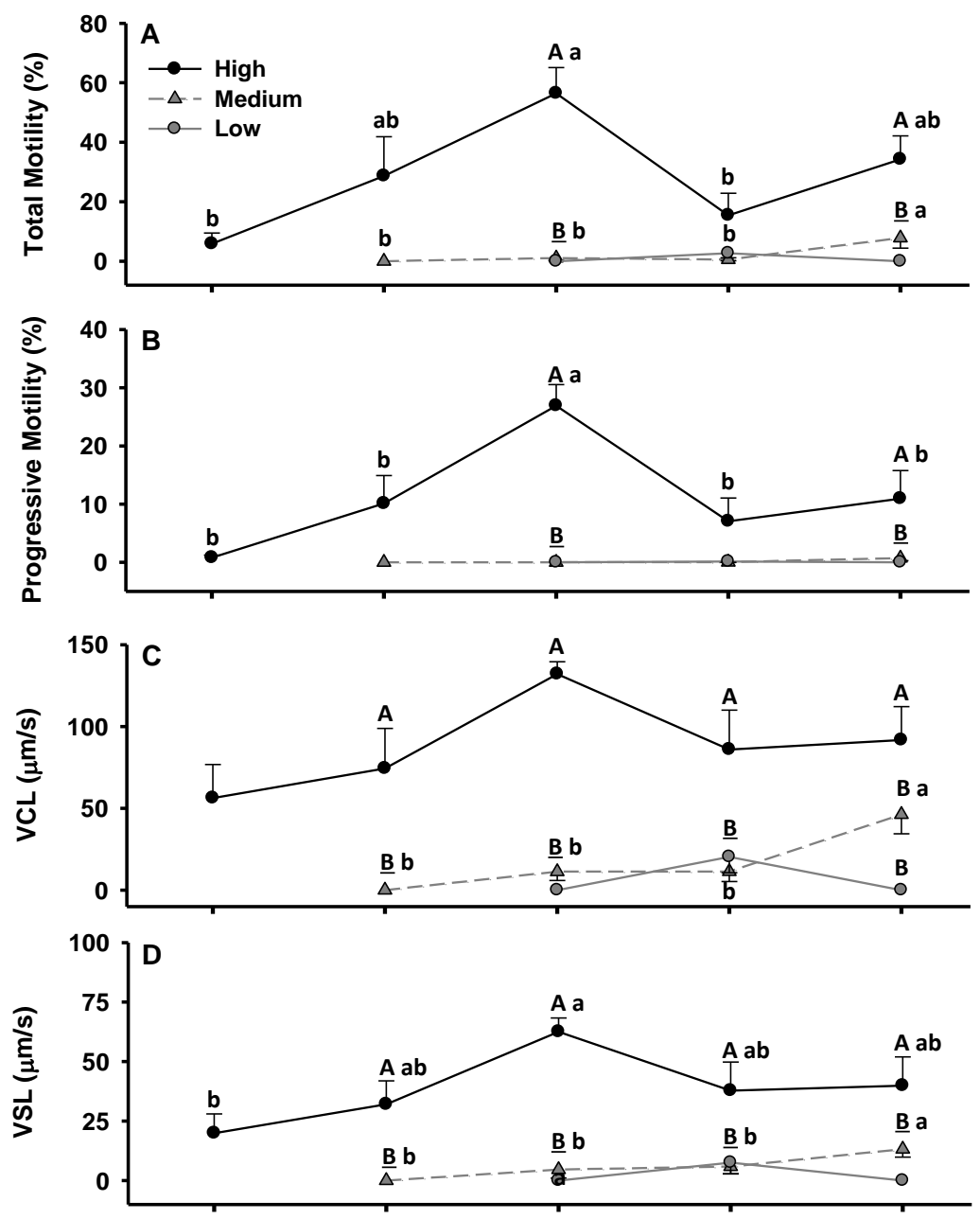

Figure 18. Evolution of sperm kinetic parameters throughout the recombinant gonadotropin treatments (High, Medium and Low) in the experiment 2. A) Total motility; B) Progressive motility; C) Curvilinear velocity (VCL); and D) Rectilinear velocity (VSL). Data are expressed as mean \pm SEM ( $n=3-7$ per sampling and treatment). Capital letters indicate statistical differences between groups (treatments), and lowercase letters indicate statistical differences over the time in the same treatment. 
A comparative tissue distribution study in silvering migrating females, a high transcription of both Lh receptors but no Fsh receptor transcription was reported in eye tissue. This therefore would indicate that aarLh is the main factor involved in inducing eye development and El increase.

The FC became darker throughout the course of maturation, irrespective of the treatment. This could mean that both rGths stimulate this process. Rohr et al. (Rohr et al. 2001) proposed that 11KT was responsible for silvering in shortfinned eel (Anguilla australis). This hipothesis is supported by our results, since darker fins and higher $11 \mathrm{KT}$ plasma levels were registered in the same weeks.

All hormonal treatments were able to promote spermatogenesis, but only group F/LI induced a significant increase in the GSI (around 4\%). This value was lower than the values previously registered using rhCG hormones with maximum values of $10 \%$, hormonal treatment which have been demonstrated until now the most effective to mature male eel in captivity (Baeza et al. 2014; Gallego et al. 2012), what indicates that the treatments used in the first experiment can be improved.

The lowest GSI values were obtained in the groups $L$ and $F / L$, what may indicate that the stimulation of the Fsh receptor is crucial in order to complete spermatogenesis, since a total or temporary lack of Fsh has a negative impact on gonad development. On the other hand, in Japanese eel, the administration of only ajrLh (produced in baculovirus-silkworm larvae system) was able to induce a higher GSI than ajrFsh alone (Hayakawa et al. 2008b; Kobayashi et al. 2010). The differences in these studies could be explained by the fact that different systems have been used to produce the rGths, meaning that their bioactivity and half-life could differ (Molés et al. 2011a). In fact, the level of testis development in Japanese eel reached using ajrGths was lower than that obtained in this study with either aarGths (Fig. 7) or hCG (Pérez et al. 2009; 
Mylonas et al. 2017), both of which resulted in complete testis maturation. Therefore, further in vivo studies on the interaction between Gths and their receptors are necessary.

\section{Progression of gonad development}

All the treatments, with the exception of group L (treated with only aarLh), induced complete spermatogenesis, with the most advanced stages of gonad development (SPZ1 and 2) being reached. aarFsh was able not only to induce complete spermatogenesis, as previously observed in vitro in Japanese eel (Ohta et al. 2007; Kazeto et al. 2008), but even $50 \%$ of spermiating males. Fish from treatment $\mathrm{F} / \mathrm{L}$, in which aarFsh administration was arrested after 4 weeks, showed abnormal testis development, with a few spermatozoa cysts in small gonads (GSI 0.15-0.16\%) showing type A spermatogonia, but no spermatocytes nor spermatids, which is the common feature when spermatozoa are present. Two processes could explain this: either the spermatocytes, spermatids, or most type B spermatogonia, have undergone an apoptotic process and were not present in the testes, leaving some spermatozoa cysts, or an abnormal restricted meiosis and spermiogenesis have happened only in a few cysts. We consider the first hypothesis, a regression after Fsh cessation, to be more likely, as apoptotic cells were found.

aarLh stimulated the onset of testis maturation, but it did not induce complete spermatogenesis by itself, unlike Japanese eel rLhs (Hayakawa et al. 2008b). In fact, in Japanese eel, ajrLh (produced by silkworm larvae) resulted in a higher level of testis development than ajrFsh (Kobayashi et al. 2010). Other studies on Japanese eel have shown that ajrFsh (produced in a Drosophila expression system) was able to stimulate the recombinant Fsh receptor even at low doses, but not the Lh receptor. Furthermore ajrLh activated both Gths receptors, although only at high doses (Kazeto et al. 2008). Similar results have been 
observed in other teleosts (Vischer et al. 2003; So et al. 2005; Zmora et al. 2007). Therefore, one possible explanation for the differences found between the Japanese and European eel results could be the fact that the minimum aarLh dose required to stimulate both receptors and obtain a complete spermatogenesis is higher than the one we used in the current study. Moreover, other factors, such as the number of receptors or their sensitivity could also have an effect, and therefore new studies are required in order to understand the mechanism.

\section{Steroid evolution during hormonal treatment}

In previous studies, all Japanese eel rGths were able to induce testis steroidogenesis (Kamei et al. 2005, 2006b; Kazeto et al. 2008; Kobayashi et al. 2010), increasing the T and $11 \mathrm{KT}$ levels both in vitro and in vivo. Furthermore, it is known that in Japanese eel $11 \mathrm{KT}$ alone is able to induce complete spermatogenesis in vitro (Ohta et al. 2007). In the present study, when both aarGths were administered separately they were able to induce androgen steroidogenesis, and resulted in similar profiles. Thus, a lack of $11 \mathrm{KT}$ in aarLhtreated fish (group L, Fig. 10A) would not explain the differences in maturation between aarLh and aarFsh treated fish.

Similar androgen production levels were observed using a sequential treatment; first aarFsh and later aarLh (group F/L). But, the abnormal testis development found in the F/L group would suggest that, unlike what happens in Japanese eel testis in vitro (Ohta et al. 2007), the androgen synthesis was not enough to achieve complete spermatogenesis in vivo. This is corroborated by studies on zebrafish which have shown that Fsh has a direct effect on the testis, not mediated by androgen production. Zebrafish testes cultured with rFsh and trilostane (a $3 \beta$-hydroxisteroid dehydrogenase inhibitor blocking the steroid production), showed an up-regulation of gene transcription in Leydig cells: ins/3, 
cyp17a1 (García-López et al. 2010) and Igf3 (Nóbrega et al. 2015). This in turn stimulated the proliferation and differentiation of the spermatogonia, as well as the beginning of meiosis and development into adult zebrafish testis (Nóbrega et al. 2015). On the other hand, 11KT production was higher in the fish treated with both aarGths (groups F/LI and FD/LI). These groups reached the last stages of maturation and induced sperm production earlier than the other groups.

\section{Sperm quality parameters}

In previous studies, complete in vivo spermatogenesis of immature Japanese eel males has been accomplished after treatment with rGths, but unlike the current study no spermiating male has been obtained (Hayakawa et al. 2008a, 2008b; Kobayashi et al. 2010). Treatment with rGths has resulted in spermiating males in Japanese eel and other teleosts (Kobayashi et al. 2003; Mazón et al. 2013), but the treated fish were already sexually mature. Therefore, as far as we know, this is the first study where spermiating males have been obtained after rGths treatment using totally immature male fish.

The sperm quality was different depending on the hormonal treatment. Although the histological features from the testis in SPZ1 or SPZ2 from treatments $\mathrm{F}, \mathrm{F} / \mathrm{LI}$ and $\mathrm{FD} / \mathrm{LI}$ were similar, the best sperm quality was observed in group $\mathrm{F} / \mathrm{LI}$, with almost $100 \%$ spermiating males and $20 \%$ sperm motility. This group also showed higher levels of testis growth (GSI), sperm volume and sperm density, indicating that a sustained level of aarFsh and an increasing level of aarlh is a good system for inducing the highest sperm production and quality. Even so, the sperm quality was significantly lower than that registered when using rGths of human origin (rhCG; Gallego et al. 2012, 2014b). Consequently, taking into account the results observed in Experiment 1, new hormonal treatments were assayed in Experiment 2. 


\subsubsection{Experiment 2}

In this second experiment, we confirmed that the combination of both rGths is necessary to induce the sex maturation of European eel in captivity. The High treatment group showed similar results in terms of gonad development to the High group in experiment 1. $2.8 \mu \mathrm{g}$ aarFsh/fish was established as the minimum effective dose to induce maturation in male European eel. Moreover, doses higher than $2 \mu \mathrm{g}$ aarLh/fish registered better results in terms of sperm quality.

\section{Biometric parameters: El, FC and GSI}

Generally, El levels were higher in this second experiment than in the first. The aarLh doses were higher in this second experiment, supporting the hypothesis that aarLh is main factor contributing to the increase in El. In terms of FC change, the results were similar to those of the first experiment, with high $11 \mathrm{KT}$ levels coinciding with darker fins.

Unlike in Experiment 1, all the treatments in Experiment 2 resulted in a significant increase in the GSI, confirming that combining both rGths is the best method of inducing eel maturation. No significant differences were observed in the GSI of group F/LI from Experiment 1 (3.83\%; $4 \mu \mathrm{g}$ aarFsh/fish) and that of the High treatment group from Experiment 2 (4.3\%; $2.8 \mu \mathrm{g}$ aarFsh/fish). This suggests that $2.8 \mu \mathrm{g}$ aarFsh/fish is the minimum effective dose for inducing gonad development.

\section{Progression of gonad development}

All three treatments (High, Medium and Low) induced complete spermatogenesis, but the progression of gonad development was delayed and the percentage of fish observed in the spermiating stages (SPZ1 and 2) was lower in the Medium and Low groups. These results suggest that the administration of 
rFsh is relevant for the advancement of spermatogenesis. On the other hand, in previous experiences, rhCG treatments reported faster progression in spermatogenesis and a higher percentage of spermiating males (Peñaranda et al. 2010b; Gallego et al. 2012; Baeza et al. 2014). Thus, further studies are necessary to test if any alternative treatments are able to yield the same or better results than those observed using the traditional method with rhCG.

\section{Steroid evolution during hormonal treatment}

The androgen profiles in this second experiment were similar to those obtained in experiment 1, with higher levels (only significant in the High group) being reached at around week 6 and levels later decreasing (around week 9). However, although the androgen profiles were similar, the results in terms of gonad development were different, with the fish in the second experiment maturing further (reaching the SPD stage at least). These results support the theory that androgen levels on their own are not enough to induce complete spermatogenesis in vivo, and that rGths may have a direct effect on the testes. In fact, 11KT implants in male short-finned eel (Anguilla australis) were not able to induce the same stage of maturation as hCG treatment (Lokman et al. 2016).

\section{Sperm quality parameters}

Motilities close to $60 \%$ were registered in the High treatment group. These values are 3 times higher than the best values obtained in experiment 1, and similar to those reported with the use of rhCG (Gallego et al. 2014a, 2012, 2014b). With regards to other sperm parameters, such as density, progressive motility and kinetic parameters (VCL and VSL), the values observed were similar to those reported in experiments using rhCG (Gallego et al. 2012). Nevertheless, the volume was lower than that achieved by hCG treatments (Peñaranda et al. 2010b). Moreover, after a progressive increase in sperm quality up to week 10 , a subsequent decrease was observed, while longer spermiation periods were 
found with rhCG treatments (Gallego et al. 2012).

In this second experiment, the combination of both aarGths and higher levels of aarLh resulted in an improvement in sperm quality compared to experiment 1 , but without reaching the values reported with rhCG treatments. In consequence, further studies are necessary in order to find out the proper aarGth amount and/or timing of administration.

In conclusion, this study has demonstrated that aarGths are able to induce the spermiation in European eel, and confirmed that the half-life of these rGths is long enough to induce in vivo effects. Nevertheless, due to the fact that a decrease in sperm quality was observed at the end of the treatment, further experiments combining these recombinant hormones are required in order to improve hormonal treatments.

\subsection{Acknowledgements}

This project has received funding from the European Union's Horizon 2020 research and innovation programme under the Marie Sklodowska-Curie grant agreement No 642893 (ETN IMPRESS), the Spanish Ministry of Economy, Industry and Competitiveness (Project REPRO-TEMP; AGL2013-41646-R), Generalitat Valenciana (PROMETEOII/2014/051), VLC/CAMPUS Program (SP20140630) and the COST Office (COST Action FA1205: AQUAGAMETE). VG has a postdoc grant from the UPV (PAID-10-14). We would like to thank M.S. Ibañez for carrying out the ELISAs. 


\section{CHAPTER 2: Cold seawater induces early}

\section{maturational stages in the BPG axis of European eel}

\section{males}

Christoffer Rozenfeld ${ }^{1 \dagger}$, Víctor García-Carpintero ${ }^{2 \dagger}$, Luz Pérez ${ }^{1}$, Victor Gallego ${ }^{1}$, Juan Germán Herranz-Jusdado', Helge Tveiten ${ }^{3}$, Helge K. Johnsen ${ }^{4}$, Romain Fontaine $^{5}$, Finn-Arne Weltzien ${ }^{5}$, Joaquín Cañizares ${ }^{2}$, Juan F. Asturiano ${ }^{1,}{ }^{*}$, David S. Peñaranda ${ }^{1}$

† These authors contributed equally to this work.

1 Grupo de Acuicultura y Biodiversidad. Instituto de Ciencia y Tecnología Animal. Universitat Politècnica de València. Edificio 7G, Camino de Vera s/n, 46022. Valencia, Spain.

2 Instituto de Conservación y Mejora de la Agrodiversidad Valenciana, Universitat Politècnica de València, Camino de Vera s/n, 46022. Valencia, Spain.

3 Norwegian Institute of Fisheries and Food Research - Nofima AS, Muninbakken 9-13, Breivika, 9291 Troms $\varnothing$, Norway.

4 UiT The Arctic University of Norway, Faculty of Biosciences, Fisheries and Economics, Norwegian College of Fishery Science, Muninbakken 21, N-9037, Troms $\varnothing$, Norway.

5 Norwegian University of Life Sciences, Faculty of Veterinary Medicine, Department of Basic Sciences and Aquatic Medicine, Oslo, Norway.

\section{Under review in BMC genomics}




\section{Abstract}

Background: The impossibility of closing the life cycle of the European eel (Anguilla anguilla) in captivity troubles the future of this critically endangered species. In addition, the European eel is a highly valued and demanded resource, thus the successful closing of its life cycle would have a substantial economic and ecological impact. With the aim of obtaining the highest gamete quality, the study of the effects of environmental factors, such as temperature, on reproductive performance may prove valuable. This is especially true for the exposure to cold water, which has been reported to improve sexual maturation in multiple other Actinopterygii species.

Results: European eel males treated with cold seawater $\left(10^{\circ} \mathrm{C}\right.$; T10) for 2 weeks showed an increase in the proliferation of differentiated spermatogonial type $A$ cells, and elevated testosterone and 11-ketotestosterone plasma levels. Transcriptomes from the tissues of the brain-pituitary-gonad (BPG) axis of T10 samples revealed a differential gene expression profile compared to the other experimental groups, with clustering in a principal component analysis and in heat maps of all differentially expressed genes. Furthermore, a functional analysis of differentially expressed genes revealed enriched gene ontology terms involved in the regulation of circadian rhythm, histone modification, meiotic nuclear division, and others.

Conclusions: Cold seawater treatment had a clear effect on the activity of the BPG-axis of European eel males. In particular, our cold seawater treatment induces the synchronization and increased proliferation of specific spermatogonial cells. In the transcriptomic results, genes related to thermoception were observed. This thermoception may have caused the observed effects through epigenetic mechanisms, since all analysed tissues further revealed differentially expressed genes involved in histone modification. 
The presented results support our hypothesis that a low temperature seawater treatment induces an early maturational stage in European eels. This hypothesis is logical given that the average temperature experienced by eels in the early stages of their oceanic reproductive migration is highly similar to that of this cold seawater treatment. Further studies are needed to test whether a cold seawater treatment can improve the response of European eels to artificial hormonal treatment, as the results suggest.

\subsection{Background}

The decrease in the wild population of the European eel (Anguilla anguilla) has led to this species being listed as critically endangered by the International Union for Conservation of Nature (Jacoby, D. and Gollock 2014). Although it is possible to induce sexual maturation in eel using exogenous hormones (Peñaranda et al. 2018; Pérez et al. 2000; Butts et al. 2014; Mylonas et al. 2017), these treatments are long (several months), expensive, result in highly variable rates of fertilization and hatching, and have never resulted in an adult F1 generation. Therefore, it is necessary to improve these procedures in order to reproduce eels in captivity, which in turn would reduce the fishing pressure. Spawning European eels have never been observed in the wild, and the precise environmental conditions under which maturation happens are thus unknown. However, it is commonly hypothesized that maturation is initiated early on in the oceanic reproductive migration, and first comes to completion after or in the late stages of this migration (van Ginneken et al. 2005; Aarestrup et al. 2009). During the last decade, satellite pop-up tag experiments have shown that, after the eels leave the continental shelf $\left(>10^{\circ}\right.$ West longitude), they all migrate at similar temperatures (average of $\sim 10{ }^{\circ} \mathrm{C}$ ), ranging from up to $\sim 12{ }^{\circ} \mathrm{C}$ at night and down to $\sim 8{ }^{\circ} \mathrm{C}$ during the day, due to daily vertical migration (Righton et al. 2016; Aarestrup et al. 2009). The hypothetical spawning area, the Sargasso Sea, is believed to be $\sim 20^{\circ} \mathrm{C}$ at the predicted time of spawning (Boëtius and Boëtius 
1967). Therefore, most artificial European eel maturation experiments have been performed at $\sim 20{ }^{\circ} \mathrm{C}$ (Pérez et al. 2000; Butts et al. 2014; Peñaranda et al. 2010b; Asturiano et al. 2006), but the apparent discrepancy between artificial maturation temperatures and the natural temperatures eels experience during early maturation is an obvious candidate for investigation. Furthermore, cold temperatures in particular, can be beneficial for Actinopterygii sexual maturation, e.g. in white sturgeon (Acipenser transmontanus) 3 months of cold water at 10-12 으, instead of 16-24 으, have been shown to improve late oogenesis, prevent ovarian regression and increase blood estradiol (E2) and 11ketotestosterone (11KT) levels (Webb et al. 1999, 2001). Also, lower fecundity and egg quality in wild Actinopterygii populations have been observed in years with warmer winters, e.g. seen in striped bass (Morone saxatilis; Clark et al. 2005), white sturgeon (Webb et al. 1999, 2001), and others (for review see Hokanson 1977; Wang et al. 2010). Cold water treatments have additionally been shown to be a modulating factor of sexual maturation induction in several teleosts; Particularly in wolffish (Anarhichas lupus; Tveiten and Johnsen 1999), cod (Gadus morhua; Davie et al. 2007; Hansen et al. 2001), pollack (Pollachius pollachius; Suquet et al. 2005), European sea bass (Dicentrarchus labrax; Prat et al. 1999; Mañanós et al. 1997), Eurasian perch (Perca fluviatilis; Migaud et al. 2002), and yellow perch (Perca flavescens; Hokanson 1977).

Previous temperature studies on European eel have illustrated the importance of this environmental factor (Baeza et al. 2014; Pérez et al. 2011; Peñaranda et al. 2016; Mazzeo et al. 2014; Ahn et al. 2012; Gallego et al. 2012). E.g. in hormonally treated females, higher E2 plasma levels and follicle-stimulating hormone beta subunit $(f s h b)$ expression was registered at low temperatures (10 ${ }^{\circ} \mathrm{C}$; Pérez et al. 2011), meanwhile in hormonally treated males, a temperature higher than $10^{\circ} \mathrm{C}$ was necessary in order to achieve complete gonad maturation (Peñaranda et al. 2016). In all these studies, a combination of temperature and 
hormonal treatment effects were studied. If a cold seawater treatment is, in fact, needed for the initiation of early maturation, this should be tested without the administration of hormonal treatments, which bypass the natural endocrine control of maturation.

Thus, we hypothesized that a thermal treatment of low temperatures would be able to stimulate early maturation in the European eel, and could possibly improve current artificial maturation procedures. In order to test the effect of a cold seawater treatment, we exposed European eel males to 3 different temperature regimes, including a constant low temperature $\left(10{ }^{\circ} \mathrm{C}\right.$; T10), a constant high temperature $\left(20^{\circ} \mathrm{C}\right.$; T20) and a variable temperature (Tvar) over the course of 2 weeks. From these fish, we analyzed changes in biometric characteristics (length, weight, fin index, eye index, and hepatosomatic index), key male sex-steroids: namely testosterone $(T)$ and $11 \mathrm{KT}$, pituitary gonadotropin protein levels, the effect on transcriptomes of the BPG axis (brain, pituitary and testis), and histologically identified and quantified spermatogonial cells.

\subsection{Materials and methods}

\section{$\underline{7.2 .1 \text { Fish maintenance }}$}

110 farmed European eel males (mean body weight $97.5 \pm 1.97 \mathrm{~g}$ ) were supplied by Valenciana de Acuicultura S.A. (Puzol, Valencia, Spain) and transported to the Aquaculture Laboratory at the Universitat Politècnica de València (Valencia, Spain), in 2 batches. The fish were kept in 200-L tanks, equipped with individual recirculation systems, temperature control systems (with heaters and coolers), and aeration. The fish were gradually acclimated to seawater (final salinity $37 \pm$ $0.3 \%$ o), over the course of 2 weeks. The temperature, oxygen level and $\mathrm{pH}$ of

rearing were $20^{\circ} \mathrm{C}, 7-8 \mathrm{mg} / \mathrm{L}$ and $\sim 8.2$, respectively. The tanks were covered to keep the level of light as low as possible and to reduce fish stress. The fish were 
not fed throughout the experiment and were sacrificed using an overdose of anesthesia (benzocaine).

\subsubsection{Experimental design}

The following experiment was conducted twice with the same acclimation, control, and treatment but with different n's and samples collected. The first experimental run was conducted with a total of 70 fish while the second run included 40 fish. In both runs, before the experiments began, ten fish were sacrificed at the end of the acclimation period to act as the Control group, and biometric measurements were collected. The biometric measurements included: total weight, total length, vertical and horizontal eye diameters, fin color, liver weight, and pectoral fin length. From these measurements, the eye index (Pankhurst 1982), fin index (Durif et al. 2006) and HSI were calculated as: (eye area / total length) X 100, (fin length / total length) X 100, and (liver weight / total weight) $\times 100$, respectively. Precise gonadosomatic indexes could not be calculated due to the low testes weight, as a consequence of the early maturation state.

In the first run of the experiment, blood samples from the caudal vein were taken from all sacrificed fish and kept in heparinized vials, centrifuged (3500 rpm, $15 \mathrm{~min})$, and blood plasma was stored at $4{ }^{\circ} \mathrm{C}$. Sampled pituitaries, forebrain (telencephalon, diencephalon, and olfactory bulb), and testes from 3 fish were stored in RNA-later at $4{ }^{\circ} \mathrm{C}$ for $24 \mathrm{~h}$ and then at $-20{ }^{\circ} \mathrm{C}$ until RNA extraction. Additional testis samples were fixed in 10\% paraformaldehyde (PFA) diluted in PBS ( $\mathrm{pH} \mathrm{7.4;} \mathrm{10 \%} \mathrm{PFA-PBS)} \mathrm{for} \mathrm{histological} \mathrm{analysis.} \mathrm{In} \mathrm{the} \mathrm{second} \mathrm{run}$ of the experiment, only the pituitaries were sampled and immediately fixed in ice-cold 4\% PFA in PBST (PBS with $0.1 \%$ Tween 20, $\mathrm{pH}=7.4$ ). 
After this control sampling, in both runs, the remaining fish were randomly distributed into 3 200-L tanks with the same conditions that the fish experienced after seawater and temperature acclimation. These 3 tanks were then set up to expose the fish to 3 different temperature regimes for 2 weeks. The 3 regimes included 2 with a constant temperature of $10^{\circ} \mathrm{C}$ (T10) or $20^{\circ} \mathrm{C}$ (T20), and 1 with a variable temperature regime (Tvar) which alternated between 10 and $20{ }^{\circ} \mathrm{C}$ every 12 hours. No hormonal treatments were administered at any time. After the 2 weeks of thermal treatment, biometric measurements were collected from all the fish from both experimental runs. From the first experimental run 3 samples of brain, pituitary, and testes, were collected from 3 fish per group for transcriptome analysis and blood was collected for RIA steroid analysis from all the sacrificed fish. From the second experimental run, the pituitaries of 10 fish per group were sampled for immunofluorescence visualization of gonadotropins.

\subsubsection{Histology}

The testis samples collected from the first experimental run and fixed in $10 \%$ PFA-PBS, were dehydrated in increasing percentages of ethanol, after which the samples were embedded in paraffin. Sections 5-10 $\mu \mathrm{m}$ thick were cut with a Shandom Hypercut manual microtome and stained with hematoxylin and eosin. The slides were then observed with a Nikon Eclipse E-400 microscope, and pictures were taken with a Nikon DS-5M camera attached to the microscope. Cell types (Fig. 19) were categorized following the description suggested by Schulz et al. (Schulz et al. 2010). As such, the most undifferentiated SPG type A cells (SPGAund*; Fig. 19) were characterized as single cells, surrounded by Sertoli cells, with irregular or convoluted nuclear envelopes, with low nuclear heterochromatin, 1 or 2 nuclei, and containing large perinuclear amounts of the electron-dense material called "nuage". The second most undifferentiated SPG type A cells (SPGAund; Fig. 19) were characterized as single cells, surrounded by 
Sertoli cells, with regular nuclear envelopes, 1 prominent nucleolus, with low levels of nuclear heterochromatin, and containing low amounts of perinuclear nuage. Differentiated SPG type A cells (SPGAdiff; Fig. 19) were characterized as cells found in clusters of 2-8 cells surrounded by Sertoli cells, with regular and round or oval nuclear envelopes, 1 or more nucleolus, and with low levels of nuclear heterochromatin or perinuclear nuage. Early SPG type B cells (early SPGB; Fig. 19) were characterized as smaller cells, with little cytoplasmic volume, found in clusters of many cells, with an oval or round nucleus with large amounts of heterochromatin. Furthermore, some cells were identified as SPG cells but could not be distinguished into a specific SPG type (Undefined cells) e.g. due to unclear Sertoli cell projections, broken cells, unfocused field area etc. The number of each cell type was counted, using FIJI/ImageJ software, from 5 microscope fields per sample, and from ten samples per treatment group and the Control.

\subsubsection{Steroid analysis}

Heparinized blood plasma samples were assayed for plasma T and $11 \mathrm{KT}$ levels by radioimmunoassays (RIA) following the protocol described by Schulz (Schulz 1985). Assay characteristics and cross-reactivities of T antisera have previously been examined by Frantzen et al. (Frantzen et al. 2004) and further validated for eel plasma by Mazzeo et al. (Mazzeo et al. 2014). The cross-reactivity of the $11 \mathrm{KT}$ antiserum used in the current study has previously been described by Johnsen et al. (Johnsen et al. 2013) and validated for European eel plasma by Baeza et al. (Baeza et al. 2015b). In summary, $5 \mathrm{~mL}$ diethylether was used to extract free steroids from 100-300 $\mu \mathrm{L}$ plasma by mixing and shaking for $4 \mathrm{~min}$. The aqueous phase was then frozen in liquid nitrogen and the organic phase was transferred to a glass tube. Diethylether was then evaporated in a water bath at $45^{\circ} \mathrm{C}$ and the sample was then reconstituted by the addition of $3 X$ volume of RIA-buffer (300-900 $\mu \mathrm{L})$ and then assayed for each steroid. 


\subsubsection{RNA extraction and sequencing}

Total RNA of brain, pituitary and testis samples of 3 fish were extracted using Ambion (mirVana) and Qiagen (AllPrep) columns following the protocol of PeñaLlopis and Brugarolas (Peña-Llopis and Brugarolas 2013). Resulting RNA was quality and quantity tested on a bioanalyser (Agilent Technologies, USA). RNA samples with RIN values $>8$ and with $>3 \mu \mathrm{g}$ of total RNA were selected for sequencing. Total RNA samples were shipped to the company Macrogen Korea (Seoul, South Korea). Here, mRNA purification was carried out using Sera-mag Magnetic Oligo (dT) Beads, followed by buffer fragmentation. Reverse transcription was followed by PCR amplification to prepare the samples for sequencing, in an Illumina Hiseq-4000 sequencer (Illumina, San Diego, USA), keeping the strand information. The resulting raw sequences are available at the NCBI Sequence Read Archive (SRA) as stated in the section titled "Availability of data and materials".

\subsubsection{Transcriptome analysis}

Raw reads obtained from Macrogen were quality assessed using fastQC software (Andrews 2010) and were quantified with RSEM (Li and Dewey 2011) using our de novo European eel transcriptome (Rozenfeld et al. 2017) as a template. The differentially expressed transcripts were annotated using the Trinotate functional annotation pipeline (Haas et al. 2013) and assigned GO terms by blasting them to the EggNOG gene family database (Huerta-cepas et al. 2016). Successfully annotated transcripts have been described as genes in the results and discussion sections. Fisher's analysis of enrichment was performed on these GO terms (Alexa and Rahnenfuhrer 2016), to assess significantly affected functions and processes. 


\section{$\underline{\text { 7.2.7 Immunofluorescence }}$}

The experiment (explained above) was repeated with ten fish per treatment group and from the Control. Immunolabelling of European eel Lh $\beta$ and Fsh $\beta$ proteins was carried out using the pituitaries of these fish. For this procedure the fixed pituitaries were dehydrated in an increasing gradient series of ethanol solutions and preserved in $100 \%$ methanol at $-20{ }^{\circ} \mathrm{C}$ until rehydration in decreasing concentrations of ethanol, embedding in $3 \%$ agarose, and then cutting into $60 \mu \mathrm{m}$ thick sagittal sections with a vibratome (Leica VT 1000 S, Leica Biosystems GmbH, Nussloch, Germany). 5-10 sections per sample were divided into 2 sets and incubated with agitation for $1 \mathrm{~h}$ at room temperature in blocking solution (normal goat serum 4\%, dimethyl sulfoxide 1\%, and Triton X-100 (Sigma-Aldrich) $0.3 \%$, in PBST) followed by overnight incubation at $4{ }^{\circ} \mathrm{C}$, with agitation, with a rabbit antibody specific to European eel Fsh $\beta$ or $\operatorname{Lh} \beta$ (Rara Avis Biotec S.L., Valencia, Spain), in either set. Hereafter the sections were incubated for $4 \mathrm{~h}$ at room temperature with a goat anti-rabbit IgG coupled to Rb488 (Jackson Immuno Research Europe Ltd.) as the secondary antibody. Finally, sections were treated with DAPI (4,6-diamidino-2-phenylindole dihydrochloride, 1:1000, Sigma-Aldrich) for overnight nuclear counterstaining at $4{ }^{\circ} \mathrm{C}$. The stained sections were mounted on slides using Vectashield H-1000 (Vector laboratories, Burlingame, CA). The results were evaluated with a fluorescence microscope and the fields were captured with the same image parameters. Signal intensity was evaluated on a scale of 1-5 in a blind test. The highest signal from each group is presented in the results section as pictures taken with a Zeiss LSM710 laser scanning confocal microscope equipped with a 10X Plan Neofluar objective lens (N.A. 0.3). The presented pictures were adjusted for brightness and contrast using FIJl/ImageJ software (Fig. 24). Control experiments were performed on tissue slices using the same protocol but without the primary antibody. 


\subsubsection{Statistics}

Results are shown as the mean \pm standard error of the mean (SEM) and differences were considered significant when P-values $<0.05$, when not otherwise specified. We used R version 3.1.3 (R core team, 2015) to perform Pearson's Chi-squared tests with simulated P-values to compare the distribution of fin colour between the 3 treatment groups (T10, T20, and Tvar) and the Control group. After establishing data normality using the asymmetry standard coefficient and Curtosis coefficient we also used $R$ to run general linear models (GLM) to identify significant differences between the groups in the remaining biometric parameters as well as differences in steroid levels. We used a generalized linear mixed model with a negative binominal distribution, and with "field" as a random effect, to compare cell counts and proportions of the histological testis analysis. These tests were also executed with $\mathrm{R}$ version 3.1.3. We furthermore used R to perform a Principal Component Analysis (PCA) for all the quantified expression data from the RNA-sequencing results. Only principal component 1 and 2 were included in the results as they together account for $>98 \%$ of the variance in the data, from all tissues. Significantly differentially expressed transcripts were located with DEseg (Anders and Huber 2010) with a threshold for a false discovery corrected P-value (FDR) of $<0.05$. R was also used to run one-way ANOVA tests of the transcripts per million (TPM) of both gonadotropin beta-subunits from the pituitaries; in the case of Ihb a log transformation of the data was performed to improve the homogeneity of variance across the groups. Finally, $R$ was used to create heat maps and unsupervised hierarchical clusters using a Euclidean distribution of all significantly differentiated expressed genes from each tissue. 


\subsection{Results}

\subsubsection{Biometric parameters}

No differences between the Control and the treated groups were seen in total length, total weight, fin color, eye index, or hepatosomatic index. However, significantly shorter fin lengths were found in the T10 and T20 groups (18.08 \pm 0.36 and $18.190 .36 \mathrm{~mm}$, respectively) compared to the Control and Tvar groups (19.37 \pm 0.38 and $19.31 \pm 0.39 \mathrm{~mm}$, respectively; Table 4).

Table 4. Average biometric measurements observed in the 3 treatment groups and Control. Total fish weight (total weight), total fish length (total length), standardized European eel eye index (eye index), pectoral fin color (fin color), pectoral fin length (fin length), standardized pectoral fin index (fin index), total liver weight (liver weight) and hepatosomatic index (HSI) were measured. Avg. indicates group averages and SEM indicates standard error of the mean.

\begin{tabular}{cccccc}
\hline Parameter\Group & & Control & T10 & T20 & Tvar \\
\hline Total weight & Avg. & 96.67 & 96.04 & 96.19 & 101.06 \\
(g) & SEM & 3.64 & 4.19 & 3.41 & 3.94 \\
Total length & Sign. & $\mathrm{a}$ & $\mathrm{a}$ & $\mathrm{a}$ & $\mathrm{a}$ \\
(cm) & Avg. & 36.88 & 38.21 & 38.02 & 38.11 \\
& SEM & 0.68 & 0.60 & 0.43 & 0.49 \\
Eye Index & Sign. & $\mathrm{a}$ & $\mathrm{a}$ & $\mathrm{a}$ & $\mathrm{a}$ \\
& Avg. & 4.15 & 3.62 & 3.94 & 4.11 \\
Fin Length & SEM & 0.31 & 0.21 & 0.11 & 0.13 \\
(mm) & Sign. & $\mathrm{a}$ & $\mathrm{a}$ & $\mathrm{a}$ & $\mathrm{a}$ \\
Fin index & Avg. & 19.37 & 18.08 & 18.19 & 19.31 \\
& SEM & 0.38 & 0.36 & 0.31 & 0.39 \\
& Sign. & $\mathrm{a}$ & $\mathrm{b}$ & $\mathrm{b}$ & $\mathrm{a}$ \\
Liver weight & Avg. & 5.25 & 4.75 & 4.79 & 5.07 \\
(g) & SEM & 0.07 & 0.11 & 0.07 & 0.10 \\
& Sign. & $\mathrm{a}$ & $\mathrm{b}$ & $\mathrm{b}$ & $\mathrm{a}$ \\
HSI & Avg. & 0.67 & 0.86 & 0.72 & 0.76 \\
& SEM & 0.04 & 0.04 & 0.04 & 0.04 \\
& Sign. & $\mathrm{a}$ & $\mathrm{b}$ & $\mathrm{a}$ & $\mathrm{ab}$ \\
& Avg. & 0.69 & 0.78 & 0.75 & 0.75 \\
& SEM & 0.03 & 0.06 & 0.03 & 0.03 \\
& Sign. & $\mathrm{a}$ & $\mathrm{a}$ & $\mathrm{a}$ & $\mathrm{a}$
\end{tabular}

These differences also resulted in significantly lower fin indexes ( $P$-value $=0.008)$ in the $\mathrm{T} 10$ and $\mathrm{T} 20$ groups ( $4.75 \pm 0.11$ and $4.79 \pm 0.07$, respectively) compared 
to the Control and Tvar groups $(5.25 \pm 0.07$ and 5.07 \pm 0.10 , respectively; Table 4).

\subsubsection{Gonad histology}

SPGAund* (Fig. 19) composed a significantly higher average proportion of the cells identified in the Control samples (11.7 $\pm 1.4 \%$ cells per field) compared to all the 3 treatment groups ( $<1 \%$ cells per field; Fig. 20).

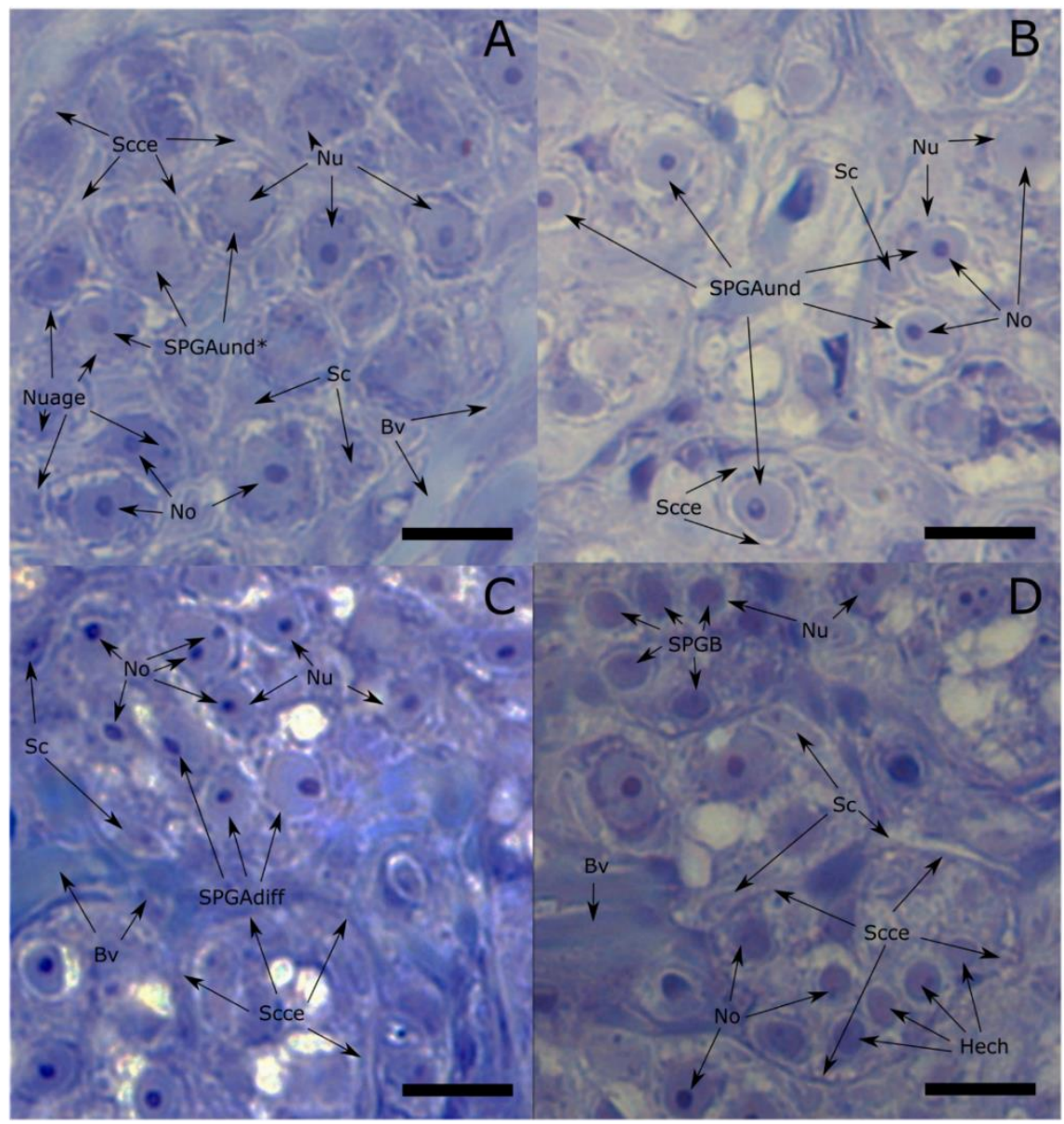

Figure 19. Forty times magnification fields of selected histological sections representing the spermatogonia stages: the most undifferentiated spermatogonia type A (SPGAund*; panel A), the second most undifferentiated spermatogonia type A (SPGAund; panel B), differentiated spermatogonia type A cells (SPGAdiff; panel C), and early spermatogonia type B cells (SPGB; panel $D)$. These identifiable characteristics are further labelled with arrows: Blood vessels (BV), nucleus (Nu), nucleoli (No), Sertoli cells (Sc), Sertoli cell cytoplasmic extensions (Scce), heterochromatin (Hech) and nuage (Nuage). 

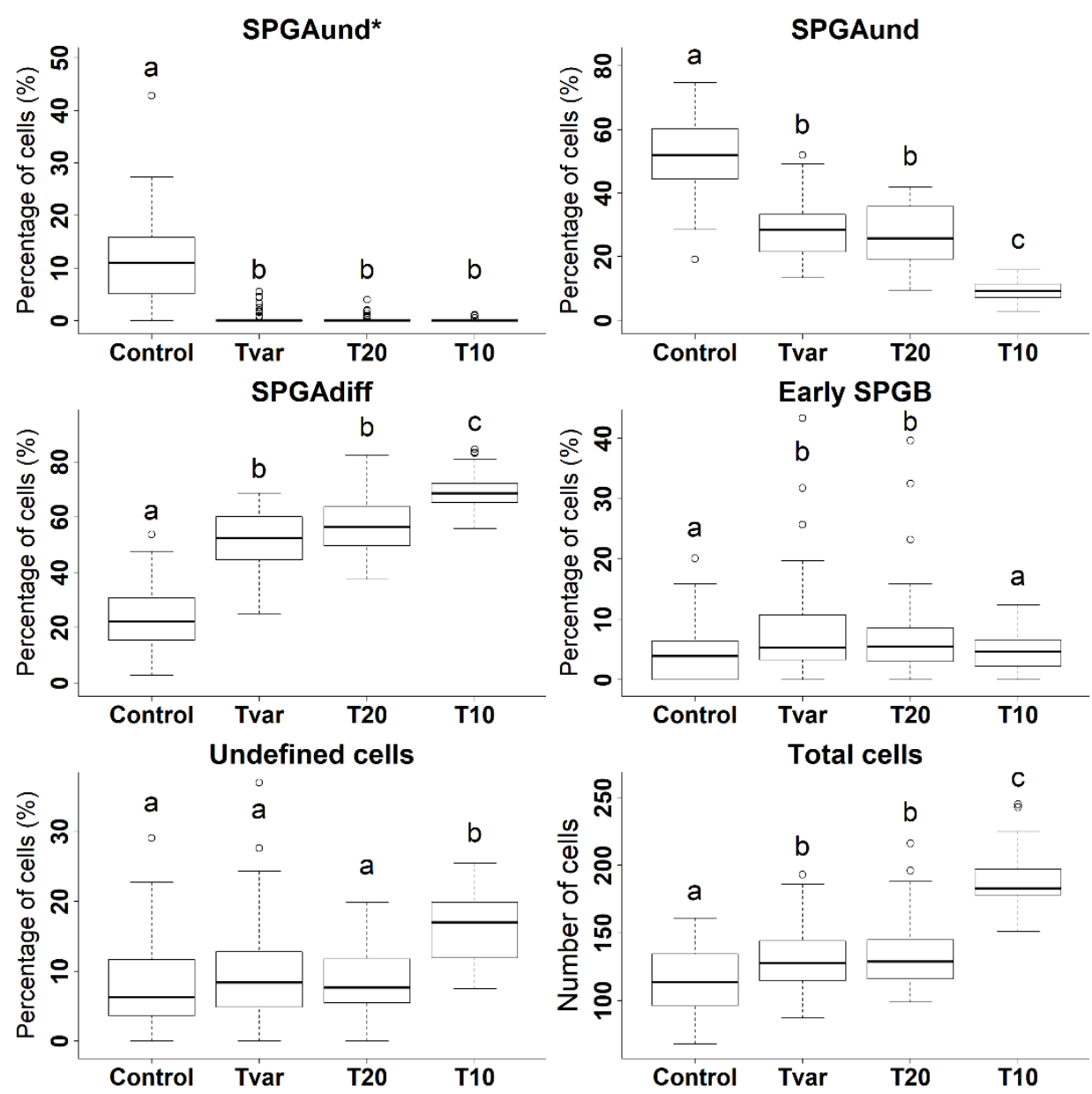

Figure 20. Boxplots of cell counting results for the T10, T20, Tvar and Control groups. The panels show the percentage proportion of the most undifferentiated spermatogonia type $A$ cells (SPGAund*), the second most undifferentiated spermatogonia type A cells (SPGAund), the differentiated spermatogonia type A cells (SPGAdiff), and the early spermatogonia type $B$ cells (Early SPGB) in each group. The panels labelled "Undefined cells" presents the percentage proportion of cells in each group, which were identified as spermatogonial cells but could not be distinguished between the specific spermatogonial cell types. The panels labelled "Total cells" presents the accumulated cells count of all identified cell types in each group. Letters indicate significant differences. 
The Control samples also contained a higher average proportion of SPGAund (Fig. 19) cells per field (52.1 $\pm 1.9 \%)$ compared to Tvar, T20, and T10 (28.7 \pm 1.2 , $26.8 \pm 1.3$, and $9.3 \pm 0.4 \%$, respectively). The proportion of SPGAund cells had an inverse relationship with the proportion of SPGAdiff cells with the T10 samples contained a significantly higher average proportion of SPGAdiff cells per field $(69.6 \pm 1.0 \%)$ compared to the T20, Tvar and Control groups (57.1 \pm 1.5 , $52.3 \pm 1.5$, and $23.8 \pm 1.9 \%$, respectively). Undefined cells were also registered in higher proportions in the T10 samples. Although all the experimental groups contained relatively low average proportions of early SPGB cells (Fig. 19), the T20 and Tvar groups (7.5 \pm 1.1 and $8.2 \pm 1.2 \%$, respectively) reported a higher proportion than the T10 and Control groups $(4.7 \pm 0.5$ and $4.5 \pm 0.8 \%$, respectively). Finally, the average total number of SPG cells per field was significantly higher in the T10 samples (189.9 \pm 3.0 cells per field), compared to the T20, Tvar, and Control groups $(134.0 \pm 3.7,130.7 \pm 3.6$, and $117 \pm 3.8$ cells per field, respectively), while the average total number of SPG cells per field was significantly lower in the Control samples compared to T20 and Tvar (Fig. 20).

\subsubsection{Steroid analysis}

The plasma T analysis revealed a basal level of $0.99 \pm 0.12 \mathrm{ng} / \mathrm{ml}$ in the Control group, which increased significantly to $2.32 \pm 0.17 \mathrm{ng} / \mathrm{ml}$ after rearing the fish for 2 weeks at $10{ }^{\circ} \mathrm{C}$. No differences were observed in the rest of the experimental groups (Fig. 21). The basal 11KT plasma level was $1.67 \pm 0.31$ $\mathrm{ng} / \mathrm{ml}$, which increased significantly after 2 weeks of rearing to $4.46 \pm 0.43 \mathrm{ng} / \mathrm{ml}$ and $3.37 \pm 0.30 \mathrm{ng} / \mathrm{ml}$ at 10 or $20^{\circ} \mathrm{C}$, respectively (Fig. 21). 


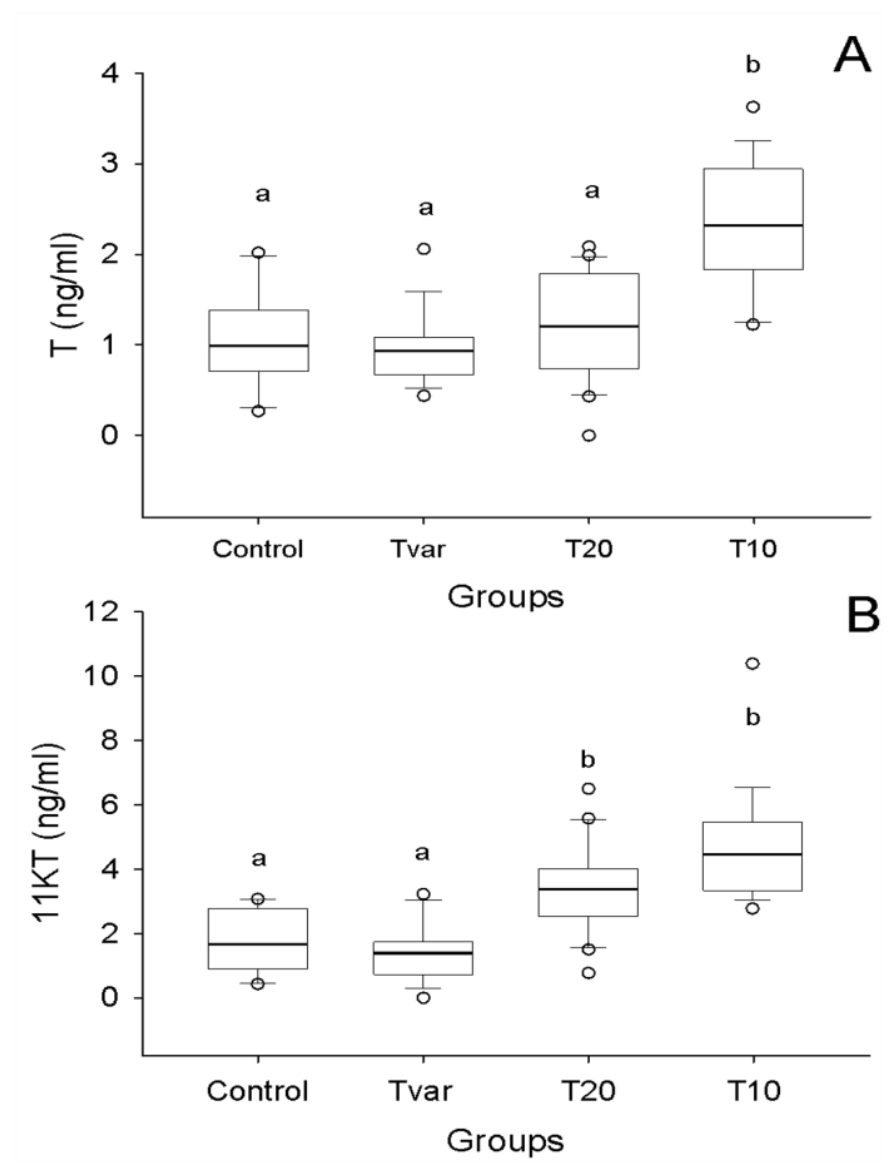

Figure 21. Boxplots of radioimmunoassay steroid results from the blood of fish from the T10, T20, Tvar and control groups. Significant differences are indicated with letters. Panel A shows the testosterone $(T)$ results, while panel B shows the 11-ketotestosterone $(11 \mathrm{KT})$ results.

\subsubsection{Gonadotropin analysis}

Due to their biological relevance, $f s h b$ and luteinizing hormone beta subunit (Ihb) were chosen as target genes for additional analysis. In particular, the TPM for these genes in the pituitary transcriptome were pulled (Fig. 22) and the variance between the groups was analysed with a one-way analysis of Variance (ANOVA). The analysis indicated that temperature caused a significant change to the $/ h b(P$-value $=0.0296)$ expression, while the differences observed in fshb were insignificant $(P$-value $=0.0746)$. 
Ihb

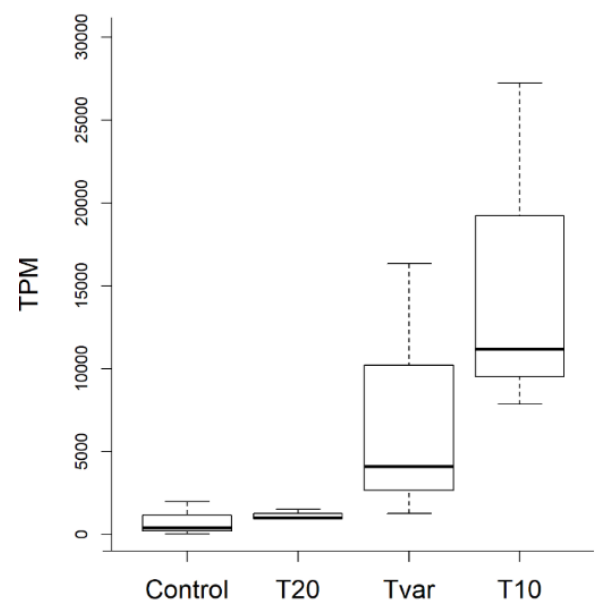

fshb

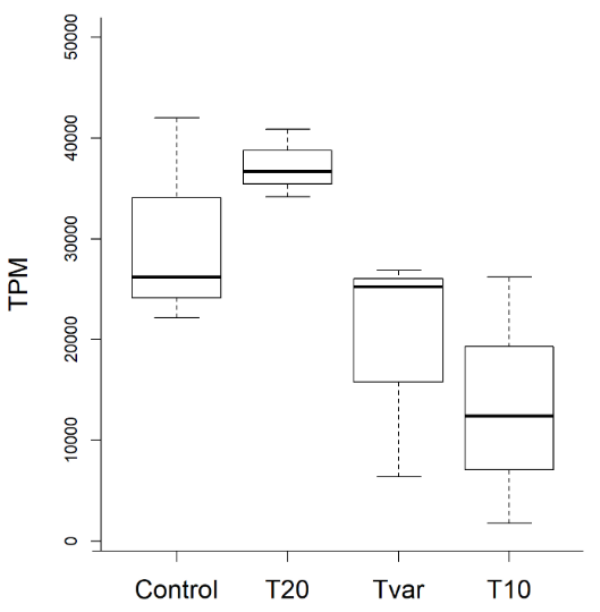

Figure 22. Boxplot of follicle stimulating hormone beta subunit gene expression (fshb) and luteinizing hormone beta subunit gene expression (Ihb), from the pituitary transcriptome analysis. Results are presented for the control group ("Control"), the $10{ }^{\circ} \mathrm{C}$ treated group ("T10"), the $20^{\circ} \mathrm{C}$ treated group ("T20"), and the variable temperature treated group ("Tvar"). Expression values are presented as transcripts per million (TPM). A tendency of decreased fsh$B$ expression and increased Ih- $B$ expression is seen after T10 treatment, with the variable temperature treatment presenting intermediate values.

Furthermore, additional fish were treated in a different experimental run, under the same conditions, and the pituitaries of these fish were sampled. Fsh $\beta$ and Lh $\beta$ immunofluorescence labelling was performed on these pituitaries. The TPM of Tvar were in all cases close to the mean between the expression of T10 and Control or of T10 and T20 (Fig. 22), thus we decided not to include this group in the analysis. Due to loss of pituitary tissue during laboratory analysis (e.g. pituitary drying during incubation or breaking during sectioning), initial " $\mathrm{n}$ " (10) decreased to 6,5 , and 4 for T10, Control, and T20, respectively, for the $\operatorname{Lh} \beta$ immunofluorescence labelling, and to 2, 2, and 3 for T10, Control, and T20 respectively for the Fsh $\beta$ immunofluorescence labelling. All remaining pituitaries were successfully labelled with both $\operatorname{Fsh} \beta$ and $\operatorname{Lh} \beta$; however, no reliable difference could be observed from the Fsh $\beta$ immunofluorescence labelling (Fig. 23), possibly due to the low $n$. On the other hand, a reliably stronger Lh $\beta$ signal 
was seen in the pituitaries of T10 treated fish compared to either Control or T20 (Fig. 24).

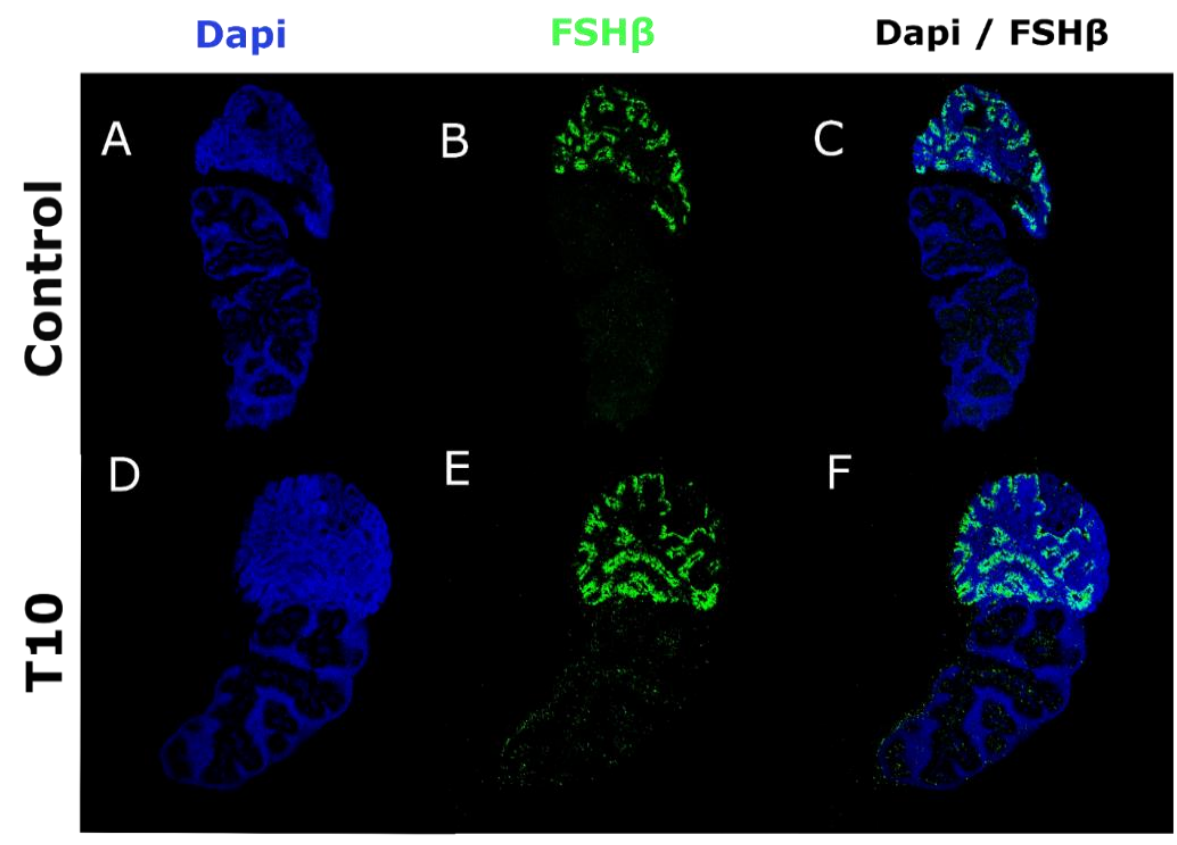

Figure 23. Confocal images of the histochemical labeled European eel (Anguilla anguilla) male pituitaries, which showed the strongest FSHB signal from each of the successfully analyzed groups: the two week $10^{\circ} \mathrm{C}$ pretreated group (T10; panel D, E, and F), and control (Panel A, B, and C). "Dapi" indicates pictures filtered to only reveal fluorescents labeled to 4,6-diamidino-2phenylindole dihydrocholride (Panel $A$ and D). "FSHB" indicates pictures filtered to only reveal fluorescents labeled to follicle stimulating hormone beta subunit protein (Panel B and E). "Dapi / FSHB" indicates pictures filtered to reveal both fluorescents labeled to follicle stimulating hormone beta subunit protein and 4,6-diamidino-2-phenylindole dihydrocholride (Panel $C$ and F).

Due to the nature of immunofluorescence labelling and the use of an objective "quantitative" measuring technique, these results should only be considered as suggestive evidence of $\operatorname{Lh} \beta$ protein level changes. 


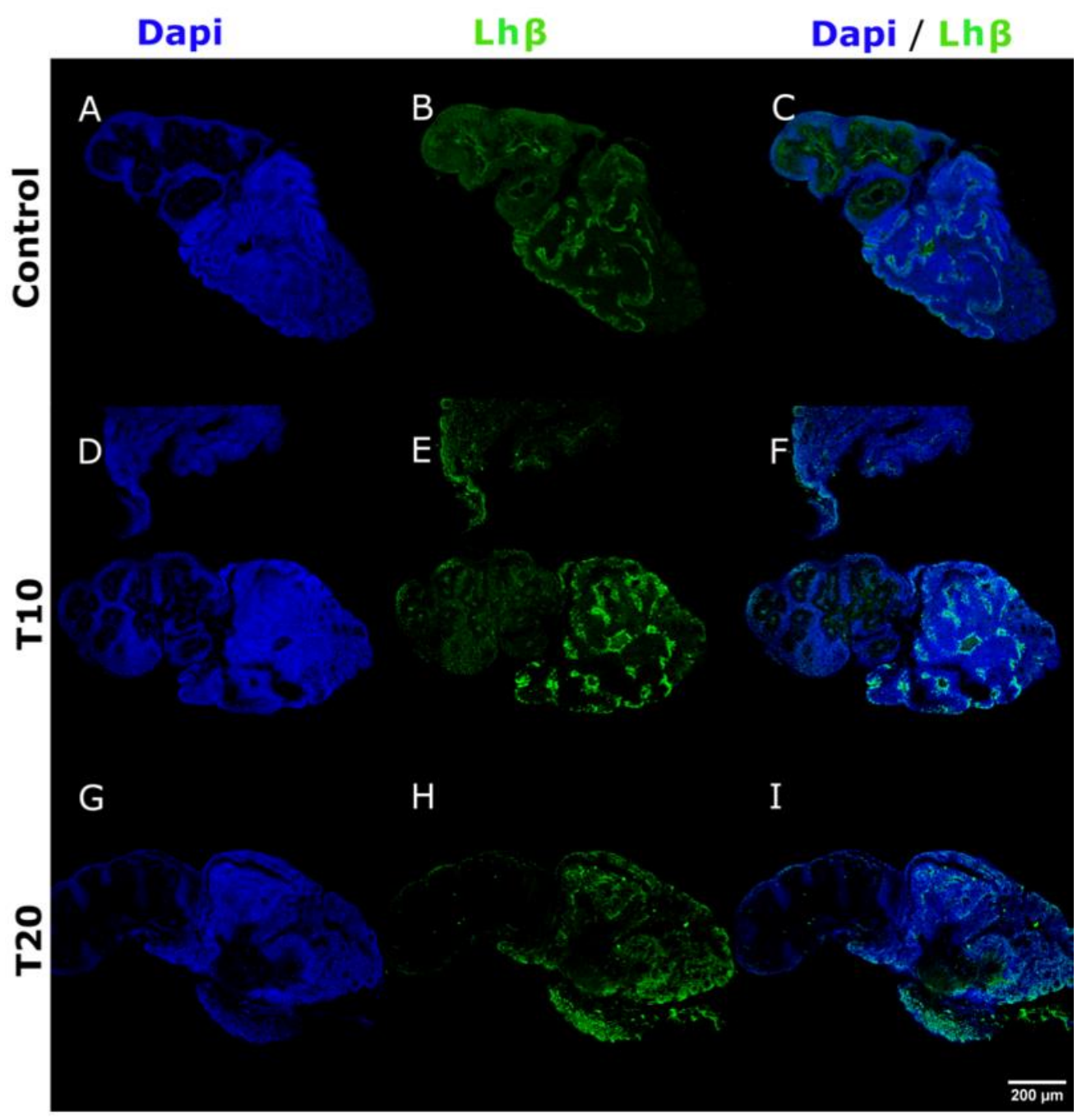

Figure 24. Confocal images of the immunofluorescence labelled European eel (Anguilla anguilla) male pituitaries, which showed the strongest LhB signal from each of the analyzed groups: the 2 week 10 ${ }^{\circ} \mathrm{C}$ pretreated group (T10; panel D, E, and F), the 2 week $20^{\circ} \mathrm{C}$ pretreated group (T20; panel $G, H$, and I), and Control (Panel $A, B$, and C). "DAPI" indicates pictures filtered to only reveal fluorescents labeled to 4,6-diamidino-2-phenylindole dihydrochloride (Panel A, D, and G). "LhB" indicates pictures filtered to only reveal fluorescents labeled to luteinizing hormone beta subunit protein (Panel B, E, and H). "DAPI / LhB" indicates pictures filtered to reveal both fluorescents labelled to luteinizing hormone beta subunit protein and 4,6-diamidino-2-phenylindole dihydrochloride (Panel C, F, and I). 


\subsubsection{RNA-sequencing}

Our raw Illumina data contained between 48 and 75 million 101 bp paired-end reads, sense strand, per library. Using BWA-MEM (Li and Durbin 2010) to map our transcripts to our de novo transcriptome resulted in a mapping percentage range of 89 to $96 \%$. Out of the 77,247 transcripts in our transcriptome, 25,368 protein coding genes were predicted. Using DEseq, differentially expressed transcripts $(F D R<0.05)$ were determined between the 3 treatment groups (T10, T20, and Tvar) and the Control group, in all combinations and for the 3 tissues: brain, pituitary, and testes. Approximately half of the differentially expressed transcripts could be annotated with a gene symbol and assigned gene ontology (GO) terms, with little variation between groups (Table 5). All differentially expressed genes have been accumulated into 3 heat maps (one per tissue), which can be found in figure 25-27.

Table 5. Quantitative data of differential transcript and gene expression between transcriptomes from brain, pituitary, and testis samples. E.g. The row header "T10 vs Control" indicates differentially expressed transcripts and genes between $T 10$ and Control. The quantity of transcripts characterized as differentially expressed by DEseq analysis provided in columns labeled "DEseq (down)", the number in the parenthesis indicates the quantity, which was found to be down regulated in the first group of the row headers. "ANNOT" indicates the quantity for the differentially expressed genes, which could successfully be annotated. "GO" indicates the quantity of differentially expressed genes, which could be assigned GO terms.

\begin{tabular}{llll|lll|lll} 
& $\begin{array}{l}\text { Brain } \\
\text { DESeq } \\
\text { (down) }\end{array}$ & ANNOT & GO & $\begin{array}{l}\text { Testis } \\
\text { DESeq } \\
\text { (down) }\end{array}$ & ANNOT & GO & $\begin{array}{l}\text { Pituitary } \\
\text { DESeq } \\
\text { (down) }\end{array}$ & ANNOT & GO \\
\hline T10 vs Control & $377(124)$ & 210 & 190 & $76(34)$ & 31 & 28 & $350(204)$ & 182 & 159 \\
T20 vs Control & $37(14)$ & 11 & 9 & $20(17)$ & 4 & 3 & $25(15)$ & 11 & 6 \\
TVar vs Control & $25(11)$ & 9 & 6 & $18(15)$ & 7 & 6 & $39(27)$ & 14 & 11 \\
Tvar vs T10 & $322(192)$ & 178 & 158 & $476(207)$ & 246 & 223 & $731(401)$ & 461 & 419 \\
Tvar vs T20 & $24(17)$ & 14 & 10 & $57(41)$ & 32 & 28 & $42(31)$ & 24 & 23 \\
T10 vs T20 & $385(147)$ & 237 & 204 & $241(105)$ & 104 & 94 & $343(186)$ & 150 & 133
\end{tabular}




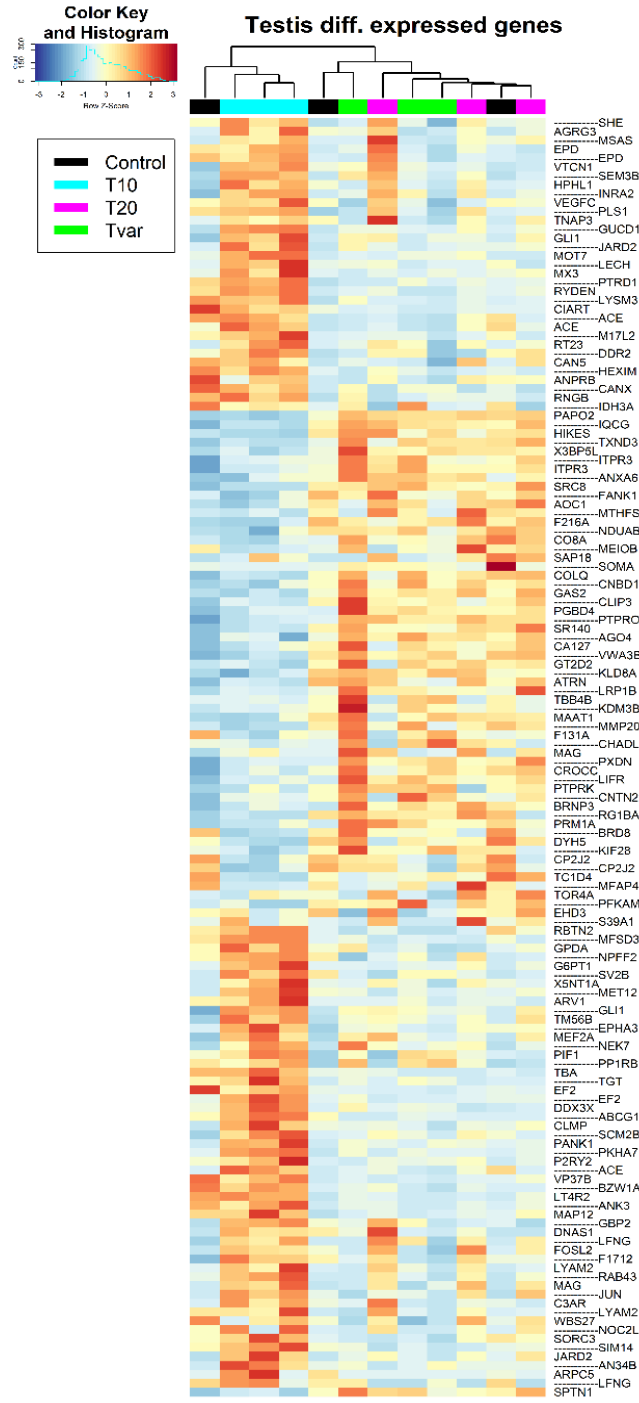

Heat map Continuous

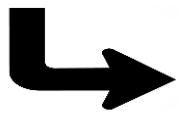

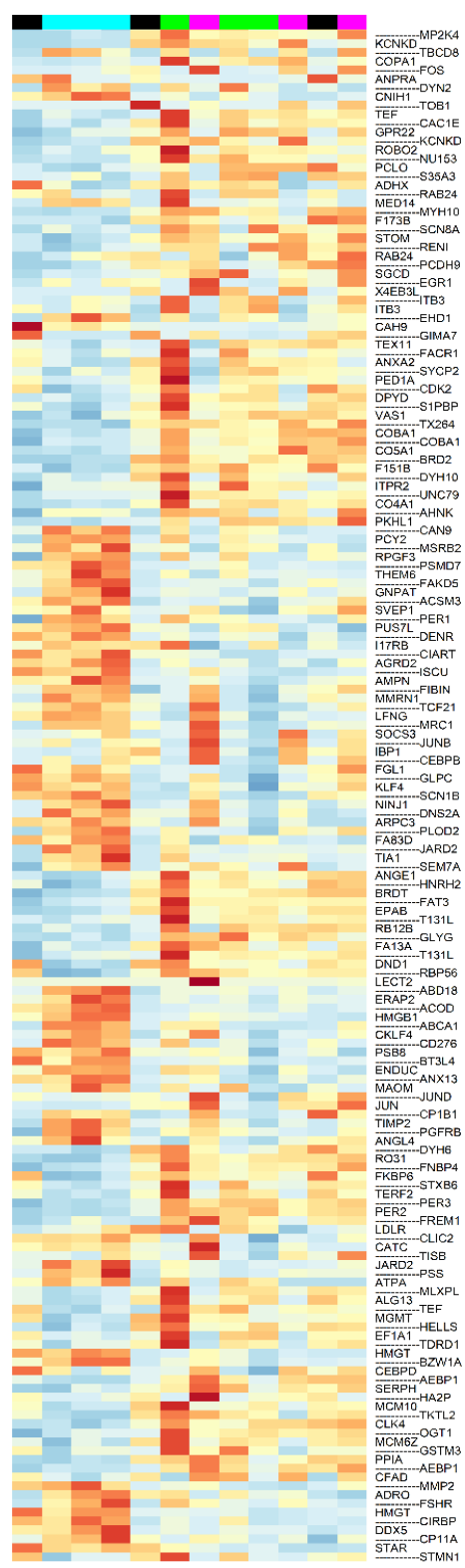

Figure 25. Heat map displaying Z-score of all differentially expressed genes between the testis samples found from all combinations of the 4 sample groups (Control, T10, T20, and Tvar), these genes are ordered into hierarchical clusters. Z-score color key and histogram of the Z-score distributions are presented in the top left-hand corner. Each row of the heat map represents a gene illustrated by the protein symbol to the right of the row. Each column represents a sample. Each column is labeled at the top with a color code according to the treatment group to which the sample belongs (-Control, -T10, -T20, -Tvar). The heat map has been split into two sections (one left and one right). A dendrogram which presenting the sample similarities is printed above the right-hand heat map section. 

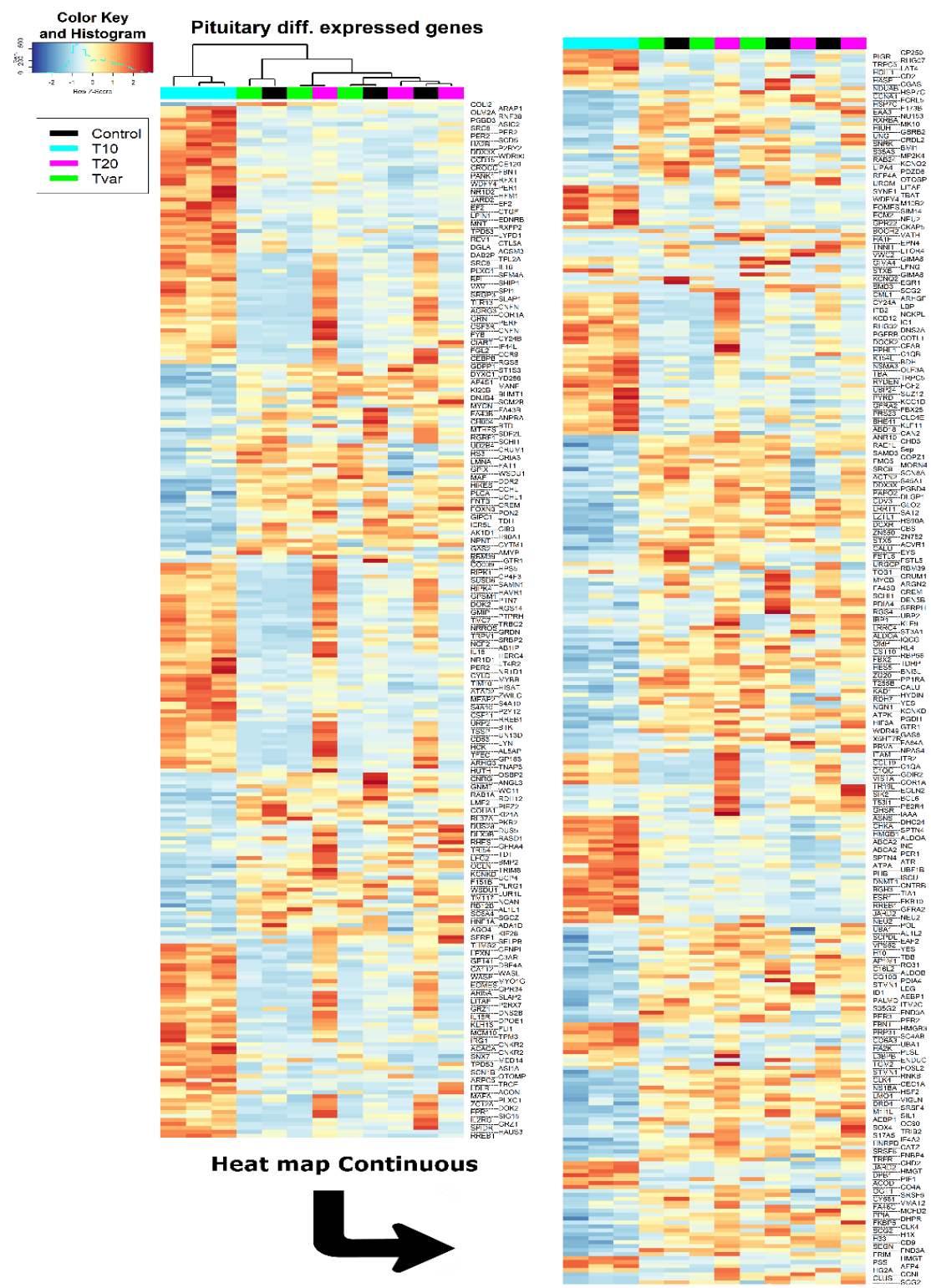

Figure 26. Heat map displaying Z-score of all differentially expressed genes between the pituitary samples found from all combinations of the 4 sample groups (Control, T10, T20, and Tvar), these genes are ordered into hierarchical clusters. Z-score color key and histogram of the $Z$-score distributions are presented in the top left-hand corner. Each row of the heat map represents a gene illustrated by the protein symbol to the right of the row. Each column represents a sample. Each column is labeled at the top with a color code according to the treatment group to which the sample belongs (- Control, -T10, -T20, -Tvar). The heat map has been split into two sections (one left and one right). A dendrogram which presenting the sample similarities is printed above the right-hand heat map section. 

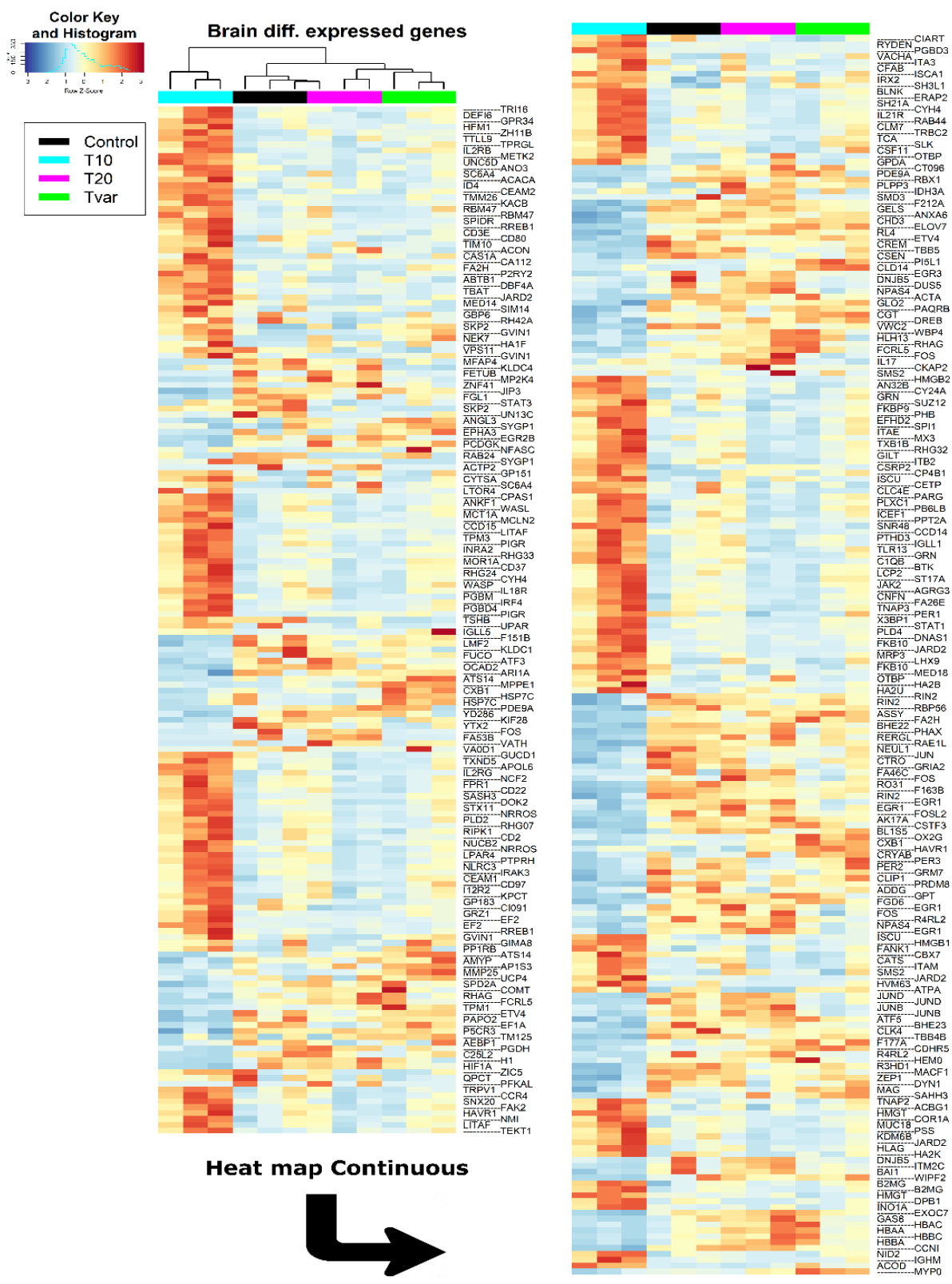

Figure 27. Heat map displaying Z-score of all differentially expressed genes between the brain samples found from all combinations of the 4 sample groups (Control, T10, T20, and Tvar), these genes are ordered into hierarchical clusters. Z-score color key and histogram of the Z-score distributions are presented in the top left-hand corner. Each row of the heat map represents a gene illustrated by the protein symbol to the right of the row. Each column represents a sample. Each column is labeled at the top with a color code according to the treatment group to which the sample belongs ( - Control, -T10, -T20, -Tvar). The heat map has been split into two sections (one left and one right). A dendrogram which presenting the sample similarities is printed above the right-hand heat map section. 
In general, differentially expressed transcripts were more frequently found in T10 samples relative to any other group for all tissues (Table 5 and Fig. 28).

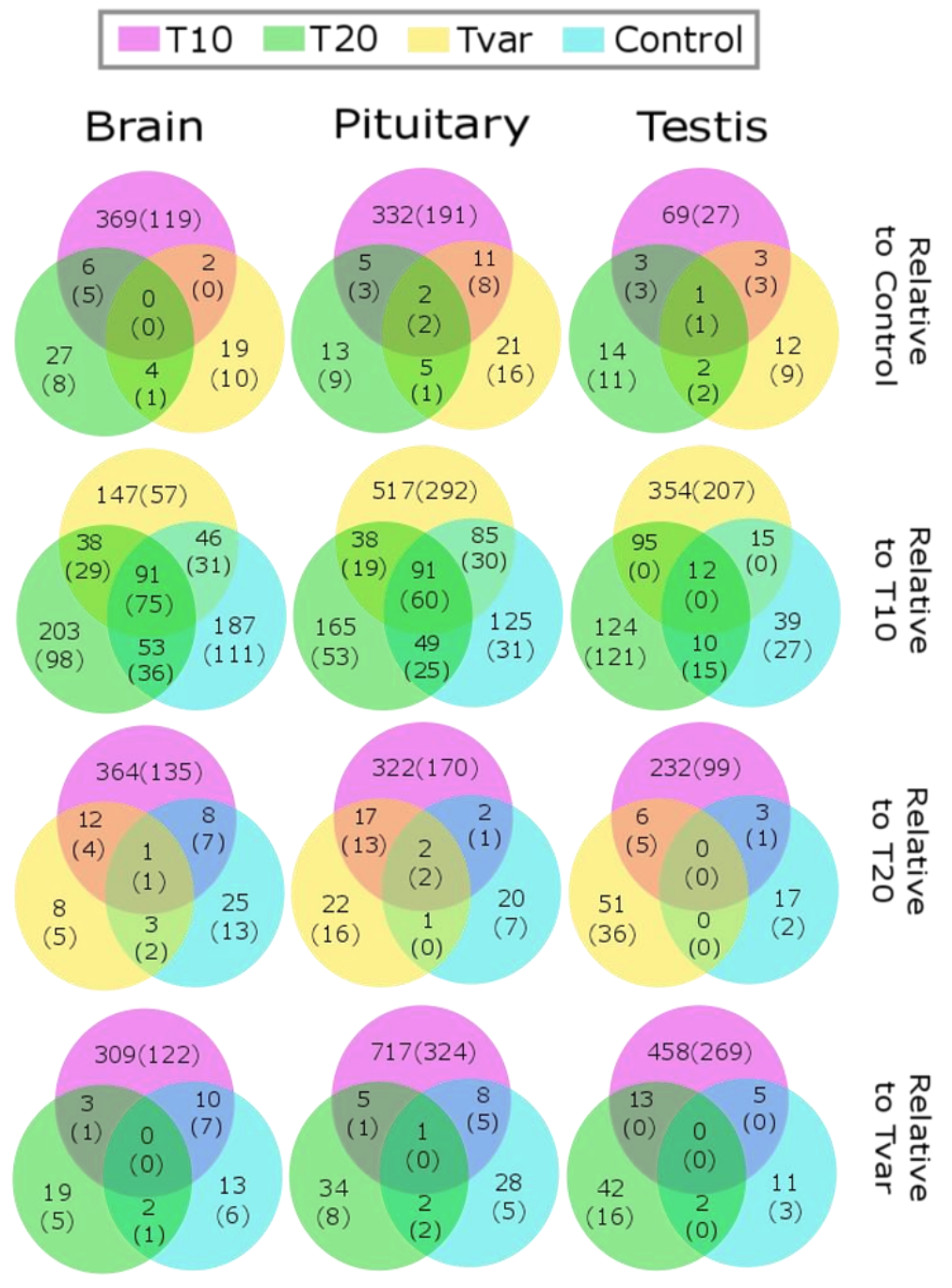

Figure 28. Venn diagrams of differentially expressed (FDR $<0.05)$ transcripts, from the 3 tissues (brain, pituitary, and testes), and from the 3 treatments (T10, T20, and Tvar) and Control groups. Values in brackets indicate downregulated genes relative to the group indicated in the row label. Magenta circles include transcripts differentially expressed in T10 relative to the group indicated in the row label. Green circles include transcripts differentially expressed in T2O relative to the group indicated in the row label. Yellow circles include transcripts differentially expressed in Tvar relative to the group indicated in the row label. Cyan circles include transcripts differentially expressed in Control relative to the group indicated in the row label. 
Tvar pituitary and testis samples had the highest number of differentially expressed transcripts compared to T10 (Table 5 and Fig. 28). In the brain samples, the quantities of differentially expressed transcripts between groups relative to T10 were more similar; however, T20 showed the highest number of differentially expressed genes (Fig. 28). In a PCA analysis, clusters of T10 samples were observed from the normalized expression data of the pituitary and testis samples, while no cluster could be seen among the brain samples (Fig. 29).
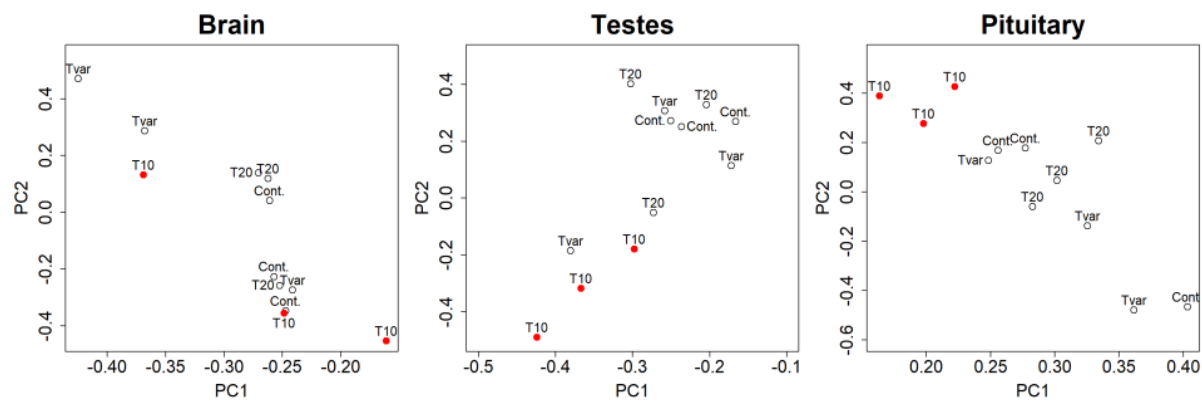

Figure 29. Principal component 2 (PC2) over principal component 1 (PC1) from 3 principal component analysis of all normalized expression data from all transcriptomes of the pituitary, testes, and brain samples. Hollow circles labeled "Cont.", "T20", and "Tvar" represents transcriptomes of Control, T20 and Tvar samples, respectively. T10 samples are marked with red filled circles, and labelled "T10".

Additionally, all the differentially expressed genes from each tissue were hierarchically clustered in 3 heat maps presented in the additional file 1 (Fig. 2527). This analysis revealed clusters of T10 in all the tissues, and of the Tvar samples in the brain. Some of the genes the were found to be upregulated in the in the brain and pituitary of the T10 group are known for their involvement in thermoception e.g. heat shock protein HSP 90-alpha 1 (h90a1) and transient receptor potential cation channel subfamily $\mathrm{V}$ member 1 (trpv1; Fig. 26 and 27). Several genes involved in reproduction were also found to be differentially expressed in the T10 group including, dopamine receptor $d r d 4$ and the estrogen receptor esr1 (Fig. 26 and 27). In the testes, some reproductively relevant genes were found to be upregulated in the T10 group e.g. follicle-stimulating hormone 
receptor (fshr), EH domain-containing protein 1 (ehd1; Fig. 25 and several growth factor related genes including platelet-derived growth factor receptor beta (pgfrb) or vascular endothelial growth factor C (vegfc; Fig. 25). Meanwhile other interesting reproduction-related genes were found to be downregulated in the testes of the T10 group e.g. OB domain-containing protein (meiob), synaptonemal complex protein 2 (Sycp2), testis expressed protein 11 (tex11), bromodomain testis-specific protein (brdt), and bromodomain-containing protein 2 (brd2; Fig. 25).

\section{Pituitary T10 vs Tvar BP}

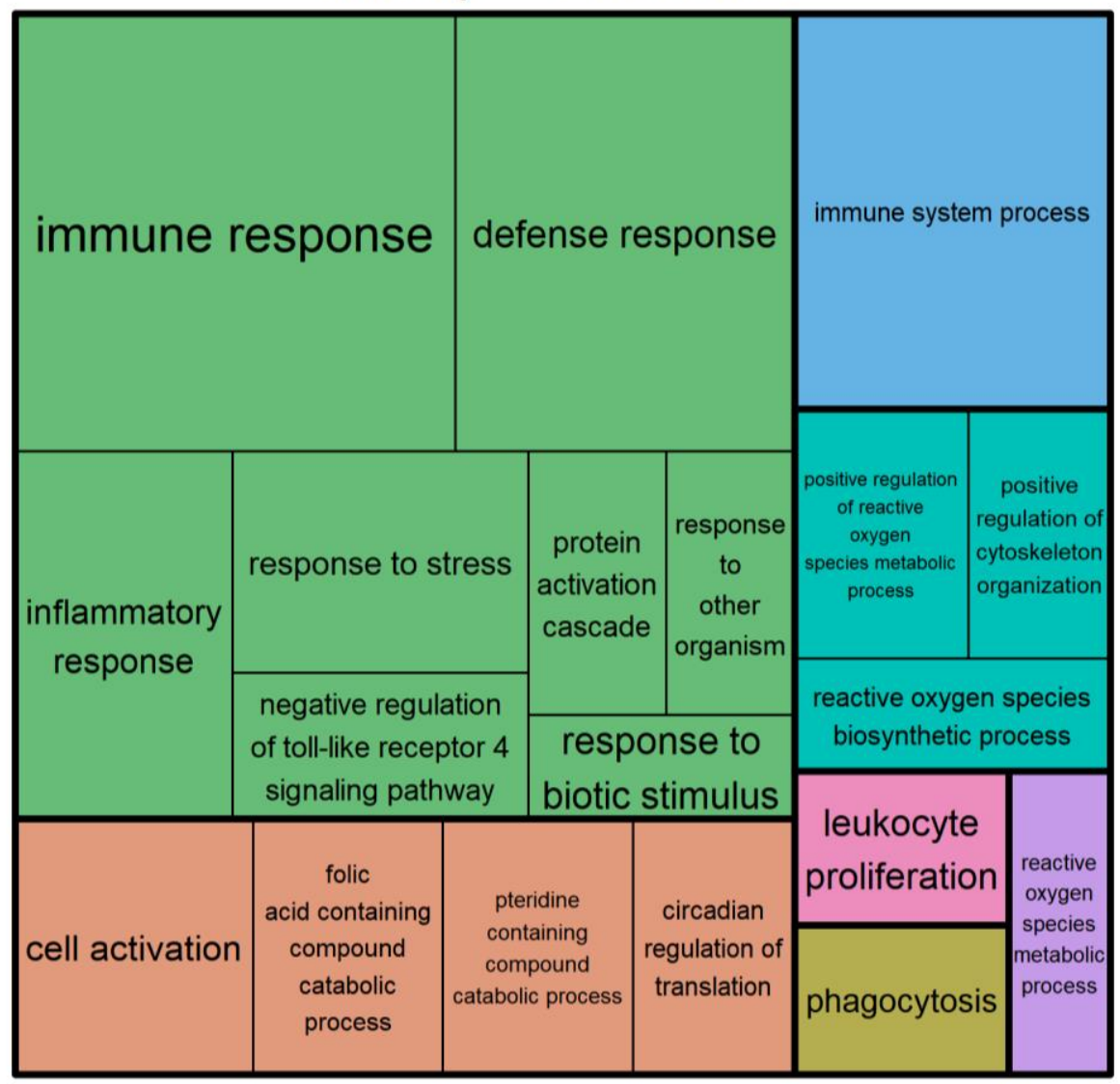

Figure 30. Treemap of the significantly enriched biological process GO term from the significantly differentially expressed genes found between the T10 and Tvar groups from the pituitary samples. Each rectangle represents a single cluster of related terms. Loosely related single cluster rectangles are clustered together in superclusters of the same color. The size of each cluster is adjusted to reflect the false discovery rate corrected P-value (FDR) of the enrichment of the GO tem (larger rectangles indicates lower FDR). 


\subsubsection{Functional annotation}

The Fisher's exact test found enriched GO terms among the differentially expressed genes (Table 6-10 and Fig. 30 and 31).

\section{Brain T10 BP}

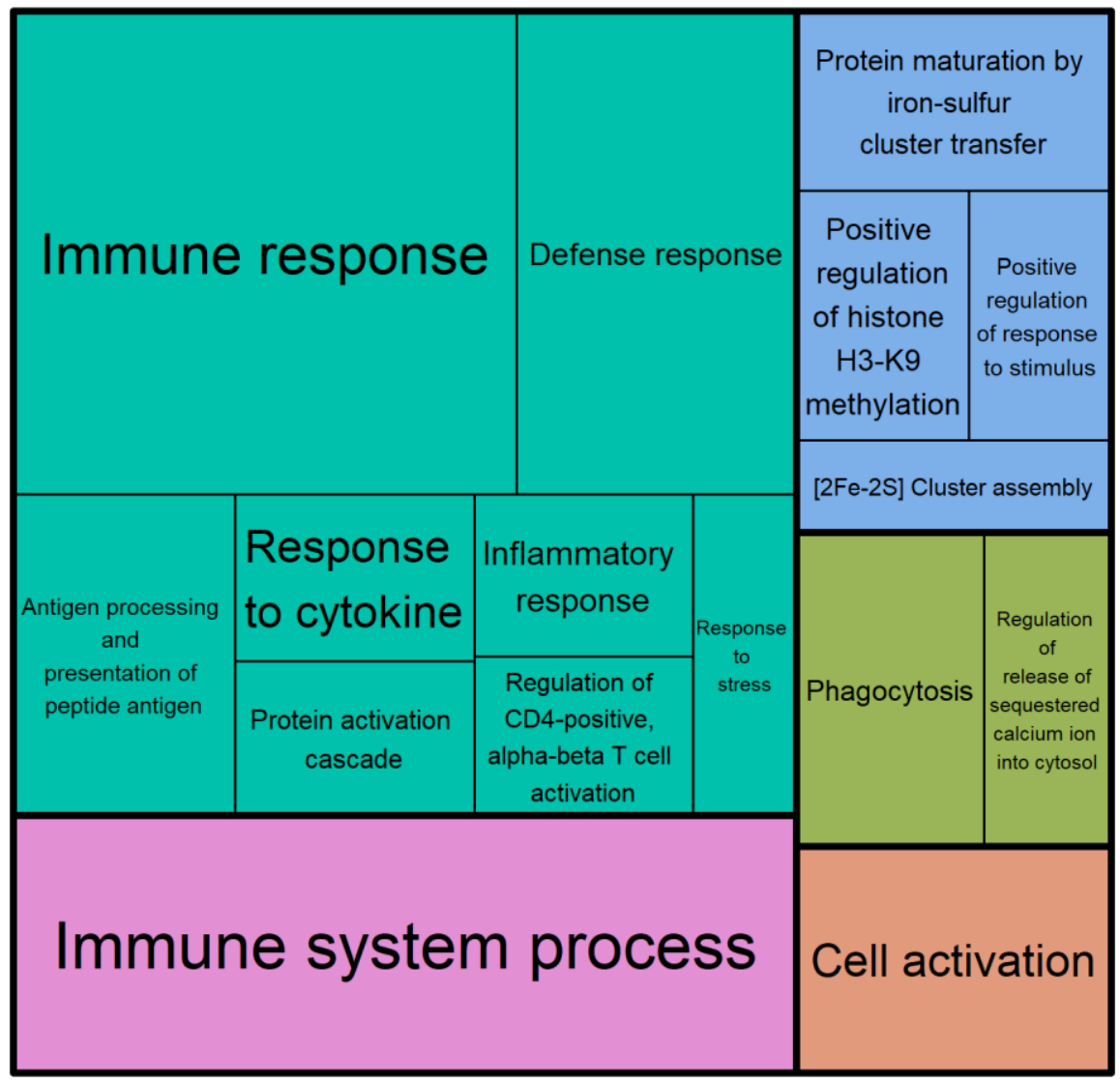

Figure 31. Treemap of the significantly enriched biological process $G O$ terms from the significantly differentially expressed genes found between the T10 and Control groups from the brain samples. Each rectangle represents a single cluster of related terms. Loosely related single cluster rectangles are clustered together in superclusters of the same color. The size of each cluster is adjusted to reflect the false discovery rate corrected P-value (FDR) of the enrichment of the GO terms (larger rectangles indicates lower FDR). 
Table 6. Enriched GO terms from the differentially expressed genes found between T10 and Control, in the testes. OVER/UNDER indicates whether a term is over or under represented, respectively. GO Categories are biological processes (BP), and molecular function (MF). False discovery rate corrected $P$-values are presented in the column labeled FDR.

\begin{tabular}{|c|c|c|c|c|c|c|}
\hline & \multicolumn{2}{|l|}{ OVER/UNDE } & \multirow[b]{2}{*}{ GO Term } & \\
\hline & $\mathrm{R}$ & GO ID & & Category & FDR & P-Value \\
\hline & & GO:005157 & positive regulation of histone & & & \\
\hline \multirow[t]{2}{*}{1} & OVER & 4 & H3-K9 methylation & $\mathrm{BP}$ & 0.0013 & $6.92 \mathrm{E}-08$ \\
\hline & & GO:000368 & & & & \\
\hline \multirow[t]{2}{*}{2} & OVER & & chromatin binding & MF & 0.0327 & $6.96 \mathrm{E}-06$ \\
\hline & & GO:005157 & regulation of histone $\mathrm{H} 3-\mathrm{K} 9$ & & & \\
\hline \multirow[t]{2}{*}{3} & OVER & 0 & methylation & BP & 0.0327 & 3.56E-06 \\
\hline & & GO:003106 & negative regulation & & & \\
\hline \multirow[t]{2}{*}{4} & OVER & 1 & histone methylation & $\mathrm{BP}$ & 0.0327 & $5.46 \mathrm{E}-06$ \\
\hline & & GO:004886 & & & & \\
\hline \multirow[t]{2}{*}{5} & OVER & 3 & stem cell differentiation & $\mathrm{BP}$ & 0.0432 & $1.15 \mathrm{E}-05$ \\
\hline & & GO:005156 & & & & \\
\hline 6 & OVER & 7 & histone $\mathrm{H3}-\mathrm{K} 9$ methylation & $\mathrm{BP}$ & 0.0433 & $1.38 \mathrm{E}-05$ \\
\hline
\end{tabular}

Most notably, the enriched terms found in the brain and pituitary included several GO terms related to immune response. However, several terms related to epigenetic alterations were also found to be enriched among the differentially expressed genes from all the tissues (Table 7, 9, and 10, and Fig. 31).

Table 7. Enriched GO terms from the differentially expressed genes found between T10 and TVar, in the testes. OVER/UNDER indicates whether a term is over or under represented, respectively. GO Categories are biological processes (BP), molecular function (MF), and cellular component (CC). False discovery rate corrected P-values are presented in the column labeled FDR.

\begin{tabular}{|c|c|c|c|c|c|c|}
\hline & OVER/UNDER & GO ID & GO Term & GO Category & FDR & P-Value \\
\hline 1 & OVER & GO:0051574 & $\begin{array}{l}\text { positive regulation of histone } \mathrm{H} 3- \\
\mathrm{K} 9 \text { methylation }\end{array}$ & BP & 0.0081 & $4.34 \mathrm{E}+08$ \\
\hline 2 & OVER & GO:0030198 & extracellular matrix organization & $\mathrm{BP}$ & 0.0470 & $1.70 \mathrm{E}+11$ \\
\hline 3 & OVER & GO:0005576 & extracellular region & CC & 0.0470 & $8.77 E+09$ \\
\hline 4 & OVER & GO:0007140 & male meiotic nuclear division & $\mathrm{BP}$ & 0.0470 & $9.31 \mathrm{E}+09$ \\
\hline 5 & OVER & GO:0008238 & exopeptidase activity & MF & 0.0470 & $1.71 \mathrm{E}+10$ \\
\hline 6 & OVER & GO:0008241 & peptidyl-dipeptidase activity & MF & 0.0470 & $1.41 \mathrm{E}+11$ \\
\hline 7 & OVER & GO:0043062 & $\begin{array}{l}\text { extracellular structure } \\
\text { organization }\end{array}$ & BP & 0.0470 & $1.75 \mathrm{E}+10$ \\
\hline
\end{tabular}


Table 8. Enriched GO terms from the differentially expressed genes found between $T 10$ and Control, in the pituitary. OVER/UNDER indicates whether a term is over or under represented, respectively. GO Categories are biological processes (BP), and molecular function (MF). False discovery rate corrected $P$-values are presented in the column labeled FDR.

\begin{tabular}{|c|c|c|c|c|c|c|}
\hline & OVER/UNDER & GO ID & GO Term & GO Category & FDR & P-Value \\
\hline 1 & OVER & GO:0097167 & circadian regulation of translation & BP & $4.54 \mathrm{E}-05$ & $2.42 \mathrm{E}-09$ \\
\hline 2 & OVER & GO:0070932 & histone $\mathrm{H} 3$ deacetylation & BP & 0.001734 & $1.85 \mathrm{E}-07$ \\
\hline 3 & OVER & GO:0007623 & $\begin{array}{l}\text { circadian rhythm } \\
\text { monocarboxylic acid biosynthetic }\end{array}$ & $\mathrm{BP}$ & 0.007124 & $1.14 \mathrm{E}-06$ \\
\hline 4 & OVER & GO:0072330 & process & BP & 0.013066 & $2.78 \mathrm{E}-06$ \\
\hline 5 & OVER & GO:0048511 & rhythmic process & BP & 0.036725 & 1.17E-05 \\
\hline 6 & OVER & GO:0002028 & $\begin{array}{l}\text { regulation of sodium ion transport } \\
\text { positive regulation of histone } \mathrm{H} 3-\mathrm{K} 9\end{array}$ & $\mathrm{BP}$ & 0.036725 & $1.03 \mathrm{E}-05$ \\
\hline 7 & OVER & GO:0051574 & methylation & BP & 0.037242 & $1.39 \mathrm{E}-05$ \\
\hline 8 & OVER & GO:0016575 & histone deacetylation & BP & 0.044083 & $1.88 \mathrm{E}-05$ \\
\hline 9 & OVER & GO:0035582 & $\begin{array}{l}\text { sequestering of BMP in extracellular } \\
\text { matrix }\end{array}$ & BP & 0.047353 & 4.03E-05 \\
\hline 10 & OVER & GO:1900920 & $\begin{array}{l}\text { regulation of L-glutamate import } \\
\text { regulation of glutamate uptake involved }\end{array}$ & BP & 0.047353 & 4.03E-05 \\
\hline 11 & OVER & GO:0051946 & $\begin{array}{l}\text { in transmission of nerve impulse } \\
\text { regulation of amino acid uptake involved }\end{array}$ & BP & 0.047353 & 4.03E-05 \\
\hline 12 & OVER & GO:0051941 & $\begin{array}{l}\text { in synaptic transmission } \\
\text { regulation of amino acid transmembrane }\end{array}$ & BP & 0.047353 & 4.03E-05 \\
\hline 13 & OVER & GO:1903789 & transport & BP & 0.047353 & 4.03E-05 \\
\hline 14 & OVER & GO:0016053 & $\begin{array}{l}\text { organic acid biosynthetic process } \\
\text { negative regulation of transcription }\end{array}$ & BP & 0.047353 & 3.71E-05 \\
\hline 15 & OVER & GO:2000678 & regulatory region DNA binding & BP & 0.047353 & $2.94 \mathrm{E}-05$ \\
\hline 16 & OVER & GO:0046394 & carboxylic acid biosynthetic process & BP & 0.047353 & $3.52 \mathrm{E}-05$ \\
\hline 17 & OVER & GO:0033218 & amide binding & MF & 0.04807 & 4.35E-05 \\
\hline
\end{tabular}

In particular, various functions and processes related to histone modification

e.g. "positive regulation of histone H3-K9 methylation", "histone H3 deacetylation", "chromatin binding", or "histone displacement" (Table 5) were found to be enriched. In the pituitary and testes GO terms related to circadian rhythm were also found to be significantly enriched as a result of the T10 treatment (Table 7; Fig. 30). Other GO terms found to be enriched among the differentially expressed genes in the testes included the term "male meiotic nuclear division" and "stem cell differentiation". Specifically, the differentially expressed genes found between T10 and T20 in the pituitary only included 1 enriched GO term "neurohypophyseal hormone activity", while the biological process of "response to steroid hormone" was highly significant $(p=0.00006)$ before FDR correction but not after ( $F D R=0.16181)$. 
Table 9. Enriched GO terms from the differentially expressed genes found between T10 and Tvar, in the brain. OVER/UNDER indicates whether a term is over or under represented, respectively. GO Categories are biological processes (BP), molecular function (MF), and cellular component (CC). False discovery rate corrected $P$-values are presented in the column labeled FDR.

\begin{tabular}{|c|c|c|c|c|c|c|}
\hline & OVER/UNDER & GO ID & GO Term & $\begin{array}{l}\text { GO } \\
\text { Category }\end{array}$ & FDR & P-Value \\
\hline 1 & OVER & GO:0006955 & immune response & BP & $5.83 \mathrm{E}-08$ & $3.10 \mathrm{E}-12$ \\
\hline 2 & OVER & GO:0002376 & immune system process & BP & 8.94E-07 & $9.52 \mathrm{E}-11$ \\
\hline 3 & OVER & GO:0006952 & defense response & BP & $1.09 \mathrm{E}-04$ & $1.74 \mathrm{E}-08$ \\
\hline 4 & OVER & GO:0002684 & positive regulation of immune system process & BP & $5.86 \mathrm{E}-04$ & $1.25 \mathrm{E}-07$ \\
\hline 5 & OVER & GO:0050778 & positive regulation of immune response & $\mathrm{BP}$ & 0.0017 & $5.71 \mathrm{E}-07$ \\
\hline 6 & OVER & GO:0045087 & innate immune response & $\mathrm{BP}$ & 0.0017 & $5.11 \mathrm{E}-07$ \\
\hline 7 & OVER & GO:0042571 & immunoglobulin complex, circulating & $\mathrm{CC}$ & 0.0027 & $1.03 \mathrm{E}-06$ \\
\hline 8 & OVER & GO:0009897 & external side of plasma membrane & $\mathrm{CC}$ & 0.0060 & $2.57 \mathrm{E}-06$ \\
\hline 9 & OVER & GO:0050776 & regulation of immune response & BP & 0.0070 & $3.36 \mathrm{E}-06$ \\
\hline 10 & OVER & GO:0006909 & phagocytosis & BP & 0.0070 & $3.75 \mathrm{E}-06$ \\
\hline 11 & OVER & GO:0002682 & regulation of immune system process & BP & 0.0079 & 4.63E-06 \\
\hline 12 & OVER & GO:0002253 & activation of immune response & BP & 0.0087 & 5.59E-06 \\
\hline 13 & OVER & GO:0002449 & lymphocyte mediated immunity & BP & 0.0111 & $8.53 \mathrm{E}-06$ \\
\hline 14 & OVER & GO:0003823 & antigen binding & MF & 0.0111 & $8.16 \mathrm{E}-06$ \\
\hline 15 & OVER & GO:0034987 & $\begin{array}{l}\text { immunoglobulin receptor binding } \\
\text { positive regulation of histone } \mathrm{H} 3-\mathrm{K} 9\end{array}$ & MF & 0.0111 & $8.88 \mathrm{E}-06$ \\
\hline 16 & OVER & GO:0051574 & $\begin{array}{l}\text { methylation } \\
\text { antigen processing and presentation of }\end{array}$ & BP & 0.0166 & $1.41 \mathrm{E}-05$ \\
\hline 17 & OVER & GO:0048002 & peptide antigen & BP & 0.0173 & 1.57E-05 \\
\hline 18 & OVER & GO:0006956 & complement activation & BP & 0.0196 & $1.88 \mathrm{E}-05$ \\
\hline 19 & OVER & GO:0019814 & immunoglobulin complex & $\mathrm{CC}$ & 0.0209 & $2.11 \mathrm{E}-05$ \\
\hline 20 & OVER & GO:0072376 & protein activation cascade & BP & 0.0213 & $2.27 \mathrm{E}-05$ \\
\hline 21 & OVER & GO:0005773 & vacuole & CC & 0.0250 & $2.79 \mathrm{E}-05$ \\
\hline 22 & OVER & GO:0006089 & lactate metabolic process & BP & 0.0256 & $3.00 \mathrm{E}-05$ \\
\hline 23 & OVER & GO:0045321 & leukocyte activation & BP & 0.0303 & $3.71 \mathrm{E}-05$ \\
\hline 24 & OVER & GO:0006910 & $\begin{array}{l}\text { phagocytosis, recognition } \\
\text { immune response-regulating signaling }\end{array}$ & BP & 0.0321 & 4.11E-05 \\
\hline 25 & OVER & GO:0002764 & pathway & BP & 0.0321 & 4.27E-05 \\
\hline 26 & OVER & GO:0005764 & lysosome & $\mathrm{CC}$ & 0.0326 & $5.12 \mathrm{E}-05$ \\
\hline 27 & OVER & GO:0006954 & $\begin{array}{l}\text { inflammatory response } \\
\text { immune response-activating signal }\end{array}$ & BP & 0.0326 & $5.06 \mathrm{E}-05$ \\
\hline 28 & OVER & GO:0002757 & transduction & BP & 0.0326 & $5.01 \mathrm{E}-05$ \\
\hline 29 & OVER & GO:0000323 & Iytic vacuole & $\mathrm{CC}$ & 0.0326 & $5.21 \mathrm{E}-05$ \\
\hline 30 & OVER & GO:0009986 & cell surface & $\mathrm{CC}$ & 0.0326 & 4.94E-05 \\
\hline 31 & OVER & GO:0098797 & plasma membrane protein complex & $\mathrm{CC}$ & 0.0329 & $5.43 \mathrm{E}-05$ \\
\hline 32 & OVER & GO:0042611 & MHC protein complex & $\mathrm{CC}$ & 0.0338 & $5.75 \mathrm{E}-05$ \\
\hline 33 & OVER & GO:0019882 & antigen processing and presentation & BP & 0.0409 & 7.39E-05 \\
\hline 34 & OVER & GO:0006958 & complement activation, classical pathway & BP & 0.0409 & 7.29E-05 \\
\hline 35 & OVER & GO:0002250 & adaptive immune response & BP & 0.0421 & $7.85 \mathrm{E}-05$ \\
\hline 36 & OVER & GO:0098552 & side of membrane & $\mathrm{CC}$ & 0.0426 & $8.16 \mathrm{E}-05$ \\
\hline
\end{tabular}


Table 10. Enriched GO terms from the differentially expressed genes found between $T 10$ and $T 20$, in the brain. OVER/UNDER indicates whether a term is over or under represented, respectively. GO Categories are biological processes $(B P)$, molecular function $(M F)$, and cellular component $(C C)$. False discovery rate corrected $P$-values are presented in the column labeled FDR.

\begin{tabular}{|c|c|c|c|c|c|c|}
\hline & OVER/UNDER & GO ID & GO Term & $\begin{array}{l}\text { GO } \\
\text { Category }\end{array}$ & FDR & P-Value \\
\hline 1 & OVER & GO:0006955 & immune response & $\mathrm{BP}$ & $2.51 \mathrm{E}-08$ & $1.34 \mathrm{E}-12$ \\
\hline 2 & OVER & GO:0002376 & immune system process & $\mathrm{BP}$ & $1.21 \mathrm{E}-06$ & $1.29 \mathrm{E}-10$ \\
\hline 3 & OVER & GO:0045087 & innate immune response & $\mathrm{BP}$ & $1.29 \mathrm{E}-05$ & 2.06E-09 \\
\hline 4 & OVER & GO:0005344 & oxygen carrier activity & MF & $1.72 \mathrm{E}-05$ & $4.55 \mathrm{E}-09$ \\
\hline 5 & OVER & GO:0005833 & hemoglobin complex & $\mathrm{CC}$ & $1.72 \mathrm{E}-05$ & 4.57E-09 \\
\hline 6 & OVER & GO:0006952 & defense response & $\mathrm{BP}$ & $5.73 \mathrm{E}-05$ & $1.83 \mathrm{E}-08$ \\
\hline 7 & OVER & GO:0009897 & $\begin{array}{l}\text { external side of plasma membrane } \\
\text { positive regulation of immune system }\end{array}$ & $\mathrm{CC}$ & $1.98 \mathrm{E}-04$ & $7.38 \mathrm{E}-08$ \\
\hline 8 & OVER & GO:0002684 & process & BP & $4.00 \mathrm{E}-04$ & $1.70 \mathrm{E}-07$ \\
\hline 9 & OVER & GO:0140104 & $\begin{array}{l}\text { molecular carrier activity } \\
\text { positive regulation of histone } \mathrm{H} 3-\mathrm{K} 9\end{array}$ & MF & $4.42 \mathrm{E}-04$ & $2.12 \mathrm{E}-07$ \\
\hline 10 & OVER & GO:0051574 & methylation & $\mathrm{BP}$ & $5.85 \mathrm{E}-04$ & $3.11 \mathrm{E}-07$ \\
\hline 11 & OVER & GO:0002682 & regulation of immune system process & $\mathrm{BP}$ & 0.0031 & $2.00 \mathrm{E}-06$ \\
\hline 12 & OVER & GO:0045321 & leukocyte activation & $\mathrm{BP}$ & 0.0031 & $1.86 \mathrm{E}-06$ \\
\hline 13 & OVER & GO:0003823 & antigen binding & MF & 0.0037 & 2.71E-06 \\
\hline 14 & OVER & GO:0050776 & regulation of immune response & $\mathrm{BP}$ & 0.0037 & $2.78 \mathrm{E}-06$ \\
\hline 15 & OVER & GO:0006950 & response to stress & $\mathrm{BP}$ & 0.0052 & 4.13E-06 \\
\hline 16 & OVER & GO:0034097 & response to cytokine & $\mathrm{BP}$ & 0.0106 & $9.00 \mathrm{E}-06$ \\
\hline 17 & OVER & GO:0019825 & oxygen binding & MF & 0.0133 & $1.28 \mathrm{E}-05$ \\
\hline 18 & OVER & GO:0046649 & lymphocyte activation & BP & 0.0133 & $1.23 \mathrm{E}-05$ \\
\hline 19 & OVER & GO:0050778 & positive regulation of immune response & BP & 0.0151 & $1.60 \mathrm{E}-05$ \\
\hline 20 & OVER & GO:0098552 & side of membrane & $\mathrm{CC}$ & 0.0151 & $1.61 \mathrm{E}-05$ \\
\hline 21 & OVER & GO:0002696 & positive regulation of leukocyte activation & $\mathrm{BP}$ & 0.0300 & 3.36E-05 \\
\hline 22 & UNDER & GO:0003824 & catalytic activity & MF & 0.0340 & 4.00E-05 \\
\hline 23 & OVER & GO:0050867 & positive regulation of cell activation & BP & 0.0340 & 4.16E-05 \\
\hline 24 & OVER & GO:0002449 & lymphocyte mediated immunity & $\mathrm{BP}$ & 0.0420 & $5.38 \mathrm{E}-05$ \\
\hline 25 & OVER & GO:0071345 & cellular response to cytokine stimulus & BP & 0.0447 & $5.95 \mathrm{E}-05$ \\
\hline 26 & OVER & GO:0051570 & regulation of histone $\mathrm{H} 3-\mathrm{K} 9$ methylation & $\mathrm{BP}$ & 0.0498 & $6.90 \mathrm{E}-05$ \\
\hline 27 & OVER & GO:0001775 & cell activation & $\mathrm{BP}$ & 0.0498 & 7.16E-05 \\
\hline 28 & OVER & GO:0002253 & activation of immune response & BP & 0.0561 & 8.36E-05 \\
\hline
\end{tabular}




\subsection{Discussion}

\subsubsection{Histological development, biometric parameters and plasma levels of androgens}

The highest level of spermatogonial proliferation was observed as a consequence of the cold seawater treatment (Fig. 20). However, the lower proportion of SPGAund* and SPGAund, and furthermore the higher total cell counts of all the treatments compared to the Control, indicate that prolonged housing after saltwater acclimation promotes spermatogonial differentiation and proliferation in European eel testes, regardless of the housing temperature (between 20 and $10^{\circ} \mathrm{C}$; Fig. 20). These processes are likely induced by steroids (Schulz et al. 2010; Miura and Miura 2003) and are thus an expected consequence of the increases in plasma steroid levels. Several studies on European eel males (Morini et al. 2017b; Peñaranda et al. 2016; Baeza et al. 2015b) have documented increased plasma steroid levels as a result of saltwater acclimation alone, and it is, therefore, likely that even the Control group in this experiment represents a state of elevated steroid levels compared to freshwater housed eels, with resulting SPG proliferation and differentiation.

However, the histological data also indicate that the T10 treatment in particular promotes differentiation and proliferation of SPGAund cells into SPGAdiff cells and that the T10 treatment is the only treatment for which prolonged housing did not promote a significant increase in the proportion of SPGB cells (Fig. 20). In an experiment where complete sexual maturation of European eel males was induced through weekly hormonal injections, plasma $11 \mathrm{KT}$ levels increased from $1.14 \pm 0.5 \mathrm{ng} / \mathrm{ml}$ to $4.7 \pm 0.37 \mathrm{ng} / \mathrm{ml}$ after 1 week of treatment and did not change significantly after the second week (Peñaranda et al. 2010b). In comparison, our cold seawater treatment induced an increase in the average blood plasma level from $1.67 \pm 0.31 \mathrm{ng} / \mathrm{ml}$ to $4.46 \pm 0.43 \mathrm{ng} / \mathrm{ml} 11 \mathrm{KT}$. This 
similarity may suggest that a similar process is initially induced by both types of treatment; however, while the hormonally injected eels all contained spermatocytes in their testis after 2 weeks of treatment, the fish from the T10 group did not contain cells of maturation stages higher than SPGB. Therefore, the androgen levels observed, together with the histological results, indicates that the effect of androgens on European eel SPG cell differentiation beyond SPGAdiff is actively being inhibited, during cold seawater treatment. This phenomenon has previously been observed during hormonally induced maturation of European eel males at $10^{\circ} \mathrm{C}$ (Peñaranda et al. 2016).

Interestingly, while the T10 treatment may induce elevated Lh $\beta$ protein levels, the observed histological stage of the T10 samples is highly similar to the stages which eel testes could not surpass during recombinant Lh $\beta$ injections (Peñaranda et al. 2018).

Together, the proliferation, differentiation, and repression indicate that a cold seawater treatment promotes synchronization and increased proliferation of SPG cells at the SPGAdiff stage. It seems reasonable to assume that the synchronization and proliferation of SPG cells observed here also occur in nature, given that the environmental temperature eels experience during their early oceanic migration (Righton et al. 2016) is approximately the same as that of our T10 treatment (Righton et al. 2016; Aarestrup et al. 2009).

The observed proliferation might have been stimulated by androgens since the T10 group contained significantly higher amounts of T and 11KT than the Control group. Furthermore, higher plasma androgen levels have been correlated with European eel SPGA proliferation in previous studies (Peñaranda et al. 2016). As mentioned above, increases in steroid levels have been reported in European eel after salinity acclimation (Morini et al. 2017b; Peñaranda et al. 2016; Baeza et al. 2014); however, the duration of these increases has not been reported. 
Since the Control and T20 groups share all the same parameters except exposure time, the observed increase in $11 \mathrm{KT}$ levels (Fig. 20) may well be the result of a continued increase in $11 \mathrm{KT}$ levels rather than a specific increase that happens in the $2^{\text {nd }}$ and $4^{\text {th }}$ weeks of seawater housing.

Few significant differences were registered in terms of the measured biometric parameters. This was to be expected due to the short treatment period, and lack of hormonal injections. Only lower fin index was observed, which has been traditionally attributed to a less mature sexual developmental stage of European eels (Pankhurst 1982; Peñaranda et al. 2010b), although fin length has not been found to correlate with maturity stage in other studies (Durif et al. 2006). Interestingly, the T20 group also showed a significantly lower fin index compared to the Control group, and therefore this change may not be a result of the temperature treatment, but rather a result of the prolonged fasting or housing in seawater during the experiment. A similar tendency was seen in the Tvar group, although without significant differences.

\subsubsection{Gonadotropins}

Pituitary gonadotropins stimulate testicular spermatogenesis and steroidogenesis. In both European eel males and females, Ihb and fshb were shown to be differentially expressed in the pituitary during gametogenesis, with an maximum of $f s h b$ expression occurring early on in the maturation process, and a later maximum of Ihb expression (Schmitz et al. 2005; Peñaranda et al. 2010b). In eels, both gonadotropins have further been shown to induce 11KT and T production from the testes (Peñaranda et al. 2018; Kazeto et al. 2008). While 11KT can induce complete spermatogenesis in vitro (Ohta et al. 2007; Miura et al. 1991b), this is not the case in vivo (Lokman et al. 2016); however, $11 \mathrm{KT}$ has been shown to stimulate the expression of the Fsh receptor (fshr; Levavi-Sivan et al. 2010) and thereby Fsh sensitivity and activity (García-López et 
al. 2009; Planas and Swanson 1995). In Japanese eel, Fsh is an important factor in spermatogonial proliferation; however, only in combination with steroidogenesis (Ohta et al. 2007). Furthermore, a positive feedback loop of sex steroids on gonadotropins appears to exist in European eels, as androgens have been shown to stimulate $L h b$ expression from the pituitary (Huang et al. 1997). Our immunofluorescence labeling of Fsh did indicate that Fsh was present in all collected pituitaries, therefore it is plausible that Fsh was a mediating factor of the observed steroid increase and/or the documented proliferation in the T10 group. We draw this conclusion based on the expression of fshr in the testes, which was up-regulated by our cold seawater treatment (Fig. 25), thus Fsh sensitivity and activity in the testes may have been enhanced. Our immunofluorescence labelling of $\operatorname{Lh} \beta$ indicates that our cold seawater treatment induces a reliably stronger Lh $\beta$ signal in the pituitary. Higher Lh levels could, in turn, also be a stimulating factor generating the observed increases in androgens and thereby fshr expression and proliferation; however, since androgens can also stimulate $\operatorname{Lh} \beta$ production, the question remains as to which factor came first. Furthermore, since $\operatorname{Lh} \beta$ release was not analyzed in this study it is possible that the lower Lh $\beta$ levels suggested in the T20 and Control groups are in fact a result of a higher Lh release. However, increased Ihb expression supports a hypothesis of increased protein production in the pituitaries of the eels from the T10 group.

The FDR correction applied in this study to all gene expression analyses is rather conservative, making the significant results obtained after FDR correction reliable (Anders and Huber 2010). This claim is further supported by the immunofluorescence labelling results of $\operatorname{Lh} \beta$, as the $\operatorname{lh} b$ gene expression differences observed were not significant after FDR correction, yet strong enough for a reliably stronger Lh $\beta$ signal. Furthermore, the concurrence of the immunofluorescence labelling results and DEseq analysis results suggests that 
our findings are reproducible, at least for $I h b$, since the fish used for immunofluorescence labelling were treated in the second experimental run, while those used for the transcriptome analysis were treated in the first experimental run. Of course, as only Lh $\beta$ was successfully analysed, this result is only conclusive for the Lh $\beta$ signal itself, and only provides suggestive evidence of the reproducibility of our experiment and of the validity of the FDR correction applied.

\subsubsection{Transcriptomic analysis}

\section{Differential brain and pituitary gene expression}

The significant effect of the cold seawater treatment indicates that some mechanisms of thermoception were activated. Specifically, some genes found differentially expressed in the brain and pituitary are known for their involvement in thermoception e.g. h90a1 and trpv1 (Fig. 25 and 26) and thus these genes may be involved in the registration of temperature differences, which could be the driver of the changes observed in this study.

Although the GO term "response to steroid hormone" was not significantly enriched after FDR correction, some interesting significantly differentially expressed genes were assigned this term. Among these were $d r d 4$ and esr1. It has been suggested that dopamine may be involved in the maturational blockage of puberty in European eels (Vidal et al. 2004) and the D2-like receptor, $d r d 4$, was significantly down-regulated in the pituitary after the cold seawater treatment (Fig. 26). Although speculative, this could indicate a weakening of dopamine-mediated neuroendocrine inhibition of eel puberty. The pituitary is a major target for estrogen in European eel (Morini et al. 2017b). In our data, esr1 expression increased significantly in the pituitary after the T10 treatment (Fig. 26). This result may suggest stimulation of maturation, as the expression of esr1 
has been shown to increase in the pituitary of European eel males early on in artificial maturation (Morini et al. 2017b).

The most notable results from the transcriptomic data from all the tissues were the enrichment of GO terms related to the immune response in the brain and pituitary. No visual signs of infection were seen on the animals during the experiment or at sampling, which would be expected if the massive differential expression of immune related genes was caused by an infection. Additionally, the brain and pituitary are not the most likely organs to observe differential expression patterns caused by an infection. Interestingly, several studies have documented a neural function for most of the enriched immune response GO terms found in this study (reviewed by Komal and Nashmi 2015; Boulanger 2009). E.g. cytokines (Huising et al. 2004), Toll-like receptors (Huising et al. 2004), major histone complexes (MHC; Corriveau et al. 1998; Shatz 2009; Needleman et al. 2010), and T-cell receptors (Syken and Shatz 2003; Komal and Nashmi 2015; Komal et al. 2014) have documented functions in neural development. Specifically, T-cell receptor signaling has been shown to be conveyed through cell-cell contact through MHC (Komal et al. 2014) and it has been speculated that the pruning of synapsis of the visual system (Lee et al. 2014) can be facilitated by MHC/T-cell receptor signaling (Komal and Nashmi 2015). As such, there seems to be a high occurrence of genes with documented and connected neural functions among the differentially expressed genes related to immune functions found in the brain and pituitary in the current study. The hypothesized involvement of these genes in the pruning of synapsis of the visual system leads to the speculation that the cold seawater treatment affects the synapsis of the visual system in the eel brain. Since the light environment of migrating eels is vastly different from that of premature eels foraging in shallow freshwaters, changes to the synapsis of the visual system have been hypothesized to be part of the adaptation of eels in preparation for 
migration (Pankhurst and Lythgoe 1983). Furthermore, the upregulation of genes involved in photo signal transduction and visual system development (Churcher et al. 2014), and alterations to the retina, have previously been observed in developing European eels (Pankhurst and Lythgoe 1983).

\section{Differential testes gene expression}

The GO terms found to be enriched among the genes differentially expressed between T10 and Tvar groups, included the term "male meiotic nuclear division". As previously discussed, a mechanism repressing spermatogonial differentiation towards meiosis may have been activated by the T10 treatment, as a decreased in differentiation beyond SPGA-diff was observed. This mechanism could be driven by an active downregulation of genes involved in later maturational processes, including meiosis, which could serve to optimize the synchronization of sexual maturation. The genes annotated to the GO term "male meiotic nuclear division", could be involved in such a process, as the vast majority of these genes were down regulated in the T10 testis samples. Some of these downregulated genes were meiob, Sycp2, tex11, brdt, and brd2 (Fig. 25), all of which may, therefore, be interesting factors to analyse in future studies on the latter developmental stages of the European eel.

\section{Epigenetic factors}

The GO terms found to be enriched among the differentially expressed genes found in the testes, between the T10 and the Control groups, were often related to epigenetic alterations, similar to those seen in the pituitary and the brain (Table 7, 9, and 10, Fig. 23, 25 and 31). In particular, various functions and processes related to histone modification were found to be enriched. Histone modification can affect the alteration of transcription as a result of posttranslational modifications in the $\mathrm{N}$-terminal tail of the histone proteins (Jenuwein and Allis 2001; Strahl and Allis 2000). Specifically methylation changes 
of H3-K9 have, interestingly, been shown to be dependent on cold temperatures in Arabidopsis thaliana (Berr et al. 2011) and regulate gametogenesis specifically at the meiotic prophase in mice (Tachibana et al. 2007).

\section{Circadian rhythm factors}

GO terms related to circadian rhythm were also found to be significantly enriched in the testes and pituitary as a result of the T10 treatment (Table 7; Fig. 23 and 30). The circadian clock is a central oscillator, which coordinates endogenous rhythms in the host. Although light is the strongest modulator, temperature has also been shown to influence the circadian rhythm system, especially in the absence of a light cycle (López-Olmeda and Sánchez-Vázquez 2009; Lahiri et al. 2005). The strong regulation of the circadian rhythm system, caused by our T10 treatment, supports our hypothesis that the T10 treatment may have initiated alterations that the eels would naturally experience during early migration.

\section{Other differentially expressed genes}

Among the other significantly upregulated genes which were not related to enriched pathways were fshr, and ehd1 (Fig. 25). These genes are particularly important for the stimulation of early teleost maturation. ehd1 specifically, has been shown to be expressed in both Sertoli cells and spermatogonia, and to be vital in the pre-pubertal maturation and spermatogenesis of mice (Rainey et al. 2010). Furthermore, the genes found to be differentially expressed in the testes between the T10 and Control groups, also included several growth factor related genes including pgfrb or vegfc (Fig. 25). Growth factor related genes have been associated with early maturation in teleost testes with decreasing expressions at later developmental stages (Schulz et al. 2010). 
No GO terms were found to be significantly enriched (FDR<0.05) among the 94 differentially expressed genes found between T10 and T20 in the testes. Since the Control and the T20 groups shared all the same conditions other than exposure time, a similar array of enriched GO terms were expected to be found within the differentially expressed genes from these groups relative to T10. Notably, when expanding the significance threshold to 0.1 (FDR<0.1), the GO terms "positive regulation of histone H3-K9 methylation", "regulation of transcription involved in meiotic cell cycle", "positive regulation of transcription involved in meiotic cell cycle" and "histone displacement" were found to be enriched. As the genes annotated to these GO terms are significantly differentially expressed following the same criteria as all the others, this indicates that the processes affected are similar in groups T20, Control and Tvar and therefore differ in a similar fashion to those of T10. Nevertheless, as shown in the histological results, the differences between T10 and T20 seem less pronounced than those found between T10 and Control.

\subsection{Conclusion}

In this study, clear effects of a cold seawater treatment were observed in European eel males, including increase in proliferation of SPGAdiff cells, decrease in the differentiation of SPGAdiff cells into early SPGB cells, changes in blood plasma steroid levels, possible increase in pituitary Lh $\beta$ protein levels, and BPG-axis transcriptomes. These results support our hypothesis that a cold seawater treatment causes a physiological transition that European eels naturally experience during the early stages of their oceanic migration. This hypothesis is logical given that the average temperature experienced by the eels in the early stages of their oceanic migration is highly similar to that of our cold seawater treatment. Apart from preparing the eels for migration, the hypothesized natural transition could improve the reproductive potential of eel males, which is indicated by the increased androgen levels (Burgerhout et al. 
2016) and by increasing spermatogonial proliferation and synchronization. However, further studies would need to be conducted to test whether the cold seawater treatment can improve the eels' response to hormonal treatments. 
8. CHAPTER 3: de novo European eel transcriptome provides insights into the evolutionary history of duplicated genes in teleost lineages

Christoffer Rozenfeld ${ }^{1} \mathbf{\Delta}$, Jose Blanca ${ }^{2 \mathbf{\Delta}}$, Victor Gallego ${ }^{1}$, Víctor GarcíaCarpintero ${ }^{2}$, Juan Germán Herranz-Jusdado ${ }^{1}$, Luz Pérez ${ }^{1}$, Juan F. Asturiano $^{{ }^{*}}$, Joaquín Cañizares ${ }^{2 \dagger}$, David S. Peñaranda ${ }^{1 \dagger}$

${ }^{1}$ Grupo de Acuicultura y Biodiversidad. Instituto de Ciencia y Tecnología Animal. Universitat Politècnica de València. Camino de Vera s/n, 46022 Valencia, Spain

${ }^{2}$ Instituto de Conservación y Mejora de la Agrodiversidad Valenciana, Universitat Politècnica de València, Camino de Vera 14, 46022, Valencia, Spain. 


\section{Abstract}

Paralogs pairs are more frequently observed in eels (Anguilla sp.) than in other teleosts. The paralogs often show low phylogenetic distances; however, they have been assigned to the third round of whole genome duplication (WGD), shared by all teleosts (3R), due to their conserved synteny.

The apparent contradiction of low phylogenetic difference and $3 R$ conserved synteny led us to study the duplicated gene complement of the freshwater eels. With this aim, we assembled de novo transcriptomes of two highly relevant freshwater eel species: The European (Anguilla anguilla) and the Japanese eel (Anguilla japonica).

The duplicated gene complement was analysed in these transcriptomes, and in the genomes and transcriptomes of other Actinopterygii species. The study included an assessment of neutral genetic divergence (4dTv), synteny, and the phylogenetic origins and relationships of the duplicated gene complements. The analyses indicated a high accumulation of duplications (1217) among freshwater eel genes, which may have originated in a WGD event after the Elopomorpha lineage diverged from the remaining teleosts, and thus not at the 3R. However, very similar results were observed in the basal Osteoglossomorpha and Clupeocephala branches, indicating that the specific genomic regions of these paralogs may still have been under tetrasomic inheritance at the split of the teleost lineages.

Therefore, two potential hypotheses may explain the results: i) The freshwater eel lineage experienced an additional WGD to $3 R$, and ii) Some duplicated genomic regions experienced lineage specific rediploidization after $3 R$ in the ancestor to freshwater eels. The supporting/opposing evidence for both hypotheses has been discussed. 


\subsection{Introduction}

Large accumulations of gene duplications can originate from one single event, like a whole genome duplication (WGD; Ohno 1970) or from multiple small duplication events such as small segmental duplications (SDs; Gu et al. 2002), which are often found in tandem. Any of these duplication events may contribute to species evolution by providing raw genetic material for new phenotypic variation (Cañestro et al. 2013; Gu et al. 2002; Ohno 1970).

Relatively recent SDs are often found in tandem and have been found in high abundance in several organisms including yeast (Llorente et al. 2000), daphnia (Colbourne et al. 2011), humans (Bailey et al. 2002; Gu et al. 2002; Vallente Samonte and Eichler 2016) and teleosts (Blomme et al. 2006; David et al. 2003; Jaillon et al. 2004; Lu et al. 2012; Rondeau et al. 2014). Soon after a SD, one paralog is most commonly lost (Ohno 1970) possibly due to an accumulation of deleterious mutations or genetic drift (Albalat and Cañestro 2016). In a few cases, a high abundance of SDs can persist for millions of years as seen in yeast (Llorente et al. 2000), common carp (David et al. 2003) and humans (Bailey et al. 2002; Gu et al. 2002; Hafeez et al. 2016). This process has been associated with adaptation to new environments (Colbourne et al. 2011; Tautz and Domazetlošo 2011; Chain et al. 2014). On the other hand, WGDs are presumed rare in mammals (Mable et al. 2004), but are recurrently found in amphibians and reptiles (Otto and Whitton 2000) and have frequently been suggested in insects (Otto and Whitton 2000), fungi (Albertin and Marullo 2012), and plants (Schmutz et al. 2010; Del Pozo and Ramirez-Parra 2015; Soltis et al. 2014; Masterson 1994). Recent WGD events have traditionally been observed by cytological studies through the observation of additional chromosomes (Soltis et al. 2014); however, ancient WGD events are often hidden (Parisod et al. 2010; Soltis et al. 2014; Blanc 2004; Sémon and Wolfe 2007a) by massive gene losses (Inoue et al. 2015; Wolfe 2001; Kassahn et al. 2009) and the fusion or loss of duplicated 
chromosomes (Wang et al. 2015; Glasauer and Neuhauss 2014; Albertin and Marullo 2012; Chester et al. 2012; Gordon et al. 2011). Therefore, an ancient WGD event can only be discovered through specific analysis at a whole genome level. Consequently, discoveries of WGD events have accelerated as sequencing techniques have improved and genome-scale data has become more accessible (Parisod et al. 2010; Soltis et al. 2014; Sémon and Wolfe 2007a). It has been suggested that early on in the vertebrate lineage two WGDs (1R and $2 R$ ) occurred resulting in species radiation and evolution of new traits (Cañestro et al. 2013; Dehal and Boore 2005; Gu et al. 2002; Ohno 1970). In teleosts, strong genomic evidence supports the existence of an additional WGD called the teleost specific $3^{\text {rd }}$ round of vertebrate WGD (3R), which occurred in the base of the teleost lineage between 350 and 320 million years go (MYA) (Christoffels et al. 2004; Vandepoele et al. 2004).

In addition to $3 \mathrm{R}, \mathrm{WGD}$ events appear to be a reoccurring phenomenon in Actinopterygians even when only considering cytological evidence (Leggatt and Iwama 2003; Comber and Smith 2004). Furthermore, Inoue et al. (Inoue et al. 2015) found that $70-80 \%$ of the genes originating from the 3R WGD get lost after just 60 million years. Similarly, other studies have found that in most teleosts 3$20 \%$ of the genes generated during $3 R$ are conserved today (Glasauer and Neuhauss 2014). Moreover, extensive chromosome reorganizations have been suggested in the teleost lineage associated with 3R (Braasch et al. 2016; Bian et al. 2016) and after the salmonid specific $4^{\text {th }}$ round of WGD (Ss4R; Lien et al. 2016). Therefore, it has been suggested that further discoveries of new WGDs in teleosts may increase following the development of sequencing techniques and the increase in the number of studies specifically analysing the temporal distribution and quantity of gene duplications (Glasauer and Neuhauss 2014). This phenomenon of accelerating rates of WGD discoveries is currently observed 
in plant genomics (Schmutz et al. 2010; Del Pozo and Ramirez-Parra 2015; Soltis et al. 2014; Blischak et al. 2018).

Following a WGD event, paralog genes will start to diverge after the recombination between duplicated genes has stopped at the transition from tetrasomic to disomic inheritance (Robertson et al. 2017; Lien et al. 2016; Martin and Holland 2014), also referred to as cytological rediploidization. However, after autotetraploidization tetrasomic segregation may continue due to the high similarity between the duplicated chromosomes, and thus rediploidization may be vastly delayed after a WGD event (Robertson et al. 2017). Therefore, variations in phylogenetic divergences between paralog gene pairs originating from the same WGD event can appear in cases where a genomic region is under tetrasomic inheritance, at the time of a speciation event (Robertson et al. 2017). The resulting phylogenetic gene family trees from such event are virtually indistinguishable from gene trees where additional gene duplications have occurred (Martin and Holland 2014). In particular, in salmonids, strong evidence suggests that rediploidization after the Ss4R has been protracted in time for approximately a quarter of the genome (Lien et al. 2016; Wright et al. 1983). In turn, this mechanism has led to several salmonid gene duplicates to not present 1:1 orthology relationships among different salmonid species, despite being created at the Ss4R (Lien et al. 2016; Berthelot et al. 2014; Allendorf and Thorgaard 1984). A protracted pseudotetraploid period has also been suggested in teleosts after 3R (Martin and Holland 2014). In particular, the peculiar Hox gene complement of the African butterfly fish (Pantodon buchholzi) is most parsimoniously explained by a hypothesis which includes protracted rediploidization for some genomic regions (Martin and Holland 2014). However, unequivocal support of protracted rediploidization beyond salmonids will require further careful phylogenomic analysis (Robertson et al. 2017). 
Several studies have revealed a high occurrence of duplicated genes in freshwater eels (Anguilla spp., Elopomorpha; Dufour et al. 2005; Pasqualini et al. 2009; Henkel et al. 2012; Pasquier et al. 2012; Maugars and Dufour 2015; Morini et al. 2015; Lafont et al. 2016; Rozenfeld et al. 2016; Morini et al. 2017a, 2017b). While these duplicated genes often present weak conserved synteny, suggesting a $3 \mathrm{R}$ origin, they also present low phylogenetic divergence between paralogs, indicating that they recently started to diverge. For example, Lafont et al. (Lafont et al. 2016) hypothesize that the entire genomic region containing the gene gper could have been duplicated in freshwater eels, and maybe also in other teleosts; and that the retention of duplicated genes may be higher in these eels than in other teleosts.

The occurrence of duplicated genes in freshwater eels seems to be higher than for most teleost lineages, and specifically, the remarkably high conservation of duplicated gene sequences since 3R, often hypothesized for freshwater eel genes (Dufour et al. 2005; Pasqualini et al. 2009; Henkel et al. 2012; Pasquier et al. 2012; Maugars and Dufour 2015; Morini et al. 2015; Lafont et al. 2016; Rozenfeld et al. 2016; Morini et al. 2017a, 2017b), would be unique (Ravi and Venkatesh 2018). Owing to the fact that the availability of genetic raw material has been suggested to increase the potential of novel adaptation (Blischak et al. 2018), information on the duplicated gene complement of eels may prove valuable in understanding the biology of these endangered species. Therefore, the peculiarity of the published data led us to quantify and analyse duplications in the most relevant freshwater eel species and investigate the temporal distribution of the events that created them. To this end, we assembled de novo transcriptomes of Japanese (Anguilla japonica) and European eel (Anguilla anguilla) from downloaded and newly generated Illumina RNA sequencing data, respectively. Furthermore, we performed phylogenetic reconstructions, assigned paralog pairs to branches of the resulting species tree, and calculated fourfold synonymous third-codon transversion (4dTv) distances for each paralog 
pair identified within these transcriptomes. These analyses were run on our de novo transcriptomes and on multiple other fish transcriptomes and genomes. Our analysis supports the commonly suggested hypothesis of a high abundance of paralog pairs, unique to the freshwater eel species. However, the phylogenetic and 4dTv analyses suggest a post 3R origin, and a strong signal of synteny between the genomic environments of these paralogs opposes a hypothesis of a SD origin. Similar results were also obtained from the included Osteoglossomorpha branches and the basal Clupeocephala branch. This, in turn, suggests that the results were generated by protracted rediploidization in teleosts after the 3R. These results thus open a discussion on whether these duplicated genes are the result of a 4R WGD in a common ancestor to freshwater eels or rather have been conserved on chromosomal regions, which have experienced delayed rediploidization after the $3 R$.

\subsection{Materials and methods}

\subsubsection{Fish husbandry}

Ten immature farm Euroepan eel males (mean body mass $96.7 \pm 3.6 \mathrm{~g} \pm$ SEM) supplied by Valenciana de Acuicultura S.A. (Puzol, Valencia, Spain) were transported to the Aquaculture Laboratory at the Universitat Politècnica de València, Spain. The fish were kept in a 200-L tank, equipped with individual recirculation systems, a temperature control system (with heaters and coolers), and aeration. The fish were gradually acclimatized to seawater (final salinity 37 $\pm 0.3 \%$ o), over the course of two weeks. The temperature, oxygen level and $\mathrm{pH}$ of rearing were $20 \stackrel{\circ}{ }{ }^{\circ}, 7-8 \mathrm{mg} / \mathrm{L}$ and $\sim 8.2$, respectively. The tank was covered to maintain, as far as possible, a constant dark photoperiod, and the fish were starved throughout the holding period. After acclimation, the fish were sacrificed in order to collect samples of the forebrain (telencephalon, diencephalon, and olfactory bulb), pituitary, and testis tissues. 


\subsubsection{Human and animal rights}

This study was carried out in strict accordance with the recommendations given in the Guide for the Care and Use of Laboratory Animals of the Spanish Royal Decree 53/2013 regarding the protection of animals used for scientific purposes (BOE 2013), and in accordance with the European Union regulations concerning the protection of experimental animals (Dir 86/609/EEC), Guidelines of the European Union (2010/63/EU). The protocol was approved by the Experimental Animal Ethics Committee from the Universitat Politècnica de València (UPV) and final permission was given by the local government (Generalitat Valenciana, Permit Number: 2014/VSC/PEA/00147). The fish were sacrificed using an overdose of anaesthesia.

\subsubsection{RNA extraction and sequencing}

High quality RNA was extracted from the forebrain, pituitary, and testis samples of one individual male eel (weight: $105.4 \mathrm{~g}$, length: $38.5 \mathrm{~cm}$, and eye index: 4.62), following the protocol developed by Peña-Llopis and Brugarolas (Peña-Llopis and Brugarolas 2013). The quantity and quality were tested using a bioanalyser (Agilent Technologies, USA), the samples with sufficient RNA integrity number (RIN) values (RIN > 8.2) and RNA amounts ( $>3 \mu \mathrm{g}$ of total RNA) were selected. Total RNA of the three samples were shipped to the company Macrogen Korea (Seoul, South Korea). mRNA purification was carried out on these samples, using Sera-mag Magnetic Oligo (dT) Beads, followed by buffer fragmentation. Reverse transcription was followed by PCR amplification to prepare the samples for sequencing following the TruSeq stranded mRNA LT sample prep kit (Illumina, San Diego, USA). The strand information was kept in an Illumina Hiseq-4000 sequencer (Illumina, San Diego, USA). Resulting raw sequences were 101bp paired-end reads which are available at the NCBI Sequence Read Archive (SRA) under the accession no. SRP126643. 


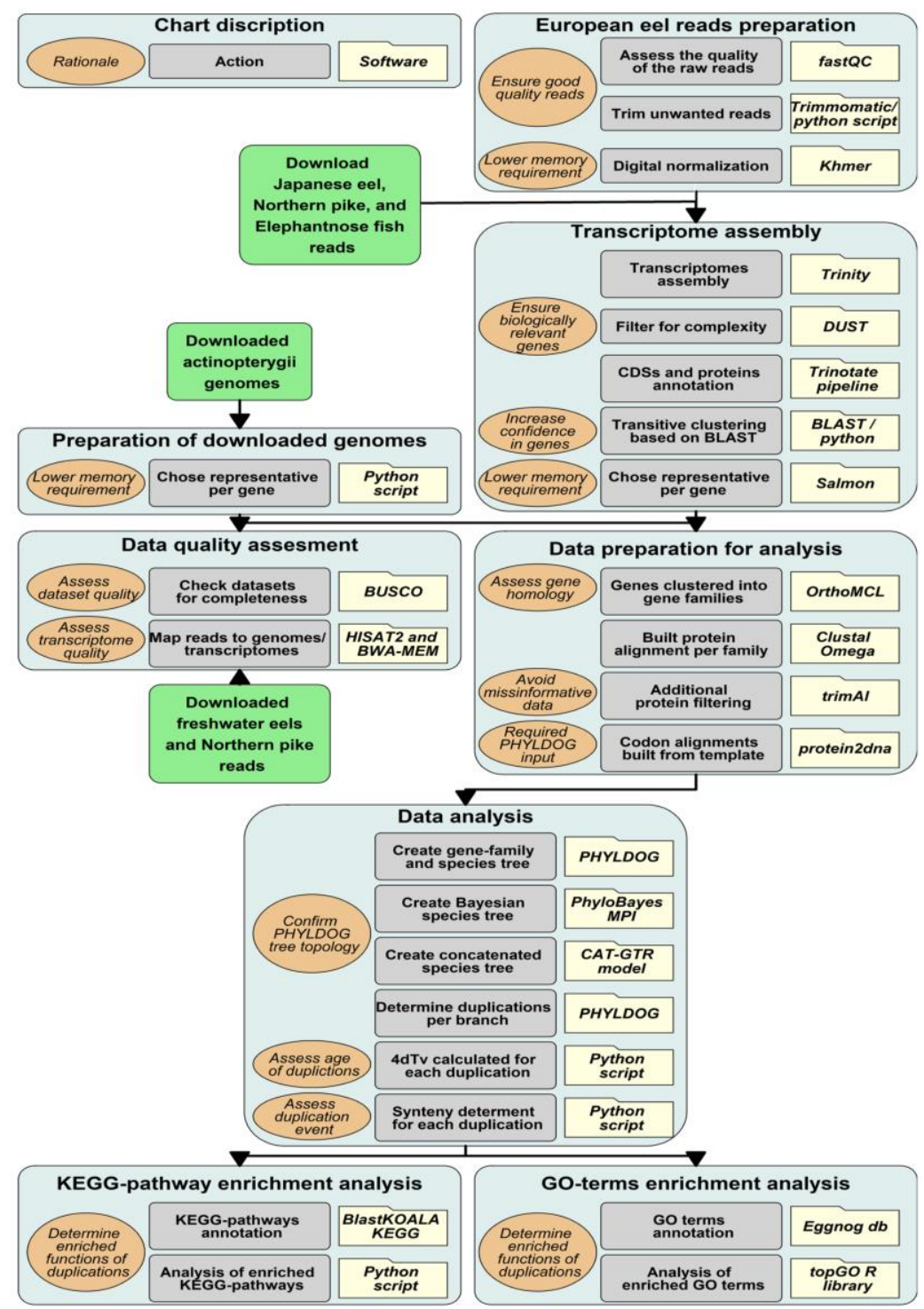

Figure 32. Pipeline of the bioinformatics methodology. Folders describe the software used, light grey boxes describe the action taken, light brown bobbles describes the rationale for selected actions, and light blue boxes describe the specific goal of each section. Finally, green boxes represent external data input.

\subsubsection{Transcriptome assemblies and genomes}

The bioinformatics methodology described below is illustrated in figure 32 . Specifically, FastQC (Andrews 2010) software was used to assess the quality of 
the raw reads generated by Macrogen. Thereafter, trimmomatic (Bolger et al. 2014) was used to trim the reads, eliminating known adaptor sequences, and low quality regions. Finally, trimmed reads shorter than $50 \mathrm{bp}$ were filtered out. European eel reads were digitally normalized before assembly by Khmer software (Crusoe et al. 2015) using a k-mer length of 25 and a coverage of 100. Furthermore, the RNA-Seq raw reads of a Japanese eel Fertilized egg (SRA, NCBI: SRR1930110), preleptocephalus (SRA, NCBI: SRR1930112), leptocephalus (SRA, NCBI: SRR1930115) and glass eel (SRA, NCBI: SRR1930117) were downloaded from NCBI. The RNA-Seq raw reads for Northern pike (Esox lucius), elephantnose fish (Gnathonemus petersii) and silver arowana (Osteoglossum bicirrhosum) were downloaded from the PhyloFish project (Pasquier et al. 2016). All transcriptomes were then assembled using Trinity software (Haas et al. 2013), taking the strand orientation (for European eel) into account. Naturally produced transcripts may include intervals with a high bias for specific nucleotides (low-complexity), such transcripts may give high-scoring blast results but in fact be biologically insignificant. Therefore, the transcripts assembled were filtered according to their complexity (with a DUST score threshold of 7 and a DUST window of 64), length (with a minimum length of 500 bp), and level of expression (with a transcripts per million (TPM) threshold of 1 ). The DUST module from BLAST (http://blast.ncbi.nlm.nih.gov/Blast.cgi) was used for this filtering, and Salmon software was used to estimate TPM. After assembly, the coding DNA sequences (CDSs) and proteins were annotated using the Trinotate functional annotation pipeline (Haas et al. 2013). Transcripts that share k-mers were clustered by Trinity. However, these transcripts might correspond to different transcript forms of the same gene or to closely related genes from a gene family. We split these transcripts into genes by running a transitive clustering based on a blast search. In this clustering, transcripts, which shared at least $100 \mathrm{bp}$ with a minimum identity of $97 \%$, were considered to be isoforms of the same gene. Thus, some Trinity clusters were split into several 
genes. For each gene, the most expressed transcript, according to the Salmon software (Patro et al. 2017), was chosen as its representative (Fig. 32).

For the synteny analysis, the available European (Henkel et al. 2012) and Japanese (Nomura et al. 2018) eel genomes were downloaded from the ZFGenomics and the DDBJ web site, respectively. The Atlantic salmon (Salmo salar) genome assembled by the International Cooperation to Sequence the Atlantic Salmon Genome (Lien et al. 2016) and the Asian arowana (Scleropages formosus) genome (Bian et al. 2016) were downloaded from NCBI. The genomes of zebrafish (Danio rerio; Howe et al. 2013), fugu (Takifugu rubripes; Kai et al. 2011), spotted gar (Lepisosteus oculatus; Braasch et al. 2016), and platyfish (Xiphophorus maculatus; Schartl et al. 2013) were downloaded from ENSEMBL (release 87). The Northern pike genome (Rondeau et al. 2014) was downloaded from the Northern Pike Genome web site (Genbank accession GCA_000721915.1). For each gene in the genomes, the longest transcript was chosen as the representative. For the synteny analysis, the available European (Henkel et al. 2012) and Japanese (Nomura et al. 2018) eel genomes were downloaded from the ZF-Genomics and the DDBJ web site, respectively (Fig. 32).

\subsubsection{Genome and transcriptome quality assessment}

In order to assess the quality of the transcriptomes and genomes, we looked for the Benchmarking set of Universal Single-Copy Orthologues (BUSCO) conserved gene set in them (Simão et al. 2015). BUSCOs are conserved proteins which are expected to be found in complete genomes or transcriptomes. Therefore, the number of present, missing, or fragmented BUSCOs can be used as a quality control of a genome or transcriptome assembly. For this assessment, the Actinopterygii (odb9) gene set, which consists of 4584 single-copy genes that are present in at least $90 \%$ of Actinopterygii species, was used. As an additional comparison between the transcriptome and genomes of pike and eels, RNA-seq 
reads were mapped both to the genome and transcriptome assemblies using HISAT2 (Pertea et al. 2016) and BWA-MEM (Li and Durbin 2010) software, respectively (Fig. 32), using default settings in both programs.

\subsubsection{Gene families}

Genes were clustered into gene families by the OrthoMCL web service (Li et al. 2003), which uses the Markov Cluster algorithm to group homologs of all the included datasets, based on all against all BLASTP searches. Therefore, the OrthoMCL gene families were also considered gene families for this study. For each gene family, a multiple protein alignment was built. To avoid transcriptome assembly artefacts, proteins longer than 1,500 amino acids, transcripts with a DUST score higher than 7 and sequences with more than $40 \%$ gaps in the alignment, were filtered out. The software Clustal Omega (Sievers et al. 2011) carried out the protein multiple alignment and trimAl (Capella-gutiérrez et al. 2009) removed the regions with too many gaps or those difficult to align. The protein alignment was used as a template to build the codon alignment by aligning the transcript sequences against the corresponding protein using the protein2dna exonerate algorithm (Slater and Birney 2005; Fig. 32).

\subsubsection{Phylogenetic reconstruction and duplication dating}

The resulting protein alignments were used by PHYLDOG (Boussau et al. 2012) software to generate a species tree as well as a gene family tree corresponding to each alignment. Due to the high memory requirements of PHYLDOG, not all the gene families could be run in the same analysis, therefore 10 analyses were carried out, with 8,000 protein alignments being chosen at random for each. Once all runs were finished, we checked that the species tree topology of all the 10 species trees matched exactly. PHYLDOG uses a maximum likelihood 
approach to simultaneously co-estimate the species and gene family trees from all individual alignments.

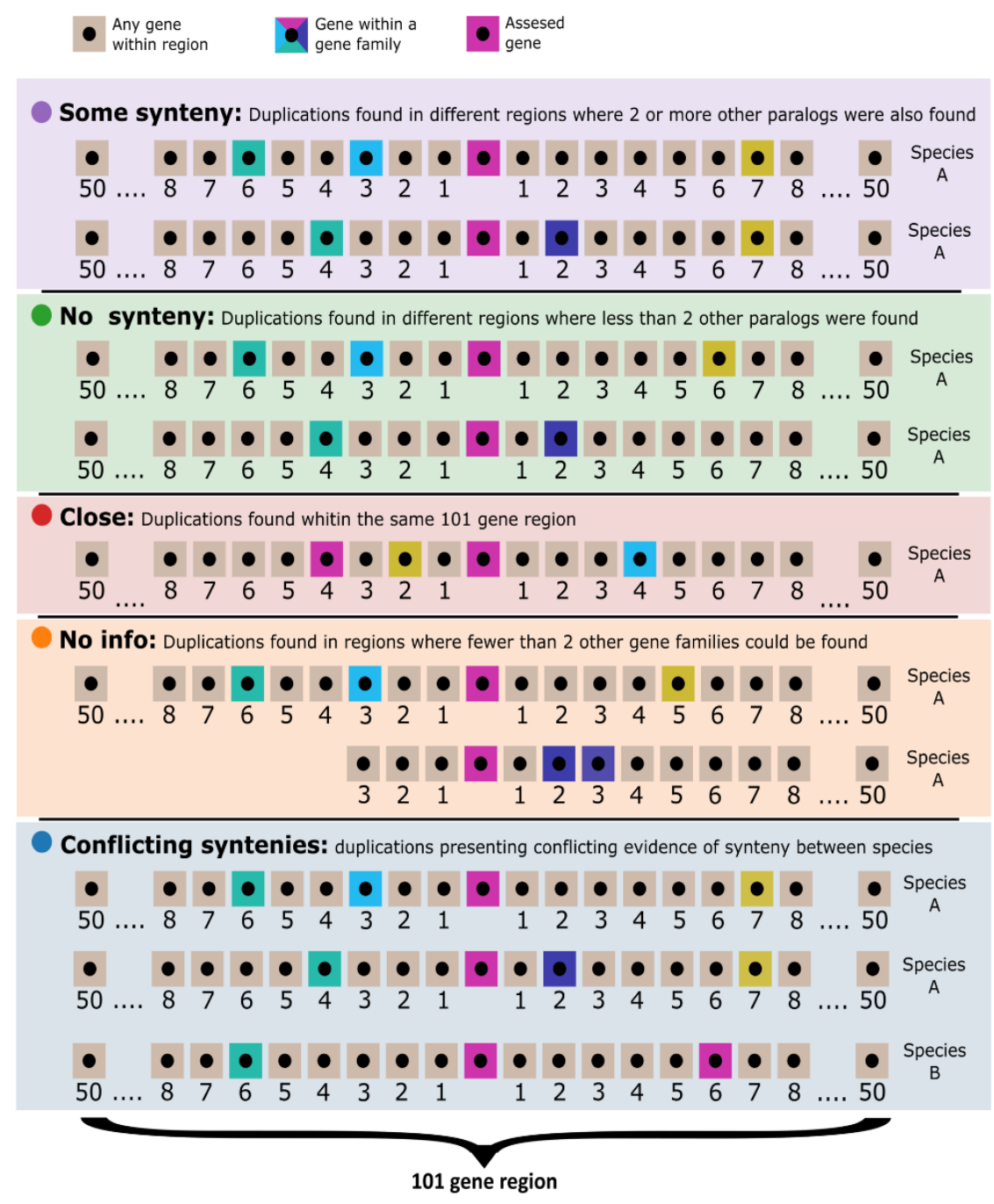

Figure 33. Visualization of the assigned synteny types: "some synteny" $(\bullet)$, paralogs of genes found close to one duplicate are also found close to the other duplicate; "no synteny" (•), less than two paralogs for other genes are found close to both paralog duplicates; "close" ( $\bullet)$, duplicated genes are close in the genome; "no information" $(\bullet)$, the duplicated genes are located in small scaffolds with too few gene families close by; "conflicting syntenies" $(\bullet)$, different synteny classification found in the genomes of the different species affected by the duplication. Sand coloured boxes represent genes which have not been assigned to a gene family, pink boxes represent the gene from which synteny is being assessed; all other colour boxes represent other genes which have been assigned to a gene family. 
In order to confirm the tree topology of the PHYLDOG species tree, the species phylogeny was also reconstructed using a Bayesian approach with PhyloBayes MPI version 1.7 (Lartillot et al. 2009). Furthermore, from the gene families that had one gene for each species, 100 were chosen at random to create a concatenated alignment of 43,566 amino acids. The model used was CAT-GTR and three independent MCMC chains were run for 39,872, 56,328, and 39,285 iterations (Fig. 32).

PHYLDOG further tagged duplications and assigned these to specific tree branches based on the gene family trees. Between any pair of duplicated sequences, the number of transversions found in the third base of the codon was divided by the number of four-fold degenerated codons resulting in the 4dTv distance. A correction to the 4dTv was applied: In (1 - $2 *$ distance) / -2. The 4dTv was calculated for all the duplications tagged by PHYLDOG within any gene family. The distribution of 4dTvs was fitted with a lognormal mixture model using the scikit-learn Gaussian Mixture class (Fig. 32).

\subsubsection{Synteny}

The kind of event that created each duplication was characterized by analysing the conserved synteny between the paralogs created by that duplication within a particular genome. Tandem SDs would create paralogs found close to each other in the genome, whereas the paralogs created by a WGD would be far apart, but surrounded by similar genes in each of the duplicated regions. Also, we have to consider that several phylogenetically close species can be affected by the same older duplication event. With this in mind, we categorized duplications as one of 4 classes (Fig. 33): i) the paralog genes that were found close to each other in the genome, within the 50 neighbouring genes to either side, were labelled as "close", ii) the paralogs which were found in syntenic regions where 2 or more paralogs from other gene families were located within 
the 50 neighbouring genes to either side, not necessarily in the same collinear order, were labelled as "some synteny", iii) the cases in which fewer than 2 gene families could be identified within the 50 neighbouring genes to either side, from either of the paralogs genes, were labelled as "no info", and iv) the cases where conflicting evidence was found in the genomes of the different species affected by the duplication were labelled as "conflicting syntenies".

This labelling of the duplications was carried out by a Python function and the Python class GenomeLocator. The location of each gene in a genome was obtained by performing a BLAST search with its representative transcript against the genome (Fig. 32).

\subsubsection{Investigation of functional category enrichment}

The EggNOG database has gene ontology (GO) annotations for each of its gene families (Huerta-Cepas et al. 2016). To match our gene families with those from the EggNOG database, the protein sequence with least gaps per each of our families was selected and a HMMER search (Finn et al. 2011) was carried out against the EggNOG position weight matrices with an e-value threshold of $10^{-4}$. The GO annotation of the best EggNOG hit in this search was transferred to our family. The enrichment analysis was carried out using the Fisher statistic and the weight algorithm of the topGO library (Alexa and Rahnenfuhrer 2016) from the Bioconductor project. Freshwater eel transcripts were annotated using the BlastKOALA KEGG service (Kanehisa et al. 2016) and a Fisher exact test was carried out, using the scipy implementation, to look for overrepresented KEGG pathways in the duplications assigned to the basal freshwater eel branch (Fig. 32). 


\subsection{Results}

\subsubsection{Transcriptome assemblies}

Forebrain, testis, and pituitary RNA samples, from an individual European eel, were sequenced, generating a total of 191 million Illumina reads (66, 60 and 65 million from the forebrain, testis, and pituitary, respectively), with a length of $101 \mathrm{bp}$. These reads were assembled into one de novo transcriptome, using the Trinity assembler after a digital normalization step (Crusoe et al. 2015) that left 75 million representative reads. The same procedure was used to generate one de novo transcriptome from Illumina RNA-sequencing reads of the Japanese eel, which was downloaded from the NCBI's Sequence Read Archive (Hsu et al. 2015). The transcriptomes of Northern pike, elephantnose fish and silver arowana were also assembled by Trinity using Illumina reads from the Phylofish database (Pasquier et al. 2016). The number of unigenes (henceforth referred to as transcripts) assembled ranged from 64,857 to 78,610 (Table 11) and the number of transcript clusters ranged from 46,585 to 55,667 (henceforth referred to as genes; Table 12).

Table 11: Metrics of included raw read datasets from European eel (Anguilla anguilla), Japanese eel (Anguilla japonica), northern Pike (Esox lucius), elephantnose fish (Gnathonemus petersi), and silver arowana (Osteoglossum bicirrhosum).

\begin{tabular}{llccc} 
Species & N.o Reads & Q30 & Transcripts & $\begin{array}{c}\text { Mean GC } \\
\text { content (\%) }\end{array}$ \\
\hline European eel & $181,322,106$ & 0.994 & 77,247 & 51.17 \\
Northern Pike & $553,710,218$ & 0.989 & 68,489 & 48.05 \\
Elephantnose fish & $498,451,616$ & 0.993 & 74,642 & 49.75 \\
Silver arowana & $490,649,254$ & 0.992 & 78,610 & 49.18 \\
Japanese eel & $458,032,126$ & 0.986 & 64,857 & 48.13
\end{tabular}


Table 12: Quantities of included genes per included species: European eel (Anguilla anguilla), Japanese eel (Anguilla japonica), zebrafish (Danio rerio), northern pike (Esox lucius), elephantnose fish (Gnathonemus petersi), spotted gar (Lepisosteus oculatus), Asian arowana (Scleropages formosus), silver arowana (Osteoglossum bicirrhosum), Atlantic salmon (Salmo salar), fugu (Takifugu rubripes), and platyfish (Xiphophorus maculatus). "Transcripts" represents unigenes, "Genes" represents the number of transcript clusters, "Representative transcripts with predicted protein" represents the number of genes with a successful protein annotation, "Gene family transcripts" represents the representative transcripts with predicted protein with a successful gene family annotation, and "\% of genes assigned to a gene family" represents the percentage of representative transcripts with predicted protein with successful gene family annotation.

\begin{tabular}{lccccc} 
Species & Transcripts & Genes & $\begin{array}{c}\text { Representative } \\
\text { transcripts with } \\
\text { predicted protein }\end{array}$ & $\begin{array}{c}\text { Gene family } \\
\text { transcripts }\end{array}$ & $\begin{array}{c}\text { \% of genes } \\
\text { assigned to a } \\
\text { gene family }\end{array}$ \\
\hline European eel & 77,247 & 54,879 & 27,696 & 25,862 & 93.38 \\
Japanese eel & 64,857 & 46,585 & 23,780 & 23,098 & 97.13 \\
Zebrafish & 58,274 & 32,189 & 25,790 & 22,703 & 88.03 \\
Northern pike & 68,489 & 49,154 & 23,843 & 21,696 & 90.99 \\
Elephantnose fish & 74,642 & 50,455 & 24,857 & 22,036 & 88.65 \\
Spotted gar & 22,483 & 18,341 & 18,341 & 17,872 & 97.44 \\
Silver arowana & 78,610 & 55,667 & 24,938 & 21,604 & 86.63 \\
Asian arowana & 43,354 & 23,799 & 22,740 & 20,637 & 90.75 \\
Atlantic salmon & 109,584 & 55,104 & 48,593 & 42,625 & 87.72 \\
Fugu & 47,841 & 18,523 & 18,523 & 17,698 & 95.55 \\
Platyfish & 20,454 & 20,379 & 20,379 & 19,807 & 97.19
\end{tabular}

\subsubsection{Genome and transcriptome quality}

The genomes and transcriptomes considered for inclusion in the analysis were quality tested by a BUSCO assessment of completeness. In general, when available, genomes were used instead of transcriptomes, except for pike, and European eel, where the transcriptomes outperformed the genomes according to the BUSCO assessment (Fig. 34). Furthermore, the Japanese eel transcriptome was preferred due to a problem with the Japanese eel genome annotation. These transcriptomes also provided a higher mapping of RNA sequencing reads 
compared to their corresponding genomes. The percentage of reads that mapped concordantly against the genome and the transcriptome were 65.8 and 91.9\%, respectively, for European eel, 74.3 and $88.4 \%$ for Japanese eel and 44.6 and $85.8 \%$ for pike. Furthermore, previously published European eel RNAsequencing experiments were also mapped to the available European eel genome and our de novo transcriptome. In this case, 52.2\% (Coppe et al. 2010), 57.9\% (Burgerhout et al. 2016), and 66.18\% (Ager-Wick et al. 2013) reads mapped concordantly against the eel genome whereas 84.3\% (Coppe et al. 2010), 69.5\% (Burgerhout et al. 2016), and 87.32\% (Ager-Wick et al. 2013) mapped against the transcriptome.

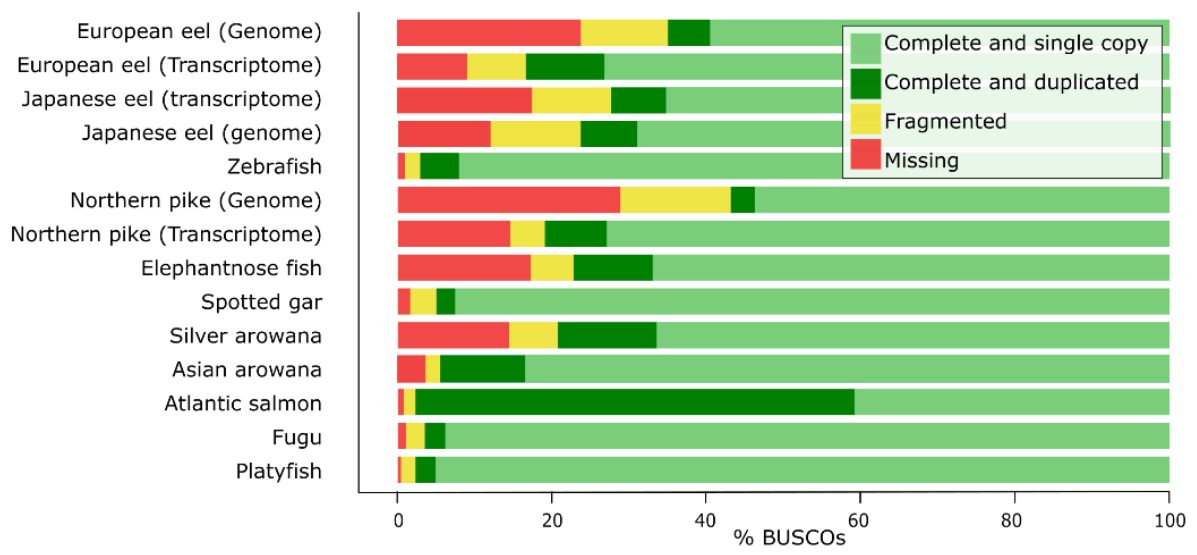

Figure 34. BUSCO (Benchmarking set of Universal Single-Copy Orthologues) result for included genome and transcriptome. The sequence of a BUSCO gene can be found complete or fragmented in each genome and it can be found once (single copy), more than once (duplicated) or not found (missing). Included genomes are: European eel (Anguilla anguilla), Japanese eel (Anguilla japonica), Asian arowana (Scleropages formosus), zebrafish (Danio rerio), northern pike (Esox lucius), spotted gar (Lepisosteus oculatus), fugu (Takifugu rubripes), platyfish (Xiphophorus maculatus) and Atlantic salmon (Salmo salar). Included transcriptomes: European eel, Japanese eel, northern pike, elephantnose fish (Gnathonemus petersii) and silver arowana (Osteoglossum bicirrhosum).

\subsubsection{Gene families}

Genes were assigned to gene families according to the gene family categorization of OrthoMCL ( $\mathrm{Li}$ et al. 2003). The percentage of genes with 
predicted proteins assigned to a family by the OrthoMCL web service (Li et al. 2003) ranged from $86.6 \%$ (silver arowana) to $97.4 \%$ (spotted gar; Table 12). Overall, 15,771 gene families were covered, from which 13,972 protein and codon alignments were built. These families contained between 2 and 172 genes, with 11 genes per family being the mode.

\subsubsection{Phylogenetic reconstruction and duplication characteristics}

PHYLDOG software was used to tag gene duplications, create a species tree, and assign duplications to tree branches, based on gene family phylogenetic trees. Overall, trees for 10,714 gene families were created by PHYLDOG and based on the tree topology, branches in which a gene appeared to duplicate were labelled. The resulting PHYLDOG species tree matched the species tree topology created by phylobayes (Lartillot et al. 2009) and the resulting tree of the concatenated alignment; a cladogram of these trees is included in figure 35. Since PHYLDOG distinguishes between gene divergence at speciation events and duplications, all genes resulting from tagged duplications are assumed to be paralogs. The assigned duplications were subsequently characterized by synteny and $4 d T v$ distance. The $4 d T v$ distance is used to estimate the accumulation of synonymous mutation, which can be used to estimate the time that has passed from when mutations started to accumulate. The assigned synteny classes include: "close" which indicates SDs that are a result of tandem duplications; "some synteny" which indicates a potential WGD origin (or at least a potential duplication event containing >100 genes); and "no synteny", which supports neither a SD nor a WGD origin (Fig 33).

PHYLDOG labelled 5,063 duplications to the basal teleost branch, after the split of the spotted gar, with a 4dTv mode of 0.75 (Fig 35, Node 3). Of the paralogs created by these duplications, $73.8 \%$ were located in regions with some synteny, $1.5 \%$ were close to each other, and $22.5 \%$ had no synteny (Fig 35, Node 3 ). These percentages were calculated without taking into account the duplications where 
no information regarding the physical location of the genes could be established. The duplications assigned to this basal teleost branch (Fig 35, Node 3 ) included all gene families with members in both sister clades and thus are assumed to have originated at the $3 R$. This branch further included hundreds of duplications found in the eels. From these duplications, 30 families had conserved 2 paralog pairs, one of which had started to diverge at $3 \mathrm{R}$ and one in a common ancestor of freshwater eels after the split with Ostoglosomorphas. From these 30 families, all paralog pairs which had started to diverge in a common ancestor of freshwater eels (Fig 35, Node 9) were located in regions with some synteny.

1,280 duplications were assigned to the branch basal to the included Clupeocephalan teleosts: zebrafish, fugu, platyfish, northern pike, and Atlantic salmon (Fig 35, Node 4). These duplications showed a very similar distribution with those of the 3R branch, with an overall $4 \mathrm{dTV}$ mode of 0.75 (Fig 35, Node 3).

The basal freshwater eel branch was assigned 1,217 duplications of which 55.3, 15.8, and $24.3 \%$ were labelled as some synteny, close and without synteny, respectively (Fig 35, Node 9). The European and Japanese eel specific branches were assigned 510 and 127 duplications, from which 32.2, and $34.7 \%$ were labelled as some synteny, 50.0 and $48.4 \%$ were labelled as close, and 17.1 and $14.7 \%$ were labelled as without synteny, respectively (Fig 35 , Nodes 14 and 15).

The basal Osteoglossomorpha and the basal arowana branches were assigned 618 and 661 duplications, from which 95.7, and $76.2 \%$ were labelled as some synteny, 0.9 and $17.7 \%$ were labelled as close, and 3.5 and $5.1 \%$ were labelled as without synteny, respectively (Fig 35 , Nodes 8 and 12 ).

The salmon and zebrafish specific branches were assigned 8,787 and 1,525 duplications, respectively, and most of these duplications seemed recent, according to their $4 \mathrm{dTV}$ distances. In the salmon branch, most of the duplications (87.0\%) were characterized by paralogs located in syntenic regions, whereas 
most of the zebrafish paralogs (60.5\%) were characterized as "close" (Fig 35, Nodes 16 and 7).

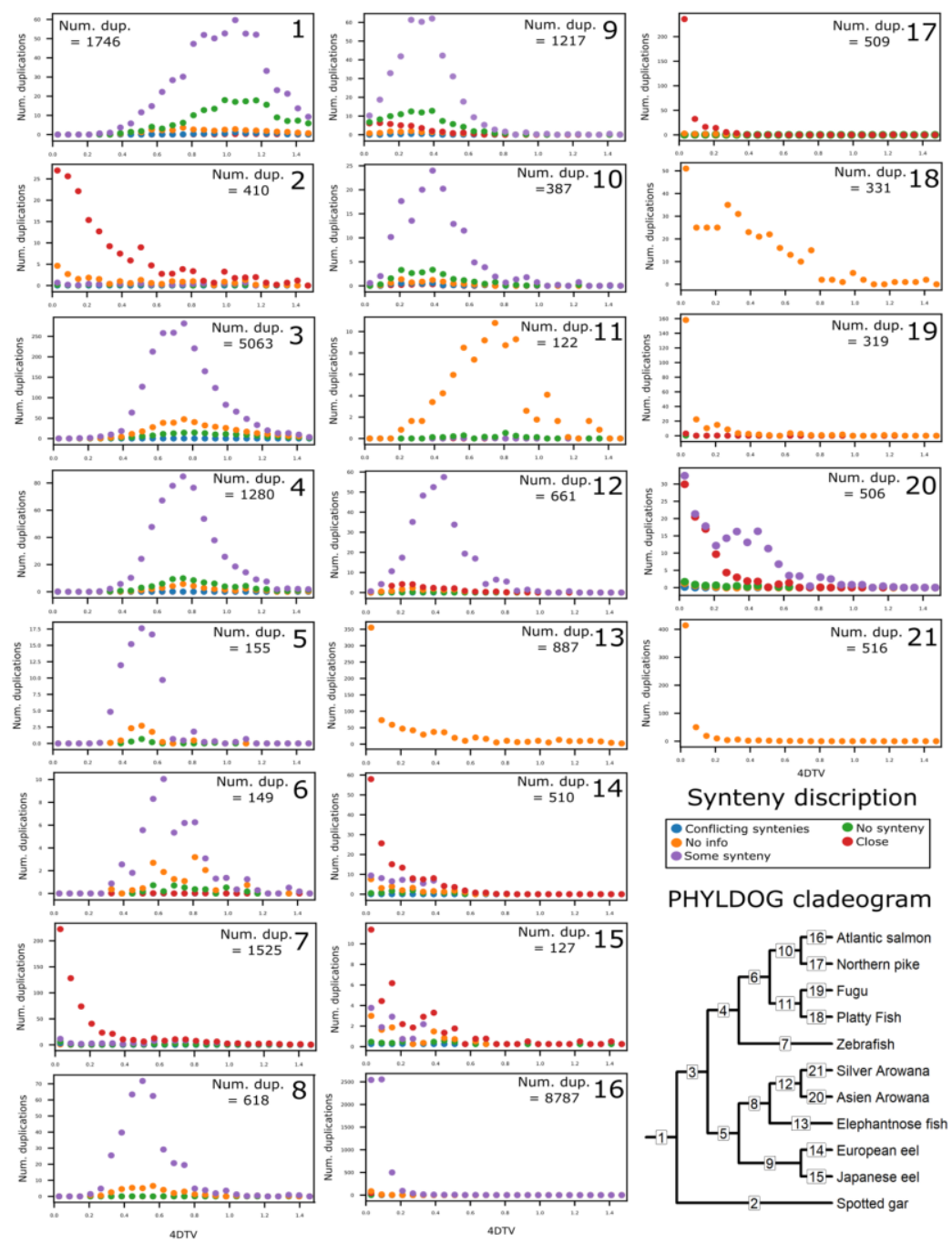

Figure 35. Quantity, $4 d T v$ and synteny distributions of duplications assigned to each branch of the PHYLDOG species tree. Each panel represents the branch with the corresponding number in the cladogram in the bottom right-hand corner. Species included in this study are: European eel (Anguilla anguilla), Japanese eel (Anguilla japonica), zebrafish (Danio rerio), northern pike (Esox lucius), spotted gar (Lepisosteus oculatus), fugu (Takifugu rubripes), platyfish (Xiphophorus maculatus), Atlantic salmon (Salmo salar), elephantnose fish (Gnathonemus petersii), Asian arowana (Scleropages formosus) and silver arowana (Osteoglossum bicirrhosum). The synteny types are the following: close $(\bullet)$, duplicated genes are close in the genome; some synteny $(\bullet)$, paralogs of genes found close to one duplicate are also found close to the other duplicate; no synteny $(\bullet)$, less than two paralogs for other genes are found close to both paralog duplicates; no information (०), the duplicated genes are located in small scaffolds with too few genes close by; conflicting syntenies (•), different synteny classifications found in the genomes of the different species affected by the duplication. 
For all the included species the "close" paralogs (tandem SDs) tended to show low divergence according to their $4 \mathrm{dTV}$, whereas the duplications found in synteny and most of the duplications without sufficient genomic location information, were more often found to have higher 4dTv distance (Fig. 35).

The duplications assigned to the basal freshwater eel branch showed a 4dTv mode of 0.4 (Fig 35, Node 9). In order to investigate the relative age of all the homolog pairs found in the eels, we ran a 4dTv distance analysis independent of the PHYLDOG tree topology. In this analysis, we compared the 4dTV distribution found for European eel homologs with Japanese eel, elephantnose fish, silver arowana and Asian arowana (Fig 36). The results showed a homolog density mode at $4 \mathrm{dTv}$ of $\sim 0.4$ for the European and Japanese eel, and 0.5 for the speciation event that separated elephantnose fish, silver arowana, and Asian arowana from the freshwater eels (Fig 36).

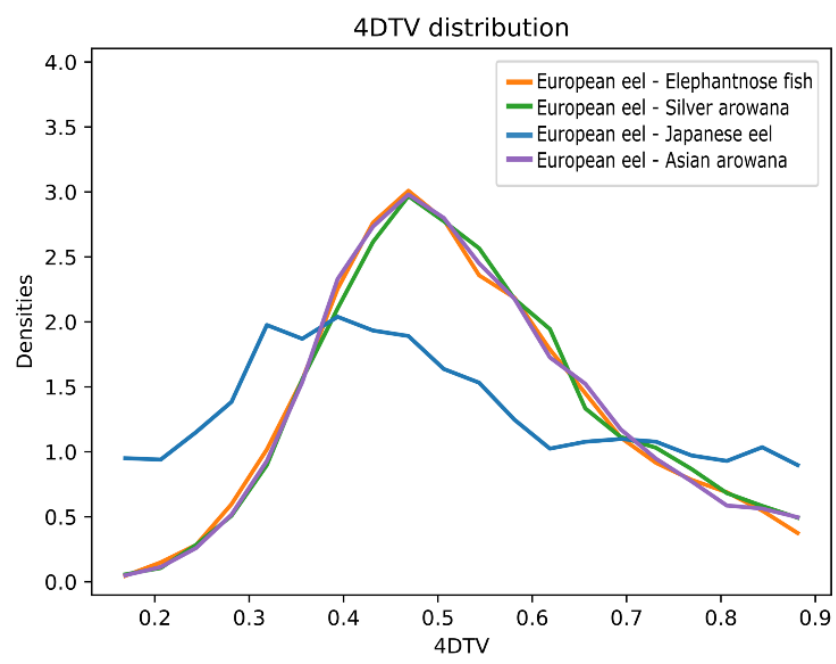

Figure 36. 4dTv distribution of European eel (Anguilla anguilla) and Japanese eel homologs (-), European eel and elephantnose fish (Gnathonemus petersii) homologs (-), and European eel, silver arowana (Osteoglossum bicirrhosum) homologs (-), and European eel and Asian arowana (Scleropages formosus) homologs (-). 

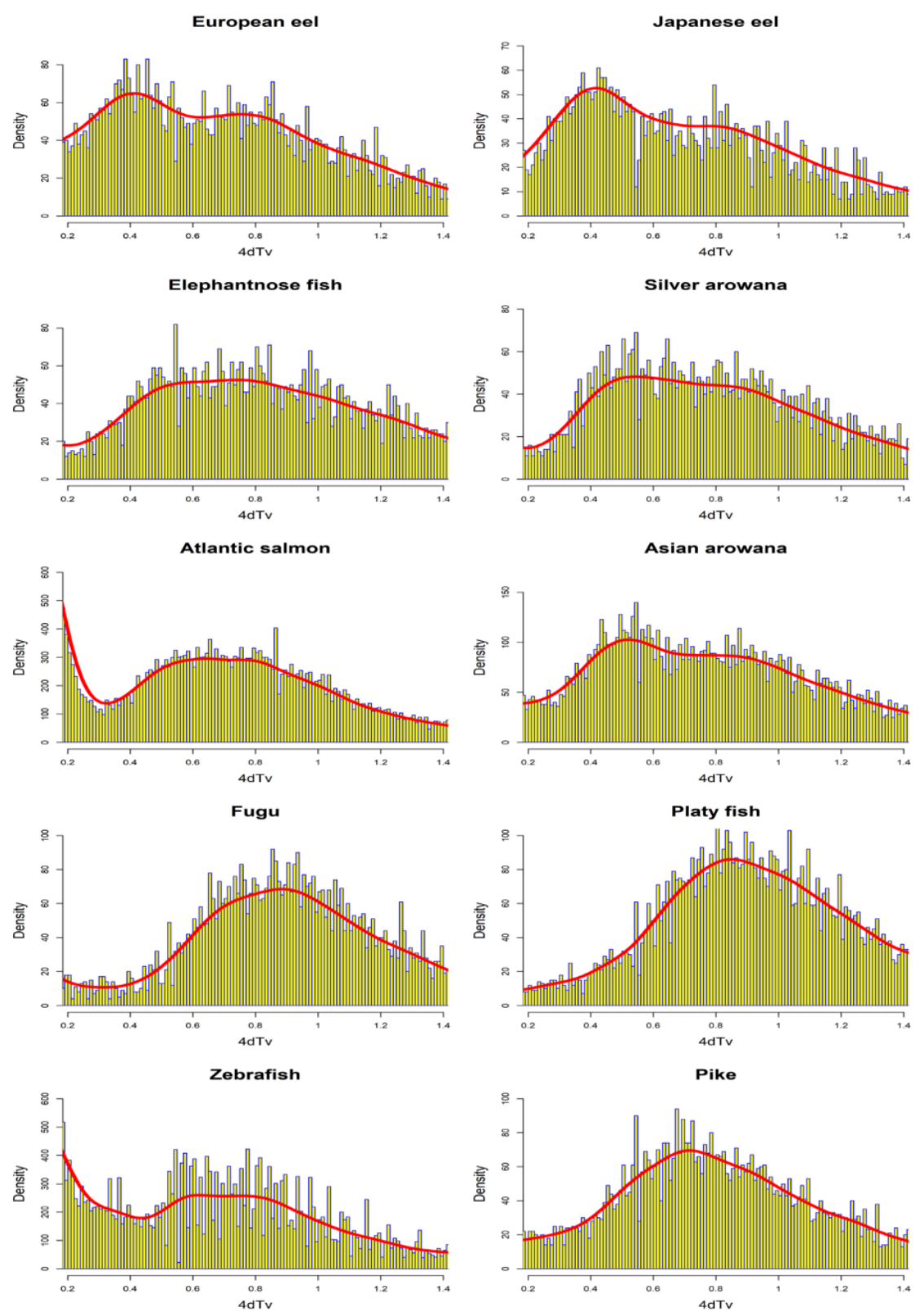

Figure 37. Histograms of all $4 d T v$ distances between paralogs of the included teleosts, presented with yellow and blue bars. Furthermore, a probability density estimate curve is plotted on top of the histograms in red. Density values (y-axis) do not correspond to the density estimate. The included species are: European eel (Anguilla anguilla), Japanese eel (Anguilla japonica), zebrafish (Danio rerio), northern pike (Esox lucius), spotted gar (Lepisosteus oculatus), fugu (Takifugu rubripes), platyfish (Xiphophorus maculatus), Atlantic salmon (Salmo salar), elephantnose fish (Gnathonemus petersii), Asian arowana (Scleropages formosus) and silver arowana (Osteoglossum bicirrhosum). 
Furthermore, in order to obtain comparisons between older eel paralogs $(>0.2$ of $4 \mathrm{dTv}$ ) and other teleosts, we produced histograms of the $4 \mathrm{dTv}$ distances calculated between all paralogs within each species from 0.2 to 1.4 of $4 \mathrm{dTv}$ (Fig 37). Additionally, a nonparametric probability density estimate was calculated, using the Gaussian mixture model and plotted on top of the histogram (Fig 37). These results show an older local density maximum (likely originating from $3 R$ ) for all teleosts ranging from 0.62 (Zebrafish) to 0.88 (Fugu) of 4dTv. Furthermore, European eel, Japanese eel, Asian arowana and possibly silver arowana showed an additional 4dTv local density maximum at $0.41,0.42,0.56$ and 0.55 of $4 \mathrm{dTv}$, respectively (Fig 37 ). A more recent local density maximum was seen in the Atlantic salmon distribution at 0.15 (Fig 35, Node 16).

\subsubsection{Functional category enrichment}

To investigate whether some functional categories were overrepresented among the paralogs assigned to the basal eel branch, two enrichment tests were carried out. First, 1,041 unique GO terms were assigned to 3,607 genes from the basal eel branch, by comparing them to the annotated EggNOG gene families. From these terms, we performed an enrichment analysis using the topGO $R$ library (Alexa and Rahnenfuhrer 2016). The resulting enriched GO terms are presented in Table 13. In many cases, these terms were involved either in signalling (e.g. receptor activity, molecular transducer activity, or small GTPase mediated signal transduction), development (e.g. embryonic camera-type eye morphogenesis, gastrulation with mouth forming second, or cell migration involved in gastrulation), ion transport (e.g. anion binding, ATP hydrolysis coupled proton transport, or organic anion transmembrane transporter activity), metabolism (e.g. carbohydrate phosphorylation, ubiquitin-dependent protein catabolic process, or lipopolysaccharide biosynthetic process), or neuronal function (e.g. forebrain development, motor neuron axon guidance, or neuromast development; Table 13). Secondly, KEGG terms were assigned to 


\section{1,674 freshwater eel genes using BlastKOALA (Kanehisa et al. 2016) and mapped} onto the KEGG pathways using the KEGG Mapper tool. A Fisher test, corrected for multiple comparisons using False Discovery Rate, was used to look for enriched KEGG pathways in the basal eel branch (Table 14). Most of the KEGG pathways found to be enriched were related to the immune system, nervous system, metabolism and signal transduction. Interestingly, the most significantly enriched KEGG pathway was "Dopaminergic synapse".

Table 13: Enriched GO terms from the duplicated genes shared by freshwater eels. "Aspects" indicates the specific $G O$ term aspect of each enriched $G O$ term $(B P=$ Biological process, $C C=$ Cellular component, and $M F=$ Molecular function. "GOID" indicates the identification number of each enriched GO term. "Term "indicates the verbal description of each enriched GO term. "Annotated" indicates the number of GO terms which are associated with each enriched GO term. "Significant" indicates the number of GO terms associated to each enriched GO term found among the duplicated genes. "Expected" indicates the number of GO terms expected to be found linked to each enriched GO term. "FDR" indicates the False Discovery Rate adjusted P-value from the Fisher exact test of enrichment.

\begin{tabular}{|c|c|c|c|c|c|c|}
\hline Aspect & GO ID & Term & Annotated & Significant & Expected & FDR \\
\hline & & GTPase mediated & & & & \\
\hline $\mathrm{BP}$ & GO:0007264 & transductio... & 256 & 43 & 22.97 & 0.000064 \\
\hline $\mathrm{BP}$ & GO:0045176 & apical protein localization & 3 & 3 & 0.27 & 0.00072 \\
\hline $\mathrm{BP}$ & GO:0008045 & motor neuron axon guidance & 10 & 5 & 0.9 & 0.00099 \\
\hline $\mathrm{BP}$ & GO:0048514 & blood vessel morphogenesis & 121 & 20 & 10.86 & 0.00257 \\
\hline $\mathrm{BP}$ & GO:0000132 & establishment of mitotic spindle orienta... & 8 & 4 & 0.72 & 0.00335 \\
\hline \multirow[t]{2}{*}{$\mathrm{BP}$} & & embryonic camera-type eye & & & & \\
\hline & GO:0048596 & morphogenesis & 11 & 4 & 0.99 & 0.00625 \\
\hline BP & GO:0015991 & ATP hydrolysis coupled proton transport & 20 & 6 & 1.79 & 0.00661 \\
\hline $\mathrm{BP}$ & GO:0008333 & endosome to lysosome transport & 2 & 2 & 0.18 & 0.00804 \\
\hline $\mathrm{BP}$ & GO:0015031 & protein transport & 284 & 39 & 25.48 & 0.00900 \\
\hline $\mathrm{BP}$ & GO:0006886 & intracellular protein transport & 156 & 19 & 14 & 0.00907 \\
\hline $\mathrm{BP}$ & GO:0007160 & cell-matrix adhesion & 16 & 5 & 1.44 & 0.01084 \\
\hline $\mathrm{BP}$ & GO:0001756 & somitogenesis & 50 & 10 & 4.49 & 0.01200 \\
\hline $\mathrm{BP}$ & GO:0060042 & retina morphogenesis in camera-type eye & 37 & 9 & 3.32 & 0.01887 \\
\hline $\mathrm{BP}$ & GO:0072358 & cardiovascular system development & 280 & 44 & 25.12 & 0.01905 \\
\hline $\mathrm{BP}$ & GO:0040023 & establishment of nucleus localization & 4 & 3 & 0.36 & 0.02262 \\
\hline $\mathrm{BP}$ & GO:0009826 & unidimensional cell growth & 3 & 2 & 0.27 & 0.02268 \\
\hline $\mathrm{BP}$ & GO:0030326 & embryonic limb morphogenesis & 3 & 2 & 0.27 & 0.02268 \\
\hline $\mathrm{BP}$ & GO:0008202 & steroid metabolic process & 34 & 3 & 3.05 & 0.02280 \\
\hline \multirow[t]{2}{*}{$\mathrm{BP}$} & & transforming growth factor & & & & \\
\hline & GO:0007179 & receptor... & 13 & 4 & 1.17 & 0.02382 \\
\hline \multirow[t]{2}{*}{$\mathrm{BP}$} & & cellular component organization or & & & & \\
\hline & GO:0071840 & bioge... & 846 & 81 & 75.91 & 0.02822 \\
\hline $\mathrm{BP}$ & GO:0048884 & neuromast development & 15 & 4 & 1.35 & 0.02854 \\
\hline BP & GO:0001569 & patterning of blood vessels & 8 & 3 & 0.72 & 0.02858 \\
\hline \multirow[t]{2}{*}{$\mathrm{BP}$} & & cell wall macromolecule & & & & \\
\hline & GO:0016998 & proces... & 8 & 3 & 0.72 & 0.02858 \\
\hline BP & GO:0046835 & carbohydrate phosphorylation & 8 & 3 & 0.72 & 0.02858 \\
\hline $\mathrm{BP}$ & GO:0043473 & pigmentation & 57 & 7 & 5.11 & 0.02863 \\
\hline \multirow[t]{2}{*}{$\mathrm{BP}$} & & embryonic retina morphogenesis in & & & & \\
\hline & GO:0060059 & camera... & 14 & 4 & 1.26 & 0.03104 \\
\hline $\mathrm{BP}$ & GO:0001702 & gastrulation with mouth forming second & 23 & 6 & 2.06 & 0.04241 \\
\hline $\mathrm{BP}$ & GO:0060034 & notochord cell differentiation & 6 & 3 & 0.54 & 0.04259 \\
\hline
\end{tabular}




\begin{tabular}{|c|c|c|c|c|c|c|}
\hline \multirow{2}{*}{$\begin{array}{l}\text { BP } \\
\text { BP }\end{array}$} & GO:0061035 & regulation of cartilage development & \multirow[t]{2}{*}{7} & \multirow[t]{2}{*}{3} & \multirow[t]{2}{*}{0.63} & \multirow[t]{2}{*}{0.04260} \\
\hline & & Componentharide & & & & \\
\hline & GO:0009103 & biosynthetic process & 4 & 2 & 0.36 & 0.04268 \\
\hline BP & GO:0043114 & regulation of vascular permeability & 4 & 2 & 0.36 & 0.04268 \\
\hline BP & GO:0015721 & bile acid and bile salt transport & 4 & 2 & 0.36 & 0.04268 \\
\hline \multirow[t]{2}{*}{ BP } & & ubiquitin-dependent protein catabolic & & & & \\
\hline & GO:0006511 & $\operatorname{pr} \ldots$ & 91 & 14 & 8.17 & 0.04728 \\
\hline BP & GO:0030900 & forebrain development & 53 & 10 & 4.76 & 0.04832 \\
\hline BP & GO:0042074 & cell migration involved in gastrulation & 37 & 9 & 3.32 & 0.04885 \\
\hline CC & GO:0031105 & septin complex & 6 & 4 & 0.54 & 0.00084 \\
\hline CC & GO:0030018 & $Z$ disc & 10 & 5 & 0.9 & 0.00099 \\
\hline CC & GO:0031461 & cullin-RING ubiquitin ligase complex & 28 & 8 & 2.52 & 0.00555 \\
\hline CC & GO:0008290 & F-actin capping protein complex & 2 & 2 & 0.18 & 0.00807 \\
\hline CC & GO:0005915 & zonula adherens & 2 & 2 & 0.18 & 0.00807 \\
\hline CC & GO:0005737 & cytoplasm & 1750 & 175 & 157.31 & 0.01734 \\
\hline CC & GO:0005768 & endosome & 47 & 8 & 4.22 & 0.01771 \\
\hline \multirow[t]{2}{*}{ CC } & & proton-transporting V-type ATPase V1 & & & & \\
\hline & GO:0033180 & do... & 10 & 4 & 0.9 & 0.01913 \\
\hline CC & GO:0030424 & axon & 7 & 3 & 0.63 & 0.01920 \\
\hline CC & GO:0000159 & protein phosphatase type $2 \mathrm{~A}$ complex & 3 & 2 & 0.27 & 0.02275 \\
\hline CC & GO:0005667 & transcription factor complex & 79 & 12 & 7.1 & 0.02336 \\
\hline $\mathrm{CC}$ & GO:0005912 & adherens junction & 7 & 4 & 0.63 & 0.04255 \\
\hline $\mathrm{CC}$ & GO:0031519 & PcG protein complex & 9 & 4 & 0.81 & 0.04258 \\
\hline \multirow[t]{2}{*}{ CC } & & sodium:potassium-exchanging ATPase & & & & \\
\hline & GO:0005890 & compl... & 4 & 2 & 0.36 & 0.04281 \\
\hline CC & GO:0043198 & dendritic shaft & 4 & 2 & 0.36 & 0.04281 \\
\hline CC & GO:0005885 & Arp2/3 protein complex & 4 & 2 & 0.36 & 0.04281 \\
\hline CC & GO:0005765 & lysosomal membrane & 16 & 4 & 1.44 & 0.04914 \\
\hline MF & GO:0005525 & GTP binding & 251 & 43 & 22.24 & $1.6 e-05$ \\
\hline MF & GO:0043168 & anion binding & 1289 & 142 & 114.24 & 0.0018 \\
\hline MF & GO:0060089 & molecular transducer activity & 778 & 56 & 68.95 & 0.0078 \\
\hline \multirow[t]{2}{*}{ MF } & & fructose-2 6-bisphosphate 2-phosphatase & & & & \\
\hline & GO:0004331 & $\ldots$ & 2 & 2 & 0.18 & 0.0078 \\
\hline MF & GO:0045296 & cadherin binding & 2 & 2 & 0.18 & 0.0078 \\
\hline \multirow[t]{2}{*}{ MF } & & proton-transporting & & & & \\
\hline & GO:0046933 & activit... & 10 & 4 & 0.89 & 0.0083 \\
\hline \multirow[t]{2}{*}{ MF } & & signaling & & & & \\
\hline & GO:0004702 & serine/threon... & 19 & 7 & 1.68 & 0.0112 \\
\hline MF & GO:0008242 & omega peptidase activity & 6 & 3 & 0.53 & 0.0113 \\
\hline \multirow[t]{2}{*}{ MF } & & G-protein beta/gamma-subunit complex & & & & \\
\hline & GO:0031683 & $\operatorname{bin} . .$. & 6 & 3 & 0.53 & 0.0113 \\
\hline MF & GO:0008013 & beta-catenin binding & 7 & 3 & 0.62 & 0.0185 \\
\hline MF & GO:0016820 & hydrolase activity acting on acid anhyd... & 38 & 8 & 3.37 & 0.0219 \\
\hline \multirow[t]{2}{*}{ MF } & & ribose phosphate diphosphokinase & & & & \\
\hline & GO:0004749 & activit... & 3 & 2 & 0.27 & 0.0221 \\
\hline \multirow[t]{2}{*}{ MF } & & protein phosphatase type $2 \mathrm{~A}$ regulator & & & & \\
\hline & GO:0008601 & ac... & 3 & 2 & 0.27 & 0.0221 \\
\hline MF & GO:0003796 & lysozyme activity & 3 & 2 & 0.27 & 0.0221 \\
\hline MF & GO:0008146 & sulfotransferase activity & 43 & 10 & 3.81 & 0.0249 \\
\hline MF & GO:0051287 & NAD binding & 22 & 5 & 1.95 & 0.0298 \\
\hline MF & GO:0003714 & transcription corepressor activity & 9 & 3 & 0.8 & 0.0388 \\
\hline \multirow[t]{2}{*}{ MF } & & organic anion transmembrane & & & & \\
\hline & GO:0008514 & transporter ... & 22 & 5 & 1.95 & 0.0399 \\
\hline MF & GO:0004872 & receptor activity & 695 & 41 & 61.59 & 0.0495 \\
\hline
\end{tabular}


Table 14: Enriched KEGG-terms from the duplicated genes shared by freshwater eels. "KEGG ID" indicates the identification number of each enriched KEGG pathway. "Term" indicates the verbal description of each enriched KEGG pathway. "Annotated" indicates the number of KEGG pathways, which are associated with each enriched KEGG pathway. "Significant" indicates the number of KEGG pathways associated with each enriched KEGG pathway found among the duplicated genes. "Expected" indicates the number of KEGG pathways expected to be found associated with each enriched KEGG pathway. "FDR" indicates the False Discovery Rate adjusted P-value from the Fisher exact test of enrichment.

\begin{tabular}{|c|c|c|c|c|c|}
\hline KEGG ID & Term & Annotated & Significant & Expected & FDR \\
\hline 04728 & Dopaminergic synapse & 38 & 283 & 12 & 0,000001 \\
\hline 03015 & mRNA surveillance pathway & 21 & 129 & 5 & 0,000082 \\
\hline 04660 & T cell receptor signaling pathway & 27 & 204 & 8 & 0,000082 \\
\hline 04071 & Sphingolipid signaling pathway & 29 & 238 & 10 & 0,000112 \\
\hline 05142 & Chagas disease (American trypanosomiasis) & 23 & 180 & 7 & 0,000518 \\
\hline 04659 & Th17 cell differentiation & 23 & 184 & 7 & 0,000596 \\
\hline 05162 & Measles & 21 & 168 & 7 & 0,001190 \\
\hline 04390 & Hippo signaling pathway & 29 & 282 & 11 & 0,001190 \\
\hline 04658 & Th1 and Th2 cell differentiation & 19 & 148 & 6 & 0,001601 \\
\hline 04261 & Adrenergic signaling in cardiomyocytes & 28 & 291 & 12 & 0,004378 \\
\hline 05100 & Bacterial invasion of epithelial cells & 20 & 183 & 7 & 0,005845 \\
\hline 05032 & Morphine addiction & 18 & 155 & 6 & 0,005845 \\
\hline 00625 & $\begin{array}{l}\text { Chloroalkane and chloroalkene } \\
\text { degradation }\end{array}$ & 5 & 10 & 0 & 0,005845 \\
\hline 04640 & Hematopoietic cell lineage & 12 & 79 & 3 & 0,006536 \\
\hline 04910 & Insulin signaling pathway & 26 & 276 & 11 & 0,006551 \\
\hline 04630 & Jak-STAT signaling pathway & 18 & 171 & 7 & 0,012920 \\
\hline 04016 & MAPK signaling pathway - plant & 6 & 22 & 1 & 0,014553 \\
\hline 04022 & cGMP-PKG signaling pathway & 29 & 350 & 14 & 0,015915 \\
\hline 04917 & Prolactin signaling pathway & 15 & 133 & 5 & 0,015915 \\
\hline 05130 & Pathogenic Escherichia coli infection & 13 & 108 & 4 & 0,019059 \\
\hline 05418 & Fluid shear stress and atherosclerosis & 22 & 245 & 10 & 0,022738 \\
\hline 00020 & Citrate cycle (TCA cycle) & 8 & 47 & 2 & 0,022808 \\
\hline 04080 & Neuroactive ligand-receptor interaction & 31 & 395 & 16 & 0,023393 \\
\hline 04151 & PI3K-Akt signaling pathway & 37 & 499 & 20 & 0,023393 \\
\hline 04514 & Cell adhesion molecules (CAMs) & 21 & 231 & 9 & 0,023393 \\
\hline 04391 & Hippo signaling pathway - fly & 16 & 158 & 6 & 0,034750 \\
\hline 05340 & Primary immunodeficiency & 7 & 41 & 2 & 0,036069 \\
\hline 04350 & TGF-beta signaling pathway & 16 & 164 & 7 & 0,038388 \\
\hline 05133 & Pertussis & 12 & 111 & 5 & 0,045104 \\
\hline 05152 & Tuberculosis & 21 & 247 & 10 & 0,047421 \\
\hline 04664 & Fc epsilon RI signaling pathway & 12 & 113 & 5 & 0,048089 \\
\hline 00510 & $\mathrm{~N}$-Glycan biosynthesis & 9 & 71 & 3 & 0,048943 \\
\hline 04144 & Endocytosis & 37 & 533 & 22 & 0,048943 \\
\hline 00350 & Tyrosine metabolism & 6 & 34 & 1 & 0,048943 \\
\hline 04510 & Focal adhesion & 28 & 379 & 15 & 0,048943 \\
\hline
\end{tabular}




\subsection{Discussion}

The present study found more than one thousand gene families in which the gene family tree topology indicates a duplication in a common ancestor of freshwater eels sometime after the split of Elopomorpha and Osteoglossomorpha. Only phylogenetic species tree branches with previously documented WGDs (Fig 35, Nodes 1, 3, 4, and 16) and the zebrafish specific branch (Fig 35, Node 7) were assigned more duplications than the basal freshwater eel branch (Fig 35, Node 9). The vast majority of the assigned zebrafish specific duplications formed a $4 \mathrm{dTV}$ local density maximum at $\sim 0$ and were found "close" in the genome, thus these duplications appear to be tandem SDs, the presence of which concurs with previous studies (Blomme et al. 2006; Lu et al. 2012; Howe et al. 2013).

\subsubsection{The origin of the duplications assigned to the basal freshwater eel branch}

In some cases, it has been shown that SDs could be retained at specific points in time (Chain et al. 2014; Colbourne et al. 2011; Tautz and Domazet-lošo 2011). However, most duplications assigned to the basal freshwater eel branch were detected in large syntenic blocks which opposes a hypothesis of a SD origin.

Rather the synteny results suggest that the duplications assigned to the basal freshwater eel branch originated in larger portions e.g. whole regions (large SDs), chromosomes or genomes. In particular, a WGD origin is consistent with the number of duplications observed and the 4dTv distribution (Fig 35, Node 9), which showed one distinct $4 \mathrm{dTV}$ density mode $(4 \mathrm{dTV} \sim 0.4)$ placed along the long branch leading to the freshwater eels. Figure 37 (and Fig. 36) further shows duplications which started diverging at the $3 \mathrm{R}$ in the eel transcriptome, as a $4 \mathrm{dTV}$ local density maximum of $\sim 0.75$. The notable similarity between this local 
density maximum and the local density maximum of the other $3 \mathrm{R}$ generated genes from all the included teleosts (Figs. 35 and 37) suggests that these paralogs $(4 d T v \sim 0.75)$ were created by the $3 R$. This hypothesis is further supported by the results of the phylogenetic analysis (Fig. 35, Node 3), which assigned hundreds of duplications, which are still present in the eel, to the $3 R$ branch. Moreover, no modes of comparable magnitude at $4 \mathrm{dTv} \sim 0.75$ can be seen in any of the post $3 R$ branches leading to the freshwater eels (Fig. 35, Nodes 5 and 9). Therefore, if the duplications assigned to the basal freshwater eel branch were created by a WGD event, and assuming instant rediploidization after the $3 R$, this event would be more recent and different to the $3 R$, and thus should be named a 4R WGD event.

However, cytological rediploidization is not always completed immediately after an autotetraploidization WGD event, as shown in the case of salmonids (Robertson et al. 2017). Therefore, the origin of the duplications assigned to the basal freshwater eel branch could also be explained by a hypothesis of lineagespecific rediploidization after the $3 R$. Protracted rediploidization could result in lower rates of gene losses since deleterious mutations have less time to accumulate in one paralog and thereby create a pseudogene, which could explain the high number of paralog pairs found in eel. This hypothesis could also explain both the PHYLDOG and 4dTv results, as paralog genes only start to diverge after the rediploidization of their genomic region (Robertson et al. 2017; Lien et al. 2016; Martin and Holland 2014). If the duplications assigned to the basal freshwater eel branch had, in fact, experienced delayed rediploidization from the $3 R$, the same genomic regions would have also experienced delayed rediploidization in the lineage of the remaining teleosts. Interestingly, relatively large quantities of duplications, with conserved synteny, were also assigned to the basal Clupeocephala branch and the Osteoglossomorpha branches (Fig. 35, Nodes 4, 8, and 12). This observation supports the hypothesis that the 
duplications assigned to the basal freshwater eel branch were located in genomic regions, which experienced delayed rediploidization after the $3 R$. However, lineage-specific rediploidization has only been unequivocally documented in salmonids, and more studies are needed to demonstrate this process in other species. Therefore, it remains to be determined if this mechanism is a salmonid specific phenomenon. Furthermore, due to the observed 4dTv distances, the mechanisms would have protracted rediploidization for a longer time in eels than in salmonids. Moreover, the $4 \mathrm{dTV}$ analysis revealed very similar results for the $3 \mathrm{R}$ branch and the basal Clupeocephala branch (Fig. 35, Nodes 3 and 4) and for the shared Osteoglossomorpha and Arowana branches, respectively (Fig. 35, Nodes 8 and 12). This result supports the hypothesis that these duplications were divided due to a potential PHYLDOG artefact, explained below. Additionally, 30 gene families were found which showed a topology concurring with a $3 R$ event followed by a $4 R$ event, since duplication had been conserved from both events in the same gene family. Furthermore, the suspected $4 R$ duplications were located in regions with some synteny. These trees directly oppose the hypothesis of protracted rediploidization; however, only for these 30 families. In the event of an eel $4 R$ WGD, more such trees would be expected.

\subsubsection{Possible PHYLDOG artefact}

According to PHYLDOG, the shared teleost duplications split into two events placed in the 3R branch and the basal Clupeocephala branch (Fig. 35, Nodes 3and 4). These results could be caused by an artefact from the phylogenetic analysis. Specifically, PHYLDOG software assigns duplications to branches based on the successful identification of the daughter genes on the branches of both sister clades, thus lower genomic information (fewer or less complete genomes/transcriptomes) increases the chance of not finding a gene and thus misplacing duplications. In this case, although the number of 
genomes/transcriptomes are the same, the amount of genomic information is substantially different between the two daughter clades, since the genomes/transcriptomes on one side (Figs. 35, from Node 5), are generally much less complete than those on the other side (Figs. 34 and 35, from Node 4). In support of this hypothesis is the $4 \mathrm{dTV}$ analysis, in which the duplications assigned to the $3 R$ and the basal Clupeocephala branch indicate approximately the same mode (Fig. 35, Nodes 3 and 4), suggesting that they started to diverge at the same time. Therefore, a PHYLDOG artefact, in which duplications can leak down to a daughter branch which is basal to a clade containing more genomic information, is also a parsimonious explanation for most of the duplications assigned to the basal Clupeocephala branch.

\subsubsection{Arowana results}

As an unexpected result of our analysis, the included Osteoglossomorphas also appear to contain a high quantity of duplications, which likely started diverging after the split between Elopomorphs and Osteoglossomorphas. These duplications also included a high occurrence of paralogs with some conserved synteny between them. This result suggests that these genes were duplicated in larger portions e.g. whole regions (large SDs), chromosomes or genome and not by smaller SDs. When combining the basal Osteoglossomorpha and the basal arowana branches these were assigned a similar quantity of duplications as the basal freshwater eel branch. This result supports the hypothesis that some genomic regions were still under tetrasomic inheritance, from the $3 R$, at the time of the split between Elopomorphs and Osteoglossomorphas. However, it is also possible that the duplications were generated by a separate duplication event in a common ancestor to the included Osteoglossomorphas but have leaked into the basal arowana branch and the Asian arowana specific branch in the phylogenetic analysis due to the PHYLDOG artefact described above. The PHYLDOG artefact hypothesis is supported by the $4 \mathrm{dTV}$ analysis, as the $4 \mathrm{dTV}$ 
modes of these branches are very similar, and since the Elephantnose fish transcriptomes are the least complete dataset of these branches. To generate a better supported hypothesis of the origin of these duplications a study dedicated to this purpose should be conducted.

\subsubsection{Start of divergence of the duplications assigned to the basal freshwater eel branch}

In the independent 4dTv analysis, without considering phylogenetic tree topologies, the 4dTv of the homologs between the European eel and the Japanese eel, the elephantnose fish and the arowanas, showed that European eel and Japanese eel homologs have a $4 d T v$ mode at $~ 0.4$. On the other hand, the homologs between the European eel and any Osteoglossomorpha species form a $4 \mathrm{dTV}$ mode at 0.5 (Fig. 36). This result indicates that the duplications found in the freshwater eel species started diverging after the split between Elopomorphs and Osteoglossomorphas (Fig. 36). Therefore, the phylogenetic reconstruction and the $4 \mathrm{dTv}$ distances together suggest that the duplications assigned to the basal freshwater eel branch (4dTv 0.4) started diverging after the teleost specific 3R duplication event (320-350 MYA; Vandepoele et al. 2004; Christoffels et al. 2004) and after the split between eels and Osteoglossomorphas, but before the Ss4R (88-103 MYA; Macqueen et al. 2014).

If the 4dTv mode observed in the basal freshwater eel branch was the result of new duplications, then these duplications would likely have originated in a common ancestor to all members of the anguillidae family, as these first appear 20-50 MYA (Minegishi et al. 2005). Due to the 4dTv observed, this event could also be shared by wider Elopomorpha; however, without analysing other anguilliforms or Elopomorpha transcriptomes or genomes, this hypothesis remains speculative. 


\subsubsection{Previously published related data}

In concurrence with the present study, other studies have reported data suggesting an unusually high quantity of gene duplications in eels. In the additional data included by Inoue et al. (Inoue et al. 2015), the eel and zebrafish are the species with the highest percentage of duplicated genes $(36.6 \%$ and $31.9 \%$, respectively). Furthermore, an unexpectedly high number of Hox genes (73 genes) were found in the analysis of the draft eel genome (Henkel et al. 2012). In this study (Henkel et al. 2012), the phylogenetic distance between Hox clusters was remarkably short, making it impossible to distinguish between the $3 R$ " $a$ " or " $b$ " association of 3 out of 4 cluster pairs based on DNA sequence alone. Several other studies focusing on particular genes have likewise found paralog pairs in eels, which are not found in other teleosts (Dufour et al. 2005; Pasqualini et al. 2009; Henkel et al. 2012; Pasquier et al. 2012; Maugars and Dufour 2015; Morini et al. 2015; Lafont et al. 2016; Rozenfeld et al. 2016; Morini et al. 2017a, 2017b) and similarly, an unexpected short phylogenetic distance is often found between eel paralog pairs. These results support both a $4 R$ hypothesis and a hypothesis of a $3 R$ origin followed by protracted rediploidization. However, many of the referenced studies also presented results of weak conserved local synteny indicating a $3 R$ origin. These synteny results are unexpected following both a $4 R$ hypothesis and the hypothesis of protracted rediploidization. We draw this conclusion based on the notion that the close genomic region of genes, which experienced delayed rediploidization, is highly expected to also have been under tetrasomic inheritance for an extended period (Robertson et al. 2017). Thus, these neighbouring genes should not accumulate mutations similarly to homolog regions of other teleosts, which experienced immediate rediploidization, and thus the synteny of these regions are unlikely to math. 


\subsubsection{Allele avoidance of transcriptome assemblies}

Transcriptomes of 3 tissues collected from one individual European eel were used to assemble the European eel de novo transcriptome. The decision to use one eel was made due to the fact that transcriptome assemblies based on multiple individuals are more prone to mistake allelic variants for recent gene duplications. Despite our transitive clustering, alleles could still be present in our transcriptome. However, these would resemble very similar paralogs, and be assigned a very low $4 d T v$ distance. Therefore, it is implausible that the local density maximum of eel paralogs found at $4 \mathrm{dTV} \sim 0.4$ could be alleles. Additionally, since our assessment of synteny was based on the genome, the paralog pairs from which synteny could be assessed are highly unlikely to include these potential alleles.

\subsection{Conclusions}

The data presented in this study support the hypothesis that a remarkably high amount of paralogs pairs started to diverge in a common ancestor of the freshwater eel lineage after the split from the Osteoglossomorpha lineage. The 4dTv and phylogenetic analyses revealed a clear clustering of these paralogs in the basal freshwater eel branch with a $4 d T v$ mode at $\sim 0.4$. The synteny of these paralog pairs suggests they originated in large portions, most likely from a WGD event. However, the results do not unequivocally support/oppose whether i) i) These paralogs originated from the $3 \mathrm{R}$ but are located in genomic regions which have experienced protracted rediploidization; ii) These paralogs originated in a 4R WGD in a common ancestor to freshwater eels; or iii) Both $\mathrm{i}$ and ii have contributed to these paralogs. The present results offer robust information on the duplicated gene complement of freshwater eels, thus providing novel insights into the peculiar biology of the critically endangered European eel. However, additional high quality genome resources of other Elopomorpha 
members are needed to further study the dynamics of gene duplication and conservation in early teleost evolution. 


\section{GENERAL DISCUSSION}

\subsection{Recombinant hormones for eel maturation}

Species-specific variations of gonadotropin functions (Gomez et al. 1999; Mateos et al. 2003) and sequence exist between teleosts (Levavi-Sivan et al. 2010). These findings suggest that the maturation of each teleost is fitted for homologous gonadotropins in species-specific optimal concentrations. Therefore, homologous recombinant gonadotropins in optimized concentrations might improve artificial eel maturation (Ohta et al. 2017). However, the field of recombinant gonadotropin use in fish is still developing. Our results (Chapter 1 ) indicates that recombinant gonadotropins can induce the entire spermatogenesis and spermiation process in European eel. However, the results also illustrate some of the challenges of recombinant gonadotropin use. E.g. the results are still inferior to those obtained with standard hCG treatments. This difference can likely be mitigated through optimization of the recombinant gonadotropin production protocols, as these have been subject to far less scrutiny than those of the purified/recombinant hCG.

The observed full spermatogenesis and spermiation from the aarFsh treatment in Chapter 1 were expected since recombinant Fsh has been shown to have the same effect in zebrafish (Zhang et al. 2015b) and induce spermatogenesis in Japanese eel (Kobayashi et al. 2010). However, the reverse result of the aarLhtreatment (with no aarFsh injection) was more surprising. In particular, because hCG (an Lh-analog; Pérez et al. 2000), goldfish recombinant Lh (Hayakawa et al. 2008b) and Japanese eel recombinant Lh (Ohta et al. 2017) can induce full spermatogenesis in Japanese eels. Potentially, higher hormone dosages could improve sperm quality in our study (Chapter 1 ) in general, and especially in the case of our aarLh-treatment, potentially to account for the longer half-life of hCG in circulation (Ohta and Tanaka 1997). Higher LH dosages have been used with 
better results in Japanese eel e.g. Kobayashi et al (2010) used $2000 \mu \mathrm{g} / \mathrm{kg}$ and Ohta et al. (2017) used $500 \mu \mathrm{g} / \mathrm{kg}$ recombinant $\mathrm{Lh}$, the latter example being a $\sim 20$ fold dosage compared to our aarLh-treatment ( $22.2 \mu \mathrm{g} / \mathrm{kg}$; Chapter 1$)$. This difference in concentration might explain why our aarLh-treatment only induced spermatogenesis to the pre-meiosis spermatogonial proliferation stage (Chapter 1), despite elevated steroid levels. Thus, potentially a threshold concentration of $L h$ is needed for maturation to surpass the spermatogonial proliferation stage in eels, which potentially could be related to the threshold at which Lh can activate Fshr (Kazeto et al. 2008; Schulz et al. 2010). A low Lh concentration could potentially also explain the very low sperm volumes collected (Chapter 1 ), since Lh may be the main factor for increasing sperm volume (Mylonas et al. 2017).

Alternatively, a specific ratio of Fsh and Lh could be an important factor for further development. In particular, fshb and E2 are often observed to increase in eel after saltwater acclimation (Aida and Tsukamoto 2003; Peñaranda et al. 2010b, 2016a). As the eels of Chapter 1 are exposed to saltwater acclimation before initiation of the experiment, the aarLh treatment is likely not a model for the effect of $L h$ in eel males without the influence of Fsh and other factors. Similarly, this co-transcription of $f s h b$ and $/ h b$, progressing towards similar levels, has been documented in the last stages of the silvering process (Schmitz et al. 2005; Aroua et al. 2005), at which stage the eels must be assumed to experience the pre-pubertal blockage. Thus, inhibition of Fsh and increased Lh concentration may be needed for further maturation, rather than simply increased Ih concentration. Following this hypothesis continues hCG injection may cause further elevated $l h b$ and suppressed $f s h b$ transcription (Peñaranda et al. 2010b) and therethrough forces further spermatogenesis. Supporting this hypothesis, high levels of Lh relative to the levels of Fsh may be the process 
which induces later maturation in other semelparous teleosts (Schulz et al. 2010; Gomez et al. 1999).

\subsection{Pre-pubertal neuroendocrine blockage}

The above-mentioned hypotheses of the aarLh-treatment results may be too simple. In particular, under the assumption that Sertoli cells control spermatogonial proliferation (Schulz et al. 2010), and that Sertoli cells do not express Lhr (García-López et al. 2009), the additional assumption of the activation of Fshr by high concentrations of Lh is crucial for the above hypotheses. However, hCG is capable of inducing full spermiation as well (Asturiano et al. 2005, 2006; Gallego et al. 2012; Herranz-Jusdado et al. 2019), but hCG does probably not activate Fshr like Lh, even at high concentrations (Bogerd et al. 2001; Laan et al. 2002; Kwok et al. 2005). Although hCG has been shown to affect eel pituitary gonadotropin production (Peñaranda et al. 2010b), the effect of hCG is unlikely to be a result of pituitary Lh release, since the effect of hCG is also seen in hypophysectomised eels (Boëtius and Boëtius 1967; Khan et al. 1987). Thus, it is clear that the current understanding of the induction of eel spermatogenesis is not complete. Therefore, it is also possible that the observed aarLh-treatment results could have been caused by unknown factors of the pre-pubertal neuroendocrine blockage, which is hypothesized to obstruct eel male maturation further than the pre-meiosis spermatogonial proliferation stage (Durif et al. 2005). E.g. one such factor could be the expression of actively inhibitory molecules in the testis, similar to those discussed in Chapter 2.

Commonly, this blockage of eel puberty is hypothesized to be projected through inhibition of luteinizing hormone (Lh) release (Dufour et al. 2010); However, the exact and complete mechanism of this blockage is largely unknown. E.g. some studies indicate that this blockage is, to some extent, alleviated in hermaphrodite eels (Geffroy and Bardonnet 2016; Geffroy et al. 2012). Based on 
these findings, one may hypothesize that the steroids of a female eel would mature a male eel (thus the mature testis in hermaphrodite eels). However, although the androgen profiles were similar, the results in terms of gonad development were different in Chapter 1, and although $11 \mathrm{KT}$ can induce full spermatogenesis in vitro, $11 \mathrm{KT}$ implant could generally not induce spermatogenesis further than the spermatogonial proliferation stage in European eels despite relatively high 11KT plasma levels (Lokman et al. 2016).

Furthermore, lack of Fsh, as seen in Chapter 1, may cause regression in the testis similar to what has been observed after artificial eel maturation with a single hCG injection (Boëtius and Boëtius 1967; Lokman et al. 2016). Which may be related to the observation that hCG injections appear to inhibit Fsh expression (Peñaranda et al. 2010b). An alternative hypothesis may be that the hCG treatment only affects the SPG cells present at the time of injection (Boëtius and Boëtius 1967). This hypothesis seems to concur with the results of Boëtius and Boëtius (1967) in which the maximum GSI was observed 30 days after the last hCG injection with gonads presenting only spermatozoa and spermatogonia (Boëtius and Boëtius 1967). According to this hypothesis, it appears that hCG (or factors influenced by hCG) can induce existing spermatogonia (or their Sertoli cells) to overcome a hurdle and from there on developing fully, while the remaining BPG-axis is largely not affected. Of course, these hypotheses are not mutually exclusive, and both regression and the notion of a hurdle to overcome could be true, which could indicate that some cells fail to complete their maturation and as a consequence are reabsorbed (Lokman et al. 2016).

Chapter 2 of this thesis might also provide some additional insight into this prepubertal neuroendocrine blockage. Although cold seawater likely induces some progression of early maturation it is also strongly evident that this treatment alone does not overcome the blockage (Boëtius and Boëtius 1967; Gallego et al. 2012; Peñaranda et al. 2016a). E.g. males kept at $10{ }^{\circ} \mathrm{C}$ cannot mature further 
than the spermatogonial proliferating stage despite hCG injection (Gallego et al. 2012). This phenomenon may be related to the result that the T10 treatment also appears to increase T production, which has been shown to upregulate $\mathrm{TH}$, in the brain of European eels, and therethrough increased inhibition of puberty through the action of DA (Weltzien et al. 2006). Interestingly, both the T10 and aarLh treated European eel males of Chapter 1 and 2, appeared hormonally blocked at the pre-meiosis spermatogonial proliferation stage. This stage was also seen after 2 weeks of hCG treatment at $20^{\circ} \mathrm{C}$ (Peñaranda et al. 2010b) at which point the pituitary levels of Lh and Fsh had progressed toward similar levels, highly similar to the projection of gonadotropins found in Chapter 2 (Fig. 38).
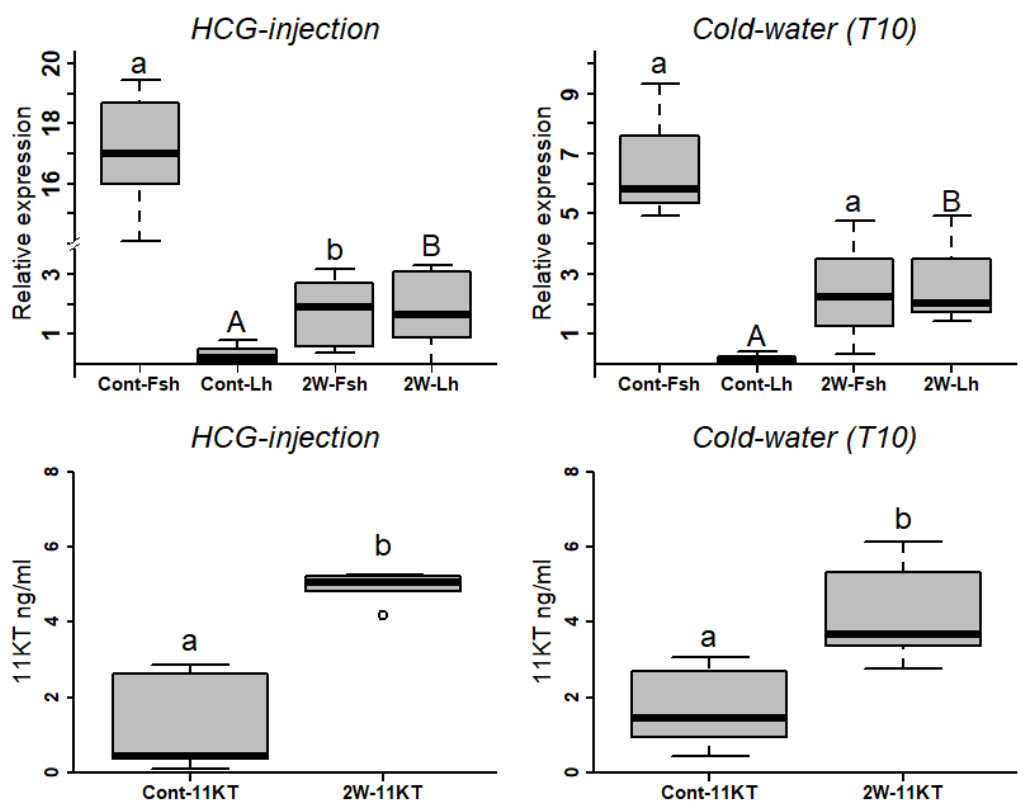

Figure 38. Boxplot comparing Lh, Fsh, and 11KT levels between Chapter 2 (Cold-water treatment), and the results of Peñaranda et al. (2010; hCG treatment), both at control and after 2 weeks $(2 W)$ of treatment.

Likewise, female Japanese eel at early vitellogenesis (the blocked stage of Japanese eel females) also contains similar levels of Fsh and Lh (Aida and Tsukamoto 2003). These results may also suggest that the pre-pubertal 
neuroendocrine blockage is induced in European eel males at the spermatogonial proliferation stage under conditions which promotes similar levels of Fsh and Lh production, similar to the observation in Chapter 1. Although caution should be applied as these suggestive results could be mere correlation rather than causation and surely more factors than Lh and Fsh levels must be involved, as hCG injection cannot overcome the blockage at $10^{\circ} \mathrm{C}$ (Gallego et al. 2012).

\subsection{A deeper look at the cold seawater treatment experiment}

A cold seawater treatment of European eel males clearly affects the BPG-axis (Chapter 2). This result is not particularly surprising as our group previously has done extensive analyses of the effect of temperature on European eels during artificially maturing (Pérez et al. 2011; Gallego et al. 2012; Baeza et al. 2014; Mazzeo et al. 2014; Peñaranda et al. 2016a). Specifically, increased spermatogonial proliferation as a result of cold seawater treatment, as shown in Chapter 2, was recently speculated in the Ph.D. thesis of Dr. Morini of our group (Morini 2016). It is, however, noteworthy that the same histological stage of the testis (the spermatogonial proliferation stage) reached after 2 weeks of the cold seawater treatment (Chapter 2 ) was also not exceeded after 2 weeks of hCG treatment at $20^{\circ} \mathrm{C}$ (Peñaranda et al. 2010b). Furthermore, the 2 week cold seawater treatment induced similar development of eye index and of liver weight (although without reaching significant differences in either case; Peñaranda et al. 2010b). Moreover, the pituitary levels of $/ \mathrm{hb}$ and $f s h b$ in both cases progressed toward similar levels (Fig. 38) and reported 11KT levels were highly similar between the two studies (Fig. 38). Similar levels of Fsh and Lh during early maturational stages, at which eels maturation is commonly blocked, have previously been reported in eels (Jeng et al. 2007; Saito et al. 2003; Pérez et al. 2011; Huang et al. 2009). 
The observed levels of $11 \mathrm{KT}$ seen in the T10 group of Chapter 2 (Fig. 21 and 38) is further similar to those observed after a single hCG injection of Japanese eel (Miura et al. 1991a, c). In particular, Miura et al. (1991a) reported 11KT levels increasing from $0.24 \pm 0.10 \mathrm{ng} / \mathrm{ml}$ to $5.86 \pm 1.1 \mathrm{ng} / \mathrm{ml}$ one day after a single hCG injection, this level later reached a maximum of $7.83 \pm 1.22 \mathrm{ng} / \mathrm{ml}$. Moreover, Miura et al. (1991c) found $11 \mathrm{KT}$ levels increasing from $0.20 \pm 0.11 \mathrm{ng} / \mathrm{ml}$ to 4.9 $\pm 1.1 \mathrm{ng} / \mathrm{ml}$ after the first hCG injection (Miura et al. 1991c). Regarding T, a similar trend of increasing levels is also observed, although the levels of $\mathrm{T}$ shown in Chapter 2 ( $T$ increased from $0.99 \pm 0.12 \mathrm{ng} / \mathrm{ml}$ to $2.32 \pm 0.17 \mathrm{ng} / \mathrm{ml}$; Fig. 21) for European eel males were higher than those presented by Miura et al. (1991a and c) for Japanese eel males. In particular, Miura et al. (1991a) showed T increases from $0.08 \pm 0.02 \mathrm{ng} / \mathrm{ml}$ to $0.88 \pm 0.22 \mathrm{ng} / \mathrm{ml}$ one day after a single $\mathrm{hCG}$ injection and Miura et al. (1991c) found that T reached $1.7 \pm 0.41 \mathrm{ng} / \mathrm{ml}$ after the first hCG injection. Thus, multiple parameters of reproductive development seem highly similar between the initial development of hCG- and low temperature-treated eel males (T10, Chapter 2), which may suggest that a similar process is initially induced by both types of treatment.

The experimental design of Chapter 2, not including hormonal treatment and the use of RNA-sequencing, has generated a tremendous amount of data, which have broadened our knowledge on some aspects of eel natural maturation. Furthermore, the vast amount of statistically significant data far exceeded the scope of Chapter 2 and thus several interesting findings were not discussed in that paper. As such the hypothesis of an important regulation of the BPG-axis function of European eel males by cold seawater is supported by more specific gene transcription data than what could be fitted into Chapter 2.

E.g. Among the genes annotated with GO terms related to histone modifications were jard2. jard2 is involved in the release of methyl groups from histone protein through $\mathrm{Fe}^{2+}$ dioxygenase activity, and thereby regulation of gene 
transcription (Takeuchi et al. 2006; Klose et al. 2006; Fodor et al. 2006; Chen et al. 2006). The function of jard2 has been associated to reproduction in Pacific oyster (Crassostrea gigas; Fellous et al. 2014) and has been found to be upregulated with resulting lower histone methylation levels at colder temperatures (Fellous et al. 2015). Furthermore, both the gene family, which jard2 belongs to and the process of histone methylation has been associated with circadian rhythm regulation (Jones et al. 2010). As shown in Chapter 2 several enriched GO terms were related to "circadian rhythm regulation". Although light is the strongest synchronizer of the circadian clock, temperature has also been shown to influence the system, especially in the absence of a light cycle (López-Olmeda and Sánchez-Vázquez 2009; Lahiri et al. 2005), e.g. Lahiri et al. (2005) found that cold temperatures increased the transcription of per $1 b$ and cry3 in zebrafish. Circadian rhythm genes have further been suggested to regulate melatonin synthesis is mammals (Korf et al. 2003) and fish (Vatine et al. 2011; Saha et al. 2018). Reversely, melatonin itself has also been shown to affect the transcription of circadian rhythm genes (Alonso-Vale et al. 2008) and to be regulated by temperature in fish (Falcón et al. 2010; Saha et al. 2018). Indeed, melatonin has been suggested as a key transmitter of environmental signals in fish (Dufour et al. 2010; Burgerhout et al. 2018), and changes in the melatonin level has been suggested as crucial for the onset of puberty (Malpaux et al. 2001; Burgerhout et al. 2018). Specifically, in eels, melatonin has been shown to upregulate Th, downregulate $f s h b$ and $/ h b$ transcription, and induce decreasing steroid levels in European eels (Sebert et al. 2008). Thus it appears plausible that high melatonin levels are a strong reinforce of the DA block of European eel puberty (Sebert et al. 2008; Dufour et al. 2010; Burgerhout et al. 2018). Although melatonin was not measured in Chapter 2, it should be considered whether the substantial differential transcription of the circadian clock genes may have affected or be affected by melatonin. 
Also among the differentially transcribed genes, from the testis, annotated to GO terms related to circadian rhythm were the zinc-finger transcription factor (gli1). gli1 is a zinc finger protein, which is involved in transcriptional regulation. gli1 has been found to be transcribed in testes specifically in type A and B spermatogonia in mice, where it has been shown to be important for spermatogenesis (Persengiev et al. 1997). The role of gli1 on spermatogenesis is possibly a result of its interaction with the desert hedgehog (Dhh) signaling pathway (Bitgood et al. 1996; Echelard et al. 1993). Several other genes found differentially transcribed in Chapter 2, have also been associated with this pathway which may be involved in an autocrine signaling loop which sustains SPGA cells in the mouse testis (Sahin et al. 2014). The Dhh pathway seems highly involved in spermatogenesis as male mice with a Dhh null mutation are sterile (Bitgood et al. 1996; Kroft et al. 2001). Furthermore, the Dhh pathway has been shown to be significantly regulated during the salmon transition into puberty (Skaftnesmo et al. 2017). Like gli1, myocyte enhancer factor 2A (mef2a) was also found differentially transcribed in the testes between the T10 group and control and was annotated with $\mathrm{GO}$ terms related to histone modification and similar to gli1, mef2a has been suggested as an important component of Dhh signaling (Wang et al. 2006).

Another enriched GO term from the testis transcriptome, which did not receive attention in Chapter 2, was "Stem cell differentiation". Among the genes annotated to this GO term was semaphorin $7 a$ and $3 b$ (sem $7 a$ and sem $3 b$ ). Various semaphorins, specifically sem $7 a$, has been shown to be essential for the GnRH-1 neuronal system possibly regulated by various sex steroids (Messina et al. 2011; Lettieri et al. 2016), and male sem7a knockout mice showed significant gonad defects (Messina et al. 2011). Whether these results of Messina et al. (2011) are caused by an insufficient GnRH-1 neuronal system or due to other functions of sem7a in the testis itself was unclear for the authors, as sem $7 a$ 
transcription has also been hypothesized in the testis (Perälä et al. 2005). Yet another significantly upregulated gene, which did not receive attention in Chapter 2 was cytochrome p450 2j2 (cp2j2). cp2j2 is an enzyme involved in the metabolism of arachidonic acid, which has been shown to stimulate $T$ production in specific teleosts (Wade et al. 1994) and to be highly important for European eel sperm production (Baeza et al. 2015a). This result may be related to the significantly higher $\mathrm{T}$ and $11 \mathrm{KT}$ plasma levels observed in T10 samples compared to the control group, of Chapter 2, or could be an indicator for sexual development.

Furthermore, as mentioned in Chapter 2, brdt, brd2, meiob, sycp2, and tex11 were annotated to the GO term "male meiotic nuclear division", were significantly downregulated in the T10 samples compared to Tvar, and were hypothesized to be involved in the inhibition of spermatogonial development (Chapter 2) in the eel testes. Interestingly, some of these genes were also observed to be upregulated in the Tvar and T20 treated samples, relative to control, which could indicate that some later spermatogenic processes are activated at higher or variating temperatures in migrating eels. Under natural conditions, this might suit the eels well, as water temperatures likely increases gradually at the late stages of their oceanic migration, while still fluctuating due to vertical migration (Wysujack et al. 2015). However, under artificial conditions, it is plausible that the timing of higher temperatures is mismatched with the developmental stage of the fish, which could cause hampering of reproductive capabilities.

Similar to the testis results, several interesting differentially transcribed or enriched genes and GO terms found in the pituitary were not discussed in Chapter 2. E.g. the GO term "sequestering of BMP in extracellular matrix". Bone morphogenetic proteins (BMP) are together with activin/inhibin, and transforming growth factor (TGF) beta among the best characterized secreted 
growth factors (Bobe et al. 2004). Furthermore, BMP signaling has been suggested to cause $\mathrm{H3}-\mathrm{k} 9$ histone demethylation resulting in control of stem cell fate (Chen et al. 2013). Finally, BMP has been shown to cause upregulation of circadian rhythm factors such as id1 (Chen et al. 2013), which also was differentially transcribed in the pituitary between T10 and Control groups, in Chapter 2. Similarly, the GO term "positive regulation of reactive oxygen species metabolic process" was also found enriched but not discussed. Reactive oxygen species (ROS) are metabolites of oxygen that are only partially reduced thus carrying reactive potential (Terasaka et al. 2017). In mammals, evidence suggests that ROS is involved in the regulation of the pulse interaction of $\mathrm{GnRH}$ on the pituitary through the MAP1/3 pathway (Kim and Lawson 2015).

Another interesting gene found differentially transcribed in the pituitary was the transcription factor npas4. npas4 is involved in the control of the number of GABA-releasing synapses and has been shown to be targeting major histocompatibility complex 1 (MHC 1; Lin et al. 2008). GABA-immunoreactive neurons have been shown to be distributed throughout the European eel brain and pituitary (Medina et al. 1994). Specifically, the superficial layer of the optic tectum, an area of massive retina projection, contains a high density of GABAreactive fibers and terminals (Medina et al. 1994). Furthermore, a liberating effect on GnRH of GABA has been seen in goldfish pituitaries, and GABA has been shown to be regulated by temperature (Fraser et al. 2002).

Apart from supporting the hypothesis of Chapter 2, the statistically significant RNA-sequencing results also advocate for several interesting aspects of natural eel maturation, which may call for further research. Interestingly, due to the nature of the RNA-sequencing analysis and the FDR-correcting (Benjamini and Hochberg 1995), hundreds of genes have likely been falsely assigned to be not differentially transcribed (false-negatives), even when only considering the testes transcriptomes. In particular, those genes that have a significant P-value 
but an insignificant FDR-corrected P-value are $\sim 95 \%$ likely to be differentially transcribed in a similar experiment in which only that gene transcription was measured (Noble 2009). Below such genes are referred to as "insignificant". Furthermore, other phenomena can also generate false-negatives. E.g. the cases where a gene is transcribed by several different cell types in the testis, while a treatment only affects the transcription of one cell type. In such cases, the truly differentially transcribed gene may be undetected by whole tissue RNAsequencing as the differential transcription of the affected cell will be diluted by the unaffected transcription of not-affected cells. In our analysis, such genes may also appear as "insignificant".

Several of these "insignificant" genes have very well documented functions in sexual maturation and spermatogenesis and may also be important in natural eel maturation. E.g. Two nuclear estrogen receptors (esr1 and 2) are among these genes (Fig. 39).
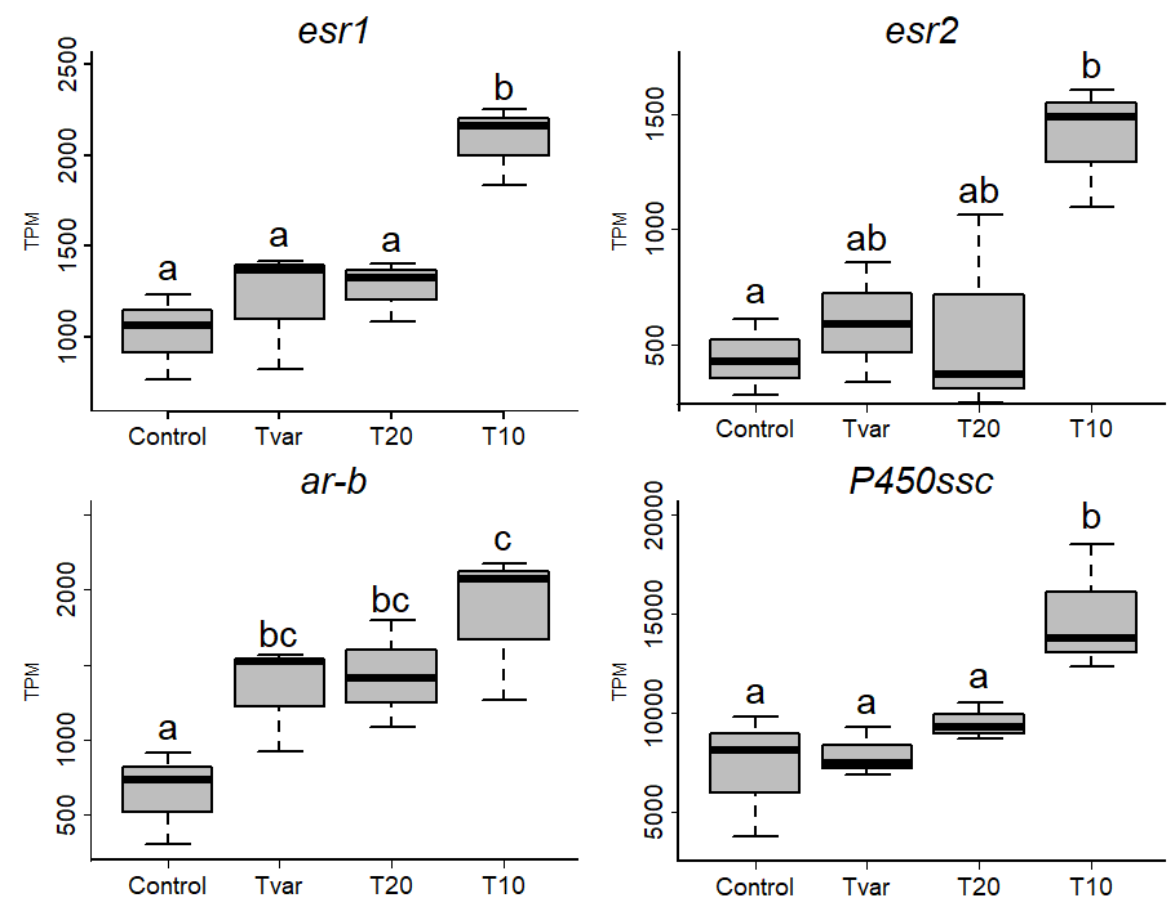
Figure 39. Boxplots of the transcription pattern of estrogen receptor 1 and 2 (esr1 and esr2), androgen receptor beta (ar-b), and cytochrome P450 cholesterol side-chain cleavage (P450scc). Different letters indicate statistical significance between treatments before FDR correction.

Estrogen receptors, on Sertoli cells, have been shown to be important for the control and preparation for early spermatogenesis and SPG proliferation as a mediator of estrogen signaling in Japanese eel (Miura et al. 1999; Miura and Miura 2011). Interestingly, estrogen-induced SPG proliferation does not promote differentiation, unlike $11 \mathrm{KT}$ - or DHP-induced proliferation. Thus this process mimics what was observed in the T10 group of Chapter 2 (Miura et al. 1999; Miura and Miura 2011). Furthermore, In European eel testis, high transcription levels of esr's were observed at early spermatogenesis and hypothesized to be mediating the role of E2 (Morini et al. 2017b).

Another interesting "insignificant" gene is the androgen receptor beta ( $a r-b$; Fig. 39). In the teleost testes ar's are mainly transcribed in Sertoli cells while the androgens are mainly produced by Leydig cells. However, ar's have also been suggested in Leydig cells, and androgens have been shown to affect steroidogenic gene transcription in these cells (Schulz et al. 2010). In particular, in European eel, $a r-b$ has been suggested as the most physiologically important ar and was shown to be particularly highly transcribed in the testis during early spermatogenesis (Peñaranda et al. 2014).

Also among the "insignificant" genes are cytochrome P450 cholesterol sidechain cleavage (P450scc; Fig. 39). P450scc is a bottleneck enzyme of steroid production. This gene has recently been shown to have increasing transcription levels correlating with the transition from yellow to fully matured (spawned) eel (Burgerhout et al. 2016), and peak expression at the spermatogonial proliferation stage (Peñaranda et al. 2016a). 
Other interesting "insignificant" genes includes: $h s p 70$ which has been shown to be involved in testis development in rainbow darter (Etheostoma caeruleum; Bahamonde et al. 2016); Ihr1, which is important for Lh activity (Maugars and Dufour 2015); kisspeptin receptor 1 (kissr1), which may be important for the onset of puberty in European eel (Pasquier et al. 2012); steroidogenic acute regulatory protein (StAR), which is important for steroidogenesis as it facilitates the transport of cholesterol into mitochondria, a prerequisite for p450scc function, and was found to be involved in ovarian development in Japanese eels (Kazeto et al. 2006; Fig. 40).
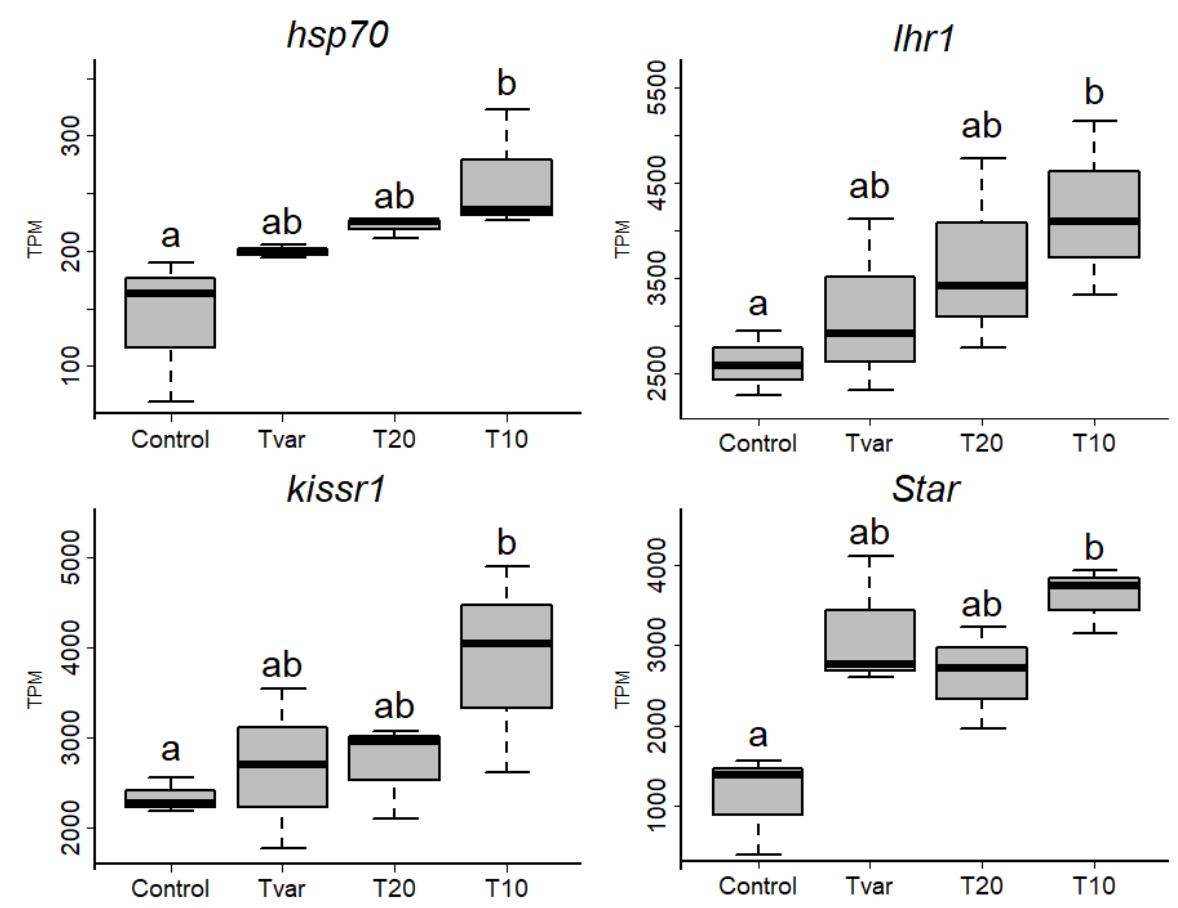

Figure 40. Boxplots of the transcription pattern of $h s p 70, \operatorname{lhr} 1$, kisspeptin receptor 1 (kissr1), and steroidogenic acute regulatory protein (StAR). Letter indicate statistical significance before FDR corrects.

Moreover the genes nanos 2 which is often used as a molecular marker of teleost SPG cells (Robles et al. 2017); the putative mammalian Sertoli cell markers gata4 and vimentin (Riboldi et al. 2012; Mali et al. 1987) should also be included as interesting "insignificant" genes (Fig. 41). 
Furthermore, additional to the significantly differentially transcribed growth factors and growth factor related genes, which have been shown to be important for spermatogonial proliferation (Schulz et al. 2010; Aida and Tsukamoto 2003), several "insignificant" growth factors and growth factor related genes were also found in our experiment. E.g. insulin like growth factor 1 (igf1; Fig. 43), igf receptor (igfr; Fig. 42), platelet-derived growth factor receptor-b (pgfrb; Fig. 42), platelet-derived growth factor-b (pdgf-b; Fig. 42), platelet-derived growth factor-c ( $p d g f-c ;$ Fig. 42 ), and pro-vaccinia growth factor (vgf; Fig. 43)
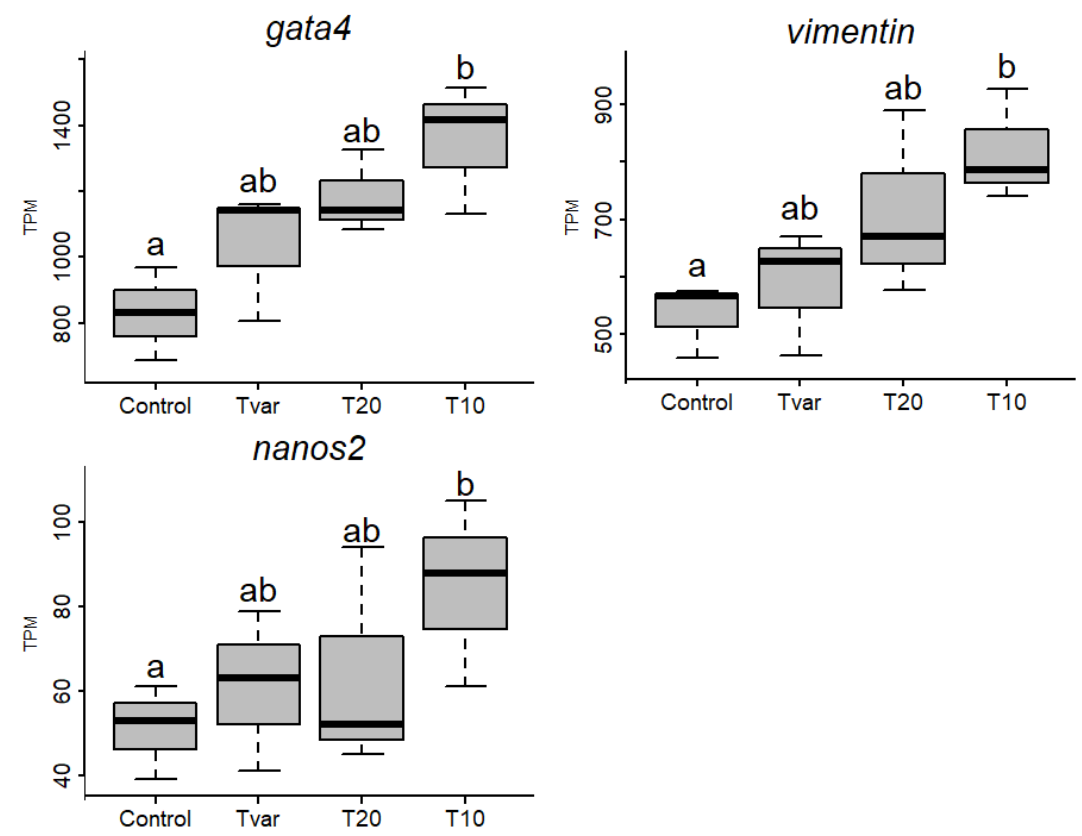

Figure 41. Boxplots of the transcription pattern of nanos2, gata4, and vimentin. Letter indicate statistical significance before FDR corrects.

Finally, interesting genes were found "insignificantly" downregulated. E.g. dmc1 (Fig. 43), which has been shown to be meiosis-specific in Japanese eel (Ozaki et al. 2006); and anti-Müllerian hormone (amh; Fig. 43), which has 
been shown to be downregulated by hCG treatment in eel testis (Schulz et al. 2010), and recombinant eel AMH was shown to suppress $11 \mathrm{KT}$-induced spermatogonial proliferation in vivo. Thus it has been hypothesized that inhibition of AMH is necessary to initiate spermatogenesis in eels (Schulz et al. 2010).
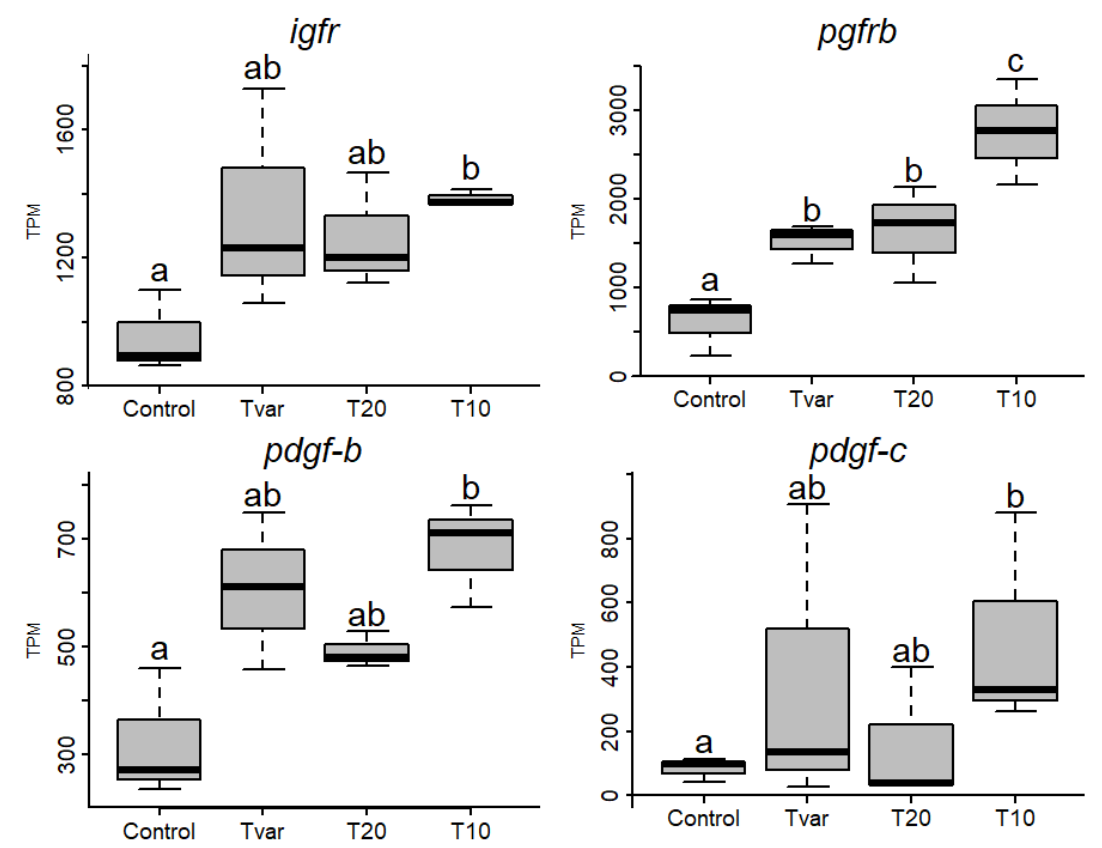

Figure 42. Boxplots of the transcription pattern of igf receptor (igfr), platelet-derived growth factor receptor-b (pgfrb), platelet-derived growth factor-b $(p d g f-b)$, platelet-derived growth factor-c (pdgf-c). Letter indicate statistical significance before FDR corrects.

As the above-mentioned genes were not significantly differentially transcribed after FDR correction, the results should only be considered suggestive evidence. However, in studies applying QPCR to evaluate the transcription of these genes, they would likely have been found significantly differentially transcribed. Therefore, in order to investigate the early stages of natural eel maturation after silvering, the transcription profile, exact function, and regulatory pathway of these genes could also be considered 
targets. Especially, considering that several of these genes present the same transcription profile as seen in the histological results of Chapter 2 (Fig. 20), e.g. higher expression in groups of higher total SPG counts (e.g. $a r-b, h s p 70$, star, or pgfrb), or higher expression in groups of higher differentiation (e.g. $a m h)$. Such relationships suggest that they are somehow connected to the same mechanism. Both the significantly differentially transcribed genes, and the "insignificantly" differentially transcribed genes shown above could potentially be used as biomarkers for the early stages of natural eel maturation. However, substantially more experimentation is needed to assess the potential of these genes as biomarkers, e.g. development of specific qPCR assays.
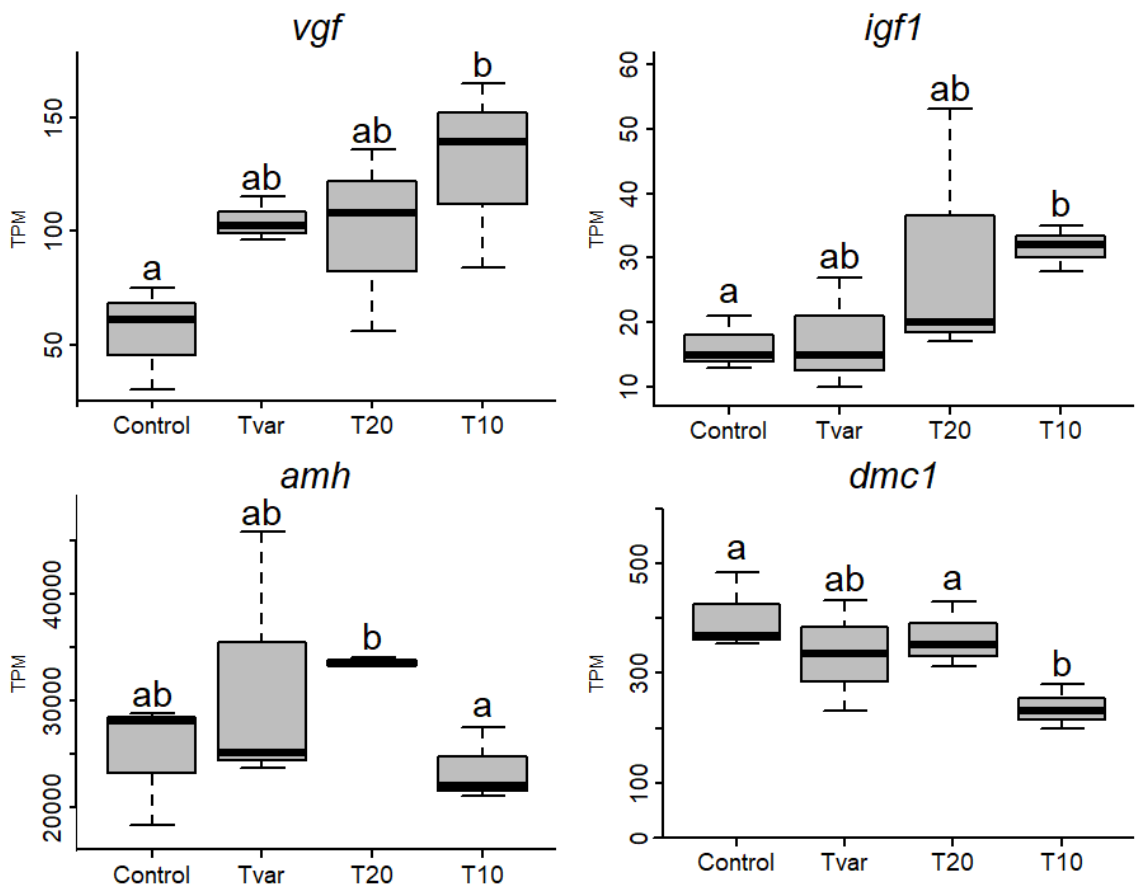

Figure 43. Boxplots of the transcription pattern of pro-vaccinia growth factor (vgf), insulin like growth factor 1 (igf1), anti-Müllerian hormone (amh), dosage suppressor of MCK1 homologue (dmc1). Letters indicate statistical significance before FDR corrects. 
Other interesting results which were not related to gene transcription, were also excluded from Chapter 2. E.g. DHP plasma levels were measured via RIA together with T and 11KT (Fig. 44).

\section{DHP}

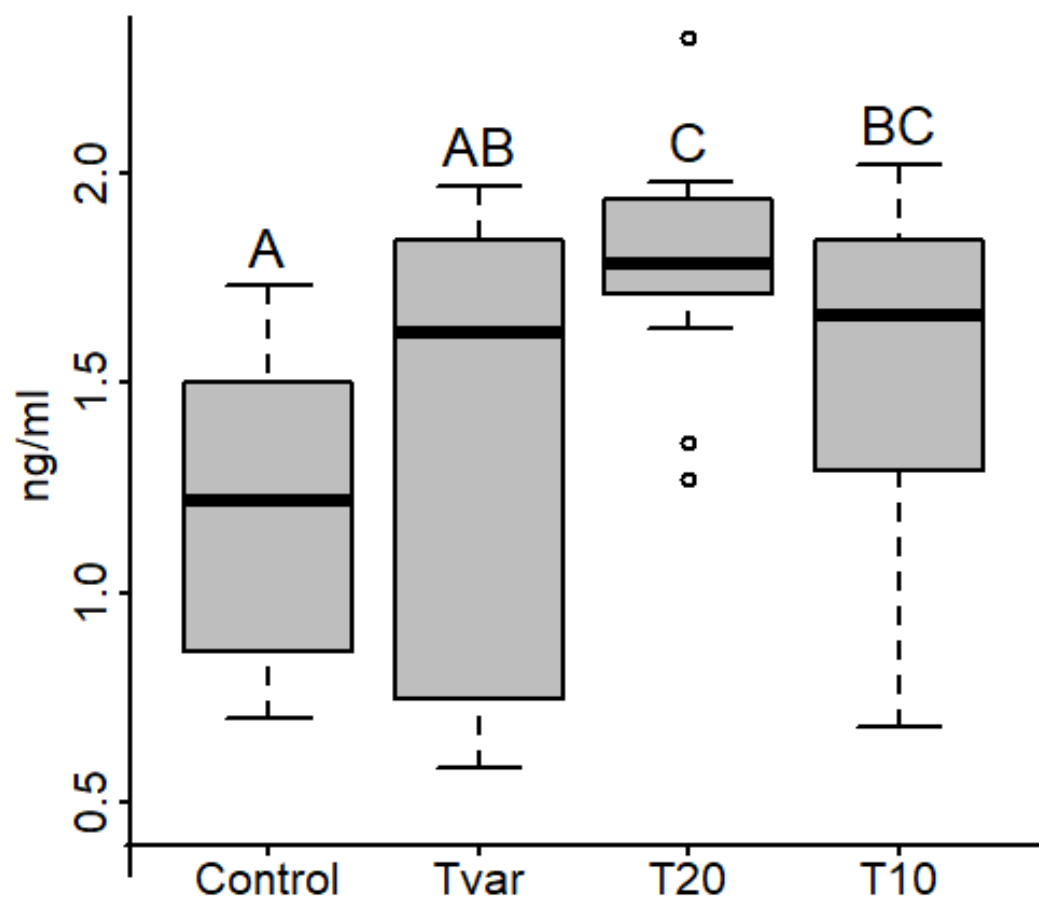

Figure 44. Boxplots of DHP radioimmunoassay steroid results from the blood of fish from the T10, T20, Tvar and control groups. Significant differences are indicated with letters.

DHP is commonly associated with late maturational processes in teleosts (Asturiano et al. 2000; Morini et al. 2017a), but this steroid (progestin) can also be measured in the blood at the onset of puberty in some fish (Amer et al. 2001) and specifically in eels during artificial maturation (Miura et al. 2006; Peñaranda et al. 2010b, 2016a). In particular, Miura et al. (2006) showed that DHP level peaks some days after the initial 11KT peak in Japanese eel blood during artificial maturation. Moreover, different DHP receptors have different cellular sites both 
in Japanese and European eels (Miura et al. 2006; Morini et al. 2017a), which supports the hypothesis of multiple functions of DHP, including an early function in maturation. Furthermore, Miura et al. (2006) showed that 11KT-induced DNA synthesis (likely indication of proliferation) may happen in two phases, one which is DHP independent and one being DHP-dependent (which could be inhibited by anti-DHP treatment). The latter phase further appeared to correlate with the pro-meiosis stage of spermatogenesis (Miura et al. 2006). These results lead these authors to the hypothesis that DHP may affect late SPG proliferation possibly at the post-meiotic stage. Similarly, our group has previously found that DHP levels increase at a stage of high differentiation of SPGA cells into SPGB (Peñaranda et al. 2016a), which indicates a role of DHP in SPGAdiff differentiation into SPGB. This hypothesis is particularly interesting as our T10 treatment, appears to inhibit differentiation towards meiosis, despite increased 11 KT levels, which according to this hypothesis (Miura et al. 2006; Peñaranda et al. 2016a), could be facilitated by DHP. However, our measurement of DHP only showed a slight insignificant decrease in the T10 group compared to T20 (Fig. 44). Interestingly, the T20 group did show significant higher DHP levels compared to the Tvar and control group (Fig. 44), which could support a hypothesis of late maturational processes being activated at higher temperatures.

\subsection{Did the European eel lineage experience a WGD after 3R?}

Gene duplication is a key driver of evolutionary innovation (Ohno 1970). In particular, the presence of a large amount of duplicated genetic material has important phenotypic consequences (Van De Peer et al. 2017; Blischak et al. 2018; and see introduction). Therefore, the question whether or not the eel lineage experienced an additional WGD is highly relevant. As shown in the introduction, the literature indicates that the assumption that WGDs are extremely rare in teleosts is not supported at the current level of knowledge and 
should not be made before substantially more teleost genomes have been sequenced and analyzed. Furthermore, the most indicative parameters observed so far rather indicates the opposite hypothesis, that WGDs are as common in teleost as they are in insects, amphibians, and reptiles, although most lineages have simply not endured enough scrutiny for any conclusion to be made. This idea is well illustrated by the following quote:

"Hence, it is probably safer to say that most lineages of life have simply not been sufficiently examined for polyploidy rather than claiming a priori that polyploidy is rare in certain lineages" (Blischak et al. 2018).

In eels in particular, previous studies have shown data suggestive of an ancient eel specific duplication event. E.g. In the additional data included by Inoue et al. (2015), in their analysis of the gene loss process that followed the teleost $3 R$ WGD, the eel is the species with the highest percentage of duplications. Supporting this result, several lineage specific (not found in other teleosts) paralog pairs have also been found and studied in eel (Dufour et al. 2005; Pasqualini et al. 2009; Henkel et al. 2012; Pasquier et al. 2012; Maugars and Dufour 2015; Morini et al. 2015; Lafont et al. 2016; Rozenfeld et al. 2016; Morini et al. 2017a, 2017b). E.g. Lafont et al. (2016) found two paralog genes of ift140, tleo2, nme4, xpo6, and unkl, in the gper genomic regions of the eel. Only one copy of these genes has been observed in other teleosts. These results led Lafont et al. to hypothesize i) that the whole region containing gper could have been duplicated in Anguilla eels, and maybe also in other teleosts, or ii) that the retention of duplicated genes may be higher in eels than in other teleosts. Most of the above-referenced studies hypothesize that the genes in question originated from $3 \mathrm{R}$, primarily due to the observation of faint conserved local synteny, and despite often finding low phylogenetic divergence. E.g. In the case of the leptin receptor (lepr), the gene "leprot" account for this synteny while the gene " $a k 4$ " is missing in " $b$ " synteny, however not consistently (Morini et al. 
2015), while very low phylogenetic distance is seen between the lepr paralogs. The low phylogenetic distances, observed in these studies, are in turn hypothesized as a consequence of a slow molecular clock affecting European eel genes, which in turn may conserve more genes from $3 R$ in eel than in other teleosts (Minegishi et al. 2005). Likewise, in the study of Henkel et al. (2012), a remarkably high number of Hox genes (73) were found in the eel (Henkel et al. 2012). It was further shown that these genes covered 8 eel Hox clusters, which makes eels the only teleost with 8 Hox clusters, which has not been confirmed to have experienced a 4R WGD event. However, 8 is the expected number of Hox clusters if no clusters have been lost since $3 \mathrm{R}$ due to a high conservation of genes in the eel, and it is also within the expected number giving a 4R WGD and subsequent loss of Hox clusters in a similar rate as observed in salmonids (Lien et al. 2016; Mungpakdee et al. 2008).

If eels have experienced a 4R WGD, it is possible that one or some of the present clusters are the results of this duplication event, rather than $3 R$. Therefore, in order to choose between these opposing hypotheses, one should investigate the evidence for or against a relatively recent origin of any of the 8 eel Hox clusters. In support of the $4 \mathrm{R}$ hypothesis, low phylogenetic distance and sometimes reversed cluster order was seen between Hox cluster pairs $\mathrm{Ba} / \mathrm{Bb}, \mathrm{Ca} / \mathrm{Cb}$, and $\mathrm{Da} / \mathrm{Db}$ (Henkel et al. 2012). Opposing this hypothesis is the conserved synteny. However, in the case of the Hox clusters $\mathrm{Ba} / \mathrm{Bb}$, this synteny was only based on one gene (ttll6), while two other genes (skap1 and snx11) were included from a different scaffold. In the case of the Hox clusters $\mathrm{Ca} / \mathrm{Cb}$, the synteny was only based on one gene (rarg), which could only be included due to extended scaffolds. In the case of the Hox clusters $\mathrm{Da} / \mathrm{Db}$, this synteny is only based on one gene (evx2), while one gene ( $m t x 2$; which is "conserved" in Db clusters) is present on both the eel $\mathrm{Da}$ and $\mathrm{Db}$ Hox clusters. The result that genes like eel mtx2 and medaka cbx3 (from Hox Aa) were presented on both $a$ and $b$ 
"conserved" syntenies (Henkel et al. 2012) indicates that great care that should be applied when drawing synteny conclusion based on only one gene. Additionally, the scaffolding software used by Henkel et al. (2012) is set to a default of a minimum of 5 connections between contigs before these can be joined into scaffolds with confidence. For the European eel genome published by Henkel et al. (2012), this value was lowered to 3, and for the extended scaffolds, this value was lowered to 2 . As such, even greater care should be applied when drawing conclusions based on one gene from an extended scaffold.

Interestingly, while the conserved synteny around the Hox clusters does indicate a $3 R$ origin, the Hox genes themselves sometimes rather indicates the opposing hypothesis. In particular, the eel Bb cluster (Henkel et al. 2012) contains more similarities in conserved genes with the Ba clusters of zebrafish, salmon (Salmo salar), pufferfish (Tetraodon), medaka (Oryzias latipes; Henkel et al. 2012), salmon and common carp Hox cluster Ba (Xu et al. 2014) than with the corresponding Bb clusters (Henkel et al. 2012; Xu et al. 2014). Similarly, the eel $\mathrm{Db}$ cluster contains more similarities in conserved genes with the Da clusters of zebrafish, pufferfish, and medaka, than with the corresponding Db clusters (Henkel et al. 2012), while the Db cluster is completely lost in salmon. Regarding the $\mathrm{C}$ clusters, no indication can be drawn as the eel $\mathrm{Ca}$ and $\mathrm{Cb}$ does share similarities with zebrafish and salmon $\mathrm{Ca}$ and $\mathrm{Cb}$ respectively, while the $\mathrm{Cb}$ clusters are completely lost in pufferfish and medaka (Henkel et al. 2012). Additionally, homologous exchanges between duplicated chromosomes, biased fractionation (Freeling 2009) and other processes (Osborn et al. 2003; Gaeta and Chris Pires 2010; Scienski et al. 2015; He et al. 2017) can strongly interfere with synteny observations, and thus collinearity rather than simply synteny is commonly used for origin determination (Blischak et al. 2018; Edger et al. 2018). However, when analysis WGDs as old as 3R or the hypothesized eel event, little 
or no collinearity can be expected, thus the most reliable methods for origin determination remains phylogenomic approaches (Blischak et al. 2018; Edger et al. 2018), similar to the approach of Chapter 3.

Other suggestive arguments for an eel $4 R$ WGD can also be found. E.g. the transcriptome of several teleosts have been sequenced (Pasquier et al. 2016), and, from these, the European eel was the species with the highest number of contigs, expected for species with a documented 4R WGD in their lineage. Moreover, the eel life history includes traits which are highly different from related species, and thus the adaptation of these traits have been hypothesized only to be possible, in one step, through the vast amount of raw genetic material which is generated by a WGD (Inoue et al. 2010). Furthermore, ancient polyploids would be expected in lineages with current incidences of polyploidy (Van De Peer et al. 2017), and several cases of existing viable eel polyploids have been documented (Ohta et al. 2003; Nomura et al. 2013). Also, WGDs are expected to be more common in organisms which produce a relatively high number of gametes (Mable et al. 2004) and eels likely produce an exceptionally high number of gametes (Barbin and McCleave 1997; MacNamara and McCarthy 2012; Gallego et al. 2012). The majority of polyploid fish and amphibian discovered until today reproduce sexually (Wendel 2000). In most cases of polyploidity of sexually reproducing species these do not possess heteromorphic sex chromosomes (Otto and Whitton 2000), and eels likely do not have sex chromosomes (Geffroy and Bardonnet 2016). Also, species radiation is often associated with WGDs (Van De Peer et al. 2017) and previous studies have proposed that $3 R$ is one of the possible causes of the massive species radiation observed in teleosts (Hoegg et al. 2004; Santini et al. 2009), in line of this result polyploids are found in 4 of the 6 most species-rich teleosts lineages, and eels belong to the $7^{\text {th }}$ (Comber and Smith 2004). Furthermore, a striking relation exists between fish orders with polyploids and orders known to hybridize 
(Comber and Smith 2004; Braasch and Postlethwait 2012), and eels do hybridize (Müller et al. 2018; Burgerhout et al. 2011). Moreover, polyploids often retain high heterozygosity (Parisod et al. 2010; Leggatt and Iwama 2003; Van De Peer et al. 2009), and eels retain high heterozygosity (Jansen et al. 2017). Furthermore, high nucleus DNA content has been used as suggestive evidence of WGDs (Lamatsch et al. 2000; Juchno and Lackowska 2010; Zhu et al. 2012). Although variable measurements have been published regarding the DNA content of European eels, ranging from 2.22 to 3.34 pg DNA per nucleus (pg/N; http://www.genomesize.com), even the lower values seem high for diploid fishes, which have an average size of $1.8 \mathrm{pg} / \mathrm{N}$ (Hardie and Hebert 2004). This is further interesting as genome sizes have been shown to be larger in freshwater species compared to marine/catadromous species (2.81 compared to $1.77 \mathrm{pg} / \mathrm{N}$; Hardie and Hebert 2004), and because Actinopterygii families, which show a higher effort of parental care, have been shown to have significantly higher genome sizes (2.48 compared to $1.79 \mathrm{pg} / \mathrm{N}$; Hardie and Hebert 2004). Although the level of parental care is not known for European eel, the hypothesized oceanic spawning of pelagic eggs (Schmidt 1923; Munk et al. 2010) suggests that their level of parental care is rather small. Furthermore, large variation in genome size not caused by WGD is rare (Lamatsch et al. 2000; Juchno and Lackowska 2010; Zhu et al. 2012), thus the eel genome size is also suggestive of the hypothesis of a 4R WGD ancient in the European eel lineage. However, it should be noted that large genome has also been associated with slow-evolving species (Hinegardner and Rosen 1972).

Thus, eels compose most traits which are commonly associated with lineages that have experienced a WGD event, and as Chapter 3 shows, the eel genomes contain an exceptional complement of duplicated genes with relatively low sequence divergence in synonymous sites and which are indicated as eel-specific in the phylogenetic analysis (PHYLDOG). The results of Chapter 3 are generally 
uncontroversial as they fit with most previous findings on both global (Inoue et al. 2015; Pasquier et al. 2016) and single gene scale (Dufour et al. 2005; Maugars and Dufour 2015; Pasqualini et al. 2009; Pasquier et al. 2012; Morini et al. 2015, 2017b; Henkel et al. 2012; Lafont et al. 2016). However, the suggestion of a $4 R$ WGD event has been strongly questioned. Traditionally, findings such as presented in Chapter 3 are considered as indicative of a recent large scale duplication event (Van De Peer 2004; Yu et al. 2017; Clarke et al. 2015; Jiao et al. 2011; Tang et al. 2008; Edger et al. 2018; Blischak et al. 2018). Additionally, WGDs cannot be determined to be rare in teleost with confidence and seem more likely to be as common in teleosts as in most other animals (except mammals). On the other hand, the most commonly selected opposing hypothesis of a slow molecular clock rate affecting eel genes has to overcome some opposing factors. E.g. if true, the eel would represent the first documented case of a teleost with a slow molecular clock rate (Glasauer and Neuhauss 2014). This, of course, does not make the hypothesis wrong but does indicate that such events are in fact very rare. Furthermore, several hundred genes were found in eels in Chapter 3, which presented all characteristics of other teleost 3R genes. Therefore, the hypothesis of a slow molecular clock rate in eels needs the ad hoc hypothesis of a mechanism which only affects some of the genes and not others. These points suggest that a 4R WGD or delayed rediploidization (presented in Chapter 3) hypothesis is the simplest (requires no ad hoc hypotheses or the invocation of highly exceptional characteristics of the eels), best supported by the evidence, and should thus be selected.

\subsection{Potentially important recently duplicated genes found in eels}

Regardless of the origin, the identified duplications of Chapter 3 may provide useful insight into eel biology. In particular, gene function analyses were carried out to study overrepresented functions among the eel specific duplications of Chapter 3. Conservation or loss of duplicated genes has been suggested to be 
associated with environmental adaptation (Tautz and Domazet-lošo 2011; Chain et al. 2014) which could happen long after the duplication event (Conant and Wolfe 2008; Blischak et al. 2018; Thompson et al. 2016). Therefore, the overrepresentations found in Chapter 3 could be linked to adaptations that have taken place throughout eel evolution, e.g. the inclusion of a leptocephali larval stage to their life history (Inoue et al. 2004), the adaptation to a catadromous lifecycle (Inoue et al. 2010), and the adaptation for DA to inhibit maturation at an exceptionally early stage compared to other teleosts (Vidal et al. 2004; Dufour et al. 1988, 2005, 2010). The hypothesized 4R duplication event or delayed rediploidization could facilitate the genes for these events although they likely occurred tens of millions of years after the duplication event as phenotypic changes can be vastly delayed compared to their WGD origin (Conant and Wolfe 2008; Blischak et al. 2018; Thompson et al. 2016).

Other mechanisms which perhaps influence the conservation of paralogs are dosage selection (Glasauer and Neuhauss 2014; Blischak et al. 2018) and segregation avoidance (Hahn 2009). It has been suggested that these mechanisms conserve duplicated genes related to specific biological processes, such as development, signaling, ion transport, metabolism and neuronal function after WGDs (Berthelot et al. 2014; Blomme et al. 2006; Brunet et al. 2006; Kassahn et al. 2009; Blischak et al. 2018; Freeling 2009; Ming et al. 2015).

Specifically, in Chapter 3, 54 GO terms and 54 KEGG pathways were found to be enriched among the duplications assigned to the freshwater eel branch. Interestingly, several of these enriched GO terms are sub-levels terms of the processes associated with a WGD origin. This result suggests that the duplication event that created the discussed genes of Chapter 3 is a WGD. If true, it is plausible that they have been conserved due to the mechanisms regulating gene conservation after WGD rather than due to specific necessities of the Anguilla species. Other GO terms that were found to be duplicated in eel are not usually 
found after other WGDs, for example, "pigmentation". As in the case of the GO terms, several of the KEGG pathways are also involved in processes associated with a WGD origin. However, the most significantly enriched pathway found in the eel duplications is the dopaminergic synapse pathway.

As GO terms and pathways such as pigmentation, olfactory transduction, and dopaminergic synapse pathway are not commonly found conserved after WGDs, their conservation might be associated with new functions acquired in the Anguilla species. Specifically, the conservation of several genes of the dopaminergic synapse pathway suggests that these conserved genes are involved in the adaptation for DA to inhibit maturation at an exceptionally early stage. Among the duplicated genes assigned to the dopaminergic synapse pathway, we found TH. The presence of two TH genes in the eel encourages suspicion of potential differential transcription or function between the two, which may prove important for the regulation of the DA induced inhibition of puberty observed in pre-migration eels. Similarly, the conservation of genes related to pigmentation and olfactory transduction may be associated with adaptation to a catadromous lifecycle. These hypotheses, although speculative, are not implausible considering that conserved duplicated genes can facilitate new adaptation long after their origin (Conant and Wolfe 2008; Blischak et al. 2018; Thompson et al. 2016).

\section{FUTURE PERSPECTIVES}

Each of the presented Chapters possesses a certain amount of novelty in methodology and findings and reaches rather broad, but this comes with the price of losing focus and depth. As mentioned in the discussion, the establishment of methodologies for production and use of recombinant eel gonadotropins, from Chapter 1, holds large potential. However, a substantial amount of work is needed to improve and optimize the protocols before actual 
progress can be achieved. Likewise, the vast amount of data generated in Chapters 2 and 3 alludes to several potentially important aspects of early natural eel maturation. However, specific in-depth analysis is needed to evaluate the potential of each aspect.

Nevertheless, some of the findings of this thesis can more easily be evaluated. E.g. it is clear that a cold seawater treatment does affect European eel males, but additional experiments are needed to evaluate whether this treatment can induce a net benefit for artificial eel reproduction. An experiment can easily be designed and conducted to test this hypothesis. If this experiment were to generate positive results, current artificial eel male maturation protocols could be significantly improved. The hypothesized treatment (cold seawater) further has the advantage of being very easy to apply by the aquaculture industry and is likely close to cost neutral, as heating of eel aquaculture systems is not an irrelevant cost, which could be saved during the treatment period.

\subsection{Other temperature treatments}

Full-scale experimentation of the effects of a cold seawater pretreatment should also consider different temperature regimes as it is far from conclusive that the conditions of Chapter 2 are optimal. As stated above, the selected experimental temperature regime should aim to mimic the natural temperature regime, which European eels experience during migration. Thus, as eel probably migrate at close to $10^{\circ} \mathrm{C}$ during early migration, and due to the results of Chapter 2 , this temperature may be a good starting point, for artificial eel maturation. However, possibly due to inhibitory factors (Chapter 2), maturation does commonly not progress at low temperatures (Boëtius and Boëtius 1967; Gallego et al. 2012; Peñaranda et al. 2016a), and as nightly temperatures increases at later stages of migration, higher temperatures later in the treatment may prove beneficial. 
While migrating eels appears to endure some daily variation in temperature all through migration (Righton et al. 2016), this variation seems to increase as migration progresses (Wysujack et al. 2015). At later stages of eel migration temperatures reaches $8-10 \stackrel{\circ}{ } \mathrm{C}$ during the day and $16-17 \stackrel{\circ}{ } \mathrm{C}$ during the night (Wysujack et al. 2015), which could be considered similar to our Tvar treatment of Chapter 2. Therefore, it might prove valuable to test a cold water regime, which develops into a variable regime over time. However, variable temperature ranges vary greatly between Anguilla species (Manabe et al. 2011; Schabetsberger et al. 2013) and the specific range is thus less likely to be a conserved factor of maturation within eels. Finally, strong evidence suggests that ovulation and spermiation happens naturally at higher temperatures (Boëtius and Boëtius 1967; Kucharczyk et al. 2016), and thus experimental temperature regimes should end at higher temperatures.

To some extent similar experiments have been conducted on both male and females European eels, although with constant hormonal injections (Pérez et al. 2011; Gallego et al. 2012; Peñaranda et al. 2016a). In particular, an increasing temperature regime affected several parameters in European eel females (as described above), from which most notable Fsh kept increasing during maturation until the mid-vitellogenic stage (Pérez et al. 2011), which also appears to happen during natural maturation of both New Zealand longfinned eel (Saito et al. 2003) and Japanese conger (Kajimura et al. 2001a), and might thus be a more natural scenario. Furthermore, in a group of hormonally treated European eel males kept at $10{ }^{\circ} \mathrm{C}$ and later introduced to gradually warmer water spermiation with increasing motility, volume, and progressive motility throughout the experiment (Gallego et al. 2012). At the termination of the experiment this group show motility values similar to the highest observed values of any other group in this experiment, and it is thus open for speculation whether the increasing tendencies would have continued (Gallego et al. 2012). 
While these studies do seem promising, additional studies should also test the possibility of a later initiation of hormonal injections. In support of this hypothesis, our 2 week T10 treatment (Chapter 2) induced similar changes in the eels as seen after 2 weeks of hCG treatment. Furthermore, European eel males which did not mature due to cold temperatures, despite hCG injection, matured fully after being introduced to warmer waters with no further hormonal injections (Boëtius and Boëtius 1967). Finally, preliminary results from one Japanese eel female showed that variable temperatures (between 5 and 15 ${ }^{\circ} \mathrm{C}$ ), without hormonal treatment, induced significant maturational progress (GSI of 8.5\%; Mikawa et al. 2008).

Therefore, these thermal treatments could potentially improve gametes quality through a more natural maturation process but more likely, at least, could help to lower the total hormone use. If experiments, as described above, prove successful on males, a natural next step would be to try out similar treatments for European eel female, since common factors are likely involved in the onset of maturation in both Anguilla sexes (Sudo et al 2012). Finally, in the scientific quest for knowledge, an in vitro study of the effect of a thermal regime and other factors on the testis, but also pituitary would greatly broaden our understanding of the mechanisms involved.

\subsection{Alternative eel species as a model}

Similar to our decision to use European eel males as our model rather than females, arguments have been made for the use of different Anguilla or even Elopomorpha species for further studies (Todd 1981; Burgerhout et al. 2011; Boëtius and Boëtius 1967; Aida and Tsukamoto 2003; Durif et al. 2005; Hagihara et al. 2012). Different Anguilla species are found to reach different stages of maturation at the initiation of migration (Durif et al. 2005; Hagihara et al. 2012). E.g. migratory shortfinned New Zealand eel males are found with late type B 
spermatogonia in their testis (Lokman and Young 1998), while spermatozoa can be found in migratory longfinned New Zealand eel (Anguilla dieffenbachii; Lokman and Young 1998). Possibly, a correlation exists between shorter reproductive migration and higher developmental stage at initiation of migration and maybe a weaker pre-pubertal neuroendocrine blockage (Todd 1981; Durif et al. 2005; Burgerhout et al. 2011; Hagihara et al. 2012), while the environmental tickers to overcome this block may be similar or the same. If true, Anguilla species with a short migratory distance seems optimal species to study environmental factors involved in natural eel maturation (Durif et al. 2005). Following this logic, it is possible that even non-Anguilla Elopomorphs could be good models of eel maturation. E.g. Conger eels have been shown to mature fully in captivity without hormonal treatments and may possess similar reproductive controlling mechanisms although obviously far weaker (Boëtius and Boëtius 1967; Aida and Tsukamoto 2003; Utoh et al. 2013). However, while less related species may show weaker pre-pubertal neuroendocrine blockage, they are also more likely to have evolved a different maturation controlling mechanism. 


\section{CONCLUSIONS}

2. Recombinant European eel specific gonadotropins can be produced to a quality which can induce full spermiogenesis and spermiation. Although optimization is needed before these practices provide a net benefit to artificial eel maturation protocols

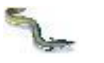

Despite the clear effect of hCG (an Lh-analog), aarLh injection did not induce significant progression of maturation in European eel males. This evidence may prove important for hypotheses about the mechanism of eel pubertal blockage

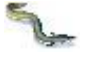

Cold seawater treatment clearly affects the BPG axis of European eel males. However, it has not been sufficiently tested whether a net benefit for reproduction can be obtained through cold seawater (pre)treatment, followed by commonly used artificial maturation at higher temperatures

Cold seawater treatments induce spermatogonial proliferation but do not induce significant progression spermatogenesis in European eel males. This evidence may prove important for hypotheses about the mechanism of the eel pubertal blockage

\footnotetext{
2- The eel genome contains a large number of paralog pairs with low phylogenetic divergence. Thus a large amount of raw genetic material has been available for eels during critical evolutionary innovations. The conserved genes from this raw material may thus provide novel insights into eel biology
} 


\section{REFERENCES}

Ager-Wick E, Dirks RP, Burgerhout E, Nourizadeh-Lillabadi R, de Wijze DL, Spaink HP, van den Thillart GEEJM, Tsukamoto K, Dufour S, Weltzien FA, Henkel Cv. 2013. The pituitary gland of the European eel reveals massive expression of genes involved in the melanocortin system. PLoS One 8: 112.

Ahn H, Yamada Y, Okamura A, Horie N, Mikawa N, Tanaka S, Tsukamoto K. 2012. Effect of water temperature on embryonic development and hatching time of the Japanese eel Anguilla japonica. Aquaculture 330-333: 100-105.

Aida K, Tsukamoto K. 2003. Eel Biology.

Aizen J, Meiri I, Tzchori I, Levavi-Sivan B, Rosenfeld H. 2005. Enhancing spawning in the grey mullet (Mugil cephalus) by removal of dopaminergic inhibition. Gen Comp Endocrinol 142: 212-221.

Albalat R, Cañestro C. 2016. Evolution by gene loss. Nat Rev Genet 17: 379-391.

Albertin W, Marullo P. 2012. Polyploidy in fungi: Evolution after whole-genome duplication. Proc R Soc B Biol Sci 279: 2497-2509.

Alexa A, Rahnenfuhrer J. 2016. topGO: Enrichment analysis for gene ontology. R package version 2.29.0.

Allendorf F, Thorgaard G. 1984. Tetraploidy and the evolution of salmonid fishes. In Evolutionary Genetics of Fishes, pp. 1-53.

Als TD, Hansen MM, Maes GE, Castonguay M, Riemann L, Aarestrup K, Munk P, Sparholt H, Hanel R, Bernatchez L. 2011. All roads lead to home: Panmixia of European eel in the Sargasso Sea. Mol Ecol 20: 1333-1346.

Amer MA, Miura T, Miura C, Yamauchi K. 2001. Involvement of Sex Steroid Hormones in the Early Stages of Spermatogenesis in Japanese Huchen (Hucho perryi). Biol Reprod 1066: 1057-1066.

Anders S, Huber W. 2010. Differential expression analysis for sequence count data. Genome Biol 11: 1-12.

Andrews S. 2010. FastQC: A quality control tool for high throughput sequence data. http://www.bioinformatics.babraham.ac.uk/projects/. 
Applegate SP, Greenwood PH, Rosen DE, Weitzman SH, Myers GS. 1967. Phyletic studies of teleostean fishes, with a provisional classification of living forms. Copeia 1967: 693.

Aristotle. 1910. The history of animals. Clarendon Press, Oxford.

Arnegard ME, Zwickl DJ, Lu Y, Zakon HH. 2010. Old gene duplication facilitates origin and diversification of an innovative communication system--twice. Proc Natl Acad Sci 107: 22172-22177.

Aroua S, Schmitz M, Baloche S, Vidal B, Rousseau K, Dufour S. 2005. Endocrine evidence that silvering, a secondary metamorphosis in the eel, is a pubertal rather than a metamorphic event. Neuroendocrinology 82: 221-232.

Asturiano JF, Sorbera LA, Ramos J, Kime DE, Carrillo M, Zanuy S. 2000. Hormonal regulation of the European sea bass reproductive cycle: An individualized female approach. J Fish Biol 56: 1155-1172.

Asturiano JF, Pérez L, Garzón DL, Peñaranda DS, Marco-Jiménez F, MartínezLlorens S, Tomás A, Jover M. 2005. Effect of different methods for the induction of spermiation on semen quality in European eel. Aquac Res 36: 1480-1487.

Asturiano JF, Marco-Jiménez F, Pérez L, Balasch S, Garzón DL, Peñaranda DS, Vicente JS, Viudes-de-Castro MP, Jover M. 2006. Effects of hCG as spermiation inducer on European eel semen quality. Theriogenology 66: 1012-1020.

Baeza R, Mazzeo I, Vílchez MC, Gallego V, Peñaranda DS, Pérez L, Asturiano JF. 2014. Effect of thermal regime on fatty acid dynamics in male European eels (Anguilla anguilla) during hormonally-induced spermatogenesis. Aquaculture 430: 86-97.

Baeza R, Mazzeo I, Vílchez MC, Gallego V, Peñaranda DS, Pérez L, Asturiano JF. 2015a. Relationship between sperm quality parameters and the fatty acid composition of the muscle, liver and testis of European eel. Comp Biochem Physiol Part A 181: 79-86.

Baeza R, Peñaranda DS, Vílchez MC, Tveiten H, Pérez L, Asturiano JF. 2015b. Exploring correlations between sex steroids and fatty acids and their potential roles in the induced maturation of the male European eel. Aquaculture 435: 328-335.

Bahamonde PA, Mcmaster ME, Servos MR, Martyniuk J, Munkittrick KR. 2016. 
Characterizing transcriptional networks in male rainbow darter (Etheostoma caeruleum) that regulate testis development over a Complete Reproductive Cycle. PloS One 1-25.

Bailey JA, Gu Z, Clark RA, Reinert K, Samonte R V, Schwartz S, Adams MD, Myers EW, Li PW, Eichler EE. 2002. Recent segmental duplications in the human genome. Science 297: 1003-1007.

Barbin GP, McCleave JD. 1997. Fecundity of the American eel Anguilla rostrata at $45 \mathrm{~N}$ in Maine, U. S. A. 51: 840-847.

Bast HD, Klinkhardt MB. 1988. Catch of a silver eel (Anguilla anguilla (L., 1758)) in the Iberian Basin (Northeast Atlantic) (Teleostei: Anguillidae). Zool Anzeiger 221: 386-398.

Benjamini Y, Hochberg Y. 1995. Benjamini Y, Hochberg Y. Controlling the false discovery rate: a practical and powerful approach to multiple testing. $J R$ Stat Soc B 57: 289-300.

Bennett MD, Leitch IJ, Price HJ, Johnston JS. 2003. Comparisons with Caenorhabditis ( $100 \mathrm{Mb}$ ) and Drosophila ( 175 Mb) using flow cytometry show genome size in Arabidopsis to be $\sim 157 \mathrm{Mb}$ and thus $~ 25 \%$ Larger than the Arabidopsis genome initiative estimate of $125 \mathrm{Mb}$. Ann Bot 91: 547-557.

Berr A, Shafiq S, Shen WH. 2011. Histone modifications in transcriptional activation during plant development. Biochim Biophys Acta-Gene Regul Mech 1809: 567-576.

Berthelot $C$, Brunet F, Chalopin D, Juanchich A, Bernard M, Noël B, Bento P, Da Silva C, Labadie K, Alberti A, Aury JM, Louis A, Dehais P, Bardou P, Montfort J, Klopp C, Cabau C, Gaspin C, Thorgaard GH, Boussaha M, Quillet E, Guyomard R, Galiana D, Bobe J, Volff JN, Genêt C, Wincker P, Jaillon O, Crollius HR, and Guiguen Y. 2014. The rainbow trout genome provides novel insights into evolution after whole-genome duplication in vertebrates. Nat Commun $\mathbf{5}$.

Bezdenezhnykh VA, Prokhorcik GA, Petrikov AM, Petukov VB, Plyuta M V. 1983. Obtaining the larvae of European eel Anguilla anguilla L. (Pisces, Anguillidae), under experimental conditions. Dokl Akad Nauk SSSR 226: 1264-1266.

Bian C, Hu Y, Ravi V, Kuznetsova IS, Shen X, Mu X, Sun Y, You X, Li J, Li X, Qiu Y,Tay $\mathrm{BH}$, Thevasagayam NM, Komissarov AS, Trifonov V, Kabilov M, Tupikin A, 
Luo J, Liu Y, Song H, Liu C, Wang X, Gu D, Yang Y, Li W, Polgar G, Fan G, Zeng $\mathrm{P}$, Zhang $\mathrm{H}$, Xiong $\mathrm{Z}$, Tang $\mathrm{Z}$, Peng $\mathrm{C}$, Ruan $\mathrm{Z}, \mathrm{Yu} \mathrm{H}$, Chen J, Fan $\mathrm{M}$, Huang $\mathrm{Y}$, Wang $M$, Zhao X, Hu G, Yang H, Wang J, Wang J, Xu X, Song L, Xu G, Xu P, Xu J, O'Brien SJ, Orbán L, Venkatesh B, and Shi Q 2016. The Asian arowana (Scleropages formosus) genome provides new insights into the evolution of an early lineage of teleosts. Sci Rep 6: 1-17.

Bitgood MJ, Shen L, McMahon AP. 1996. Sertoli cell signaling by Desert hedgehog regulates the male germline. Curr Biol 6: 298-304.

Blanc G. 2004. Widespread paleopolyploidy in model plant species inferred from age distributions of duplicate genes. Plant Cell Online 16: 1667-1678.

Blischak PD, Mabry ME, Conant GC, Pires JC. 2018. Integrating networks, phylogenomics, and population genomics for the Study of Polyploidy. Annu Rev Ecol Evol Syst 49: 253-278.

Blomme T, Vandepoele K, De Bodt S, Simillion C, Maere S, Van de Peer Y. 2006. The gain and loss of genes during 600 million years of vertebrate evolution. Genome Biol 7: 1-12.

Bobe J, Nguyen T, Jalabert B. 2004. Targeted gene expression profiling in the rainbow trout (Oncorhynchus mykiss) ovary during maturational competence acquisition and oocyte maturation. Biol Reprod 71: 73-82.

Boëtius I, Boëtius J. 1967. Studies in the European Eel, Anguilla anguilla (L.). Experimental induction of the male sexual cycle, its relation to temperature and other factors. Medd Dan Fish ser.: 339-405.

Boëtius I, Boëtius J. 1980. Experimental maturation of female silver eels, Anguilla anguilla: estimates of fecundity and energy reserves for migration and spawning. Dana 1: 1-28.

Bogerd J, Blomenröhr M, Andersson E, van der Putten HH, Tensen CP, Vischer HF, Granneman JC, Janssen-Dommerholt C, Goos HJ, Schulz RW. 2001. Discrepancy between molecular structure and ligand selectivity of a testicular follicle-stimulating hormone receptor of the African catfish (Clarias gariepinus). Biol Reprod 64: 1633-43.

Bolger AM, Lohse M, Usadel B. 2014. Trimmomatic: A flexible trimmer for Illumina sequence data. Bioinformatics 30: 2114-2120.

Bonhommeau S, Le Pape O, Gascuel D, Blanke B, Tréguier AM, Grima N, Vermard $\mathrm{Y}$, Castonguay M, Rivot E. 2009. Estimates of the mortality and the duration 
of the trans-Atlantic migration of European eel Anguilla anguilla leptocephali using a particle tracking model. J Fish Biol 74: 1891-1914.

Bonhommeau S, Castonguay M, Rivot E, Sabati R, Le Pape O. 2010. The duration of migration of Atlantic Anguilla larvae. Fish Fish 11: 289-306.

Bouilliart M, Tomkiewicz J, Lauesen P, De Kegel B, Adriaens D. 2015. Musculoskeletal anatomy and feeding performance of pre-feeding engyodontic larvae of the European eel (Anguilla anguilla). J Anat 227: 325-340.

Boulanger LM. 2009. Immune proteins in brain development and synaptic plasticity. Neuron 64: 93-109.

Boussau B, Szöll GJ, Duret L, Gouy M, Tannier E, Daubin V, Lyon U De, Lyon U. 2012. Genome-scale coestimation of species and gene trees. Life Sci 23: 323-330.

Bowers JE, Chapman BA, Rong J. 2003. Unravelling angiosperm genome evolution by phylogenetic analysis of chromosomal duplication events. 422: $433-438$.

Bromage N, Porter M, Randall C. 2001. The environmental regulation of maturation in farmed finfish with special reference to the role of photoperiod and melatonin. Aquaculture 197: 63-98.

Brunet FG, Crollius HR, Paris M, Aury JM, Gibert P, Jaillon O, Laudet V, RobinsonRechavi M. 2006. Gene loss and evolutionary rates following wholegenome duplication in teleost fishes. Mol Biol Evol 23: 1808-1816.

Brzuska E. 2001. Artificial spawning of European catfish Silurus glanis L.: Differences between propagation results after stimulation of ovulation with carp pituitary and Ovopel. Aquac Res 32: 11-19.

Braasch I, Postlethwait JH. 2012. Polyploidy in fish and the teleost genome duplication.

Braasch I, Gehrke AR, Smith JJ, Kawasaki K, Manousaki T, Pasquier J, Amores A, Desvignes T, Batzel P, Catchen J, Berlin AM, Campbell MS, Barrell D, Martin KJ, Mulley JF, Ravi V, Lee AP, Nakamura T, Chalopin D, Fan S, Wcisel D, Cañestro C, Sydes J, Beaudry FEG, Sun Y, Hertel J, Beam MJ, Fasold M, Ishiyama M, Johnson J, Kehr S, Lara M, Letaw JH, Litman GW, Litman RT, Mikami M, Ota T, Saha NR, Williams L, Stadler PF, Wang H, Taylor JS, Fontenot $Q$, Ferrara A, Searle SMJ, Aken B, Yandell M, Schneider I, Yoder 
AJ, Volff JN, Meyer A, Amemiya CT, Venkatesh B, Holland PWH, Guiguen Y, Bobe J, Shubin NH, Palma FP, Alföldi J, Lindblad-Toh K, and Postlethwait JH. 2016. Corrigendum: The spotted gar genome illuminates vertebrate evolution and facilitates human-teleost comparisons. Nat Genet 48: 427437.

Burgerhout E, Brittijn SA, Kurwie T, Decker P, Dirks RP, Palstra AP, Spaink HP, Thillart GE Van Den. 2011. First artificial hybrid of the eel species Anguilla australis and Anguilla anguilla.

Burgerhout E, Brittijn SA, Tudorache C, de Wijze DL, Dirks RP, van den Thillart GEEJM. 2013. Male European eels are highly efficient long distance swimmers: Effects of endurance swimming on maturation. Comp Biochem Physiol - A Mol Integr Physiol 166: 522-527.

Burgerhout E, Minegishi Y, Brittijn SA, de Wijze DL, Henkel CV, Jansen HJ, Spaink HP, Dirks RP, van den Thillart GEEJM. 2016. Changes in ovarian gene expression profiles and plasma hormone levels in maturing European eel (Anguilla anguilla); Biomarkers for broodstock selection. Gen Comp Endocrinol 225: 185-196.

Burgerhout E, Dirks RP, Lokman PM, van den Thillart GEEJM. 2018. The timekeeping hormone melatonin: a possible key cue for puberty in freshwater eels (Anguilla spp.). Rev Fish Biol Fish $\mathbf{3}$.

Burns KH, Matzuk MM. 2002. Minireview: Genetic models for the study of gonadotropin actions. Endocrinology 143: 2823-2835.

Butts IAE, Sørensen SR, Politis SN, Pitcher TE, Tomkiewicz J. 2014. Standardization of fertilization protocols for the European eel, Anguilla anguilla. Aquaculture 426-427: 9-13.

Butts IAE, Sørensen SR, Politis SN, Tomkiewicz J. 2016. First-feeding by European eel larvae: A step towards closing the life cycle in captivity. Aquaculture 464: 451-458.

Cacot P, Eeckhoutte P, Muon DT, Trieu NV, Legendre M, Mariojouls C, Lazard J. 2003. Induced spermiation and milt management in Pangasius bocourti (Sauvage, 1880). Aquaculture 215: 67-77.

Cañestro C, Albalat R, Irimia M, Garcia-Fernàndez J. 2013. Impact of gene gains, losses and duplication modes on the origin and diversification of vertebrates. Semin Cell Dev Biol 24: 83-94. 
Capella-Gutiérrez S, Silla-Martínez JM, Gabaldón T. 2009. trimAl: a tool for automated alignment trimming in large-scale phylogenetic analyses. Bioinformatics 25: 1972-1973.

Chai Y, Tosaka R, Abe T, Sago K, Sago Y, Hatanaka E, Ijiri S, Adachi S. 2010. The relationship between the developmental stage of oocytes in various seasons and the quality of the egg obtained by artificial maturation in the feminized Japanese eel Anguilla japonica. Aquac sci 58: 269-278.

Chain FJJ, Feulner PGD, Panchal M, Eizaguirre C, Samonte IE, Kalbe M, Lenz TL, Stoll M, Bornberg-Bauer E, Milinski M, Reusch TBH. 2014. Extensive copynumber variation of young genes across stickleback populations. PLOS Genet 10: e1004830.

Chauvigne F, Verdura S, Duncan N, Zanuy S, Go A, Mazo J, Cerdà J. 2012. Folliclestimulating hormone and luteinizing hormone mediate the androgenic pathway in Leydig cells of an evolutionary advanced teleost. Biol Reprot 87: $1-11$.

Chen Z, Zang J, Whetstine J, Hong X, Davrazou F, Kutateladze TG, Simpson M, Mao Q, Pan CH, Dai S, Hagman J, Hansen K, Shi Y, and Zhang G. 2006. Structural insights into histone demethylation by JMJD2 family members. Cell 125: 691-702.

Chen J, Liu H, Liu J, Qi J, Wei B, Yang J, Liang H, Chen Y, Chen J, Wu Y, et al. 2013. H3K9 methylation is a barrier during somatic cell reprogramming into iPSCs. Nat Genet 45: 34-42.

Chen JN, López JA, Lavoué S, Miya M, Chen WJ. 2014. Phylogeny of the Elopomorpha (Teleostei): Evidence from six nuclear and mitochondrial markers. Mol Phylogenet Evol 70: 152-161.

Chester M, Gallagher JP, Symonds V V, Cruz da Silva A V, Mavrodiev E V, Leitch AR, Soltis PS, Soltis DE. 2012. Extensive chromosomal variation in a recently formed natural allopolyploid species, Tragopogon miscellus (Asteraceae). Proc Natl Acad Sci 109: 1176-1181.

Chow S, Okazaki M, Watanabe T, Segawa K, Yamamoto T, Kurogi H, Tanaka H, Ai KI, Kawai M, Yamamoto S, Mochioka N, Manabe R, and Miyake Y. 2015. Light-sensitive vertical migration of the Japanese eel Anguilla japonica revealed by real-time tracking and its utilization for geolocation. PLoS One 10: 1-19. 
genome analysis provides evidence for a whole-genome duplication early during the evolution of ray-finned fishes. Mol Biol Evol 21: 1146-1151.

Chu L, Li J, Liu Y, Cheng CHK. 2015. Gonadotropin signaling in Zebrafish ovary and testis development: Insights from gene knockout study. Mol Endocrinol 29: 1743-1758.

Churcher AM, Pujolar J, Milan M, Hubbard PC, Martins RS, Saraiva JL, Huertas M, Bargelloni L, Patarnello T, Marino IA, Zane L, and Canário AWM. 2014. Changes in the gene expression profiles of the brains of male European eels (Anguilla anguilla) during sexual maturation. BMC Genomics 15: 799.

Clark RW, Henderson-Arzapalo A, Sullivan CV. 2005. Disparate effects of constant and annually-cycling daylength and water temperature on reproductive maturation of striped bass (Morone saxatilis). Aquaculture 249: 497-513.

Clarke TH, Garb JE, Hayashi CY, Arensburger P, Ayoub NA. 2015. Spider transcriptomes identify ancient large-scale gene duplication event potentially important in silk gland evolution. Genome Biol Evol 7: 18561870.

Clavero M, Hermoso V. 2015. Historical data to plan the recovery of the European eel. J Appl Ecol 52: 960-968.

Colbourne JK, Pfrender ME, Gilbert D, Thomas WK, Tucker A, Oakley TH, Tokishita S, Aerts A, Arnold GJ, Basu MK, et al. 2011. The ecoresponsive genome of daphnia pulex. Science 331: 555-562.

Comber SC LE, Smith C. 2004. Polyploidy in fishes: patterns and processes. Biol J Linn Soc 82: 431-442.

Conant GC, Wolfe KH. 2008. Turning a hobby into a job: How duplicated genes find new functions. Nat Rev Genet 9: 938-950.

Coppe A, Pujolar JM, Maes GE, Larsen PF, Hansen MM, Bernatchez L, Zane L, Bortoluzzi S. 2010. Sequencing, de novo annotation and analysis of the first Anguilla anguilla transcriptome: EeelBase opens new perspectives for the study of the critically endangered European eel. BMC Genomics 11.

Corriveau RA, Huh GS, Shatz CJ. 1998. Regulation of class I MHC gene expression in the developing and mature CNS by neural activity. Neuron 21: 505-520.

Cottrill PB, Davies WL, Semo M, Bowmaker JK, Hunt DM, Jeffery G. 2009. 
Developmental dynamics of cone photoreceptors in the eel. BMC Dev Biol 9: 1-9.

Crim LW, Evans DM. 1983. Influence of testosterone and/or luteinizing hormone releasing hormone analogue on precocious sexual development in the juvenile rainbow trout. Biol Reprod 29: 137-142.

Crusoe MR, Alameldin HF, Awad S, Boucher E, Caldwell A, Cartwright R, Charbonneau A, Constantinides B, Edvenson G, Fay S, Fenton J, Fenzl T, Fish J, Garcia-Gutierrez L, Garland P, Gluck J, González I, Guermond S, Guo J, Gupta A, Herr JR, Howe A, Hyer A, Härpfer A, Irber L, Kidd R, Lin D, Lippi J, Mansour T, McA'Nulty P, McDonald E, Mizzi J, Murray KD, Nahum JR, Nanlohy K, Nederbragt AJ, Ortiz-Zuazaga H, Ory J, Pell J, Pepe-Ranney C, Russ ZN, Schwarz E, Scott C, Seaman J, Sievert S, Simpson J, Skennerton CT, Spencer J, Srinivasan R, Standage D, Stapleton JA, SteinmanSR, Stein J, Taylor B, Trimble W, Wiencko HL, Wright M, Wyss B, Zhang Q, zyme E, Brown T. 2015. The Khmer software package: enabling efficient nucleotide sequence analysis. F1000 Res 4.

Cyr DG, Eales JG. 1996. Interrelationships between thyroidal and reproductive endocrine systems in fish. Rev Fish Biol Fish 6: 165-200.

da Silva FFG, Støttrup JG, Kjørsvik E, Tveiten H, Tomkiewicz J. 2016. Interactive effects of dietary composition and hormonal treatment on reproductive development of cultured female European eel, Anguilla anguilla. Anim Reprod Sci 171: 17-26.

Darwin C. 1859. On the origin of the species. Savings Dev 19: 386.

Davey AJH, Jellyman DJ. 2005. Sex Determination in freshwater eels and management options for manipulation of sex. Rev Fish Biol Fish 15: 37-52.

David L, Blum S, Feldman MW, Lavi U, Hillel J. 2003. Recent duplication of the common carp (Cyprinus carpio L.) genome as revealed by analyses of microsatellite loci. Mol Biol Evol 20: 1425-1434.

Davie A, Porter MJ, Bromage NR, Migaud H. 2007. The role of seasonally altering photoperiod in regulating physiology in Atlantic cod (Gadus morhua). Part II. Somatic growth. Can J Fish Aquat Sci 64: 98-112.

Dehal P, Boore JL. 2005. Two rounds of whole genome duplication in the ancestral vertebrate. PLOS Biol 3: 1700-1708.

Dekker W. 2000. The fractal geometry of the European eel stock. Ices J Mar Sci 
57: 109-121.

Dekker W. 2004. Status of the European eel stock and fisheries. In Eel Biology, pp. 237-254.

Dekker W, Beaulaton L. 2015. Climbing back up what slippery slope? Dynamics of the European eel stock and its management in historical perspective. ICES J Mar Sci 73: 5-13.

Del Pozo JC, Ramirez-Parra E. 2015. Whole genome duplications in plants: An overview from Arabidopsis. J Exp Bot 66: 6991-7003.

Demain AL, Vaishnav P. 2009. Production of recombinant proteins by microbes and higher organisms. Biotechnol Adv J 27: 297-306.

Di Biase A, Casalini A, Emmanuele P, Mandelli M, Lokman PM, Mordenti O. 2016. Controlled reproduction in Anguilla anguilla (L.): comparison between spontaneous spawning and stripping-insemination approaches. Aquac Res 47: 3052-3060.

Di Biase A, Lokman PM, Govoni N, Casalini A, Emmanuele P, Parmeggiani A, Mordenti O. 2017. Co-treatment with androgens during artificial induction of maturation in female eel, Anguilla anguilla: Effects on egg production and early development. Aquaculture 479: 508-515.

Dirks RP, Burgerhout E, Brittijn SA, de Wijze DL, Ozupek H, Tuinhof-Koelma N, Minegishi Y, Jong-Raadsen SA, Spaink HP, van den Thillart GEEJM. 2014. Identification of molecular markers in pectoral fin to predict artificial maturation of female European eels (Anguilla anguilla). Gen Comp Endocrinol 204: 267-276.

Dufour S, Fontaine M. 1985. La migration de reproduction de l'anguille européenne (Anguilla anguilla L.): un rôle probable de la pression hydrostatique dans la stimulation de fonction gonadotrope. B Soc Zool Fr 110: 291-299.

Dufour S, Lopez E, Le Menn F, Le Belle N, Baloche S, Fontaine AY. 1988. Stimulation of gonadotropin release and of ovarian development, by the administration of a gonadoliberin agonist and of dopamine antagonists, in female silver eel pretreated with estradiol. Gen Comp Endocrinol 70: 2030.

Dufour S, Weltzien F, Sebert M-E, Le Belle N, Vidal B, Vernier P, Pasqualini C. 2005. Dopaminergic inhibition of reproduction in teleost fishes: 
ecophysiological and evolutionary implications. Ann N Y Acad Sci 1040: 921.

Dufour S, Sebert M, Weltzien F, Rousseau K. 2010. Neuroendocrine control by dopamine of teleost. J Fish Biol 76: 129-160.

Duncan NJ, Sonesson AK, Chavanne H. 2013. Principles of finfish broodstock management in aquaculture: Control of reproduction and genetic improvement. Woodhead Publishing Limited.

Durif CMF, Dufour S, Elie P. 2005. The silvering process of Anguilla anguilla: a new classification from the yellow resident to the silver migrating stage. $J$ Fish Biol 2-2.

Durif CMF, Dufour S, Elie P. 2006. Impact of silvering stage, age, body size and condition on reproductive potential of the European eel. Mar Ecol Prog Ser 327: 171-181.

Echelard Y, Epstein DJ, Mcmahon JA, Mcmahon AP. 1993. Sonic hedgehog, a member of a family of putative signaling molecules, is implicated in the regulation of CNS polarity. Cell 75: 1417-1430.

Edger PP, McKain MR, Bird KA, VanBuren R. 2018. Subgenome assignment in allopolyploids: challenges and future directions. Curr Opin Plant Biol 42: 76-80.

Elder P the. 1855. The natural history. Taylor and Francis, London.

F.G. da Silva F, Jacobsen C, Kjørsvik E, G. Støttrup J, Tomkiewicz J. 2018. Oocyte and egg quality indicators in European eel: Lipid droplet coalescence and fatty acid composition. Aquaculture 496: 30-38.

Falcón J, Migaud H, Muñoz-Cueto JA, Carrillo M. 2010. Current knowledge on the melatonin system in teleost fish. Gen Comp Endocrinol 165: 469-482.

Fellous A, Favrel P, Guo X, Riviere G. 2014. The Jumonji gene family in Crassostrea gigas suggests evolutionary conservation of Jmj-C histone demethylases orthologues in the oyster gametogenesis and development. Gene 538: 164-175.

Fellous A, Favrel P, Riviere G. 2015. Temperature influences histone methylation and mRNA expression of the Jmj-C histone-demethylase orthologues during the early development of the oyster Crassostrea gigas. Mar Genomics 19: 23-30. 
Finn RD, Clements J, Eddy SR. 2011. HMMER web server: Interactive sequence similarity searching. Nucleic Acids Res 39: 29-37.

Fodor BD, Kubicek S, Yonezawa M, O'Sullivan RJ, Sengupta R, Perez-Burgos L, Opravil S, Mechtler K, Schotta G, Jenuwein T. 2006. Jmjd2b antagonizes $\mathrm{H} 3 \mathrm{~K} 9$ trimethylation at pericentric heterochromatin in mammalian cells. Genes Dev 20: 1557-1562.

Fontaine M. 1936. Sur la maturation complète des organes génitaux de l'anguille mâle et l'émission spontanée de ses produits sexuels. 202: 1312-1315.

Fontaine M, Bertrand E, Lopez E, Callanmand O. 1964. Sur la maturation des organes génitaux de l'anguille femelle (Anguilla anguilla L.) et l'émission spontanée des oeufs en aquarium. CR Acad Sci 259: 2907-2910.

Fostier A, Jalabert B, Billard R, Breton B, Zohar Y. 1983. The Gonadal Steroids.

Frantzen M, Arnesen AM, Damsgård B, Tveiten H, Johnsen HK. 2004. Effects of photoperiod on sex steroids and gonad maturation in Arctic charr. Aquaculture 240: 561-574.

Fraser EJ, Bosma PT, Trudeau VL, Docherty K. 2002. The effect of water temperature on the GABAergic and reproductive systems in female and male goldfish (Carassius auratus). Gen Comp Endocrinol 125: 163-175.

Freeling M. 2009. Bias in plant gene content following different sorts of duplication: tandem, or by transposition. Annu Rev Plant Biol 60: 433-453.

Gaeta RT, Chris Pires J. 2010. Homoeologous recombination in allopolyploids: The polyploid ratchet. New Phytol 186: 18-28.

Gallardo MH, Kausel G, Jiménez A, Bacquet C, González C, Figueroa J, Köhler R, Ojeda N. 2004. Whole-genome duplications in South American desert rodents (Octodontidae). 82: 443-451.

Gallego V, Mazzeo I, Vílchez MC, Peñaranda DS, Carneiro PCF, Pérez L, Asturiano JF. 2012. Study of the effects of thermal regime and alternative hormonal treatments on the reproductive performance of European eel males (Anguilla anguilla) during induced sexual maturation. Aquaculture 354355: 7-16.

Gallego V, Carneiro PCF, Mazzeo I, Vílchez MC, Peñaranda DS, Soler C, Pérez L, Asturiano JF. 2013. Standardization of European eel (Anguilla anguilla) sperm motility evaluation by CASA software. Theriogenology 79: 1034- 
1040.

Gallego V, Pérez L, Asturiano JF, Yoshida M. 2014a. Sperm motility parameters and spermatozoa morphometric characterization in marine species: $A$ study of swimmer and sessile species. Theriogenology 82: 668-676.

Gallego V, Vílchez MC, Peñaranda DS, Pérez L, Herráez MP, Asturiano JF, Martínez-Pastor F. 2014b. Subpopulation pattern of eel spermatozoa is affected by post-activation time, hormonal treatment and the thermal regimen. Reprod Fertil Dev: A-O

Ganem NJ, Godinho SA, Pellman D. 2009. A mechanism linking extra centrosomes to chromosomal instability. Nature 460: 278-282.

García-López Á, Bogerd J, Granneman JCM, Van Dijk W, Trant JM, Taranger GL, Schulz RW. 2009. Leydig cells express follicle-stimulating hormone receptors in African catfish. Endocrinology 150: 357-365.

García-López Á, De Jonge H, Nóbrega RH, De Waal PP, Van Dijk W, Hemrika W, Taranger GL, Bogerd J, Schulz RW. 2010. Studies in zebrafish reveal unusual cellular expression patterns of gonadotropin receptor messenger ribonucleic acids in the testis and unexpected functional differentiation of the gonadotropins. Endocrinology 151: 2349-2360.

Geffroy B, Fostier A, Guiguen Y, Bardonnet A. 2012. Unusual Cases of adult intersexuality in the European eel Anguilla anguilla. Sex Dev 6: 316-319.

Geffroy B, Bardonnet A. 2016. Sex differentiation and sex determination in eels: Consequences for management. Fish Fish 17: 375-398.

Gen K, Okuzawa K, Senthilkumaran B, Tanaka H, Moriyama S, Kagawa H. 2000. Unique expression of gonadotropin-I and -II subunit genes in male and female red seabream (Pagrus major) during sexual maturation. Biol Reprod 63: 308-19.

Glasauer SMK, Neuhauss SCF. 2014. Whole-genome duplication in teleost fishes and its evolutionary consequences. Mol Genet Genomics 289: 1045-1060.

Gomez JM, Weil C, Ollitrault M, Le Bail PY, Breton B, Le Gac F. 1999. Growth hormone $(\mathrm{GH})$ and gonadotropin subunit gene expression and pituitary and plasma changes during spermatogenesis and oogenesis in rainbow trout (Oncorhynchus mykiss). Gen Comp Endocrinol 113: 413-428.

Gordon JL, Byrne KP, Wolfe KH. 2011. Mechanisms of chromosome number 
evolution in yeast. PLoS Genet 7: e1002190.

Grassi GB. 1896. The reproduction and metamorphosis of the common eel (Anguilla vulgaris). Proc R Soc London 60: 260-271.

Gu X, Wang Y, Gu J. 2002. Age distribution of human gene families shows significant roles of both large- and small-scale duplications in vertebrate evolution. Nat Genet 31: 205-209.

Hafeez M, Shabbir M, Altaf F, Abbasi AA. 2016. Phylogenomic analysis reveals ancient segmental duplications in the human genome. Mol Phylogenet Evol 94: 95-100.

Hagihara S, Aoyama J, Limbong D, Tsukamoto K. 2012. Morphological and physiological changes of female tropical eels, Anguilla celebesensis and Anguilla marmorata, in relation to downstream migration. J Fish Biol 81: 408-426.

Hahn MW. 2009. Distinguishing among evolutionary models for the maintenance of gene duplicates. J Hered 100: 605-617.

Hansen T, Karlsen $\varnothing$, Taranger GL, Hemre GI, Holm JC, Kjesbu OS. 2001. Growth, gonadal development and spawning time of Atlantic cod (Gadus morhua) reared under different photoperiods. Aquaculture 203: 51-67.

Hardie DC, Hebert PD. 2004. Genome-size evolution in fishes. Can J Fish Aquat Sci 61: 1636-1646.

Hayakawa Y, Morita T, Kitamura W, Kanda S, Banba A, Nagaya H, Hotta K, Sohn YC, Yoshizaki G, Kobayashi M. 2008a. Biological activities of single-chain goldfish follicle-stimulating hormone and luteinizing hormone. Aquaculture 274: 408-415.

Hayakawa Y, Nagaya H, Kaki H, Hotta K, Kobayashi M. 2008b. Induction of spermatogenesis in Japanese eel by recombinant goldfish gonadotropins. Fish Sci 75: 137-144.

He Z, Wang L, Harper AL, Havlickova L, Pradhan AK, Parkin IAP, Bancroft I. 2017. Extensive homoeologous genome exchanges in allopolyploid crops revealed by mRNAseq-based visualization. Plant Biotechnol J 15: 594-604.

Henkel C V., Burgerhout E, de Wijze DL, Dirks RP, Minegishi Y, Jansen HJ, Spaink HP, Dufour S, Weltzien F-A, Tsukamoto K, GEEJM van den Thillart. 2012. Primitive duplicate Hox clusters in the European eel's genome. PLoS One 7: 
e32231.

Herranz-Jusdado JG, Rozenfeld C, Morini M, Pérez L, Asturiano JF, Gallego V. 2019. Recombinant vs purified mammal gonadotropins as maturation hormonal treatments of European eel males. Aquaculture 501: 527-536.

Hinegardner R, Rosen DE. 1972. Cellular DNA content and the evolution of teleostean fishes. Am Nat 106: 621-644.

Hoegg S, Brinkmann H, Taylor JS, Meyer A. 2004. Phylogenetic timing of the fishspecific genome duplication correlates with the diversification of teleost fish. J Mol Evol 59: 190-203.

Hokanson KEF. 1977. Temperature requirements of some percids and adaptations to the seasonal temperature cycle. J Fish Res Board Canada 34: 1524-1550.

Holland MCH, Gothilf Y, Meiri I, King JA, Okuzawa K, Elizur A, Zohar Y. 1998. Levels of the native forms of $\mathrm{GnRH}$ in the pituitary of the gilthead seabream. Gen Comp Endocrinol 405: 394-405.

Horváth L, Székely C, Boczonádi Z, Mészáros E, Bercsényi M, Urbányi $B$, Müller T. 2011. Induced oogenesis of the European eel (Anguilla anguilla L.) in freshwater condition. Acta Biol Hung 62: 485-488.

Howe K, Clark MD, Torroja CF, Torrance J, Berthelot C, Muffato M, Collins JEJE, Humphray S, McLaren K, Matthews L, McLaren S, Sealy I, Caccamo M, Churcher C, Scott C, Barrett JC, Koch R, Rauch GJ, White S, Chow W, Kilian B, Quintais LT, Guerra-Assunção JA, Zhou Y, Gu Y, Yen J, Vogel JH, Eyre T, Redmond S, Banerjee R, Chi J, Fu B, Langley E, Maguire SF, Laird GK, Lloyd $D$, Kenyon E, Donaldson S, Sehra H, Almeida-King J, Loveland J, Trevanion J, Jones M, Quail M, Willey D, Hunt A, Burton J, Sims S, McLay K, Plumb B, Davis J, Clee C, Oliver K, Clark R, Riddle C, Elliot D, Threadgold G, Harden G, Ware D, Begum S, Mortimore B, Kerry B, Heath P, Phillimore B, Tracey A, Corby N, Dunn N, Johnson C, Wood J, Clark S, Pelan S, Griffiths G, Smith M, Glithero R, Howden P, Barker N, Lloyd C, Stevens C, Harley J, Holt K, Panagiotidis G, Lovell J, Beasley H, Henderson C, Gordon D, Auger K, Wright D, Collins J, Raisen C, Dyer L, Leung K, Robertson L, Ambridge K, Leongamornlert D, McGuire S, Gilderthorp R, Griffiths C, Manthravadi D, Nichol S, Barker G, Whitehead S, Kay M, Brown J, Murnane C, Gray E, Humphries M, Sycamore N, Barker D, Saunders D, Wallis J, Babbage A, Hammond S, Mashreghi-Mohammadi M, Barr L, Martin S, Wray $P$, Ellington A, Matthews N, Ellwood M, Woodmansey R, Clark G, Cooper JD, Tromans A, Grafham D, Skuce C, Pandian R, Andrews R, Harrison E, Kimberley A, 
Garnett A, Fosker N, Hall R, Garner P, Kelly D, Bird C, Palmer S, Gehring I, Berger A, Dooley CM, Ersan-Ürün Z, Eser C, Geiger H, Geisler M, Karotki L, Kirn A, Konantz J, Konantz M, Oberländer M, Rudolph-Geiger S, Teucke M, Lanz C, Raddatz G, Osoegawa K, Zhu B, Rapp A, Widaa S, Langford C, Yang F, Schuster SC, Carter NP, Harrow J, Ning Z, Herrero J, Searle SMJ, Enright A, Geisler R, Plasterk RHA, Lee C, Westerfield M, de Jong PJ, Zon LI, Postlethwait JH, Nüsslein-Volhard C, Hubbard TJP, Crollius HJ, Rogers J, and Stemple DL. 2013. The zebrafish reference genome sequence and its relationship to the human genome. Nature 496: 498-503.

Hsu HY, Chen SH, Cha YR, Tsukamoto K, Lin CY, Han YS. 2015. De novo assembly of the whole transcriptome of the wild embryo, preleptocephalus, leptocephalus, and glass eel of Anguilla japonica and deciphering the digestive and absorptive capacities during early development. PLoS One 10: 1-18.

Huang YS, Schmitz M, Le Belle N, Chang CF, Quérat B, Dufour S. 1997. Androgens stimulate gonadotropin-II $\beta$-subunit in eel pituitary cells in vitro. Mol Cell Endocrinol 131: 157-166.

Huang H, Zhang Y, Huang WR, Li SS, Zhu P, Liu Y, Yin SW, Liu XC, Lin HR. 2009. Molecular characterization of marbled eel (Anguilla marmorata) gonadotropin subunits and their mRNA expression profiles during artificially induced gonadal development. Gen Comp Endocrinol 162: 192202.

Huerta-Cepas J, Szklarczyk D, Forslund K, Cook H, Heller D, Walter MC, Rattei T, Mende DR, Sunagawa S, Kuhn M, Jensen L, von Mering J, and Bork P. 2016. eggNOG 4.5: a hierarchical orthology framework with improved functional annotations for eukaryotic, prokaryotic and viral sequences. Nucleic Acids Res 44: 286-293.

Huertas M, Scott AP, Hubbard PC, Canário AVM, Cerdà J. 2006. Sexually mature European eels (Anguilla anguilla L.) stimulate gonadal development of neighbouring males: possible involvement of chemical communication. Gen Comp Endocrinol 147: 304-13.

Hufton AL, Panopoulou G. 2009. Polyploidy and genome restructuring: a variety of outcomes. Curr Opin Genet Dev 19: 600-606.

Hughes T, Liberles REDA. 2008. Whole-genome duplications in the ancestral vertebrate are detectable in the distribution of gene family sizes of tetrapod species. J Mol Evol: 343-357. 
Huising MO, Stet RJM, Savelkoul HFJ, Verburg-van Kemenade BML. 2004. The molecular evolution of the interleukin-1 family of cytokines; IL-18 in teleost fish. Dev Comp Immunol 28: 395-413.

Haas BJ, Papanicolaou A, Yassour M, Grabherr M, Blood PD, Bowden J, Couger MB, Eccles D, Li B, Lieber M, MacManes MD, Ott M, Orvis J, Pochet N, Strozzi F, Weeks N, Westerman R, William T, Dewey CN, Henschel R, Le Duc $\mathrm{RD}$, Friedman N, and Regev A. 2013. De novo transcript sequence reconstruction from RNA-seq using the Trinity platform for reference generation and analysis. Nat Protoc 8: 1494-1512.

ICES. 1999. Report of the ICES advisory committee on fisheries management. ICES coop res report, Int Counc Explor Sea 393-405.

ICES. 2018. Report of the working group on eels (WGEEL) 2018. Copenhagen.

Ijiri S, Tsukamoto K, Chow S, Kurogi H, Adachi S, Tanaka H. 2011. Controlled reproduction in the Japanese eel (Anguilla japonica), past and present. Aquac Eur 36: 13-17.

Inoue JG, Miya M, Miller MJ, Sado T, Hanel R, Hatooka K, Aoyama J, Minegishi Y, Nishida M, Tsukamoto K. 2010. Deep-ocean origin of the freshwater eels. Biol Lett 6: 363-366.

Inoue J, Sato Y, Sinclair R, Tsukamoto K, Nishida M. 2015. Rapid genome reshaping by multiple-gene loss after whole-genome duplication in teleost fish suggested by mathematical modeling. Proc Natl Acad Sci 112: 1491814923.

Jackson K, Goldberg D, Ofir M, Abraham M, Degani G. 1999. Blue gourami (Trichogaster trichopterus) gonadotropic b subunits (I and II) cDNA sequences and expression during oogenesis. J Mol Endocrinol 23: 177-187.

Jacoby, D, and Gollock M. 2014. Anguilla anguilla. The IUCN Red List of Threatened Species. IUCN.

Jaillon O, Aury J, Brunet F, Petit J-L, Stange-Thomann N, Mauceli E, Bouneau L, Fischer C, Ozouf-Costaz C, Bernot A, Nicaud S, Jaffe D, Fisher S, Lutfalla G, Dossat C, Segurens B, Dasilva C, Salanoubat M, Levy M, Boudet N, Castellano S, Anthouard V, Jubin C, Castelli V, Katinka M, Vacherie B, Biemont C, Skalli Z, Cattolico L, Poulain J, de Berardinis V, Cruaud C, Duprat S, Brottier P, Coutanceau JP, Gouzy J, Parra G, Lardier G, Chapple C, McKernan KJ, McEwan P, Bosak S, Kellis M, Volff JN, Guigo R, Zody MC, Mesirov J, Lindblad-Toh K, Birren B, Nusbaum C, Kahn D, Robinson-Rechavi 
M, Laudet V, Schachter V, Quétier F, Saurin W, Scarpelli C, Wincker P, Lander ES, Weissenbach J, and Crollius HR. 2004. Genome duplication in the teleost fish Tetraodon nigroviridis reveals the early vertebrate protokaryotype. Nature 431: 946-957.

Jeng S, Dufour S, Chang CF. 2005. Differential expression of neural and gonadal aromatase enzymatic activities in relation to gonadal development in Japanese eel , Anguilla japonica. 812: 802-812.

Jeng SR, Yueh WS, Chen GR, Lee YH, Dufour S, Chang CF. 2007. Differential expression and regulation of gonadotropins and their receptors in the Japanese eel, Anguilla japonica. Gen Comp Endocrinol 154: 161-173.

Jenuwein T, Allis CD. 2001. Translating the histone code. Science 293: 10741080.

Jiao Y, Wickett NJ, Ayyampalayam S, Chanderbali AS, Landherr L, Ralph PE, Tomsho LP, Hu Y, Liang H, Soltis PS, et al. 2011. Ancestral polyploidy in seed plants and angiosperms. Nature 473: 97-100.

Johnson GD, Ida H, Sakaue J, Sado T, Asahida T, and Miya M. 2011. A 'living fossil' eel (Anguilliformes: Protanguillidae, fam. nov.) from an undersea cave in Palau. Proc R Soc Lond: 1-10

Johnsen $H$, Tveiten $H$, Torgersen JS, Andersen $\varnothing$. 2013. Divergent and sexdimorphic expression of the paralogs of the Sox9-Amh-Cyp19a1 regulatory cascade in developing and adult Atlantic cod (Gadus morhua L.). Mol Reprod Dev 80: 358-370.

Jones MA, Covington MF, DiTacchio L, Vollmers C, Panda S, Harmer SL. 2010. Jumonji domain protein JMJD5 functions in both the plant and human circadian systems. Proc Natl Acad Sci 107: 21623-21628.

Juchno D, Lackowska $\mathbb{E} B$ B. 2010. DNA content of hepatocyte and erythrocyte nuclei of the spined loach (Cobitis taenia L .) and its polyploid forms. 523529.

Kagawa H, linuma N, Tanaka H, Ohta H, Okuzawa K. 1998. Effects of rearing period in seawater on induced maturation in female Japanese eel Anguilla japonica. Fish Sci 64: 77-82.

Kagawa H. 2003. Artifcial induction of oocyte maturation and ovulation. In: Aida, K., Tsukamoto, K., Yamauchi, K. (Eds.), Eel Biology. pp. 401-414. 
Kagawa H, Tanaka H, Ohta H, Unuma T, Nomura K. 2005. The first success of glass eel production in the world: basic biology on fish reproduction advances new applied technology in aquaculture. Fish Physiol Biochem 31: 193-9.

Kai W, Kikuchi K, Tohari S, Chew AK, Tay A, Fujiwara A, Hosoya S, Suetake H, Naruse K, Brenner S, Suzuki Y, and Venkatesh B. 2011. Integration of the genetic map and genome assembly of evolution in teleosts and mammals. Genome Biol Evol 3: 424-442.

Kajimura S, Yoshiura Y, Suzuki M, Utoh T, Horie N, Oka H, Aida K. 2001a. Changes in the levels of mRNA coding for gonadotropin $I \beta$ and $\| \beta$ subunits during vitellogenesis in the common Japanese conger Conger myriaster. Fish Sci 67: 1053-1062.

Kajimura S, Yoshiura Y, Suzuki M, Aida K. 2001b. cDNA cloning of two gonadotropin $\beta$ subunits (GTH-I $\beta$ and $-I I \beta)$ and their expression profiles during gametogenesis in the Japanese flounder (Paralichthys olivaceus). Gen Comp Endocrinol 122: 117-129.

Kamei H, Oshira T, Yoshiura Y, Uchida N, Aida K. 2003. Androgen secretion activity of recombinant follicle-stimulating hormone of Japanese eel, Anguilla japonica in immature and maturing eel testes. Fish Physiol Biochem 28: 97-98.

Kamei H, Kawazoe I, Kaneko T, Aida K. 2005. Purification of follicle-stimulating hormone from immature Japanese eel, Anguilla japonica, and its biochemical properties and steroidogenic activities. Gen Comp Endocrinol 143: 257-266.

Kamei H, Kaneko T, Aida K. 2006a. In vivo gonadotropic effects of recombinant Japanese eel follicle-stimulating hormone. Aquaculture 261: 771-775.

Kamei H, Kaneko T, Aida K. 2006b. Steroidogenic activities of follicle-stimulating hormone in the ovary of Japanese eel, Anguilla japonica. Gen Comp Endocrinol 146: 83-90.

Kanehisa M, Sato Y, Morishima K. 2016. BlastKOALA and GhostKOALA: KEGG tools for functional characterization of genome and metagenome sequences. J Mol Biol 428: 726-731.

Kassahn KS, Dang VT, Wilkins SJ, Kassahn KS, Dang VT, Wilkins SJ, Perkins AC, Ragan MA. 2009. Evolution of gene function and regulatory control after whole-genome duplication: Comparative analyses in vertebrates. Genome 
Res 19: 1404-1418.

Kazeto Y, ljiri S, Adachi S, Yamauchi K. 2006. Cloning and characterization of a cDNA encoding cholesterol side-chain cleavage cytochrome P450 (CYP11A1): Tissue-distribution and changes in the transcript abundance in ovarian tissue of Japanese eel, Anguilla japonica, during artificially induced sexual development. J Steroid Biochem Mol Biol 99: 121-128.

Kazeto Y, Kohara M, Miura T, Miura C, Yamaguchi S, Trant JM, Adachi S, Yamauchi K. 2008. Japanese eel follicle-stimulating hormone (Fsh) and luteinizing hormone (Lh): production of biologically active recombinant Fsh and Lh by drosophila S2 cells and their differential actions on the reproductive biology. Biol Reprod 79: 938-946.

Khan IA, Lopez E, Tey JL. 1987. Induction of spermatogenesis and spermiation by a single injection of human chorionic gonadotropin in intact and hypophysectomized immature European eel (Anguilla anguilla L .). Gen Comp Endocrinol 91-103.

Kim T, Lawson MA. 2015. GnRH regulates gonadotropin gene expression through $\mathrm{NADPH} /$ dual oxidase-derived reactive oxygen species. Endocrinology 156: 2185-2199.

Klose RJ, Yamane K, Bae Y, Zhang D, Erdjument-Bromage H, Tempst P, Wong J, Zhang Y. 2006. The transcriptional repressor JHDM3A demethylates trimethyl histone H3 lysine 9 and lysine 36. Nature 442: 312-316.

Kobayashi M, Kato Y, Yoshiura Y, Aida K. 1997. Molecular cloning of cDNA encoding two types of pituitary gonadotropin $\alpha$ subunit from the goldfish, Carassius auratus. Gen Comp Endocrinol 105: 372-378.

Kobayashi M, Morita T, Ikeguchi K, Yoshizaki G, Suzuki T, Watabe S. 2003. Production of recombinant goldfish gonadotropins by baculovirus in silkworm larvae. Fish Physiol Biochem 28: 469-471.

Kobayashi M, Hayakawa Y, Park W, Banba A, Yoshizaki G, Kumamaru K, Kagawa H, Kaki H, Nagaya H, Chang Y. 2010. Production of recombinant Japanese eel gonadotropins by baculovirus in silkworm larvae. Gen Comp Endocrinol 167: 379-386.

Komal P, Gudavicius G, Nelson CJ, Nashmi R. 2014. T-cell receptor activation decreases excitability of cortical interneurons by inhibiting 7 nicotinic receptors. J Neurosci 34: 22-35. 
Komal P, Nashmi R. 2015. T-cell receptors modify neuronal function in the central nervous system. Biochem Pharmacol 97: 512-517.

Komatsu T, Bhandari RK, Kobayashi Y, Nakamura S, Nakamura M. 2006. GnRHaaccelerated spermatogenesis in the testes of underyearling golden rabbitfish, Siganus guttatus (Bloch). Aquaculture 257: 558-565.

Korf H, Gall C Von, Stehle J,. 2003. The circadian system and melatonin: lessons from rats and mice. 20: 697-710.

Kroft TL, Patterson J, Yoon JW, Doglio L, Walterhouse DO, lannaccone PM, Goldberg E. 2001. GLI1 localization in the germinal epithelial cells alternates between cytoplasm and nucleus: upregulation in transgenic mice blocks spermatogenesis. Biol Reprod 1671: 1663-1671.

Kucharczyk D, Kujawa R, Luczynski M, Glogowski J, Babiak I, Wyszomirska E. 1997. Induced spawning in bream, Abramis brama (L.), using carp and bream pituitary extract and hCG. Aquac Res 28: 139-144.

Kucharczyk D, Czarkowski T, Nowosad J, Targońska K, Kupren K, Wyszomirska E, Kujawa R, Horváth L, Müller T. 2016. Influence of temperature on successful European eel female maturation under controlled conditions. Cut Tool Eng 28: 477-482.

Kumakura N, Sakai K, Takashima F. 2003. Reproductive cycle and human chorionic gonadotropin-induced ovulation in hatchery reared Japanese catfish Silurus asotus. Fish Sci 69: 495-504.

Kwok H-F, So W-K, Wang Y, Ge W. 2005. Zebrafish Gonadotropins and their receptors: I. Cloning and characterization of zebrafish follicle-stimulating hormone and luteinizing hormone leceptors - evidence for their distinct functions in follicle development. Biol Reprod 72: 1370-1381.

Lafont AG, Rousseau K, Tomkiewicz J, Dufour S. 2016. Three nuclear and two membrane estrogen receptors in basal teleosts, Anguilla sp.: Identification, evolutionary history and differential expression regulation. Gen Comp Endocrinol 235: 177-191.

Lahiri K, Vallone D, Gondi SB, Santoriello C, Dickmeis T, Foulkes NS. 2005. Temperature regulates transcription in the zebrafish circadian clock. PLoS Biol 3: 2005-2016.

Lamatsch DK, Steinlein C, Schmid M, Schartl M. 2000. Noninvasive determination of genome size and ploidy level in fishes by flow cytometry: 
Detection of triploid Poecilia formosa. 95: 91-95.

Lartillot N, Lepage T, Blanquart S. 2009. PhyloBayes 3: A Bayesian software package for phylogenetic reconstruction and molecular dating. Bioinformatics 25: 2286-2288.

Le Gac F, Blaise O, Fostier A, Le Bail PY, Loir M, Mourot B, Weil C. 1993. Growth hormone (GH) and reproduction: a review. Fish Physiol Biochem 11: 219232.

Leal MC, Cardoso ER, Nóbrega RH, Batlouni SR, Bogerd J, França LR, Schulz RW. 2009. Histological and stereological evaluation of Zebrafish (Danio rerio) spermatogenesis with an emphasis on spermatogonial generations. Biol Reprod 81: 177-187.

Lecomte-Finiger R. 1994. The early life of the European eel. Nature 370: 424.

Lee H, Brott BK, Kirkby LA, Adelson JD, Cheng S, Feller MB, Datwani A, Shatz CJ. 2014. Synapse elimination and learning rules co-regulated by MHC class $i$ H2-Db. Nature 509: 195-200.

Leggatt RA, Iwama GK. 2003. Occurrence of polyploidy in the fishes. Rev Fish Biol Fish 13: 237-246.

Lennox RJ, $\varnothing$ kland F, Mitamura H, Cooke SJ, Thorstad EB. 2018. European eel Anguilla anguilla compromise speed for safety in the early marine spawning migration. ICES J Mar Sci.

Lethimonier C, Madigou T, Muñoz-Cueto JA, Lareyre JJ, Kah O. 2004. Evolutionary aspects of GnRHs, GnRH neuronal systems and $\mathrm{GnRH}$ receptors in teleost fish. Gen Comp Endocrinol 135: 1-16.

Lettieri A, Oleari R, Gimmelli J, André V, Cariboni A. 2016. The role of semaphorin signaling in the etiology of hypogonadotropic hypogonadism. Minerva Endocrinol 41: 266-278.

Levavi-Sivan B, Bogerd J, Mañanós EL, Gómez A, Lareyre JJ. 2010. Perspectives on fish gonadotropins and their receptors. Gen Comp Endocrinol 165: 412437.

Li L, Stoeckert CJJ, Roos DS. 2003. OrthoMCL: identification of ortholog groups for eukaryotic genomes. Genome Res 13: 2178-2189.

Li H, Durbin R. 2010. Fast and accurate long-read alignment with Burrows- 
Wheeler transform. Bioinformatics 26: 589-595.

Li B, Dewey CN. 2011. RSEM: accurate transcript quantification from RNA-Seq data with or without a reference genome. BMC Bioinformatics 12: 323.

Lien S, Koop BF, Sandve SR, Miller JR, Matthew P, Leong JS, Minkley DR, Zimin A, Grammes F, Grove H, Gjuvsland A, Walenz B, Hermansen RA, von Schalburg K, Rondeau EB, Genova AD, Samy JKA, Vik JO, Vigeland MD, Caler L, Grimholt U, Jentoft S, Våge DI, de Jong P, Moen T, Baranski M, Palti Y, Smith DR, Yorke JA, Nederbragt AJ, Tooming-Klunderud A, Jakobsen KS, Jiang $X$, Fan D, Hu Y, Liberles DA, Vidal R, Iturra P, Jones SJM, Jonassen I, Maass A, Omholt SW, and Davidson WS. 2016. The Atlantic salmon genome provides insights into rediploidization. Nature 533: 200-205.

Lin Y, Bloodgood BL, Hauser JL, Lapan AD, Koon AC, Kim TK, Hu LS, Malik AN, Greenberg ME. 2008. Activity-dependent regulation of inhibitory synapse development by Npas4. Nature 455: 1198-1204.

Linhart O, Peter RE, Rothbard S, Zohar Y, Kvasnička P. 1995. Spermiation of common tench (Tinca tinca L.) stimulated with injection or implantation of $\mathrm{GnRH}$ analogues and injection of carp pituitary extract. Aquaculture 129: 119-121.

Linhart O, Gela D, Rodina M, Kocour M. 2004. Optimization of artificial propagation in European catfish, Silurus glanis L. Aquaculture 235: 619632.

Liu S, Liu Y, Yang X, Tong C, Edwards D, Parkin IAP, Zhao M, Ma J, Yu J, Huang S, Wang X, Wang J, Lu K, Fang Z, Bancroft I, Yang TJ, Hu Q, Wang X, Yue Z, Li $H$, Yang L, Wu J, Zhou Q, Wang W, King GJ, Pires JC, Lu C, Wu Z, Sampath P, Wang Z, Guo H, Pan S, Yang L, Min J, Zhang D, Jin D, Li W, Belcram H, Tu J, Guan M, Qi C, Du D, Li J, Jiang L, Batley J, Sharpe AG, Park BS, Ruperao P, Cheng $F$, Waminal NE, Huang $Y$, Dong C, Wang L, Li J, Hu Z, Zhuang M, Huang Y, Huang J, Shi J, Mei D, Liu J, Lee TH, Wang J, Jin H, Li Z, Li X, Zhang J, Xiao L, Zhou Y, Liu Z, Liu X, Qin R, Tang X, Liu W, Wang Y, Zhang Y, Lee J , Kim HH, Denoeud F, Xu X, Liang X, Hua W, Wang X, Wang J, Chalhoub B, and Paterson AH. 2014. The brassica oleracea genome reveals the asymmetrical evolution of polyploid genomes. Nat Commun 5: 1-11.

Llorente B, Malpertuy A, Neuviéglise C, De Montigny J, Aigle M, Artiguenave F, Blandin G, Bolotin-Fukuhara M, Bon E, Brottier $P$, Casaregola S, Durrens $P$, Gaillardin C, Läpingle A, Ozier-Kalogëropoulos O, Potier S, Saurin W, Tekaia F, Toiano-Nioche C, Wësolowski-Louvel W, Wincker P, Weissenbach J, SoucietcJL, Dujon B. 2000. Genomic exploration of the hemiascomycetousy 
yeasts: 18. comparative analysis of chromosome maps and synteny with Saccharomyces cerevisiae. FEBS Lett 487: 101-112.

Lokman PM, Vermeulen GJ, Lambert JGD, Young G. 1998. Gonad histology and plasma steroid profiles in wild New Zealand freshwater eels (Anguilla dieffenbachii and $A$. australis) before and at the onset of the natural spawning migration. I. Females. Fish Physiol Biochem 19: 325-338.

Lokman PM, Young G. 1998. Gonad histology and plasma steroid profiles in wild New Zealand freshwater eels (Anguilla dieffenbachii and A. australis) before and at the onset of the natural spawning migration. II. Males. Fish Physiol Biochem 339-347.

Lokman PM, Wylie MJ, Downes M, Di A, Damsteegt EL. 2015. Artificial induction of maturation in female silver eels, Anguilla australis: The benefits of androgen pre-treatment. Aquaculture 437: 111-119.

Lokman PM, Damsteegt EL, Wallace J, Downes M, Goodwin SL, Facoory LJ, Wylie MJ. 2016. Dose-responses of male silver eels, Anguilla australis, to human chorionic gonadotropin and 11-ketotestosterone in vivo. Aquaculture 463: 97-105.

Lopez-Nieves S, Yang Y, Timoneda A, Wang M, Feng T, Smith SA, Brockington SF, Maeda HA. 2017. Relaxation of tyrosine pathway regulation underlies the evolution of betalain pigmentation in Caryophyllales. New phyto 1: 1-13.

López-Olmeda JF, Sánchez-Vázquez FJ. 2009. Zebrafish temperature selection and synchronization of locomotor activity circadian rhythm to ahemeral cycles of light and temperature. Chronobiol Int 26: 200-218.

Lu J, Peatman E, Tang H, Lewis J, Liu Z. 2012. Profiling of gene duplication patterns of sequenced teleost genomes: evidence for rapid lineage-specific genome expansion mediated by recent tandem duplications. $B M C$ Genomics 13: 1-10.

Lynch M, Conery JS. 2000. The evolutionary fate and consequences of duplicate genes. Science 290: 1151-1155.

Laan M, Richmond H, He C, Campbell RK. 2002. Zebrafish as a model for vertebrate reproduction: Characterization of the first functional zebrafish (Danio rerio) gonadotropin receptor. Gen Comp Endocrinol 125: 349-364.

Mable BK, Leitcha R, Soltis DE, Soltis PS, Leitch IJ, Pires JC. 2004. Why polyploidy is rarer in animals than in plants': myths and mechanisms. Biol J Linn Soc 
Biol J Linn Soc Blackwell Sci 82: 453-466.

MacNamara R, McCarthy TK. 2012. Size-related variation in fecundity of European eel (Anguilla anguilla). ICES J Mar Sci 69: 1333-1337.

Macqueen DJ, Johnston IA, Macqueen DJ. 2014. A well-constrained estimate for the timing of the salmonid whole genome duplication reveals major decoupling from species diversification. Proc $R$ Soc $B$ 281: 1-8.

Mali P, Virtanen I, Parvinen M. 1987. Vimentin expression in spermatogenic and sertoli cells is stage-related in rat Seminiferous epithelium. Andrologia 19: 644-653.

Malpaux B, Migaud M, Tricoire H, Chemineau P. 2001. Biology of mammalian photoperiodism and the critical role of the pineal gland and melatonin. $J$ Biol Rhythms 16: 336-347.

Manabe R, Aoyama J, Watanabe K, Kawai M, Miller MJ, Tsukamoto K. 2011. First observations of the oceanic migration of Japanese eel, from pop-up archival transmitting tags. 437: 229-240.

Mañanós EL, Zanuy S, and Carrillo M. 1997. Photoperiodic manipulations of the reproductive cycle of sea bass (Dicentrarchus labrax) and their effects on gonadal development, and plasma 17 beta-estradiol and vitellogenin levels. Fish Physiol Biochem 16: 211-222.

Mañanós E, Duncan N, Mylonas C. 2009. Reproduction and control of ovulation, spermiation, and spawning in cultured fish. In Methods in reproductive aquaculture: Marine and freshwater species.

Martin J, Daverat F, Pécheyran C, Als TD, Feunteun E, Réveillac E. 2010. An otolith microchemistry study of possible relationships between the origins of leptocephali of European eels in the Sargasso Sea and the continental destinations and relative migration success of glass eels. Ecol Freshw Fish 19: 627-637.

Martin KJ, Holland PWH. 2014. Enigmatic orthology relationships between Hox clusters of the African butterfly fish and other teleosts following ancient whole-genome duplication. 31: 2592-2611.

Masterson J. 1994. Stomatal size in fossil plants: Evidence for polyploidy in majority of angiosperms. Science 264: 421-424.

Masuda Y, Imaizumi H, Oda K, Hashimoto H, Usuki H, Teruya K. 2012. Artificial 
completion of the Japanese eel, Anguilla japonica, life cycle: Challenge to mass production. Bull Fish Res Agency 35: 111-117.

Mateos J, Mañanós E, Martínez-Rodríguez G, Carrillo M, Querat B, Zanuy S. 2003. Molecular characterization of sea bass gonadotropin subunits $(\alpha, \mathrm{FSH} \beta$, and $\mathrm{LH} \beta$ ) and their expression during the reproductive cycle. Gen Comp Endocrinol 133: 216-232.

Maugars G, Dufour S. 2015. Demonstration of the coexistence of duplicated LH receptors in teleosts, and their origin in ancestral actinopterygians. PLOS One 10: e0135184.

Mazón MJ, Zanuy S, Muñoz I, Carrillo M, Gómez A. 2013. Luteinizing hormone plasmid therapy results in long-lasting high circulating $\mathrm{Lh}$ and increased sperm production in European sea bass (Dicentrarchus labrax). Biol Reprod 88: 32.

Mazón MJ, Gómez A, Yilmaz O, Carrillo M, Zanuy S. 2014. Administration of follicle-stimulating hormone in vivo triggers testicular recrudescence of juvenile European sea bass (Dicentrarchus labrax). Biol Reprod 90: 1-10.

Mazzeo I, Peñaranda DS, Gallego V, Baloche S, Nourizadeh-Lillabadi R, Tveiten H, Dufour S, Asturiano JF, Weltzien F-A., Pérez L. 2014. Temperature modulates the progression of vitellogenesis in the European eel. Aquaculture 434: 38-47.

Mcfarland AKC, Sprengel R, Phillips HS, Köhler M, Nikolics K, Segaloff DL, Seeburg PH, Mcfarland KC, Sprengel R, Phillips HS, et al. 1989. Lutropinchoriogonadotropin receptor: an unusual member of the $\mathrm{G}$ proteincoupled receptor family. Science 245: 494-499.

Medina M, Reperant J, Dufour S, Ward R, Belle N Le, Miceli D. 1994. Anatomy and embryolo the distribution of GABA-immunoreactive neurons in the brain of the silver eel (Anguilla anguilla L.). Anat Embryol (Berl) 25-39.

Mes D, Dirks RP, Palstra AP. 2016. Simulated migration under mimicked photothermal conditions enhances sexual maturation of farmed European eel (Anguilla anguilla). Aquaculture 452: 367-372.

Messina A, Ferraris N, Wray S, Cagnoni G, Donohue DE, Casoni F, Kramer PR, Derijck AA, Adolfs Y, Fasolo A, Pasterkamp RJ and GiacobiniP. 2011. Dysregulation of Semaphorin7A/b 1-integrin signaling leads to defective GnRH-1 cell migration, abnormal gonadal development and altered fertility. Hum Mol Genet 20: 4759-4774. 
Migaud H, Fontaine P, Sulistyo I, Kestemont P, Gardeur JN. 2002. Induction of out-of-season spawning in Eurasian perch Perca fluviatilis: Effects of rates of cooling and cooling durations on female gametogenesis and spawning. Aquaculture 205: 253-267.

Migaud H, Davie A, Taylor JF. 2010. Current knowledge on the photoneuroendocrine regulation of reproduction in temperate fish species. 44: 27-68.

Mikawa N, Horie N, Yamada Y, Utoh T, Okamura A, Tanaka S. 2008. Maturation induction in female Japanese eel without treatment and improvement of fertilization method. In World Aquaculture 2008, Busan (Korea), p. (book of abstracts).

Minegishi Y, Aoyama J, Inoue JG, Miya M. 2005. Molecular phylogeny and evolution of the freshwater eels genus Anguilla based on the whole mitochondrial genome sequences. Mol Phylogenet Evol 34: 134-146.

Ming R, VanBuren R, Wai CM, Tang H, Schatz MC, Bowers JE, Lyons E, Wang ML, Chen J, Biggers E, Zhang J, Huang L, Zhang L, Miao W, Zhang J, Ye Z, Miao C, Lin Z, Wang H, Zhou H, Yim WC, Priest4, Zheng C, Woodhouse M, Edger PP, Guyot R, Guo HB, Guo H, Zheng G, Singh R, Sharma A, Min X, Zheng Y, Lee $H$, Gurtowski J, Sedlazeck FJ, Harkess A, McKain MR, Liao Z, Fang J, Liu J, Zhang X, Zhang Q, Hu W, Qin Y, Wang K, Chen LY, Shirley N, Lin YR, Liu LY, Hernandez AG, Wright CL, Bulone V, Tuskan GA, Heath K, Zee F, Moore PH, Sunkar R, Leebens-Mack JH, Mockler T, Bennetzen JL, Freeling M, Sankoff D, Paterson AH, Zhu X, Yang X, Smith JCA, Cushman JC, Paull RE, and Yu Q. 2015. The pineapple genome and the evolution of CAM photosynthesis. Nat Genet 47: 1435-1442.

Miura C, Miura T. 2011. Analysis of spermatogenesis using an eel model. 4: 105129.

Miura T, Yamauchi K, Nagahama Y, Takahashi H. 1991a. Induction of spermatogenesis in male Japanese eel, Anguilla japonica, by a single injection of human chorionic gonadotropin. Zoolog Sci 8: 63-73.

Miura T, Yamauchi K, Takahashi H, Nagahama Y. 1991b. Hormonal induction of all stages of spermatogenesis in vitro in the male Japanese eel (Anguilla japonica). Physiology/Pharmacology 88: 5774-5778.

Miura T, Yamauchi K, Takahashi H, Nagahama Y. 1991c. Involvement of steroid hormones in gonadotropin-induced testicular maturation in male Japanese eel (Anguilla japonica). Biomed Res 12: 241-248. 
Miura T, Miura C, Ohta T, Nader MR, Todo T, Yamauchi K. 1999. Estradiol-17 stimulates the renewal of spermatogonial stem cells in males. 234: 230234.

Miura T, Miura Cl. 2003. Molecular control mechanisms of fish spermatogenesis. Fish Physiol Biochem 181-186.

Miura T, Higuchi M, Ozaki Y, Ohta T, Miura C. 2006. Progestin is an essential factor for the initiation of the meiosis in spermatogenetic cells of the eel. Proc Natl Acad Sci 103: 7333-7338.

Molés G, Gómez A, Carrillo M, Rocha A, Mylonas CC, Zanuy S. 2011a. Determination of Fsh quantity and bioactivity during sex differentiation and oogenesis in European sea bass. Biol Reprod 85: 848-857.

Molés G, Zanuy S, Muñoz I, Crespo B, Martínez I, Mañanós E, Gómez A. 2011b. Receptor specificity and functional comparison of recombinant sea bass (Dicentrarchus labrax) gonadotropins (Fsh and Lh) produced in different host systems. Biol Reprod 84: 1171-1181.

Montero M, Le Belle N, King JA, Millar RP, Dufour S. 1995. Differential regulation of the two forms of gonadotropin-releasing hormone ( $\mathrm{mGnRH}$ and $\mathrm{cGnRH}$ II) by sex steroids in the European female silver eel (Anguilla anguilla). Neuroendocrinology 61: 525-535.

Mordenti O, Biase A Di, Sirri R, Modugno S, Tasselli A. 2012. Induction of sexual maturation in wild female European eels (Anguilla anguilla) in darkness and light. Isr J Aquac 1-9.

Mordenti O, Biase A Di, Bastone G, Sirri R, Zaccaroni A, Parmeggiani A. 2013. Controlled reproduction in the wild European eel (Anguilla anguilla): Two populations compared. Aquac Int 21: 1045-1063.

Mordenti O, Emmanuele P, Casalini A, Mark P, Zaccaroni A, Di A, Albamaria B. 2017. Effect of aromatable androgen (17-methyltestosterone) on induced maturation of silver European eels (Anguilla anguilla): Oocyte performance and synchronization. Aquac Res 1-7.

Morini M, Pasquier J, Dirks R, Van Den Thillart G, Tomkiewicz J, Rousseau K, Dufour S, Lafont AG. 2015. Duplicated leptin receptors in two species of eel bring new insights into the evolution of the leptin system in vertebrates. PLoS One 10: 1-31.

Morini M. 2016. Molecular approaches related to the European eel (Anguilla 
anguilla) reproductive process. 207.

Morini M, Peñaranda DS, Vílchez MC, Nourizadeh-Lillabadi R, Lafont AG, Dufour S, Asturiano JF, Weltzien FA, Pérez L. 2017a. Nuclear and membrane progestin receptors in the European eel: Characterization and expression in vivo through spermatogenesis. Comp Biochem Physiol-Part A Mol Integr Physiol 207: 79-92.

Morini M, Peñaranda DS, Vílchez MC, Nourizadeh-Lillabadi R, Lafont AG, Dufour S, Asturiano JF, Weltzien FA, Pérez L. 2017b. The expression of nuclear and membrane estrogen receptors in the European eel throughout spermatogenesis. Comp Biochem Physiol -Part A Mol Integr Physiol 207: 79-92.

Moriyama Y, Koshiba-Takeuchi K. 2018. Significance of whole-genome duplications on the emergence of evolutionary novelties. Brief Funct Genomics 1-10.

Mungpakdee S, Seo HC, Angotzi AR, Dong X, Akalin A, Chourrout D. 2008. Differential evolution of the 13 Atlantic salmon Hox clusters. Mol Biol Evol 25: 1333-1343.

Munk P, Hansen MM, Maes GE, Nielsen TG, Castonguay M, Riemann L, Sparholt $\mathrm{H}$, Als TD, Aarestrup K, Andersen NG, et al. 2010. Oceanic fronts in the Sargasso Sea control the early life and drift of Atlantic eels. Proc Biol Sci 277: 3593-3599.

Mutti JS, Bhullar RK, Gill KS. 2017. Evolution of gene expression balance among homeologs of natural polyploids. G3; Genes/Genomes/Genetics 7: 12251237.

Müller T, Matsubara H, Kubara Y, Horváth Á, Kolics B, Taller J, Stéger V, Kovács $B$, Horváth L, Asturiano JF,

Peñaranda DS, Urányi B. 2018. Testing cryopreserved European eel sperm for hybridization (A. japonica $\times$ A. anguilla). Theriogenology 113: 153-158.

Mylonas CC, Fostier A, Zanuy S. 2010. Broodstock management and hormonal manipulations of fish reproduction. Gen Comp Endocrinol 165: 516-34.

Mylonas CC, Duncan NJ, Asturiano JF. 2017. Hormonal manipulations for the enhancement of sperm production in cultured fish and evaluation of sperm quality. Aquaculture 472: 21-44. 
Nakatani Y, Mclysaght A. 2017. Genomes as documents of evolutionary history: a probabilistic macrosynteny model for the reconstruction of ancestral genomes. Bioinformatics, 33: 369-378.

Needleman LA, Liu X-B, El-Sabeawy F, Jones EG, McAllister AK. 2010. MHC class I molecules are present both pre- and postsynaptically in the visual cortex during postnatal development and in adulthood. Proc Natl Acad Sci 107: 16999-17004.

Negatu Z, Hsiao SM, Wallace RA. 1998. Effects of insulin-like growth factor-I on final oocyte maturation and steroid production in Fundulus heteroclitus. Fish Physiol Biochem 19: 13-21.

Noble WS. 2009. How does multiple testing correction work? Nat Biotechnol 27: 1135-1137.

Nóbrega RH, De Souza Morais RDV, Crespo D, De Waal PP, De França LR, Schulz RW, Bogerd J. 2015. Fsh stimulates spermatogonial proliferation and differentiation in zebrafish via Igf3. Endocrinology 156: 3804-3817.

Nomura K, Takeda Y, Unuma T, Morishima K, Tanaka H, Arai K, Ohta H. 2013. Post-ovulatory oocyte aging induces spontaneous occurrence of polyploids and mosaics in artificial fertilization of Japanese eel, Anguilla japonica. Aquaculture 404-405: 15-21.

Nomura K, Fujiwara A, Iwasaki Y, Nishiki I, Matsuura A, Ozaki A, Sudo R, Tanaka H. 2018. Genetic parameters and quantitative trait loci analysis associated with body size and timing at metamorphosis into glass eels in captive-bred Japanese eels (Anguilla japonica). PLoS One 13: 1-18.

Nowosad J, Kucharczyk D, Czarkowski TK, Kwasek K. 2014. Changes in body weight and eye size in female European eel kept in fresh and salt water. Ital J Anim Sci 13: 382-386.

Nowosad J, Kucharczyk D, Łuczyńska J, Targońska K, Czarkowski TK, Biłas M, Krejszeff S, Horváth L, Müller T. 2015. Changes in European eel ovary development and body and ovary chemistry during stimulated maturation under controlled conditions: preliminary data. Aquac Int 23: 13-27.

Ohno S. 1970. Evolution by Gene Duplication. Springer-Verlag, New York.

Ohta H, Tanaka H. 1997. Relationship between serum levels of human chorionic gonadotropin (hCG) and 11-ketotestosterone after a single injection of hCG and induced maturity in the male Japanese eel, Anguilla japonica. 
Aquaculture 153: 123-134.

Ohta H, Kagawa H, Tanaka H, Unuma T. 2001. Control by the environmental concentration of ions of the potential for motility in Japanese eel spermatozoa. Aquaculture 198: 339-351.

Ohta H, Higashimoto $\mathrm{Y}$, Koga S, Unuma T, Nomura K, Tanaka H, Kagawa H, Arai K. 2003. Occurrence of spontaneous polyploids from the eggs obtained by artificial induction of maturation in the Japanese eel (Anguilla japonica). Fish Physiol Biochem 28: 517-518.

Ohta T, Miyake H, Miura C, Kamei H, Aida K, Miura T. 2007. Follicle-stimulating hormone induces spermatogenesis mediated by androgen production in Japanese eel, Anguilla japonica. Biol Reprod 77: 970-977.

Ohta H, Sato Y, Imaizumi H, Kazeto Y. 2017. Changes in milt volume and sperm quality with time after an injection of recombinant Japanese eel luteinizing hormone in male Japanese eels. Aquaculture 479: 150-154.

Olivereau M, Dubourg P, Chambolle P, Olivereau J. 1986. Effects of estradiol and mammalian LHRH on the ultrastructure of the pars distalis of the eel. Cell Tissue Res 246: 425-437.

Osborn TC, Butrulle D V., Sharpe AG, Pickering KJ, Parkin IAP, Parker JS, Lydiate DJ. 2003. Detection and effects of a homeologous reciprocal transposition in Brassica napus. Genetics 165: 1569-1577.

Otto SP, Whitton J. 2000. Polyploid incidence and evolution. Annu Rev Genet 34: 401-437.

Ozaki Y, Miura C, Miura T. 2006. Molecular cloning and gene expression of Spo11 during spermatogenesis in the Japanese eel, Anguilla japonica. 143: 309314.

Palm S, Dannewitz J, Prestegaard T, Wickström H. 2009. Panmixia in European eel revisited: No genetic difference between maturing adults from southern and northern Europe. Heredity (Edinb) 103: 82-89.

Palstra AP, Cohen EGH, Niemantsverdriet PRW, van Ginneken VJT, van den Thillart GEEJM. 2005. Artificial maturation and reproduction of European silver eel: Development of oocytes during final maturation. Aquaculture 249: 533-547.

Palstra AP, Curiel D, Fekkes M, de Bakker M, Székely C, van Ginneken V, van den 
Thillart G. 2007. Swimming stimulates oocyte development in European eel. Aquaculture 270: 321-332.

Palstra AP, Schnabel D, Nieveen MC, Spaink HP, Van Den Thillart GEEJM. 2008. Male silver eels mature by swimming. BMC Physiol 8: 4-7.

Palstra AP, Ginneken V, Thillart G. 2009. Effects of Swimming on Silvering and Maturation of the European Eel, Anguilla anguilla L. In Spawning Migration of the European Eel: Reproduction Index, A Useful Tool for Conservation Management, Vol. 30 of, pp. 229-251.

Palstra AP, van den Thillart GE. 2009. Artificial maturation and reproduction of the European eel. In: van den Thillart, G., Dufour S., Rankin J.C. (Eds), apawning migration of the European eel, Springer Science+Business Media B.V, Netherlands, pp. 309-331.

Palstra AP, Schnabel D, Nieveen MC, Spaink HP, van den Thillart GEEJM. 2010. Temporal expression of hepatic estrogen receptor 1, vitellogenin1 and vitellogenin2 in European silver eels. Gen Comp Endocrinol 166: 1-11.

Pankhurst NW. 1982. Relation of visual changes to the onset of sexualmaturation in the European eel Anguilla anguilla (L). J Fish Biol 21: 127140.

Pankhurst NW, Lythgoe JN. 1983. Changes in vision and olfaction during sexual maturation in the European eel Anguilla anguilla (L.). J Fish Biol 23: 229240.

Parisod C, Holderegger R, Brochmann C. 2010. Evolutionary consequences of autopolyploidy. New Phytol 186: 5-17.

Parmeggiani A, Govoni N, Zannoni A, Biase A Di, Sirri R, Forni M, Mandelli M, Mordenti O. 2015. Effect of photoperiod on endocrine profiles and vitellogenin expression in European eels Anguilla anguilla during artificially induced ovarian development. Theriogenology 83: 478-484.

Pasqualini C, Weltzien FA, Vidal B, Baloche S, Rouget C, Gilles N, Servent D, Vernier $P$, Dufour S. 2009. Two distinct dopamine D2 receptor genes in the European eel: Molecular characterization, tissue-specific transcription, and regulation by sex steroids. Endocrinology 150: 1377-1392.

Pasquier J, Lafont AG, Jeng SR, Morini M, Dirks R, van den Thillart G, Tomkiewicz J, Tostivint H, Chang CF, Rousseau K, Dufour S. 2012. Multiple kisspeptin receptors in early osteichthyans provide new insights into the evolution of 
this receptor family. PLoS One 7: e48931.

Pasquier J, Cabau C, Nguyen T, Jouanno E, Severac D, Braasch I, Journot L, Pontarotti P, Klopp C, Postlethwait JH, Guiguen Y, and Bobe J. 2016. Gene evolution and gene expression after whole genome duplication in fish: the PhyloFish database. BMC Genomics 17.

Pasquier J, Montfort J, Klopp C, Bobe J, Nguyen T, Journot L, Batzel P, Cabau C, Berthelot C, Guiguen Y, Bobe J. 2017. Evolution of gene expression after whole-genome duplication: New insights from the spotted gar genome. $J$ Exp Zool (Mol Dev Evol). 2017;1-13

Patro R, Duggal G, Love MI, Irizarry RA, Kingsford C. 2017. Salmon provides accurate, fast, and bias-aware transcript expression estimates using dualphase inference. bioRxiv 14: 417-419.

Pedersen BH. 2004. Fertilisation of eggs, rate of embryonic development and hatching following induced maturation of the European eel Anguilla anguilla. Aquaculture 237: 461-473.

Peña-Llopis S, Brugarolas J. 2013. Simultaneous isolation of high-quality DNA, RNA, miRNA and proteins from tissues for genomic applications. Nat Protoc 8: 2240-55.

Peñaranda DS, Marco-Jiménez F, Pérez L, Gallego V, Mazzeo I, Vicente JS, Jover M, Asturiano JF. 2010a. Evaluation of different diluents for short-term storage of European eel sperm under air-limited conditions. J Appl Ichthyol 26: 659-664.

Peñaranda DS, Pérez L, Gallego V, Jover M, Tveiten H, Baloche S, Dufour S, Asturiano JF. 2010b. Molecular and physiological study of the artificial maturation process in European eel males: From brain to testis. Gen Comp Endocrinol 166: 160-171.

Peñaranda DS, Mazzeo I, Gallego V, Hildahl J, Nourizadeh-Lillabadi R, Pérez L, Weltzien F, Asturiano JF. 2014. The regulation of aromatase and androgen receptor expression during gonad development in male and female European eel. Reprod Domest Anim 49: 512-21.

Peñaranda DS, Morini M, Tveiten H, Vílchez MC, Gallego V, Dirks RP, van den Thillart GEEJM, Pérez L, Asturiano JF. 2016. Temperature modulates testis steroidogenesis in European eel. Comp Biochem Physiol-Part A Mol Integr Physiol 197: 58-67. 
Peñaranda DS, Gallego V, Rozenfeld C, Herranz-Jusdado JG, Pérez L, Gómez A, Giménez I, Asturiano JF. 2018. Using specific recombinant gonadotropins to induce spermatogenesis and spermiation in the European eel (Anguilla anguilla). Theriogenology 107: 6-20.

Pérez L, Asturiano JF, Tomás A, Zegrari S, Barrera R, Espinós FJ, Navarro JC, Jover M. 2000. Induction of maturation and spermiation in the male European eel: assessment of sperm quality throughout treatment. J Fish Biol 57: 1488-1504.

Pérez L, Peñaranda DS, Jover M, Asturiano JF. 2008. Results of maturation and ovulation in European eel females. Cybium, 32, 320.

Pérez L, Peñaranda DS, Gallego V, Asturiano JF. 2009. Testis development, sperm quality evaluation and cryopreservation in the European eel. In: Van den Thillart, G.E.E.J.M., Dufour, S., Rankin, J.C. (Eds), Spawning Migration of the European Eel, Springer, New York, pp. 333-362.

Pérez L, Peñaranda DS, Dufour S, Baloche S, Palstra AP, Van Den Thillart GEEJM, Asturiano JF. 2011. Influence of temperature regime on endocrine parameters and vitellogenesis during experimental maturation of European eel (Anguilla anguilla) females. Gen Comp Endocrinol 174: 51-9.

Persengiev SP, Kondova II, Millette CF, Kilpatrick DL. 1997. Gli family members are differentially expressed during the mitotic phase of spermatogenesis. Oncogene 14: 2259-2264.

Pertea M, Kim D, Pertea GM, Leek JT, Salzberg SL. 2016. Transcript-level expression analysis of RNA-seq experiments with HISAT, StringTie and Ballgown. Nat Protoc 11: 1650-1667.

Perälä NM, Immonen T, Sariola H. 2005. The expression of plexins during mouse embryogenesis. Gene Expr Patterns 5: 355-362.

Peter RE, Chang JP, Nahorniak RJ, Sokolowska OM, Shih SH, Billard R. 1986. Interactoin of catecholamin and $\mathrm{GnRH}$ in regulation of gonadotropin secretion in teleost fish. Recent Prog Horm Res 42: 513-548.

Planas J V, Swanson P. 1995. Maturation-associated changes in the response of the salmon testis to the steroidogenic actions of gonadotropins (GTH I and GTH II) in vitro. Biol Reprod 52: 697-704.

Prat F, Zanuy S, Bromage N, Carrillo M. 1999. Effects of constant short and long photoperiod regimes on the spawning performance and sex steroid levels 
of female and male sea bass. J Fish Biol 54: 125-137.

Pujolar JM, Jacobsen MW, Als TD, Frydenberg J, Munch K, Jonsson B, Jian JB, Cheng L, Maes GE, Bernatchez L, Hansen MM. 2014. Genome-wide singlegeneration signatures of local selection in the panmictic European eel. Mol Ecol 23: 2514-2528.

Rainey MA, George M, Ying G, Akakura R, Burgess DJ, Siefker E, Bargar T, Doglio L, Crawford SE, Todd GL, Govindarajan V, Hess RA, Band V, Naramura M, and Band $H$. 2010. The endocytic recycling regulator EHD1 is essential for spermatogenesis and male fertility in mice. BMC Dev Biol 1-19.

Ramsey J, Schemske DW. 2002. Eopolyploidy in flowering plants. Annu Rev Ecol Syst 33: 589-639.

Ravi V, Venkatesh B. 2018. The divergent genomes of teleosts. Annu Rev Anim Biosci 6: 47-68.

Ren L, Cui J, Wang J, Tan H, Li W, Tang C, Qin Q, Liu S. 2017. Analyzing homoeolog expression provides insights into the rediploidization event in gynogenetic hybrids of Carassius auratus red var. x Cyprinus carpio. Sci Rep 7: 1-11.

Riboldi M, Rubio C, Pellicer A, Gil-salom M. 2012. In vitro production of haploid cells after coculture of CD49f + with Sertoli cells from testicular sperm extraction in nonobstructive azoospermic patients. Sem Con 98: 580-590.

Righton D, Westerberg H, Feunteun E, Okland F, Gargan P, Amilhat E, Metcalfe J, Lobon-Cervia J, Sjo Berg N, Simon J, Acou A, Vedor M, Walker A, Trancart T, Brämick U, and Aarestrup K. 2016. Empirical observations of the spawning migration of European eels: The long and dangerous road to the Sargasso Sea. Sci Adv 2: e1501694.

Roa J, Aguilar E, Dieguez C, Pinilla L, Tena-Sempere M. 2008. New frontiers in kisspeptin/GPR54 physiology as fundamental gatekeepers of reproductive function. Front Neuroendocrinol 29: 48-69.

Robertson FM, Gundappa MK, Grammes F, Hvidsten TR, Redmond AK, Lien S, Martin SAM, Holland PWH, Sandve SR, Macqueen DJ. 2017. Lineagespecific rediploidization is a mechanism to explain time-lags between genome duplication and evolutionary diversification. Genome Biol 18: 114.

Robles V, Riesco MF, Psenicka M, Saito T, Valcarce DG, Cabrita E, Herráez P. 2017. Biology of teleost primordial germ cells (PGCs) and spermatogonia: 
Biotechnological applications. Aquaculture 472: 4-20.

Rodríguez L, Begtashi I, Zanuy S, Carrillo M. 2000. Development and validation of an enzyme immunoassay for testosterone: Effects of photoperiod on plasma testosterone levels and gonadal development in male sea bass (Dicentrarchus labrax, L.) at puberty. Fish Physiol Biochem 23: 141-150.

Rodríguez L, Begtashi I, Zanuy S, Carrillo M. 2005. Long-term exposure to continuous light inhibits precocity in European male sea bass (Dicentrarchus labrax, L.): Hormonal aspects. Gen Comp Endocrinol 140: 116-125.

Rohr DH, Lokman PM, Davie PS, Young G. 2001. 11-Ketotestosterone induces silvering-related changes in immature female short-finned eels, Anguilla australis. Comp Biochem Physiol Part A 701-714.

Rondeau EB, Minkley DR, Leong JS, Messmer AM, Jantzen JR, Von Schalburg KR, Lemon C, Bird NH, Koop BF. 2014. The genome and linkage map of the northern pike (Esox lucius): Conserved synteny revealed between the salmonid sister group and the neoteleostei. PLoS One 9: e102089.

Roth C, Rastogi S, Arvestad L, Dittmar K, Light S, Ekman D, Liberles DA. 2007. Evolution after gene duplication: Models, mechanisms, sequences, systems, and organisms. 73: 58-73.

Roulin A, Auer PL, Libault M, Schlueter J, Farmer A, May G, Stacey G, Doerge RW, Jackson SA. 2013. The fate of duplicated genes in a polyploid plant genome. Plant J 73: 143-153.

Rozenfeld C, Butts IAE, Tomkiewicz J, Zambonino-Infante J-L, Mazurais D. 2016. Abundance of specific mRNA transcripts impacts hatching success in European eel, Anguilla anguilla L. Comp Biochem Physiol A Mol Integr Physiol 191: 59-65.

Rozenfeld C, Blanca J, Albiach VG, García-Carpintero V, Herranz-Jusdado JG, Pérez L, Asturiano JF, Cañizares J, Peñaranda DS. 2017. Large scale gene duplication affected the European eel (Anguilla anguilla) after the 3R teleost duplication. bioRxiv preprint: 232918.

Saha S, Singh KM, Bansh B, Gupta P. 2018. Melatonin synthesis and clock gene regulation in the pineal organ of teleost fish compared to mammals: Similarities and differences. Gen Comp Endocrinol. https://doi.org/10.1016/j.ygcen.2018. 07.010 
Sahin Z, Szczepny A, Mclaughlin EA, Meistrich ML, Zhou W, Ustunel I, Loveland KL. 2014. Dynamic Hedgehog signalling pathway activity in germline stem cells. Andrology 2: 267-274.

Saito K, Lokman PM, Young G, Ozaki Y, Matsubara H, Okumura H, Kazeto Y, Yoshiura Y, Aida K, Adachi S, et al. 2003. Follicle-stimulating hormone $\beta$, luteinizing hormone $\beta$ and glycoprotein hormone $\alpha$ subunit mRNA levels in artificially maturing Japanese eel Anguilla japonica and naturally maturing New Zealand longfinned eel Anguilla dieffenbachii. Fish Sci 69: 146-153.

Santini F, Harmon LJ, Carnevale G, Alfaro ME. 2009. Did genome duplication drive the origin of teleosts? A comparative study of diversification in rayfinned fishes. BMC Evol Biol 9: 194.

Schabetsberger R, $\varnothing$ kland F, Aarestrup K, Kalfatak D, Tambets M, Olmo GD, Kaiser R, Miller PI. 2013. Oceanic migration behaviour of tropical Pacific eels from Vanuatu. 475: 177-190.

Schartl M, Walter RB, Shen Y, Garcia T, Catchen J, Amores A, Braasch I, Chalopin D, Volff JN, Lesch KP, Bisazza A, Minx P, Hillier L, Wilson RK, Fuerstenberg S, Boore J, Searle S, Postlethwait JH, and Warren WC. 2013. The genome of the platyfish, Xiphophorus maculatus, provides insights into evolutionary adaptation and several complex traits. Nat Genet 45: 567-572.

Schmidt J. 1923. Breeding places and migrations of the eel. Nature 111: 51-54.

Schmitz M, Aroua S, Vidal B, Le Belle N, Elie P, Dufour S. 2005. Differential regulation of luteinizing hormone and follicle-stimulating hormone expression during ovarian development and under sexual steroid feedback in the European eel. Neuroendocrinology 81: 107-119.

Schmutz J, Cannon SB, Schlueter J, Ma J, Mitros T, Nelson W, Hyten DL, Song Q, Thelen JJ, Cheng J, Xu D, Hellsten U, May GD, Yu Y, Sakurai T, Umezawa T, Bhattacharyya MK, Sandhu D, Valliyodan B, Lindquist E, Peto M, Grant D, Shu S, Goodstein D, Barry K, Futrell-Griggs M, Abernathy B, Du J, Tian Z, Zhu L, Gill N, Joshi T, Libault M, Sethuraman A, Zhang XC, Shinozaki K, Nguyen HT, Wing RA, Cregan P, Specht J, Grimwood J, Rokhsar D, Stacey G, Shoemaker RC, and Jackson SA. 2010. Genome sequence of the palaeopolyploid soybean. Nature 463: 178-183.

Schreck CB. 2010. Stress and fish reproduction: The roles of allostasis and hormesis. Gen Comp Endocrinol 165: 549-556.

Schulz R. 1985. Measurement of five androgens in the blood of immature and 
maturing male rainbow trout, Salmo gairdneri (Richardson). Steroids 46: 717-726.

Schulz RW, Renato L, França D, Lareyre J, Legac F, Chiarini-garcia H, Henrique R, Miura T. 2010. Spermatogenesis in fish. Gen Comp Endocrinol 165: 390411.

Scienski K, Fay JC, Conant GC. 2015. Patterns of gene conversion in duplicated yeast histones suggest strong selection on a coadapted macromolecular complex. Genome Biol Evol 7: 3249-3258.

Sébert ME, Amérand A, Vettier A, Weltzien FA, Pasqualini C, Sébert P, Dufour S. 2007. Effects of high hydrostatic pressure on the pituitary-gonad axis in the European eel, Anguilla anguilla (L.). Gen Comp Endocrinol 153: 289-298.

Sebert ME, Legros C, Weltzien F, Malpaux B, Chemineau P, Dufour S. 2008. Melatonin activates brain dopaminergic systems in the eel with an inhibitory impact on reproductive function neuroendocrinology. J Neuroendocrinol 20: 917-929.

Sebert P, Barthelemy L. 1985. Effects of long-term exposure to hydrostatic pressure per se (101 ATA) on eel metabolism. Can j Physiol Pharmacol 67: 1247-1251.

Sémon M, Wolfe KH. 2007a. Consequences of genome duplication. Curr Opin Genet Dev 17: 505-512.

Sémon M, Wolfe KH. 2007b. Rearrangement rate following the whole-genome duplication in teleosts. Mol Biol Evol 24: 860-867.

Setiawan AN, Wylie MJ, Forbes EL, Lokman PM. 2012. The effects of 11ketotestosterone on occupation of downstream location and seawater in the New Zealand shortfinned eel, Anguilla australis. Zoolog Sci 29: 1-5.

Shatz CJ. 2009. MHC Class I: An unexpected role in neuronal plasticity. Neuron 64: 40-45.

Sievers F, Wilm A, Dineen D, Gibson TJ, Karplus K, Li W, Lopez R, McWilliam H, Remmert M, Söding J, Thompson JD, and Higgins DG. 2011. Fast, scalable generation of high-quality protein multiple sequence alignments using Clustal Omega. Mol Syst Biol 7: 1-6.

Simão FA, Waterhouse RM, loannidis P, Kriventseva E V., Zdobnov EM. 2015. BUSCO: Assessing genome assembly and annotation completeness with 
single-copy orthologs. Bioinformatics 31: 3210-3212.

Skaftnesmo KO, Edvardsen RB, Furmanek T, Crespo D, Andersson E, Kleppe L, Taranger GL, Bogerd J, Schulz RW, Wargelius A. 2017. Integrative testis transcriptome analysis reveals differentially expressed miRNAs and their mRNA targets during early puberty in Atlantic salmon. BMC Genomics 18: $1-12$.

Slater GSC, Birney E. 2005. Automated generation of heuristics for biological sequence comparison. BMC Bioinformatics 6: 31.

Smith SA, Brown JW, Yang Y, Bruenn R, Drummond CP, Brockington SF, Walker JF, Last N, Douglas NA, and Moore MJ. 2017. Disparity, diversity, and duplications in the Caryophyllales.

So W-K, Kwok H-F, Ge W. 2005. Zebrafish gonadotropins and their receptors: II. Cloning and characterization of Zebrafish follicle-stimulating hormone and luteinizing hormone subunits their spatial-temporal expression patterns and receptor specificity. Biol Reprod 72: 1382-1396.

Soltis DE, Visger CJ, Soltis PS. 2014. The polyploidy revolution then...and now: Stebbins revisited. Am J Bot 101: 1057-1078.

Soltis PS, Marchant DB, Peer Y Van De, Soltis DE. 2015. Polyploidy and genome evolution in plants. Curr Opin Genet Dev 35: 119-125.

Strahl BD, Allis CD. 2000. The language of covalent histone modifications. Nature 403: 41-45.

Støttrup JG, Jacobsen C, Tomkiewicz J, Jarlbaek H. 2013. Modification of essential fatty acid composition in broodstock of cultured European eel Anguilla anguilla L. Aquac Nutr 19: 172-185.

Støttrup JG, Tomkiewicz J, Jacobsen C, Butts IAE, Holst LK. 2016. Development of a broodstock diet to improve developmental competence of embryos in European eel, Anguilla anguilla. Aquac Nutr 22: 725-737.

Sudo R, Tosaka R, ljiri S, Adachi S, Suetake H, Suzuki Y, Horie N, Tanaka S, Aoyama J, Tsukamoto K. 2011. Effect of temperature decrease on oocyte development, sex steroids, and gonadotropin $\beta$-subunit mRNA expression levels in female Japanese eel Anguilla japonica. Fish Sci 77: 575-582.

Sudo R, Tosaka R, ljiri S, Adachi S, Aoyama J, Tsukamoto K. 2012. 11ketotestosterone synchronously induces oocyte development and 
silvering-related changes in the Japanese eel, Anguilla japonica. Zoolog Sci 29: 254-9.

Suquet M, Normant Y, Gaignon JL, Quéméner L, Fauvel C. 2005. Effect of water temperature on individual reproductive activity of pollack (Pollachius pollachius). Aquaculture 243: 113-120.

Syken J, Shatz CJ. 2003. Expression of T cell receptor beta locus in central nervous system neurons. Proc Natl Acad Sci U S A 100: 13048-13053.

Sørensen SR, Tomkiewicz J, Munk P, Butts IAE, Nielsen A, Lauesen P, Graver C. 2016. Ontogeny and growth of early life stages of captive-bred European eel. Aquaculture 456: 50-61.

Tachibana M, Nozaki M, Takeda N, Shinkai Y. 2007. Functional dynamics of H3K9 methylation during meiotic prophase progression. embo J 26: 3346-3359.

Takeuchi T, Watanabe Y, Takano-Shimizu T, Kondo S. 2006. Roles of jumonji and jumonji family genes in chromatin regulation and development. Dev Dyn 2449-2459.

Tanaka H, Kagawa H, Ohta H. 2001. Production of leptocephali of Japanese eel (Anguilla japonica) in captivity. Aquaculture 201: 51-60.

Tanaka H, Kagawa H, Ohta H, Unuma T, Nomura K. 2003. The first production of glass eel in captivity: fish reproductive physiology. 493-497.

Tang H, Wang X, Bowers JE, Ming R, Alam M, Paterson AH. 2008. Unraveling ancient hexaploidy through multiply-aligned angiosperm gene maps. Genome Res 18: 1944-1954.

Taranger GL, Carrillo M, Fontaine P, Felip A, Weltzien F, Dufour S, Norberg B, Andersson E, Hansen T. 2010. Control of puberty in farmed fish. Gen Comp Endocrinol 165: 483-515.

Tautz D, Domazet-lošo T. 2011. The evolutionary origin of orphan genes. Nat Publ Gr 12: 692-702.

Terasaka T, Adakama ME, Li S, Kim T, Terasaka E, Li D, Lawson MA. 2017. Reactive oxygen species link gonadotropin-releasing hormone receptor signaling cascades in the gonadotrope. Front Endocrinol (Lausanne) 8:286

Tesch FW. 2003. The eel.

Thompson A, Zakon HH, Kirkpatrick M. 2016. Compensatory drift and the 
evolutionary dynamics of dosage-sensitive duplicate genes. Genetics 202: 765-774.

Todd PR. 1981. Hormone-induced maturation in male New Zealand freshwater eels (Anguilla spp.). New Zeal J Mar Freshw Res 15: 237-246.

Tsukamoto K, Chow S, Otake T, Kurogi H, Mochioka N, Miller MJ, Aoyama J, Kimura S, Watanabe $S$, Yoshinaga $T$, Shinoda $A$, Kuroki $M$, Oya $M$, Watanabe T, Hata K, ljiri S, Kazeto S, Nomura K, and Tanaka H. 2011. Oceanic spawning ecology of freshwater eels in the western North Pacific. Nat Commun 2: 179.

Tveiten H, Johnsen HK. 1999. Temperature experienced during vitellogenesis influences ovarian maturation and the timing of ovulation in common wolffish. J Fish Biol 55: 809-819.

Unuma T, Hasegawa N, Sawaguchi S, Tanaka T, Matsubara T, Nomura K, Tanaka H. 2011. Fusion of lipid droplets in Japanese eel oocytes: Stage classification and its use as a biomarker for induction of final oocyte maturation and ovulation. Aquaculture 322-323: 142-148.

Utoh T, Horie N, Okamura A, Mikawa N, Yamada Y, Tanaka S, Oka HP, Tsukamoto K. 2013. Water temperature manipulation can induce oocyte maturation and ovulation in the common Japanese conger, Conger myriaster. Aquaculture 392-395: 120-127.

Vallente Samonte R, Eichler EE. 2016. Segmental duplications and the evolution of the primate genome. Nat Rev Genet 3: 65-72.

Van De Peer Y. 2004. Computational approaches to unveiling ancient genome duplications. Nat Rev Genet 5: 752-763.

Van De Peer Y, Maere S, Meyer A. 2009. The evolutionary significance of ancient genome duplications. Nat Rev Genet 10: 725-732.

Van De Peer Y, Mizrachi E, Marchal K. 2017. The evolutionary significance of polyploidy. Nat Rev Genet 18: 411-424.

van Ginneken V, Antonissen E, Müller UK, Booms R, Eding E, Verreth J, van den Thillart G. 2005. Eel migration to the Sargasso: remarkably high swimming efficiency and low energy costs. J Exp Biol 208: 1329-35.

van Ginneken V, Dufour S, Sbaihi M, Balm P, Noorlander K, de Bakker M, Doornbos J, Palstra AP, Antonissen E, Mayer I, van den Thillart G. 2007. 
Does a $5500-\mathrm{km}$ swim trial stimulate early sexual maturation in the European eel (Anguilla anguilla L.)? Comp Biochem Physiol A Mol Integr Physiol 147: 1095-103.

Vandepoele K, De Vos W, Taylor JS, Meyer A, Van de Peer Y. 2004. Major events in the genome evolution of vertebrates: paranome age and size differ considerably between ray-finned fishes and land vertebrates. Proc Natl Acad Sci U S A 101: 1638-1643.

Vatine G, Vallone D, Gothilf Y, Foulkes NS. 2011. It's time to swim! Zebrafish and the circadian clock. FEBS Lett 585: 1485-1494.

Vidal B, Pasqualini C, Le Belle N, Holland $\mathrm{MCH}$, Sbaihi M, Vernier P, Zohar Y, Dufour S. 2004. Dopamine inhibits luteinizing hormone synthesis and release in the juvenile European eel: a neuroendocrine lock for the onset of puberty. Biol Reprod 71: 1491-500.

Vílchez MC, Morini M, Peñaranda DS, Gallego V, Asturiano JF, Pérez L. 2016. Sodium affects the sperm motility in the European eel. Comp Biochem Physiol-Part A Mol Integr Physiol 198: 51-58.

Vischer HF, Granneman JCM, Linskens MHK, Schultz RW, Bogerd J. 2003. Both recombinant African catfish $\mathrm{LH}$ and $\mathrm{FSH}$ are able to activate the African catfish FSH receptor. J Mol Endocrinol 31: 133-140.

Vision TJ, Brown DG, Tanksley SD, Vision TJ, Brown DG, Tanksley SD. 2000. The origins of genomic duplications in Arabidopsis. 290: 2114-2117.

Viveiros ATM, Fessehaye $Y$, ter Veld M, Schulz RW, Komen J. 2002. Handstripping of semen and semen quality after maturational hormone treatments, in African catfish Clarias gariepinus. Aquaculture 213: $373-$ 386.

Viveiros ATM, Nascimento AF, Orfão LH, Isaú ZA. 2010. Motility and fertility of the subtropical freshwater fish streaked prochilod (Prochilodus lineatus) sperm cryopreserved in powdered coconut water. Theriogenology 74: 551-556.

Vøllestad LA, Jonsson B, Hvidsten N-A, Næsje TF. 1994. Experimental test of environmental factors influencing the seaward migration of European silver eels. J Fish Biol 45: 641-651.

Wade MG, Van der Kraak G, Gerrits MF, Ballantyne JS. 1994. Release and steroidogenic actions of polyunsaturated fatty acids in the goldfish testis. 
Biol Reprod 51: 131-139.

Wahlberg M, Westerberg H, Aarestrup K, Feunteun E, Gargan P, Righton D. 2014. Evidence of marine mammal predation of the European eel (Anguilla anguilla L.) on its marine migration. Deep-sea res pt 1 86: 32-38.

Wang Y, Qian L, Dong Y, Jiang Q, Gui Y, Zhong TP, Song H. 2006. Myocyte-specific enhancer factor $2 \mathrm{~A}$ is essential for zebrafish posterior somite development. Mech Dev 123: 783-791.

Wang N, Teletchea F, Kestemont P, Milla S, Fontaine P. 2010. Photothermal control of the reproductive cycle in temperate fishes. Rev Aquac 2: 209222.

Wang X, Jin D, Wang Z, Guo H, Zhang L, Wang L, Li J, Paterson AH. 2015. Telomere-centric genome repatterning determines recurring chromosome number reductions during the evolution of eukaryotes. New Phytol 205: 378-389.

Webb MAH, Van Eenennaam JP, Doroshov SI, Moberg GP, Eenennaam JP Van. 1999. Preliminary observations on the effects of holding temperature on reproductive performance of female white sturgeon, Acipenser transmontanus Richardson. Aquaculture 176: 315-329.

Webb MAH, Van Eenennaam JP, Feist GW, Linares-Casenave J, Fitzpatrick MS, Schreck CB, Doroshov SI. 2001. Effects of thermal regime on ovarian maturation and plasma sex steroids in farmed white sturgeon, Acipenser transmontanus. Aquaculture 201: 137-151.

Weltzien FA, Pasqualini C, Sébert ME, Vidal B, Le Belle N, Kah O, Vernier P, Dufour S. 2006. Androgen-dependent stimulation of brain dopaminergic systems in the female European eel (Anguilla anguilla). Endocrinology 147: 2964-2973.

Wendel JF. 2000. Genome evolution in polyploids. Plant Mol Biol 42: 225-249.

Wisecaver JH, Borowsky AT, Tzin V, Jander G, Kliebenstein DJ. 2017. A global coexpression network approach for connecting genes to specialized metabolic pathways in plants. 29: 944-959.

Wolfe KH. 2001. Yesterday's polyploids and the mystery of diploidization. Nat Rev Genet 2: 333-341.

Wright JE, Johnson K, Hollister A, May B. 1983. Meiotic models to explain 
classical linkage, pseudolinkage, and chromosome pairing in tetraploid derivative salmonid genomes. Isozymes Curr Top Biol Med Res 10: 239-60.

Wysujack K, Westerberg H, Aarestrup K, Trautner J, Kurwie T, Nagel F, Hanel R. 2015. The migration behaviour of European silver eels (Anguilla anguilla) released in open ocean conditions. Mar Freshw Res 66: 145-157.

Xu P, Zhang X, Wang X, Li J, Liu G, Kuang Y, Xu J, Zheng X, Ren L, Wang G, Zhang Y, Huo L, Zhao Z, Cao D, Lu C, Li C, Zhou Y, Liu Z, Fan Z, Shan G, Li X, Wu S, Song L, Hou G, Jiang $Y$, Jeney $Z$, Yu D, Wang L, Shao C, Song L, Sun J, Ji P, Wang J, Li Q, Xu L, Sun F, Feng J, Wang C, Wang S, Wang B, Li Y, Zhu Y, Xue W, Zhao L, Wang J, Gu Y, Lv W, Wu K, Xiao J, Wu J, Zhang Z, Yu J, and Sun $X$. 2014. Genome sequence and genetic diversity of the common carp, Cyprinus carpio. Nat Publ Gr 46: 1212-1219.

Yamamoto K, Yamauchi K. 1974. Sexual maturation of Japanese eel and production of eel larvae in the aquarium. Nature 251: 220-222.

Yaron Z. 1995. Endocrine control of gametogenesis and spawning induction in the carp. Aquaculture 129: 49-73.

Yom-Din S, Hollander-Cohen L, Aizen J, Boehm B, Shpilman M, Golan M, Hurvitz A, Degani G, Levavi-Sivan B. 2016. Gonadotropins in the Russian sturgeon: Their role in steroid secretion and the effect of hormonal treatment on their secretion. PLoS One 11: 1-23.

Yoshikawa M. 2012. Improvement in hatching rates in the Japanese eel Anguilla japonica by the control of rearing temperatures in the late stage of maturation in the female parents. Aquaculture 338-341: 223-227.

Yoshiura Y, Suetake H, Aida K. 1999. Duality of gonadotropin in a primitive teleost, Japanese eel (Anguilla japonica). Gen Comp Endocrinol 114: 121131.

Yu Y, Xiang Q, Manos PS, Soltis DE, Soltis PS, Song B-H, Cheng S, Liu X, Wong G. 2017. Whole-genome duplication and molecular evolution in Cornus $\mathrm{L}$. (Cornaceae) - Insights from transcriptome sequences. PLoS One 12: e0171361.

Zhang X, Hou J, Wang G, Jiang H, Wang Y. 2015a. Gonadal Transcriptome Analysis in Sterile Double Haploid Japanese Flounder. 1-15.

Zhang Z, Lau SW, Zhang L, Ge W. 2015b. Disruption of zebrafish folliclestimulating hormone receptor (fshr) but not luteinizing hormone receptor 
(Ihcgr) gene by talen leads to failed follicle activation in females followed by sexual reversal to males. Endocrinology 156: 3747-3762.

Zhu D, Song W, Yang K, Cao X, Gul Y, Wang W. 2012. Flow cytometric determination of genome size for eight commercially important fish species in China. Vitr Cell Dev Biol - Anim 48: 507-517.

Zmora N, Kazeto Y, Kumar RS, Schulz RW, Trant JM. 2007. Production of recombinant channel catfish (Ictalurus punctatus) FSH and LH in S2 Drosophila cell line and an indication of their different actions. J Endocrinol 194: 407-416.

Zohar Y, Muñoz-Cueto JA, Elizur A, Kah O. 2010. Neuroendocrinology of reproduction in teleost fish. Gen Comp Endocrinol 165: 438-455.

Aarestrup $K, \varnothing$ kland $F$, Hansen MM, Righton D, Gargan P, Castonguay M, Bernatchez L, Howey P, Sparholt H, Pedersen MI, McKinley RS. 2009. Oceanic spawning migration of the European eel (Anguilla anguilla). Science 325: 12-13. 